\title{
ELECTRONIC RESOURCE MANAGEMENT AND USAGE IN ACADEMIC LIBRARIES: THE GHANAIAN CONTEXT
}

By

\section{WINIFRED BENTIL}

\author{
A thesis \\ submitted to the Victoria University of Wellington \\ in fulfilment of the requirements for the degree of \\ Doctor of Philosophy \\ in Information Systems
}

Victoria University of Wellington 2020 


\begin{abstract}
Electronic resources (ERs) in academic libraries have become a global phenomenon, and as libraries rely more on these resources managing them effectively becomes crucial. Electronic resource management (ERM) has consequently become a core function which many academic libraries around the globe appear to find challenging to implement effectively. Challenges of managing ERs are particularly pronounced in developing countries such as Ghana where the introduction of ICTs has typically been characterised by inadequate resources. Although there is an extensive literature on both the management and use of ERs, little research has studied how the two aspects could affect each other. Ineffective management of ERs could negatively affect their use; likewise, low usage of ERs could negatively impact on the management of these resources. Studying the concepts of management and usage of ERs together would result in better recommendations to inform practice and eliminate the challenges.
\end{abstract}

In addition, the literature on the management of ERs is predominantly centred around libraries in the developed country context. Moreover, academic libraries in Ghana do not appear to be effective in managing ERs. There is a lack of understanding on how academic libraries in Ghana are managing ERs, and the ways in which this is affecting their usage and vice-versa. The study therefore fills the gaps by exploring the connection between the management and usage of ERs in academic libraries in a developing country context.

Placed within a post-positivist worldview, this mixed-methods research employed a multiple case study approach, involving two public and two private universities in Ghana. Stakeholders included in the study were library staff, faculty, students, and consortium executives. Semistructured interviews were conducted with library staff and members of the governing council of the Consortium of Academic and Research Libraries in Ghana (CARLIGH) concurrently with surveys of faculty and postgraduate students of the institutions investigated. These were supported by document analysis. To guide data collection and analysis, the Techniques for Electronic Resource Management (TERMS) framework (Emery \& Stone, 2013), and an initial conceptual model of factors developed using constructs from the Unified Theory of Acceptance and Use of Technology (UTAUT) (Venkatesh, Morris, Davis \& Davis 2003) and the literature underpinned the study.

The interview findings revealed inadequate planning for ERs in the case institutions owing to operational challenges including inadequate policies for ERs, inadequate funding, and understaffing. Although efforts were being made to follow standard procedures some components of ER workflow were absent in both public and private case libraries, whereas other aspects of the workflow were responsibilities of parties external to the libraries. The document analysis showed that, the total average completeness of collection development policies of case libraries was $25 \%$ which indicated the lack of vital elements in these policies. The survey findings showed a generally low awareness and usage of ERs by faculty and students due to inadequate promotional efforts by the case libraries, inadequate infrastructure, and lack of relevant content. Consequently, respondents had a negative perception on the usefulness of the ERs which may have caused the observed low usage.

The study also found three main factors as affecting the management and usage of ERs in academic libraries in Ghana which were governmental, organisational and individual factors. Governmental factors such as regulations on staffing, inadequate funding, and nationwide rationing of electricity supply were hindrances. At the organisational level, an enabler was 
collaboration with stakeholders, whereas obstacles included inadequate policies, staffing challenges, resource-related factors, lack of investment for sustainability, centralised management structure, low institutional commitment, poor communication, and low usage of ERs. Enabling individual factors consisted of religious beliefs, social influence, oral information, and interest in IT. Hindering individual factors comprised negative effects of oral information, resistance to change, fear of speaking against authority, reluctance to submit contents to institutional repository, negative perception on the ERs and lack of time.

The findings also established various ways in which the management and usage of ERs affected each other. Low user input in the selection of ERs, access related challenges, inadequate publicity, training, and evaluation of ERs negatively affected the usage of ERs. However, case libraries that occasionally allowed users to schedule training sessions observed increased attendance to training with a corresponding increase in ER usage, which provided a basis for institutional budgetary support. On the other hand, failure of users to attend training programmes after signing up, low referral of students to the ERs by faculty and low usage of ERs of the library negatively affected ERM particularly in the areas of budgeting for ER subscription and sustainability. However, faculty and students facilitated the management of ERs of the library in terms of creating awareness of the ERs among their colleagues and peers, and also accessing the resources using mobile devices to supplement the library's inadequate computers.

The TERMS framework and initial conceptual model of factors were revised based on the findings. The study adds to the Library and Information Science research relevant to the understanding of the management and usage of ERs, factors affecting both concepts and how these two concepts are related. In addition, the study contributes to practice by recommending strategies for effective ERM to encourage increased usage of ERs. It is also hoped that academic libraries in other developing countries can draw lessons from the findings. The study also provides advanced countries with a deeper insight to guide them in providing support to developing countries. The findings also have implications for policy and decision makers in terms of prioritisation and allocation of resources for effective ERM and usage in academic libraries as contemporary issues are revealed.

Keywords: Academic institutions, Academic libraries, Electronic resources, Electronic resources in Africa, Electronic resource management, Electronic resource usage 


\section{Dedication}

To the Glory of God Almighty, Jesus Christ and the Holy Spirit, for the Victory Mrs. Elizabeth Bentil

In Loving Memory of Mr. David Bentil 


\section{Acknowledgements}

Firstly, I wish to thank God Almighty for the opportunity to pursue a $\mathrm{PhD}$ study and for His Guidance, Protection and Providence throughout my PhD journey. I give Him all the Glory.

With immense gratitude, I acknowledge the invaluable support and help of my supervisors, Dr Chern Li Liew and Dr Brenda Chawner who stood by me throughout my study. This study would not have been possible without their immense knowledge, patience, kindness, and encouragement. I am also extremely thankful to Dr Daniel Dorner who supervised me at the proposal stage and continued to offer great support throughout my $\mathrm{PhD}$ journey.

I am also grateful to my examination committee; and the School of Information Management (SIM) faculty, staff, and administrative team especially Usha Varatharaju and Chris King for all the support. Special thanks go to Dr Jennifer Campbell-Meier for all the support, Dr Lauren Bennett for proofreading my thesis, and all PhD students for their immense support throughout my study. I wish to acknowledge Prof. Pak Yoong, Dr Janet Toland and Prof. Anne Goulding for their support and sympathy during the passing of my father. The support of other faculty and friends cannot go unacknowledged. I am grateful to Prof. Harry Akussah, Prof. A.A. Alemna, Dr E. Adjei, Dr M. Adams, the late Dr E.D. Markwei and all faculty of the Department of Information Studies (University of Ghana), Dr Louis Boamponsem (Christ Church, NZ), Mr Prosper Akoto (Absa Bank, Ghana), Mrs Priscilla Asare and Vera (Family Renaissance International-Ghana), and Mr Selorm Segbedzi.

My sincerest gratitude goes to Pastors Willard and Peace Katumbu for their immense spiritual support and assistance throughout my $\mathrm{PhD}$ journey, and to the entire membership of Christ for Salvation Ministries International (CFSMI) for all the support. I am also thankful to Rodreck David, Marisa McPherson, Emmanuel Amankwah, Dr Emmanuel and Mrs Olivia Yamoah, Dr Solomon Opare, Dr Setor Donne Novieto, Dr Frederick and Mrs Maud Acheampong, Dr Eric and Mrs Diana Boamah, Kobby and Adjoa Antwi-Boasiako, Bernard Tawiah, Edward Johnson, Kenny and Abigail Graham, Chooi Tan, Suzanna Ida, and the Ghanaian community in Wellington for all the support they provided in diverse ways.

I also thank the university librarians of institutions selected for this study: Prof. Perpetua Dadzie, Dr Mac Anthony Cobblah, Ms Edna Asante, Dr Theresa Adu and Ms Alice Achampong. I am equally thankful to Dr Joel Sam, the Chair of CARLIGH for facilitating this study. I am also indebted to all library staff, faculty and postgraduate students who participated in the study. The ideas they shared were essential to my study.

Finally, I am deeply grateful to the Bentil family especially my siblings for all the support, sponsorship, and encouragement they provided. "Se mennhyia!" 


\section{Table of Contents}

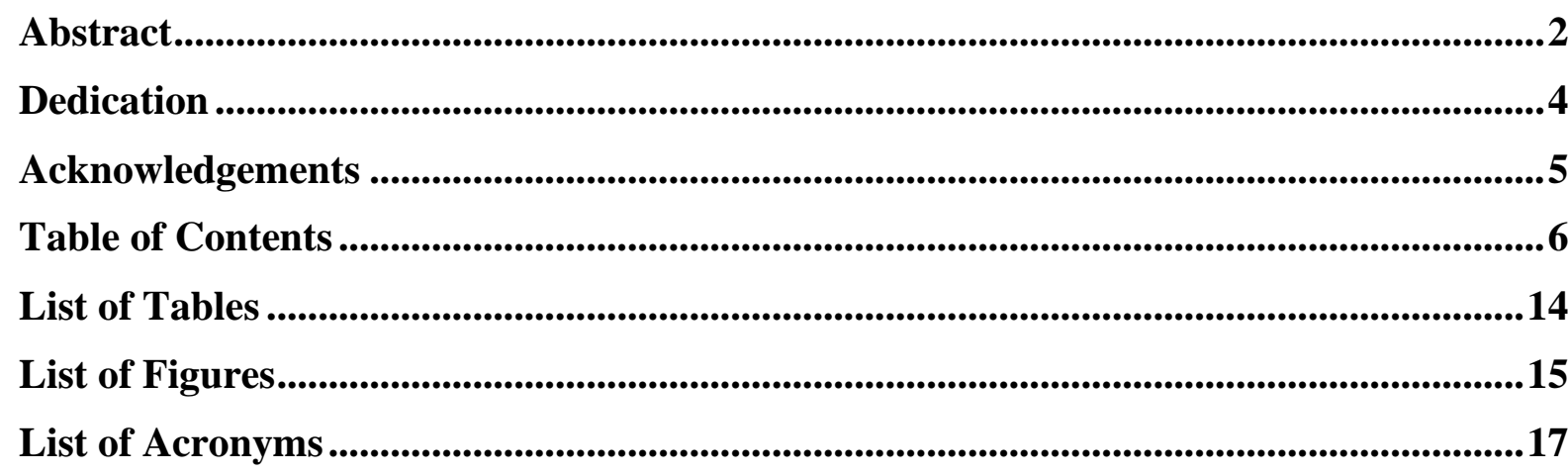

Chapter One Introduction to the Study ....................................................................19

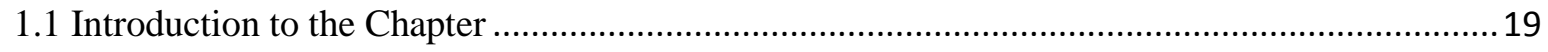

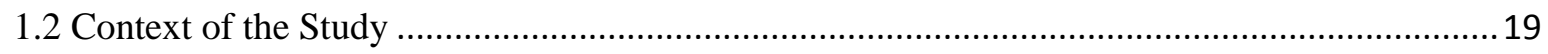

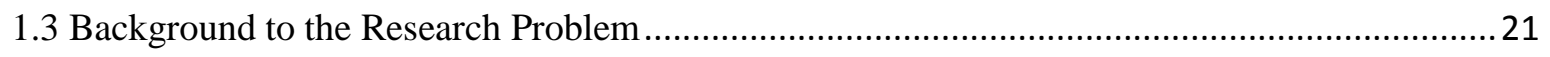

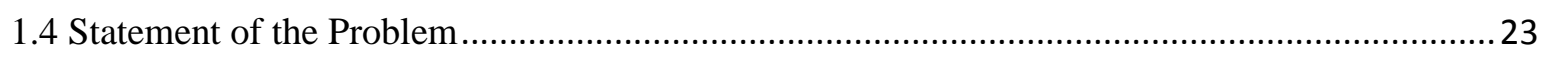

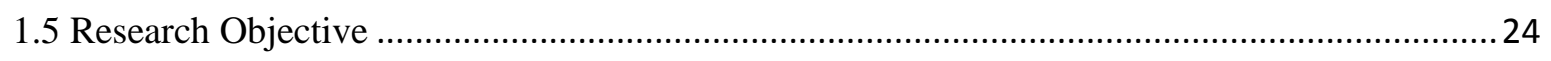

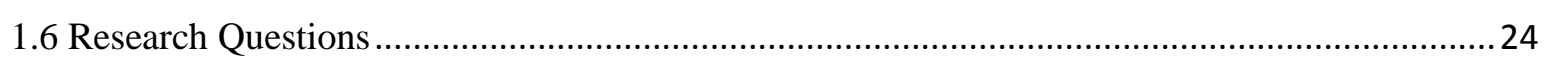

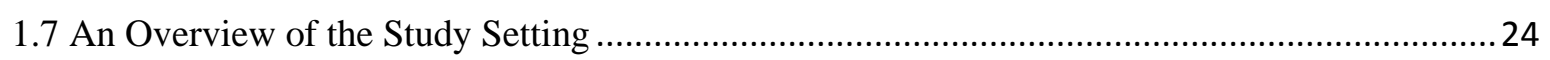

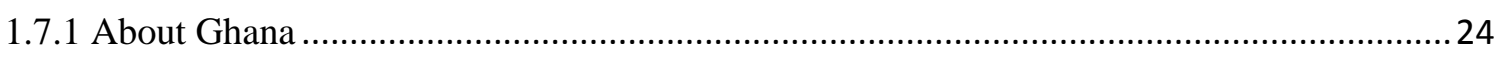

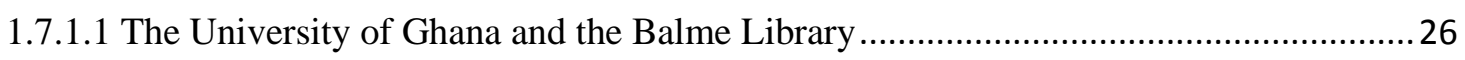

1.7.1.2 The University of Cape Coast and the Sam Jonah Library ........................................26

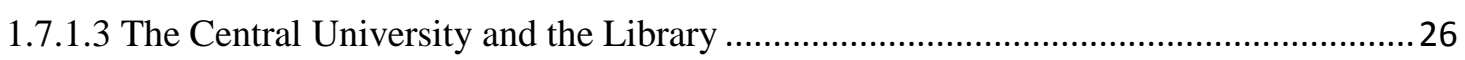

1.7.1.4 Wisconsin International University College and the Library....................................... 26

1.7.2 Access to Electronic Resources in Ghanaian Universities...................................................2 27

1.7.2.1 Access to Electronic Resources through Library Consortium .......................................2 27

1.7.2.2 Access to Electronic Resources Through Institutional Repositories .............................29

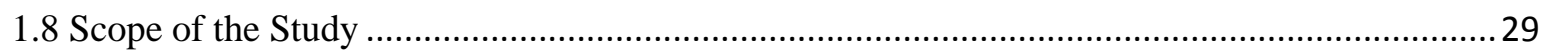

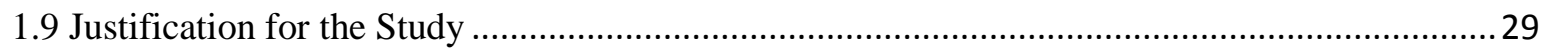

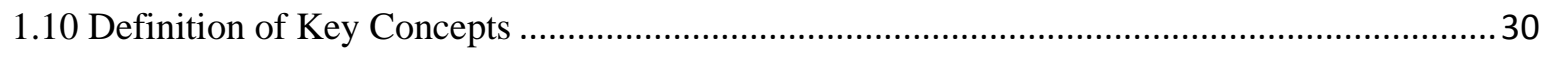

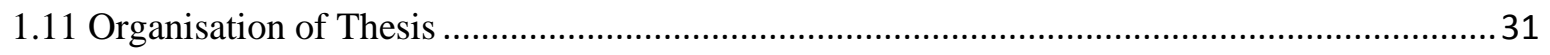

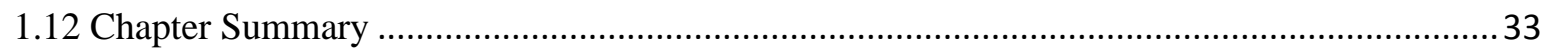

Chapter Two Literature Review .....................................................................................35

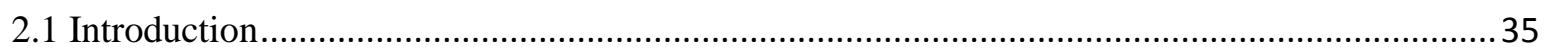

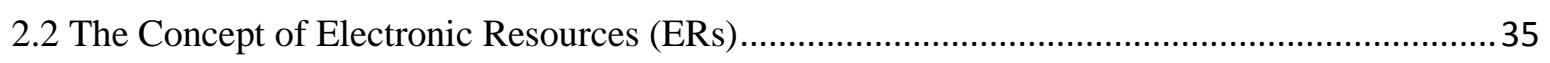


2.3 Impact of Electronic Resources on Academic Libraries......................................................... 37

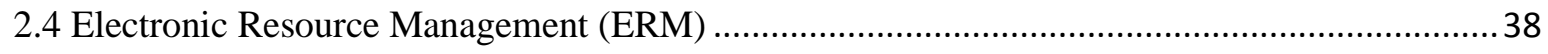

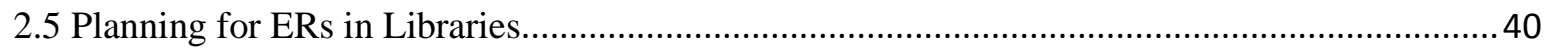

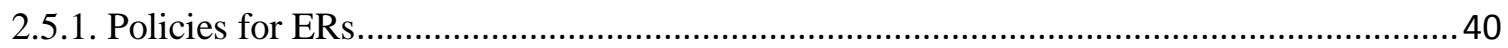

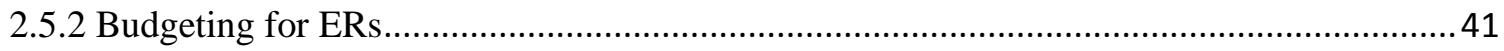

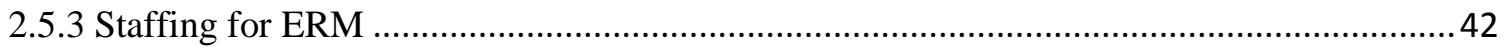

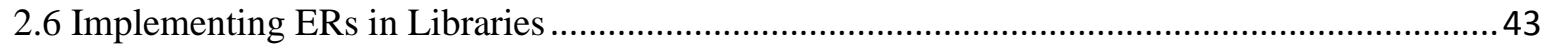

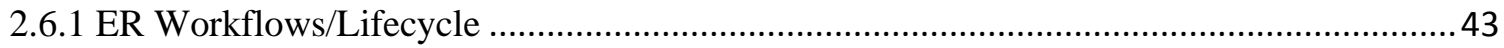

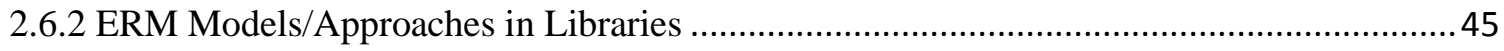

2.6.2.1 An Integrated or Centralised Approach .................................................................... 46

2.6.2.2 A Distributed Approach ............................................................................................. 46

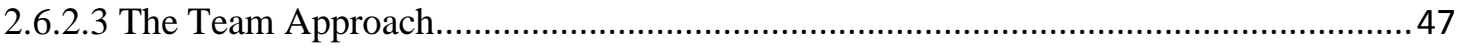

2.7 Contextual Factors Surrounding ERM in Libraries .................................................................. 49

2.7.1 Technical Complexities Associated with ERs ................................................................. 49

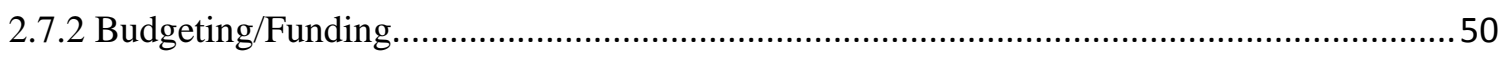

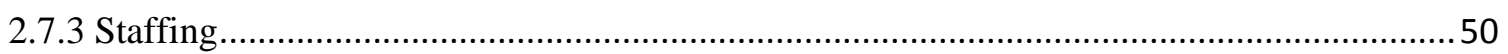

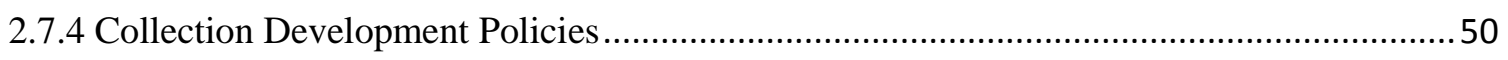

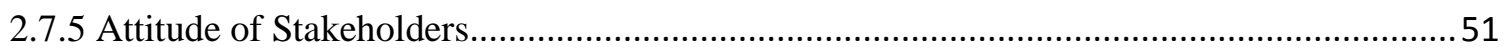

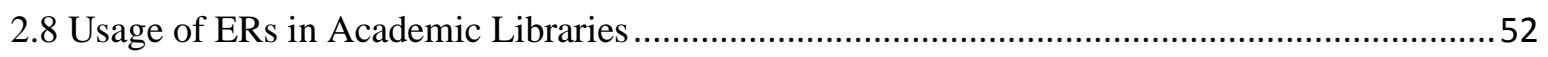

2.8.1 Factors Affecting the Usage of ERs in Academic Libraries ............................................. 52

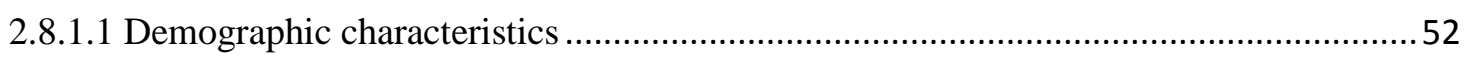

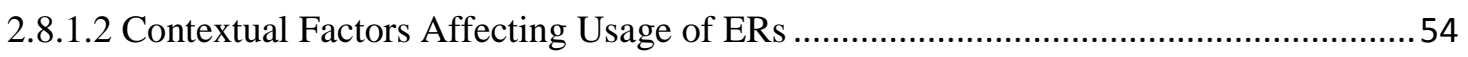

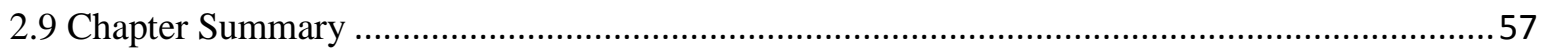

Chapter Three Theoretical Foundations .................................................................59

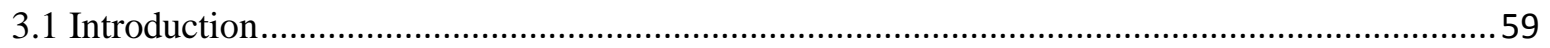

3.2 Justification for Choosing the Selected Theories................................................................... 59

3.3 Techniques for Electronic Resource Management (TERMS)...............................................60

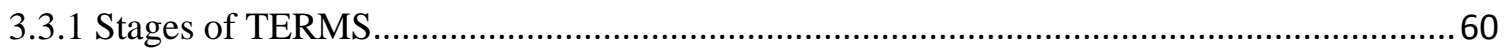

3.3.1.1 Stage One: Investigating New Content for Purchase or Addition ................................ 61

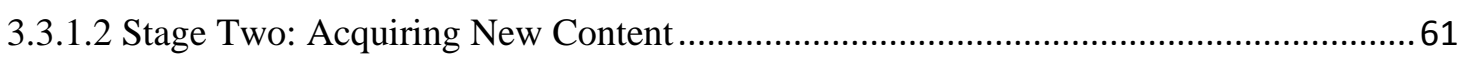

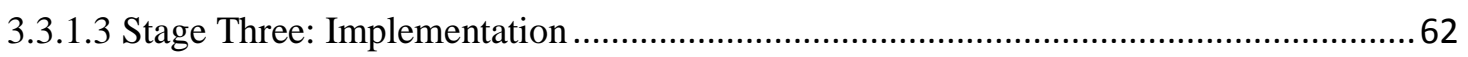

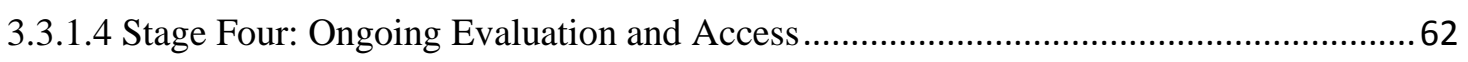

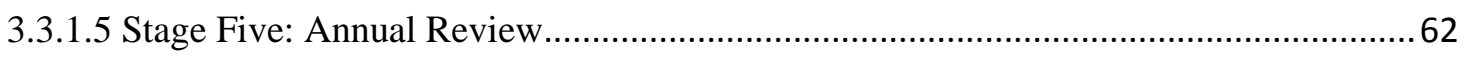

3.3.1.6 Stage Six: Cancellation and Replacement Review .................................................. 62 
3.3.2 Applications of the TERMS Framework

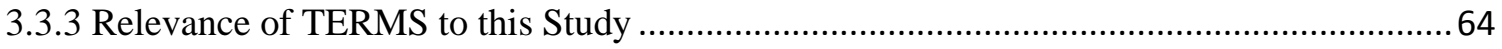

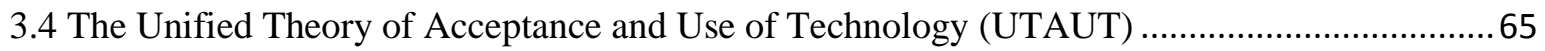

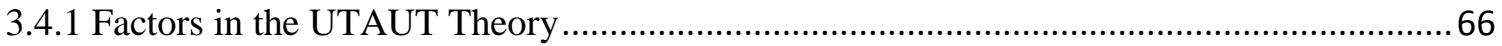

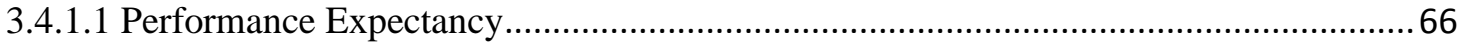

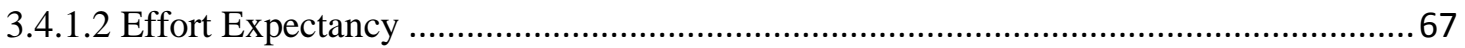

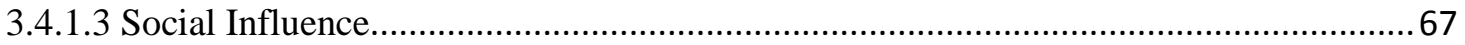

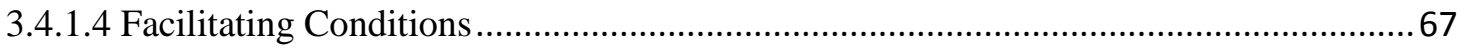

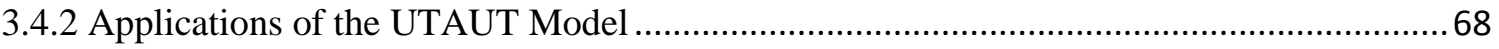

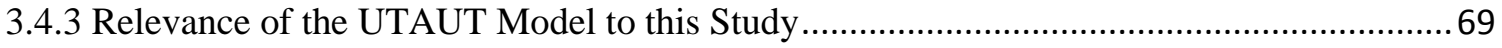

3.5 The Initial Conceptual Framework of Factors Affecting ERM and Usage ................................ 70

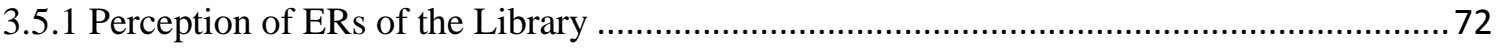

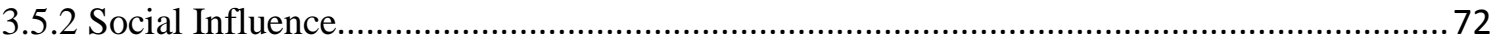

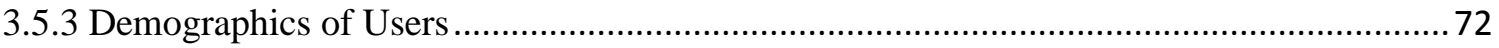

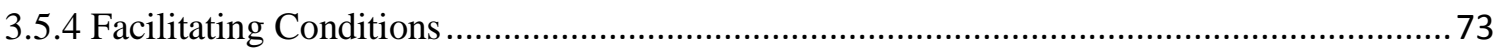

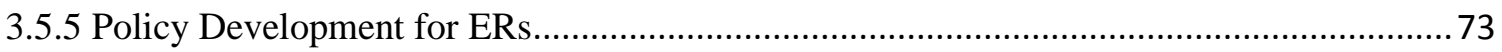

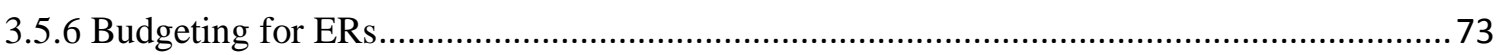

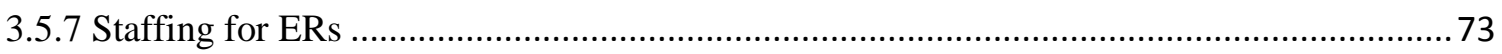

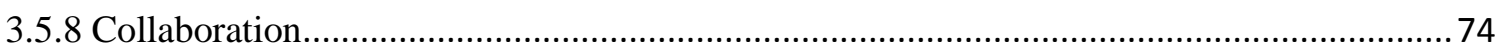

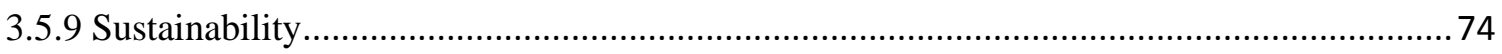

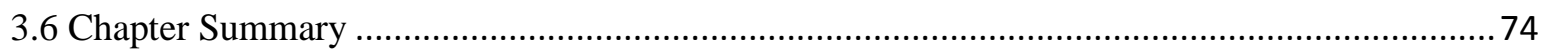

Chapter Four Research Methodology ..................................................................................................... 77

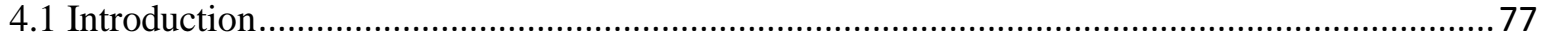

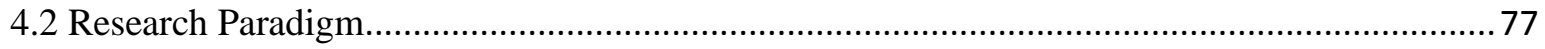

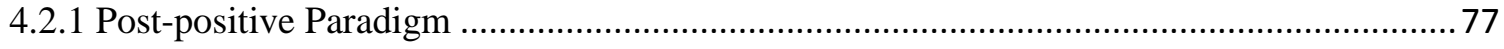

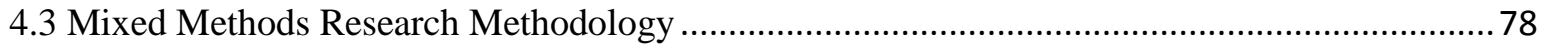

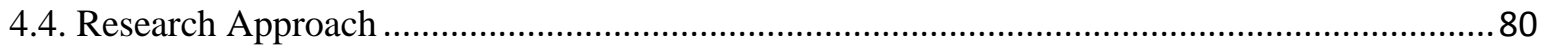

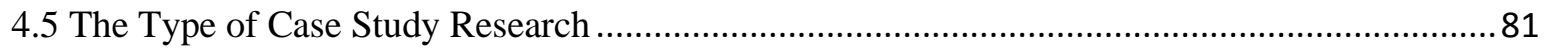

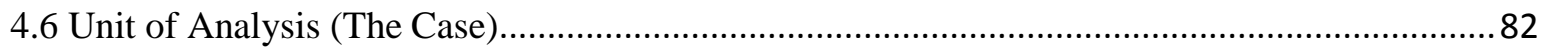

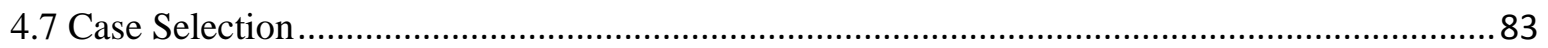

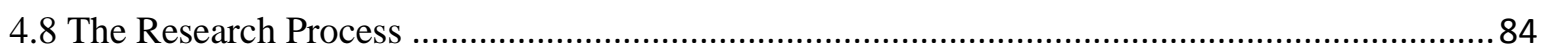

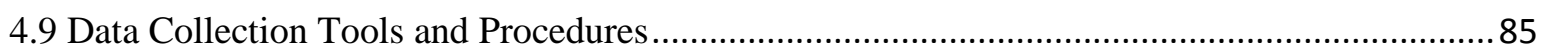

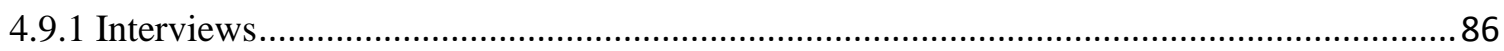

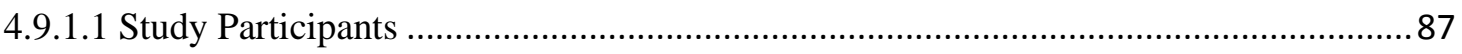




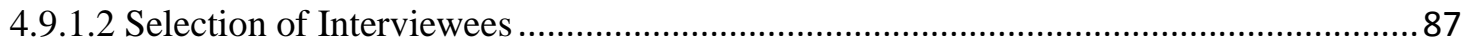

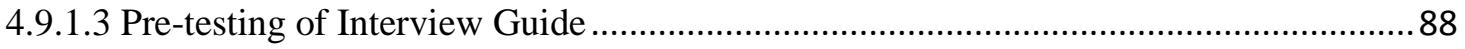

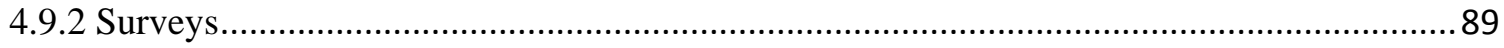

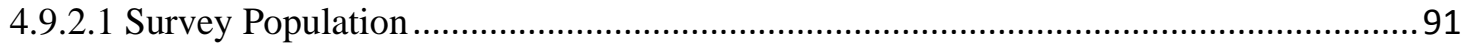

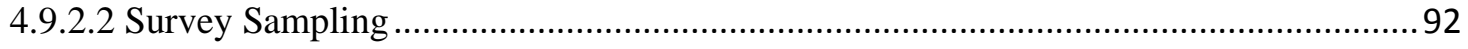

4.9.2.3 Sampling Technique for Survey Respondents ............................................................ 93

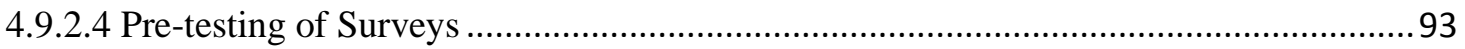

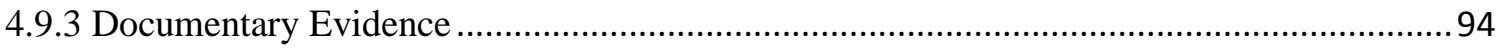

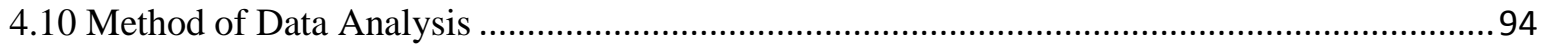

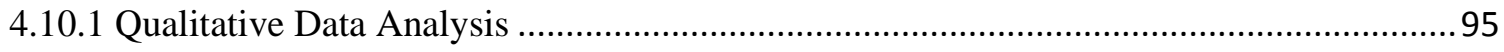

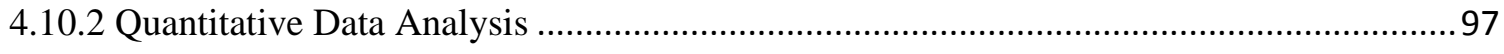

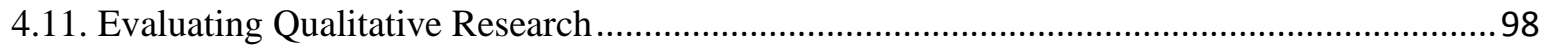

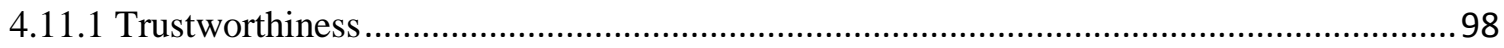

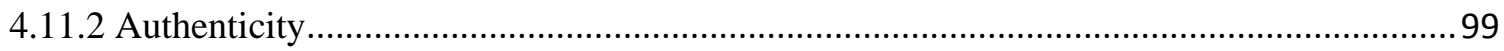

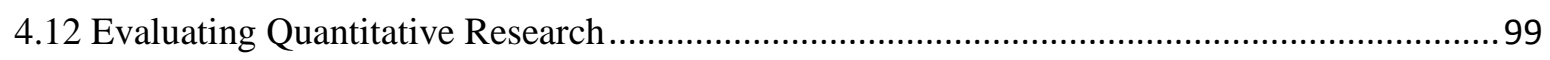

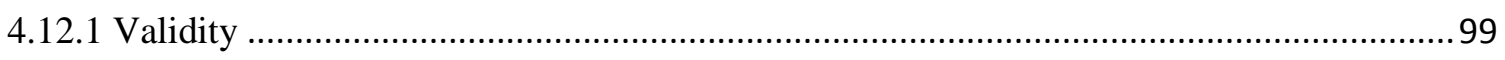

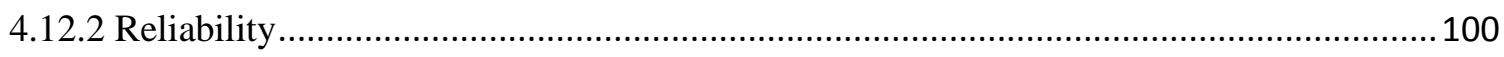

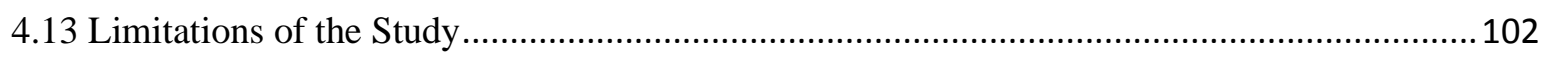

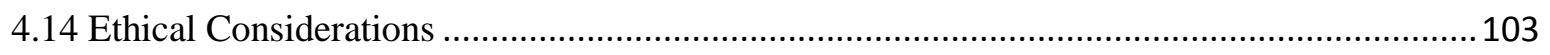

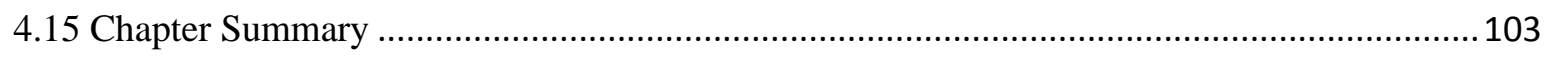

Chapter Five Findings on the Management of ERs.............................................................105

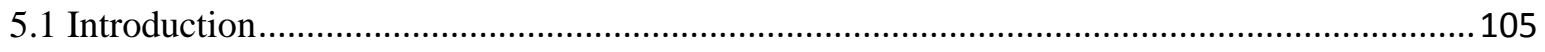

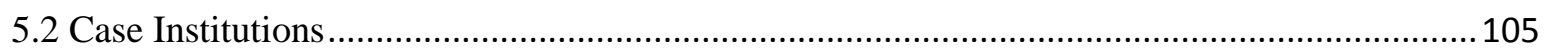

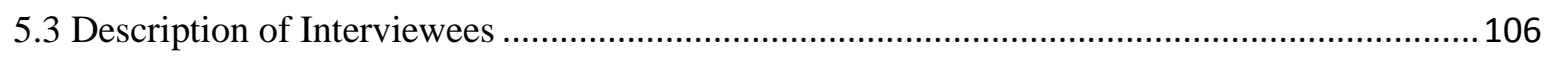

5.4 ERs/ Services and ICT Infrastructure in the Case Institutions................................................. 107

5.4.1 ERs/Services and ICT Infrastructure at The Balme Library (UG) .................................... 107

5.4.2 ERs/Services and ICT Infrastructure at The Sam Jonah Library (UCC) ...........................108

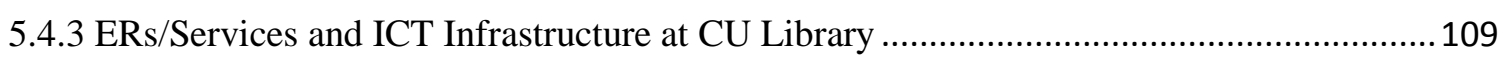

5.4.4 ERs/Services and ICT Infrastructure at WIUC Library ................................................... 109

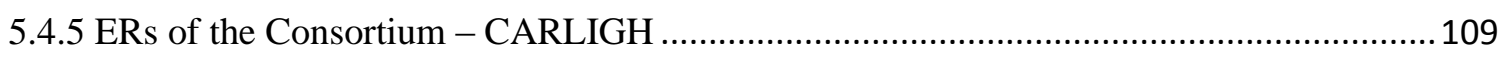

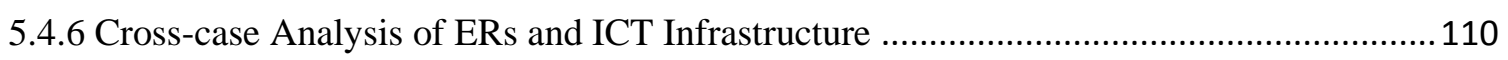

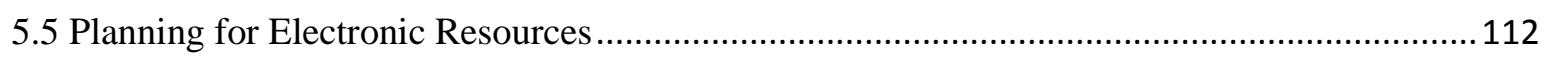

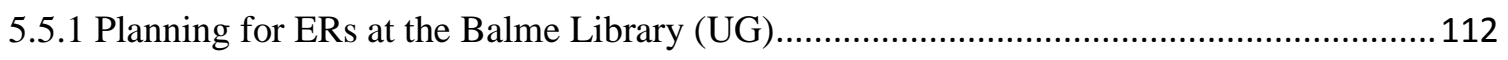

5.5.2 Planning for ERs at the Sam Jonah Library (UCC) ..................................................... 114 


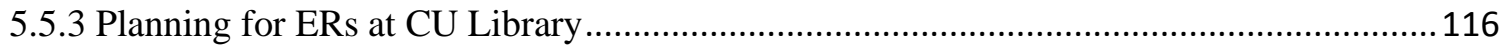

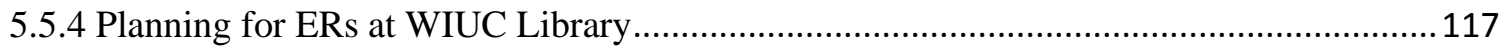

5.5.5 Planning for ERs at the Consortium Level ............................................................... 118

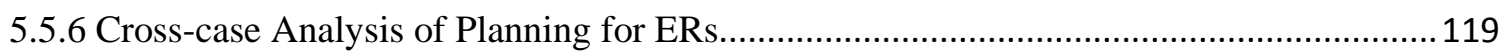

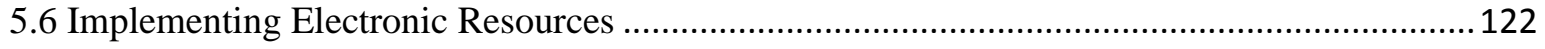

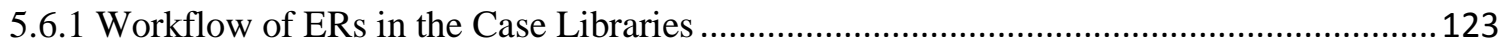

5.6.1.1 Workflow of ERs at the Balme Library (UG) ..........................................................123

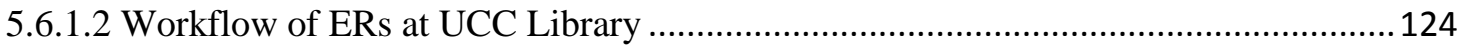

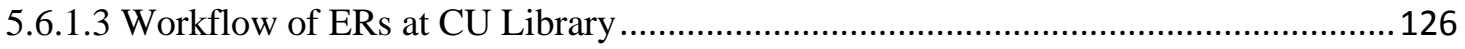

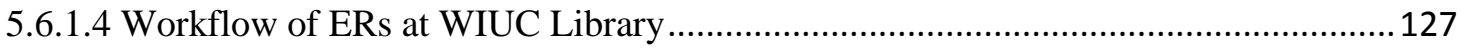

5.6.1.5 Workflow of ERs at the Consortium Level.............................................................. 128

5.6.1.6 Cross-case Analysis of workflow of ERs................................................................. 129

5.6.2 ERM Model/Approach Adopted by Case Libraries .......................................................... 134

5.7 Analysis of Collection Development Policies of Case Institutions..........................................136

5.8 Factors Affecting the Management of Electronic Resources................................................. 141

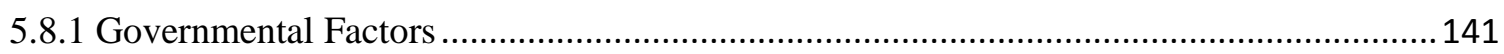

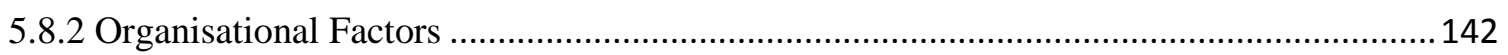

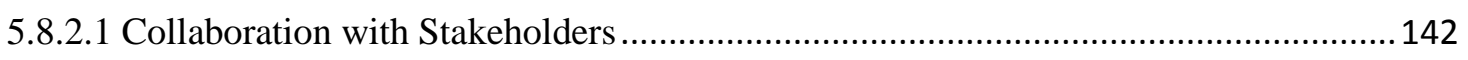

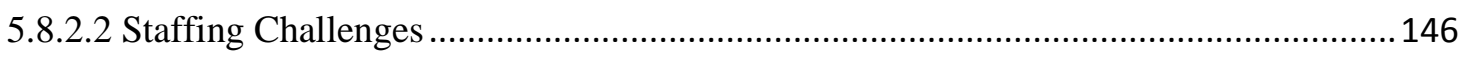

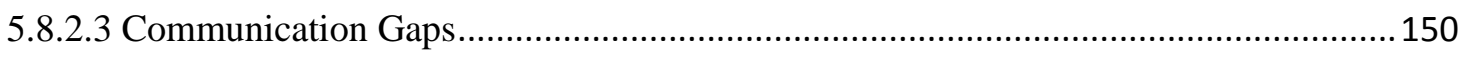

5.8.2.4 Consortium Cost Sharing Model Concerns............................................................ 151

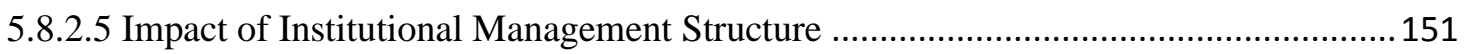

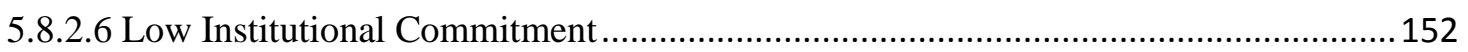

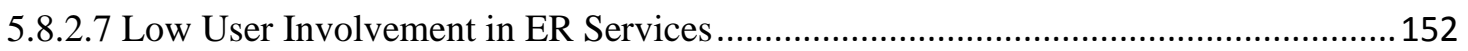

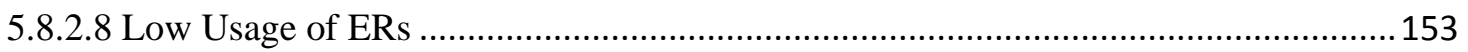

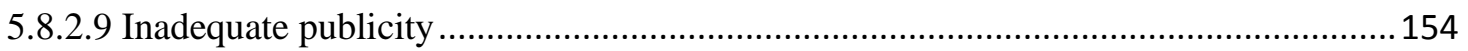

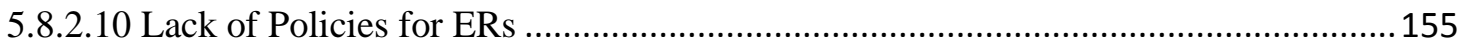

5.8.2.11 Resource-Related Factors as a Hindrance to ERM ...................................................157

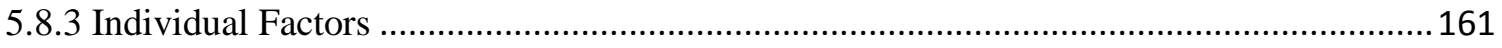

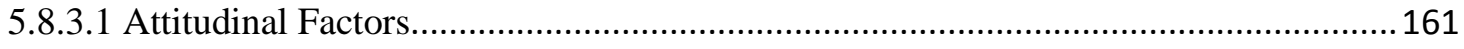

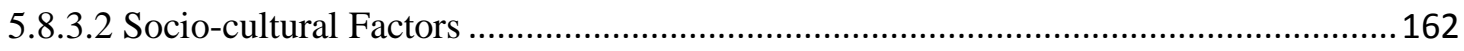

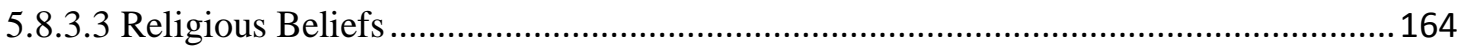

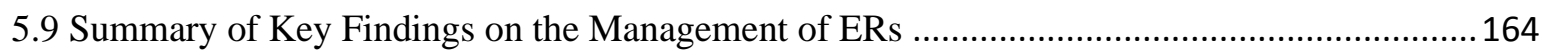

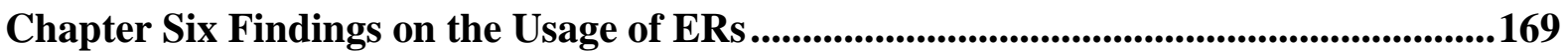

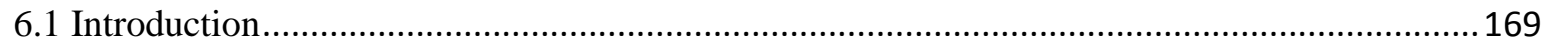




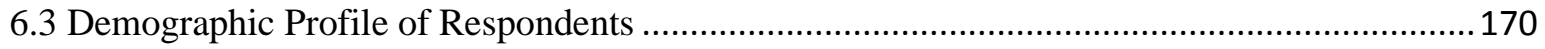

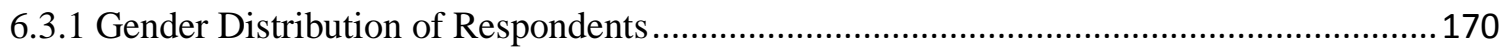

6.3.2 Age Distribution of Respondents from Case Institutions................................................. 171

6.3.3 Discipline Distribution of Respondents in the Case Institutions.......................................172

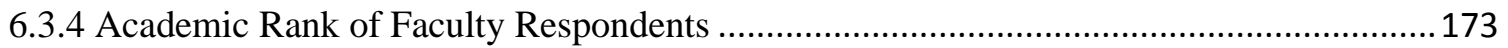

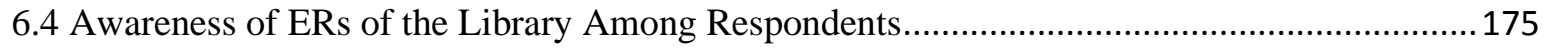

6.4.1 Channel/Mode of Awareness of ERs Among Respondents.............................................176

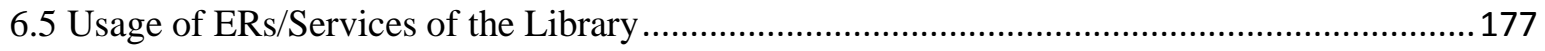

6.5.1 Types of ERs/Services Used in the Case Institutions .......................................................178

6.5.2 Time Spent in Using the ERs of the Library ..................................................................... 179

6.5.3 Location/Device for Accessing the ERs of the Library ……........................................... 180

6.5.4 Information Search Strategies of Respondents ................................................................ 181

6.5.5 Mode of learning to how to use the library's ERs ......................................................... 182

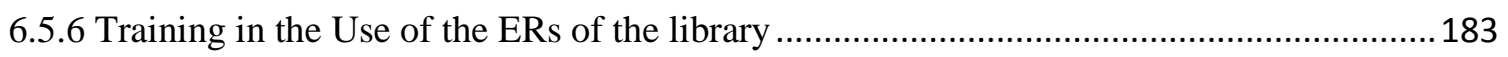

6.6 Perception and Behaviour of Respondents Towards the ERs of the Library ............................184

6.7 Respondents' Participation in the Implementation of ERs ...................................................186

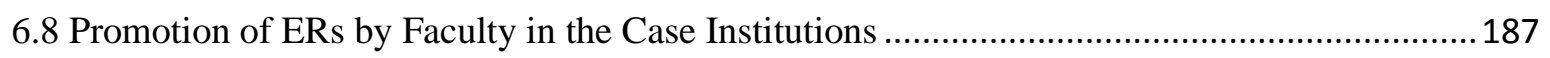

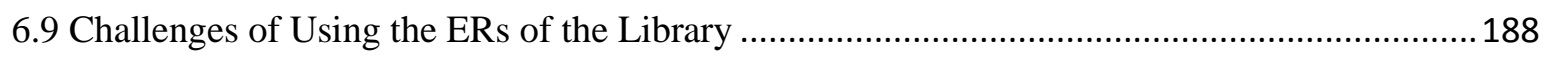

6.9.1 A National Factor as a Challenge of Using ERs of the Library ........................................189

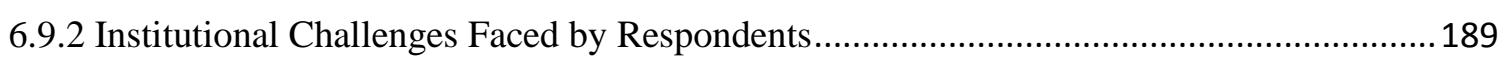

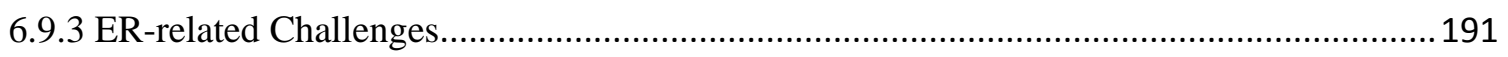

6.9.4 An Individual Factor as a Challenge of Using ERs of the Library ................................... 192

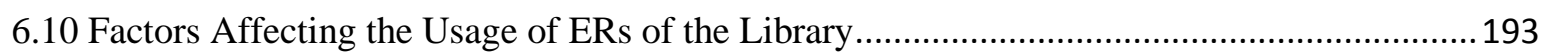

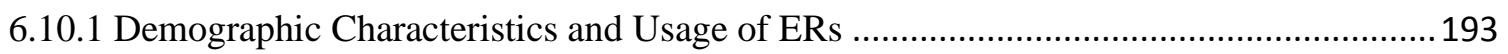

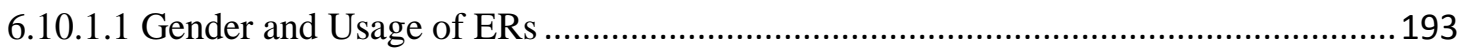

6.10.1.2 Age and Usage of ERs in the Case Institutions....................................................194

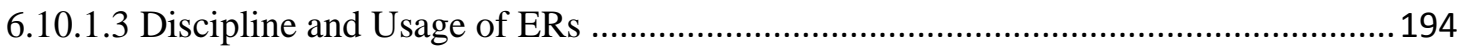

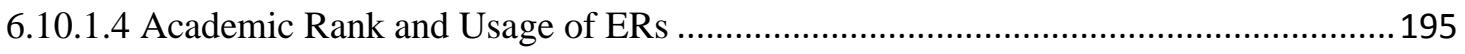

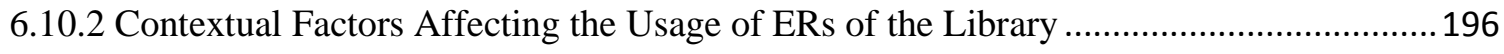

6.10.2.1 Performance Expectancy and Usage of ERs of the Library ......................................196

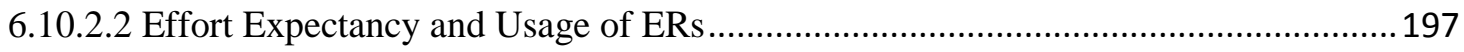

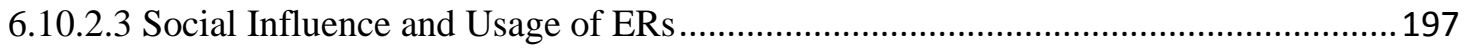

6.10.2.4 Facilitating Conditions and Usage of ERs ...........................................................20

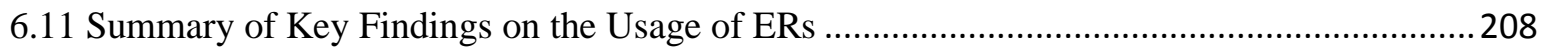




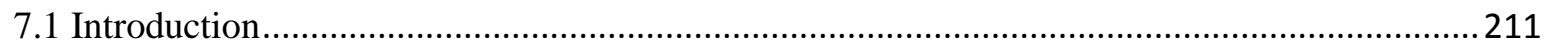

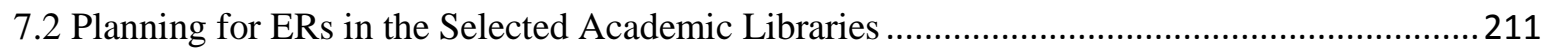

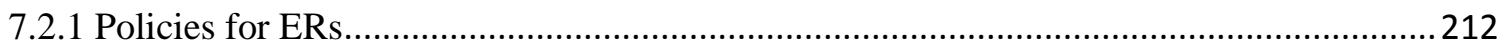

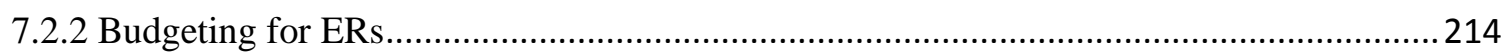

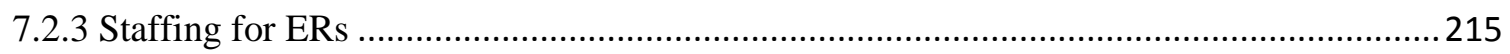

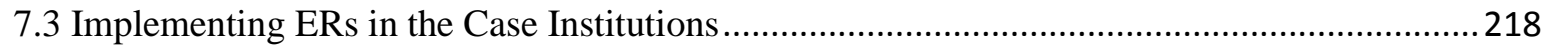

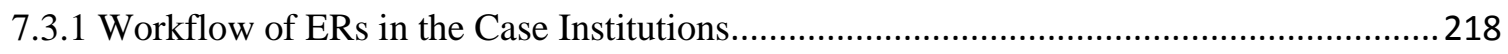

7.3.2 ERM Approach/Model Adopted by Case Libraries........................................................222

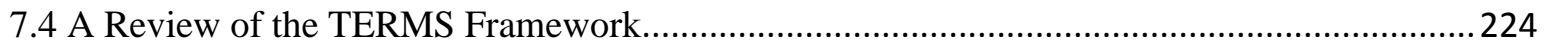

7.4.1 Mapping the TERMS Framework Components to the Findings.........................................224

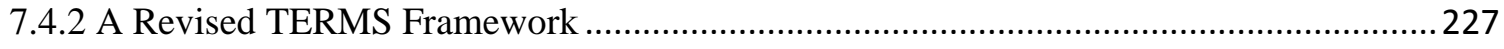

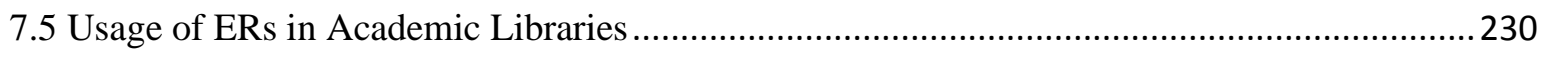

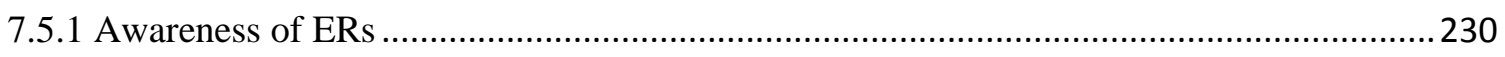

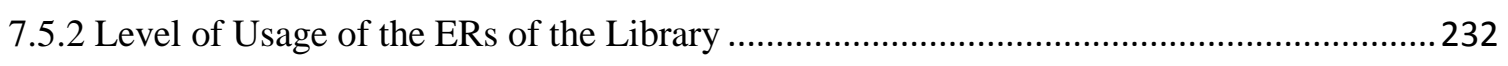

7.5.3 Perception and Behaviour Towards ERs of the library ...................................................234

7.6 Factors Affecting the Management and Usage of ERs .........................................................2. 236

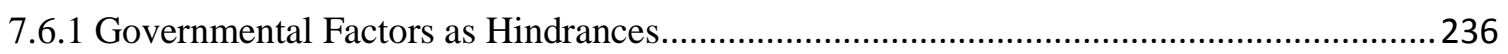

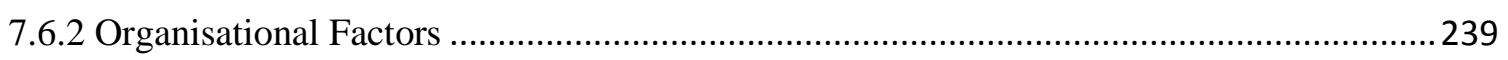

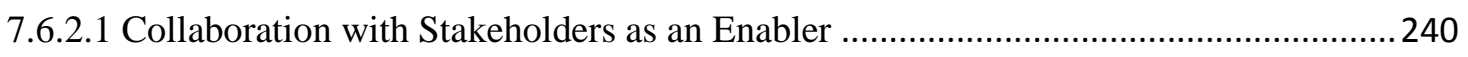

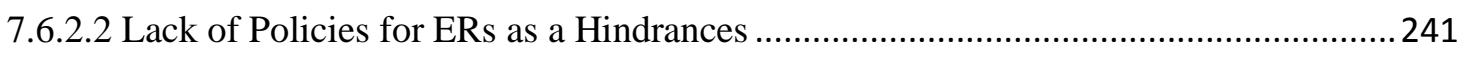

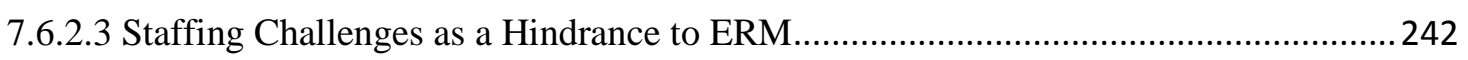

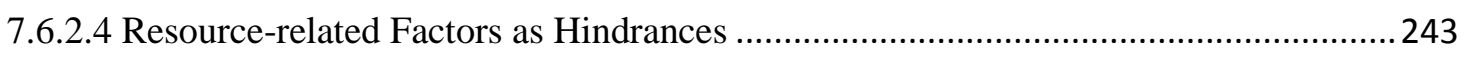

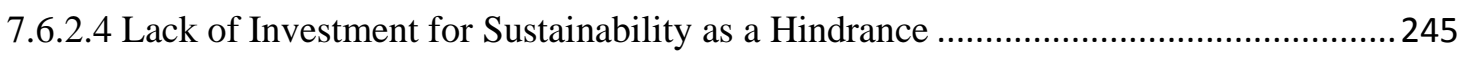

7.6.2.5 Centralised Management Structure as a Hindrance ...................................................2.246

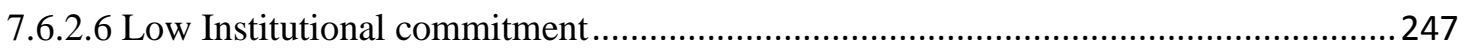

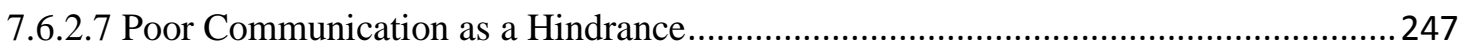

7.6.2.8 Consortium Cost Sharing Model as a Hindrance .....................................................249

7.6.2.9. Low Usage of ERs of the Library as a Hindrance....................................................250

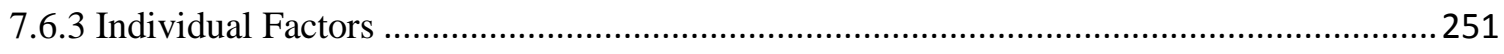

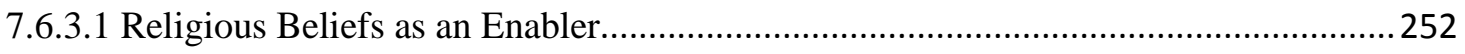

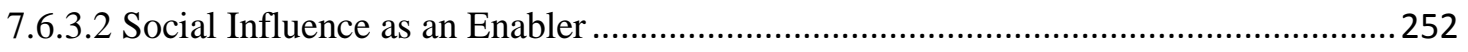

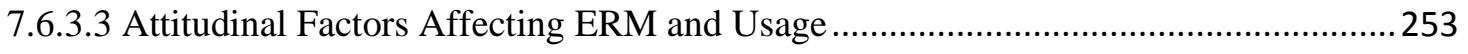

7.6.3.4 Negative Perception of Users on the ERs of the Library ….......................................25

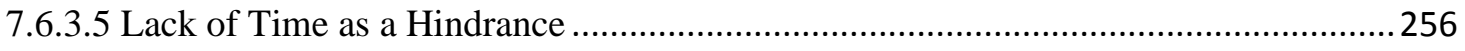

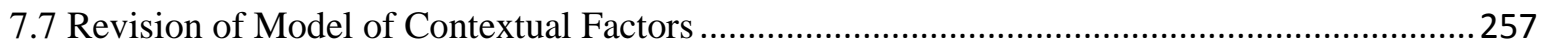


7.7.1 Change Between Initial and Revised Models of Factors of ERM and Usage.

7.7.2 The Revised Model of Factors Affecting the Management and Usage of ERs .................257

7.8 How the Management and Usage of ERs of the Library are Related ......................................260

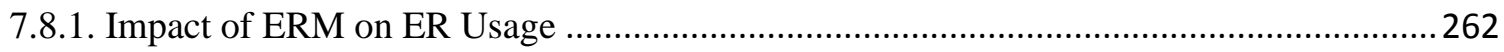

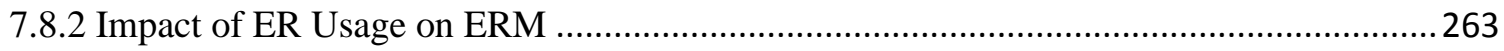

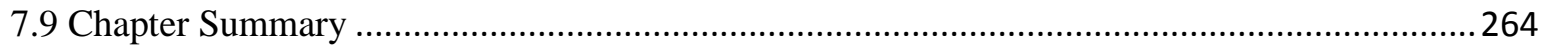

Chapter Eight Summary, Research Implications and Conclusion .....................................267

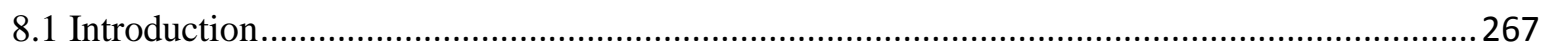

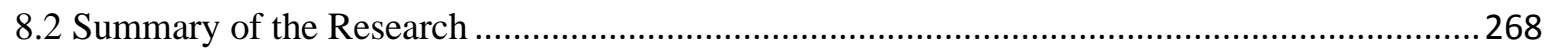

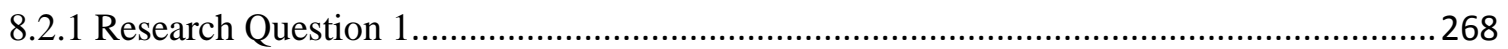

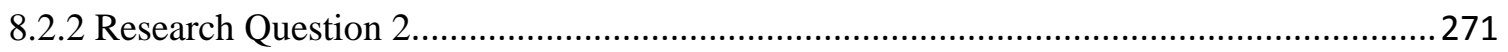

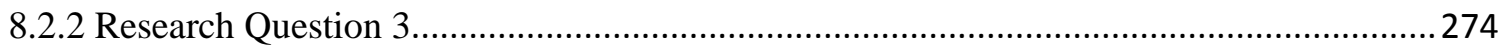

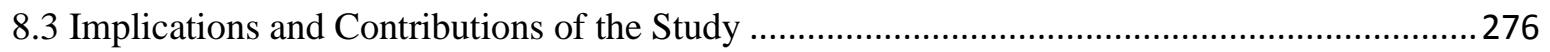

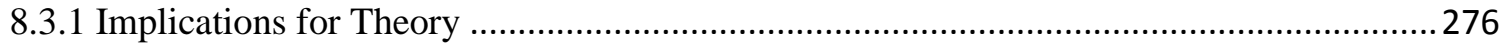

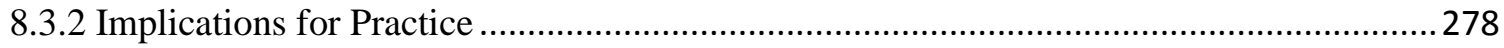

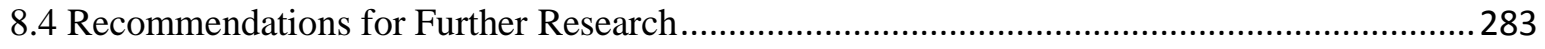

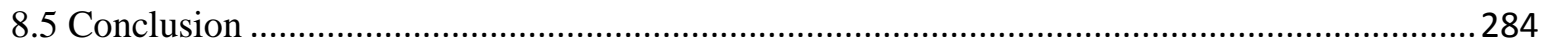

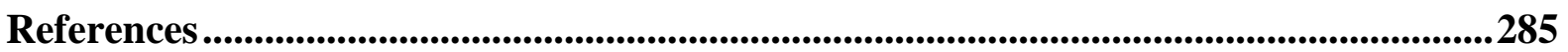

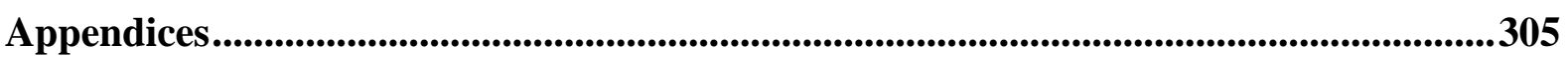

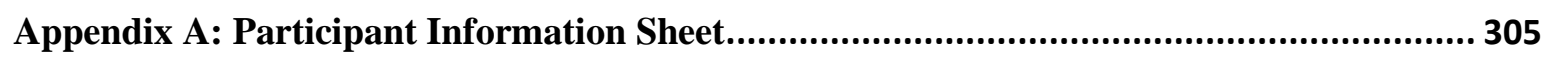

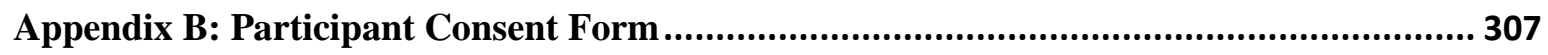

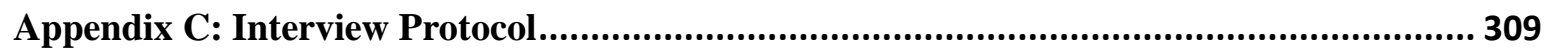

Appendix D: Survey Questionnaire on the Usage of E-Resources ..................................... 319 


\section{List of Tables}

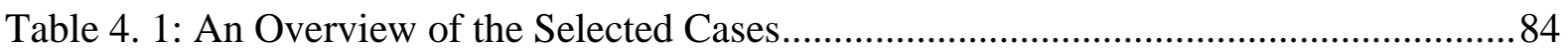

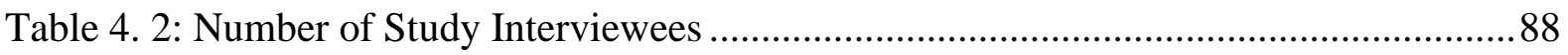

Table 4. 3 Population and Sample Sizes of Respondents ....................................................93

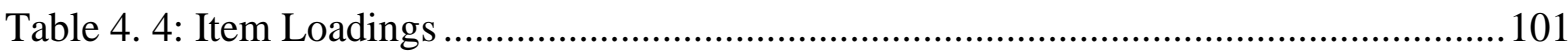

Table 4. 5: Overview of Constructs and Measurement Model ............................................ 102

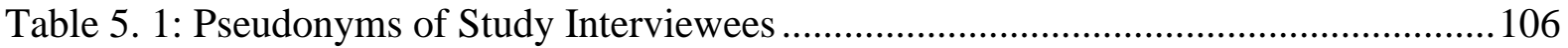

Table 5. 2: ER Services and ICT Infrastructure in the case libraries.................................... 111

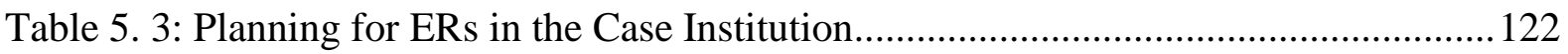

Table 5. 4: A Summary of the Workflow of ERs in the Case Institutions and CARLIGH ... 132

Table 5. 5: A summary of the ERM Approach/Model Adopted in the Case Institutions...... 135

Table 5. 6: CDP Evaluation Tool (Mangrum \& Pozzebon, 2012)........................................ 137

Table 5. 7: Analysis of CDPs of UCC, CU and WIUC libraries ........................................ 138

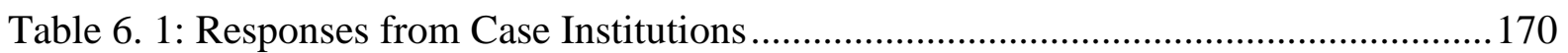

Table 6. 2a: Age Distribution of Faculty Respondents ......................................................... 172

Table 6. 2b: Age Distribution of Postgraduate Respondents .............................................. 172

Table 6. 3a: Awareness of ERs Among Faculty Respondents........................................... 175

Table 6. 3b: Awareness of ERs Among Postgraduate Respondents.................................... 175

Table 6. 4a: Channels of Awareness of ERs Among Faculty Respondents ......................... 176

Table 6. 4b: Channels of Awareness of ERs Among Postgraduate Respondents .................176

Table 6. 5a: Usage of the Various ERs/Services by Faculty Respondents ............................ 178

Table 6. 5b: Usage of the Various ERs/Services by Postgraduate Respondents .................... 178

Table 6. 6a: Hours Spent by Faculty Respondents in Using ERs of the Library ................... 179

Table 6. 6b: Hours Spent by Postgraduate Respondents in Using ERs of the Library ........... 179

Table 6. 7a: Location/Device for Accessing the ERs of the Library by Faculty Respondents

Table 6. 7b: Location/Device for Accessing the ERs of the Library by Postgraduates......... 180

Table 6. 8a: Perception and Behaviour of Faculty Towards ERs of the Library ................... 185

Table 6. 8b: Perception and Behaviour of Postgraduate Towards ERs of the Library ........... 185

Table 6. 9a: Participation of Faculty Respondents in ER Implementation............................ 187

Table 6. 9b: Participation of postgraduate Respondents in ER Implementation ....................187 
Table 6. 10: A Cross-tabulation of Gender and Usage of ERs 193

Table 6. 11: A Cross-tabulation of Age and Usage of ERs 194

Table 6. 12: A Cross-tabulation of Discipline of Respondents and Usage of ERs 194

Table 6. 13: A Cross-tabulation of Academic Rank of Faculty and Usage of ERs 195

Table 6. 14: A Cross-tabulation of Performance Expectancy and Usage of ERs. 196

Table 6. 15: A Cross-tabulation of Effort Expectancy and Usage of ERs 197

Table 6. 16: A Cross-tabulation of Publicity by the Library and Usage of ERs. 198

Table 6. 17: A Cross-tabulation of Recommendations by Colleagues and Usage of ERs .... 198

Table 6. 18: A Cross-tabulation of Promotion by Faculty and Usage of ERs by Students ... 199

Table 6. 19: Association Between Course Work Assignments and Usage of ERs................200

Table 6. 20: A Cross-tabulation of Searching Skills and Usage of ERs...............................201

Table 6. 21: A Cross-tabulation of Participation in ER Training and Usage of ERs ............202

Table 6. 22: A Cross-tabulation of Recommending ERs to the Library and Usage of ERs ..203

Table 6. 23: A Cross-tabulation of Participation in ER Trial and Usage of ERs ..................203

Table 6. 24: A Cross-tabulation of Opportunity for Feedback and Usage of ERs ................204

Table 6. 25: A Cross-tabulation of Participation in ER Assessment and Usage of ERs .......205

Table 6. 26: A Cross-tabulation of Ease of Access and Usage of ERs ..................................205

Table 6. 27: A summary of Chi-square Tests of Factors Affecting the Usage of ERs ..........207

\section{List of Figures}

Figure 1. 1. Ghana depicted on the West Africa map (Google Maps, 2017)........................25

Figure 3. 1. The TERMS framework (Emery \& Stone, 2013) ............................................61

Figure 3. 2. The UTAUT model (Venkatesh, Morris, Davis \& Davis 2003) .........................66

Figure 3. 3. Initial conceptual model of factors that guided exploration of ERM and usage

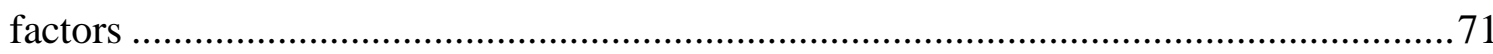

Figure 4. 1. The convergent parallel design (Adapted from Creswell \& Plano-Clark, ,..........80

Figure 4. 2. Basic types of case study design (Adapted from Yin, 2014, p. 50) ..................... 82

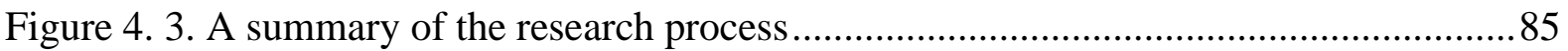

Figure 4. 4. Qualitative data analysis procedures (Adapted from Miles \& Huberman, 1994) 95

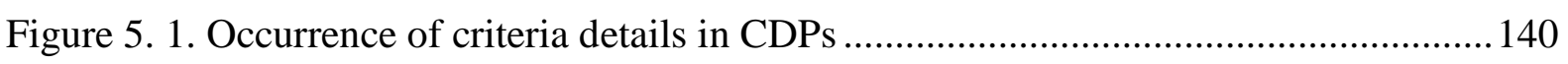

Figure 6. 1. Gender distribution of faculty and postgraduate respondents ..........................171 
Figure 6. 2. Discipline distribution of respondents in the case institutions

Figure 6. 3. Academic rank of faculty respondents from the case institutions ..................... 174

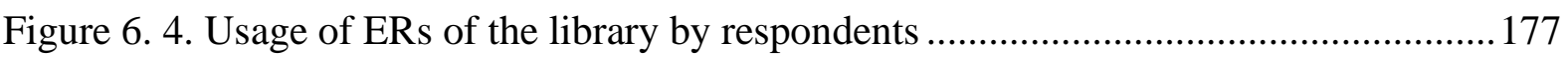

Figure 6. 5. Information search strategies of respondents in case institutions ..................... 181

Figure 6. 6. Mode of learning how to use the ERs of the library ....................................... 182

Figure 6. 7. Participation in training on ERs of the library................................................. 183

Figure 6. 8. Promotion of ERs of the library by faculty respondents .................................. 188

Figure 6. 9. A national factor as a challenge of using ERs of the library ............................. 189

Figure 6. 10. Institution-related challenges faced by respondents ...................................... 190

Figure 6. 11. ER-related challenges encountered by respondents ....................................... 191

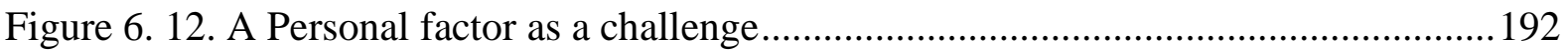

Figure 7. 1. Matching TERMS framework components to the findings .............................225

Figure 7. 2. Revised TERMS framework based on the findings ......................................228

Figure 7. 3. Government factors as hindrances to ERM and usage ....................................2237

Figure 7. 4. Organisational factors affecting the management and usage of ERs ................239

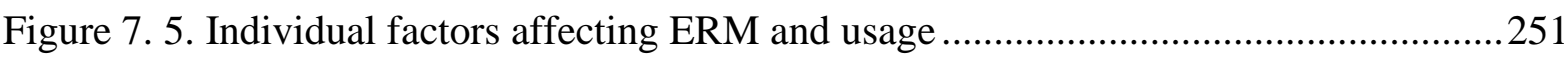

Figure 7. 6. Model of factors affecting the management and usage of ERs in Ghana .........259

Figure 7. 7. Association between management and usage of ERs........................261 


\section{List of Acronyms}

Acronym

Meaning

CARLIGH Consortium of Academic and Research Libraries in Ghana

CDP Collection development policy

CU Central University

DANIDA Danish International Development Agency

EIFL Electronic Information for Libraries

ERs $\quad$ Electronic resources

ERM Electronic resource management

ICT Information Communication Technology

INASP International Network for the Availability of Scientific Publications

IR Institutional repository

IT Information Technology

LIS Library and Information Science

PERI Programme for Enhancement of Research Information

TERMS Techniques for Electronic Resource Management

UCC University of Cape Coast

UG University of Ghana

UTAUT Unified Theory of Acceptance and Use of Technology

WIUC Wisconsin International University College 


\section{Chapter One \\ Introduction to the Study}

\subsection{Introduction to the Chapter}

This chapter introduces the research by presenting the context and background to the research problem, a statement of the problem, followed by the research objective and research questions that guided the exploration of the phenomenon. Then follows an overview of the study setting, a discussion of the scope of the study, justification for the research, definition of key concepts in the study and organisation of the thesis.

\subsection{Context of the Study}

Advances in computer applications with the attendant information explosion in the last three decades have brought radical changes in the way information is managed from creation through storage to retrieval. All around the world, governments, individuals and organisations including libraries have embraced information technologies. Whereas about two decades ago, information and communication technologies were considered as technologies used only in developed countries, today, they are recognised as valuable resources in countries worldwide including developing countries. The invention of computers in 1949 heralded the creation of electronic resources (ERs) and the first database for searching was developed in the early 1960s (Meadow, 1988).

ERs can be defined as information resources that are created, generated, sent, communicated, received, or stored by electronic means (Millar, 2009). These resources come in various forms - E-databases, E-Journals, E-books, E-theses, E-data archives, E-manuscripts, E-maps, Emagazines, E-newspaper, E-research reports, E-bibliographic databases. Research has it that, libraries were among the first adopters of information technology and the first automated systems were developed in the 1960s, with the first online ones, such as Dialog and Orbit, appearing in the early 1970s (Greig, 2014; Hawthorne, 2008). The concept of ERs in academic libraries has become a global phenomenon due to technological developments which have impacted on scholarly communication, teaching, and learning in higher education. ERs are changing the expectations of library users as well as the nature of the work of librarians (Elguindi \& Schmidt, 2012). The main impetus for the adoption of ERs in libraries are the core 
values of librarianship which strive to provide timely and convenient access to information to the user (Hawthorne, 2008).

Libraries have experienced a great change in their collection development and service structure in recent years (Akussah et al., 2015; Ani \& Ahiauzu, 2008). With the introduction of new and rapidly changing technologies and overabundance of digital information in many formats, academic libraries are now being challenged to restructure their services and adopt innovative strategies such as research assistance, collaboration with faculty, user education and provision of access to ERs (Franklin, 2012; Jaguszewski \& Williams, 2013). As libraries rely more on ERs, effective management of these resources becomes crucial to their survival (England \& Miller, 2016). Electronic resource management (ERM) involves overseeing all aspects of ERs including operations and systems that are created to manage these resources in libraries from pre-selection activities to renewal or cancellation decisions (England \& Miller, 2016; Bothmann \& Holmberg, 2008).

Managing ERs is a complicated task which is exacerbated by their rapid growth and the changing IT landscape. Studies have revealed that many libraries attempt to adopt the print workflow in managing ERs which results in inefficiencies and lack of control (Bothmann \& Holmberg, 2008; Ohler et al., 2016). Tasks associated with ERs are less routine and constantly changing making it difficult for libraries to successfully deal with (Elguindi \& Schmidt, 2012; Jacobs, 2007). Further challenges are posed by the emergence of other resources on the Internet which appear to be competing with libraries over users. These resources are gradually breaking the monopoly of academic libraries as the sole source of scholarly information. The Web with its attendant Google and other search engines which appear to be more sophisticated and yet user friendly (Jacobs, 2007) has raised the expectations of students and faculty. Rival free and open access resources provide users with a standard for comparing and assessing library services and selecting gratifying options, which could contribute to the well-known phenomenon of low usage of ERs in libraries (Hsiung, 2008; Sorensen \& Sarjeant-Jenkins, 2016).

These challenges are further compounded by pressure from parent institutions that require academic libraries to prove their relevance in this technological era to justify financial investments. Parent institutions are also experiencing the consequences of changing times. In attempting to be accountable to stakeholders, parent institutions are left with no option than to 
adjust priorities. This affects all units of the institution and the library is no exception. Each unit in the institution is required to highlight its role in helping to achieve the mission of the institution. Academic libraries are consequently required to demonstrate value and justify the use of limited resources that are on high demand in their parent institutions (Taylor \& Heath, 2012).

The pace of change, pressure from parent institutions, and demand for new services owing to technological advancements present academic libraries with the challenge to respond to the information needs of students and researchers in a proactive way. A change in the practices and work of libraries therefore is of paramount significance (Sorensen \& Sarjeant-Jenkins, 2016; Farley et al., 1998; Lewis, 2007; Stoffle et al., 1996). Despite the challenges brought by technological developments, these technologies offer academic libraries opportunities to be dynamic and innovative by restructuring their practices and services to remain relevant.

\subsection{Background to the Research Problem}

Emerging technologies have transformed most traditional libraries into hybrid libraries providing electronic and print resources both in the developed and developing countries. ERs serve as gateways to information and knowledge providing support for teaching, learning and research (Dadzie \& Walt, 2015). Technology in sub-Saharan African universities has evolved at a slow pace which is attributed among other factors to budgetary constraints, high cost of ICT facilities, inadequate ICT skills, unstable power supply, and lack of ICT strategies and policies (Thompson \& Pwadura, 2014).

Academic libraries in Africa have been selecting, acquiring, and providing electronic information services to the academic user community for over a decade (Kiondo, 2004). Ghana has not been left out. Public university libraries in Ghana began computerisation from the mid1980 s and some of them were initially successful in providing services like access to CDROMs, Internet connectivity and access to databases of full text journal articles and abstracts (Dadzie, 2005). Many universities in Ghana are presently providing access to full text journals and various online databases through their membership of CARLIGH, as well as maintaining institutional repositories (IRs) (Asamoah-Hassan, 2008; Kwafoa et al., 2014).

The management of ERs is becoming a core function of academic libraries worldwide and several researchers have revealed how academic libraries in developed countries are struggling 
to successfully manage these resources (Mangrum \& Pozzebon, 2012). For this reason, there have been some initiatives with the aim of providing guidelines to assist in the management of these resources. Notable among them is the Digital Library Federation - Electronic Resource Management Initiative (DLF - ERMI) which established common specifications, standards, and systems for managing internal processes, administration, and licensing of ERs (Jewell et al., 2004). Other researchers (Albitz, 2008; Elguindi \& Schmidt, 2012; Emery \& Stone, 2013; England \& Miller, 2016; Jacobs, 2007) have also provided guidelines and frameworks for managing ERs in libraries.

Challenges associated with the management of these resources may even be more pronounced in developing countries including Ghana. This is because unlike in the developed countries where IT has gradually and systematically evolved, the introduction of computer applications in developing countries, particularly African countries, had until recently been identified with inconsistencies and lack of co-ordination (Martey, 2004). Academic libraries in Ghana have been selecting, acquiring, and providing ER services to the user community. Students and faculty constitute parts of society who are fortunate to have access to a variety of ERs. However, ERs provided by academic libraries are under-utilised for the most part (Akussah et al., 2015; Kwadzo, 2015; Kwafoa et al., 2014). It is worth noting that improper management can hinder the development and use of ERs in academic institutions (Ugwu \& Onyegir, 2014). Managing ERs may be more challenging for a developing country like Ghana which does not have adequate enabling human and non-human resources (Adzobu, 2014; Dadzie \& Walt, 2015).

Available ERM guidelines and frameworks could provide a point of reference for academic libraries in Ghana to assist them in managing their ERs as academic libraries in Ghana appear to be ineffective in the management of ERs, which could explain the observed under usage of these resources (Akussah et al., 2015; Kwafoa et al., 2014; Kwadzo, 2015). A study by Dadzie \& Waltz (2015) reported various challenges faced by university libraries in Ghana in planning for digitisation which included inadequate skilled staff and lack of visibility of resources on library websites. Although the factors contributing to under usage of ERs could emerge from various sources such as user preference, demographic characteristics of users (age, gender, subject discipline, educational level), a number of the contextual factors contributing to low usage of ERs in academic and research libraries such as lack of awareness (Akussah et al., 2015; Kwadzo, 2015, Kwafoa et al., 2014; Anaraki \& Babalhavaeji, 2013), poor searching 
skills (Okello-Obura, 2010; Ansari, 2010) and non-availability of required information (Sheeja, 2010; Tahir, et al., 2010) can be linked to lapses in the management of these resources.

As academic institutions invest in these resources, it is only appropriate that ERs are optimally used to contribute to the academic achievements of students and faculty, so the institutions get value for financial investments (Kwadzo, 2015). Higgins (2017) admonished that academic libraries should play their role by providing adequate resources and efficient services even if the user community was not taking advantage of their services.

\subsection{Statement of the Problem}

The specific problem that this study seeks to explore is that, although there is an extensive body of literature on the management and usage of ERs in academic institutions, few researchers have taken a holistic view by studying both concepts in a single study to reveal how they are related. The issue is not simply studying the two concepts together, but to ascertain whether this would result in better recommendations for practice as recommendations made by studies that investigated only management or usage of ERs as separate concepts had not been effective in improving situations. Again, the literature on the management of ERs in libraries has predominantly focused on developed country context leaving a gap in the context of developing countries. This research therefore seeks to study both concepts and explore how they are related and focus on a developing country context with the aim of better informing practice and eliminating the problems

Previous research (Adzobu, 2014; Dadzie \& Walt, 2015; Kwafoa et al., 2014, Kwadzo, 2015) have indicated that, academic libraries in Ghana are ineffective in managing ERs, and that ERs are not well used by the academic community. The research suggests that a future avenue for research would be to examine whether ineffective management could explain observed inefficiencies and under usage of ERs.

With inadequate human and non-human resources (Adzobu, 2014; Dadzie \& Walt, 2015), there is a lack of understanding on the management of ERs in academic libraries in Ghana. Also, the contextual factors surrounding the management and usage of these resources are not wellunderstood. This necessitates an exploratory investigation to understand these issues and factors in order to recommend strategies for addressing them. 


\subsection{Research Objective}

This study investigates the management and usage of ERs in academic libraries in Ghana to unveil surrounding contextual factors and the ways in which management and usage of ERs affect each other, to provide better recommendations for improved practices.

\subsection{Research Questions}

The study was guided by the following research questions:

1. How are ERs managed and used in academic libraries in Ghana?

2. a. What are the contextual factors surrounding the management and usage of ERs in academic libraries in Ghana?

b. In what ways do these contextual factors affect the management and usage of ERs in academic libraries in Ghana?

3. In what ways does the management of ERs affect its usage and vice versa?

\subsection{An Overview of the Study Setting}

In order to place the study in its context, a brief overview of the study setting which comprises the case institutions is presented.

\subsubsection{About Ghana}

Ghana, having a population of about twenty-eight (28) million people, is in West Africa. It covers a total area of 238,540 squares kilometers and shares borders with Togo to the east, Ivory Coast to the West, Burkina Faso to the north and the Gulf of Guinea to the south, as depicted in Figure 1.1 (Ghana Web, 2017). The country is made up of over a hundred (100) linguistic groups and has no national language. Ghana was colonised by Britain and the common language used in formal and educational systems from kindergarten to the university level is English. Ghana attained independence on $6^{\text {th }}$ March 1957. At the time of independence, Ghana had only one university. Presently, there are nine (9) public universities and over twenty (20) private universities in the country. Ghana spends between thirty (30) and forty (40) percent of its annual budget on education at all levels (Ghana Web, 2017). 


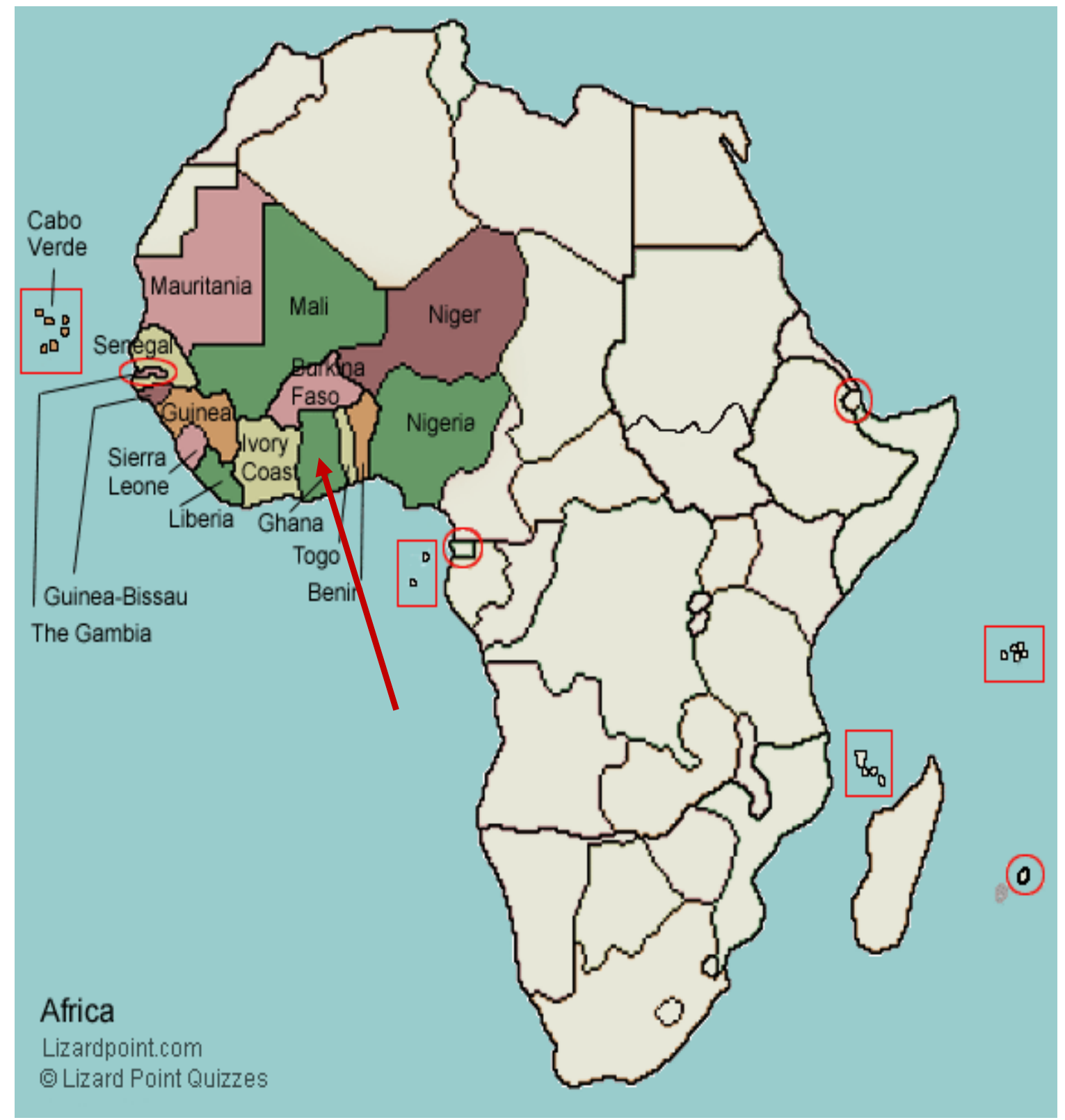

Figure 1. 1. Ghana depicted on the West Africa map (Google Maps, 2017) 


\subsubsection{The University of Ghana and the Balme Library}

The University of Ghana (UG) was founded in 1948. It is located in Legon - Greater Accra, the capital of Ghana. The university presently has a student population of 37,940 (UG Website, 2019). It is the premier and largest university in the country. The Balme Library being the main library of the university oversees the University of Ghana Library System, which comprises libraries attached to institutes, schools, departments, faculties, halls of residence and the Accra City Campus. The library has an institutional repository and makes available electronic databases and online journals to users. The library also holds over 396,000 books, 959 microfilms (currently being digitised), tapes, rare collections, prints and archives tapes (Dadzie $\&$ Walt, 2015).

\subsubsection{The University of Cape Coast and the Sam Jonah Library}

The University of Cape Coast was established in 1962. It is located in Cape Coast, the central region of Ghana. The university currently has a population of 19,963 regular students. The Sam Jonah Library, which is the main library of the university, supports 31 satellite libraries located in colleges, schools, faculties, departments, and halls. The library is one of the largest in the country. The library can seat 2000 users at a time and has the capacity for holding 750,000 volumes excluding pamphlets and journal collections. It has a digital library and makes available various ERs including electronic databases and online journals to the user community (UCC Website, 2019).

\subsubsection{The Central University and the Library}

The Central University (CU) is a private university, which was founded in 1988. It is located in the Greater Accra region of Ghana. It is the oldest and largest private university in the country. The main Central University library supports six other libraries stocking mostly books on the programmes being run on the various campuses. As its vision, the library strives for excellence in providing quality, relevant, current, and timely information to the university community. Resources and services provided by the library include access to various ERs including online databases, IR, and E-books (CU Website, 2019).

\subsubsection{Wisconsin International University College and the Library}

Wisconsin International University College (WIUC) was established in 1998. It is situated in the Greater Accra region of Ghana. The WIUC library was established in 2002 as a partner in supporting the university towards excellence in teaching, research and learning of the 
university and non-university communities. As its vision, the library seeks to be the heart of academic and research culture of WIUC to contribute to the intellectual activities of the university. The library holds collections in print format and provides ERs such as online databases to the user community (WIUC Website, 2019).

\subsubsection{Access to Electronic Resources in Ghanaian Universities}

The adoption of ERs in Ghanaian universities started in the 1980s and has now become a common phenomenon. The proliferation of these resources has been gradual and not without challenges. Academic libraries in Ghana appear to be making every effort to embrace ERs for the user community despite challenges such as inadequate infrastructure, inadequate financial and human resources. Early electronic services included CD-ROMs and Internet connectivity in some public universities including the University of Ghana and University of Cape Coast (Asamoah-Hassan, 2008; Asamoah-Hassan \& Frempong, 2008; Dadzie, 2005; Martey, 2004). There have been a number of projects and initiatives all aimed at making ERs available in Ghanaian Universities.

An early initiative which saw the introduction of electronic journals and databases in Ghana began in 2002 when the International Network for the Availability of Scientific Publication (INASP) was sponsored by the Danish International Development Agency (DANIDA) to negotiate, license and make accessible ERs to the four oldest public universities - University of Ghana (UG), Kwame Nkrumah University of Science and Technology (KNUST), University of Cape Coast (UCC), University for Development Studies (UDS), and one research institute - Institute for Scientific and Technological Information (INSTI). This marked the beginning of electronic networking in Ghana. INASP undertook this initiative through its Programme for Enhancement of Research Information (PERI) whose main aim is to assist developing countries in accessing scientific information by lobbying for funding from external sources and discounts from publishers (Asamoah-Hassan, 2008; Asamoah-Hassan \& Frempong, 2008).

\subsubsection{Access to Electronic Resources through Library Consortium}

Funding from DANIDA was short lived which necessitated having an alternative source of funding to ensure continued access to ERs in these universities. The need for consortium building was raised and subsequently the Consortium of Academic and Research Libraries in Ghana (CARLIGH) was established in 2004 with support from INASP and Electronic Information for Libraries (EIFL). In addition to these two international bodies, CARLIGH 
collaborates with Ghana Library Association (GLA) and other related associations such as the African Library Associations and Institutions (AfLIA) in undertaking its activities (CARLIGH, 2017). The Consortium aims to bring together academic and research libraries in Ghana to share resources for efficient services to the user community. It is currently the only library consortium in the country (Dzandza \& Alemna, 2011) and membership is by subscription with payments made annually (Asamoah-Hassan, 2008).

CARLIGH negotiates and licenses electronic journals and databases such as EBSCOHost, Emerald, JSTOR and AJOL for its members and provide training for professional development. It presently has a membership of forty-one (41) academic and research libraries, Advisory Board, a Management Committee, and a Governing Council. It also has five working groups: 'Bibliographic Services' which aims to assess, maintain, develop standards and maintain a National Union Catalogue and List of Serials for the Consortium; 'Information and Communication Technology' which seeks to offer its members guidance on hardware and software acquisitions; 'Training and Human Resources Development' which provide training facilities to suit identified training needs; 'Advocacy and Marketing' which undertakes publicity and encourage other institutions to join the Consortium and 'Electronic Resources' which oversees activities related to ERs such as monitoring and assessing usage. Sources of its funding are annual membership fees, external bodies, government, and proceeds from conferences, workshops, and seminars (Asamoah-Hassan, 2008; Asamoah-Hassan \& Frempong, 2008).

Asamoah-Hassan \& Frempong (2008) highlighted some of the challenges facing CARLIGH in carrying out its mandate. These include member libraries' lack of support from the management of their parent institutions. One approach CARLIGH has adopted to gain support from parent institutions is to involve them in the affairs of the Consortium by assigning management of participating institutions positions on the advisory board. Infrastructural challenges such as narrow bandwidth and power cuts have also impeded the smooth running of the operations of CARLIGH. Furthermore, lack of commitment of members to timely payment of subscription fees affects the renewal of ERs. This challenge has however been surmounted by soliciting external agencies for funds to pay for the renewal of resources to make up for any payment delays from member institutions. 
Generally, CARLIGH has been successful in carrying out its mandate. Besides providing access to licensed ERs, it has supported the GhanJol initiative where journals in Ghana are being made available online to enhance visibility and access to local content. As a future project, the Consortium seeks to develop a National E-Theses and Dissertations (ETD) platform which will provide access to dissertations and thesis of all universities in Ghana (Asamoah-Hassan, 2008; Asamoah-Hassan \& Frempong, 2008).

\subsubsection{Access to Electronic Resources Through Institutional Repositories}

An IR is a platform for collecting, storing, and disseminating the intellectual output of an academic or research institution in digital formats. Some academic libraries in Ghana make available ERs through their IRs. The first IR in Ghana was established in 2004 at the Kwame Nkrumah University of Science and Technology called KNUSTSpace. Presently, there are eleven (11) academic institutions in Ghana that have established IRs. Some challenges affecting the smooth running of the IRs in these institutions are lack of awareness, infrastructural challenges, inadequate funding, and institutional culture and politics (AgyenGyasi, Corletey \& Frempong, 2010).

\subsection{Scope of the Study}

The study explores the management and usage of ERs in selected academic institutions in Ghana. It was limited to the ERs made available via the libraries in the case institutions. The research covered library staff, faculty and postgraduate students of two public and two private universities. These are the University of Ghana (UG), University of Cape Coast (UCC), Central University (CU) and Wisconsin International University College (WIUC). Ideally, the study would cover all public and private universities in Ghana. However, this was not feasible owing to time and resource constraints. Furthermore, each of the selected cases has similar structures as the other universities in the category to which they belong. More details on the population and selected institutions are provided in Chapter Four of this thesis.

\subsection{Justification for the Study}

Although there is an extensive body of literature on ERs in academic libraries, few studies have pulled the concepts of ERM and usage together in a single study. Investigating both concepts in a single study would result in better recommendations for practice to encourage effective use of ERs. Furthermore, ERM in academic libraries has been mostly researched in 
the developed countries. Few empirical studies have been conducted on the management of ERs in developing countries such as Ghana.

The proliferation of ERs in African universities is fairly recent, and it is unclear how academic libraries are managing these resources; and how the management of ERs is affecting the usage of ERs, particularly in the Ghanaian context. Due to challenges facing developing countries such as Ghana, effective management of ERs in academic libraries becomes critical in this dynamic environment. The study therefore fills the gap and contributes to the discourse on the subject to assist in developing strategies for effective management of ERs that could contribute to an increased usage of these resources. One practical contribution is that, the findings of the study can provide a point of reference or serve as a basis from which academic libraries in Ghana and other developing countries can draw lessons. It can also inform policy and decision makers about contemporary issues regarding ERM and usage in academic libraries.

\subsection{Definition of Key Concepts}

In research, definition of concepts and terms tends to vary among researchers. It therefore becomes necessary to define key and controversial concepts to establish positions taken in research (Perry, 1994). The following are definitions adopted for the key concepts in the study.

\section{Academic Libraries}

Libraries in educational institutions at the tertiary level - universities, colleges, research institutes (Harrod's Librarian's Glossary, 2000).

\section{Academic Researchers}

Academic researchers in this study refers to faculty and postgraduate students.

\section{Electronic Resources}

Information resources that are created, generated, sent, communicated, received, or stored by electronic means - E-databases, E-journals, E-books, E-theses, E-data archives, E-manuscripts, E-maps, E-magazines, E-newspaper, E-research reports, E-bibliographic database (Millar, 2009). For the purposes of this study, ERs refer to E-journals, E-books and online databases subscribed by the case institutions, CD-ROMs, and IRs. Also, it does not mean born-digital material only, but includes any digital item. 


\section{Electronic Resource Librarianship}

Responsibility for some or many aspects of the processes inherent in the identification, selection, acquisition, organisation, description, delivery, and evaluation of ERs (Jacobs, 2007).

\section{Electronic Resource Management (ERM)}

Overseeing all aspects of ERs including operations and systems that are created to manage ERs in libraries from pre-selection activities to renewal or cancellation decisions (Bothmann \& Holmberg, 2008). In this study, ERM comprises planning for and implementation of ERs.

\section{Implementation of Electronic Resources}

In this study, implementation of ERs refers to the establishment of ER workflow and adoption of an approach for the workflow.

\section{Information Overload}

This means when too much information is received to the extent that it becomes a hindrance rather than a help (Bawden, Holtham \& Courtney, 1999).

\section{Planning for Electronic Resources}

This in this research refers to policy development, budgeting, and staffing for ERs.

\section{Private University}

A university that is not federally assisted, and depends on private funding, tuition, and fees.

\section{Public University}

A university that is mainly funded by public means through a national government.

\section{Usage of Electronic Resources}

Usage of ERs in this study is the exploitation of an ER to meet an information need.

\subsection{Organisation of Thesis}

The thesis consists of eight chapters. This chapter presents an overview of the research by presenting the context of the study, background to the research problem, statement of the 
research problem, overview of study settings, scope of the study, justification for the study and definition of concepts.

Chapter Two reviews relevant literature, bearing in mind the research questions of the study. The review provides background knowledge on ERs in academic libraries in terms of the concepts of ERs in academic libraries, impact of ERs on academic libraries, ERM, planning for ERs, implementation of ERs, usage of ERs, and identifies factors surrounding the management and usage of ERs in academic libraries.

Chapter Three discusses theoretical foundations of the study. The TERMS framework (Emery \& stone, 2013) and the Unified Theory of Acceptance and Use of Technology (UTAUT) (Venkatesh, Morris, Davis \& Davis 2003) are discussed. In addition, an initial conceptual model of factors of ERM and usage based on the literature and UTAUT is presented.

Chapter Four explains the methodology used for the study. This includes a discussion of the research paradigm, research approach, case selection, research process, data collection tools and procedures, data analysis, evaluation of research, limitations of the study and ethical considerations.

Chapter Five presents findings on the management of ERs. Data from interviews with library staff and document analysis are presented bearing in mind the research questions of the study. ERs/ICT infrastructure in the case institutions are analysed followed by analysis of planning for ERs, and implementation of ERs in the case institutions, which consists of ER workflow and approach. This is followed by analysis of collection development policies of case libraries after which findings on factors affecting the management of ERs are presented.

Chapter Six presents findings on the usage of ERs. Surveys with faculty and postgraduate institutions are analysed and presented based on the research questions. Analysis revolves around awareness, usage, and perception of ERs of the library. Challenges of using the ERs and factors affecting usage of ERs of the library are also presented.

Chapter Seven presents integrated discussions of major findings on the management and usage of ERs in the case institutions. Discussions on planning for ERs, implementation of ERs, usage of ERs and factors affecting the management and usage of ERs are presented. This is followed 
by revisions of the frameworks/models that underpinned the study, and a discussion on how the management and usage of ERs are related.

Chapter Eight provides a conclusion of the study based on the key findings. The chapter begins by summarising the findings according to the research questions, presents implications and contributions of the study to theory and practice, identifies limitations of the research, and provides directions for further studies.

\subsection{Chapter Summary}

This chapter aimed at introducing this study by presenting the context and background to the research problem, an overview of the study setting, statement of the problem, research questions and objectives. The literature and Ghanaian context provided justification for the study. The scope and definition of key concepts are also presented followed by organisation of the thesis. 



\section{Chapter Two \\ Literature Review}

\subsection{Introduction}

This chapter reviews pertinent literature on the main concepts of the study. The study involves two main concepts which are electronic resource management (ERM) and electronic resource (ER) usage. The chapter presents a review of relevant literature bearing in mind the research questions and main concepts underlying the study. It is organised under the following headings: the concept of ERs, impact of ERs, ERM, planning and implementation of ERMs, contextual factors surrounding ERM, and ER usage in libraries. A summary is provided in closing.

\subsection{The Concept of Electronic Resources (ERs)}

ERs has been defined by various authors. An early definition describes ERs as "a package of E-journals or a database of abstracts and indexes that include the full text of some or all articles referenced by the indexes" (Sadeh \& Ellingsen 2005, p.4). This definition focuses on the content point of view of ERs. Other definitions provide a more encompassing view of ERs. According to the International Federation of Library Association (IFLA) (2012), ERs are materials that can be accessed through the computer including personal or mainframe computers and mobile devices. ERs has also been defined as any electronic product that contains a set of data or any resource that requires a computer to facilitate access to its content (Johnson et al., 2012; Kenchakkanavar, 2014). Adeleke \& Nwalo (2017) defined ERs as resources that store information electronically and are accessible through electronic components and networks. It can be observed that, whereas some definitions of ERs are more encompassing, other authors provide a narrow in scope definition of ERs. The definition of ERs has evolved from a narrow to a more widened scope to include content, systems and programmes.

Research has pointed out that librarians were early adopters of technology (Grieg, 2014; Hawthorne, 2008). ERs in libraries began with the development of the machine-readable cataloguing (MARC) format by the Library of Congress in the mid-1960's, which superseded the card catalogue. The MARC format aimed to establish a standard for digital bibliographic description of library resources to promote interlibrary exchange of catalogues. In 1971 and 1973, the MARC format became a national and international standard respectively. Hawthorne 
(2008) in providing a historical account of the proliferation of ERs reported that, the use of ERs in libraries began in the early 1970s with libraries providing access to data sets such as census data and survey data.

The invention of micro-computers in the 1980s enabled libraries to acquire software and data on diskettes and make available full text databases on Compact Disc Read-Only Memory (CDROM) with search interfaces (Hawthorne, 2008). The subsequent creation of the World Wide Web (WWW) by Tim Berners-Lee in 1990 facilitated the development of Online Public Access Catalogue (OPAC) in libraries. In 1992, the Mosaic browser was developed which resulted in an increased use of the Web; and the mid-1990s saw a proliferation of web-based ERs through the development of search engines and directories such as Google and Yahoo (Hawthorne, 2008). Libraries began providing access to E-journals, E-books, bibliographic and full-text databases, and web-based catalogue via the Web. From the 1960s to date, various ERs have been developed and made available. These include online catalogues, shared cataloguing, OPAC, web-based catalogues; bibliographic databases such as Dialog database software; CDROM databases; CD-ROM books; online databases, electronic serials; World Wide Web; and electronic books (Hawthorne, 2008). Hawthorne's (2008) account appears pivotal as it shows how ERs have evolved over the years in format. Kenchakkanavar (2014) tabulated the 14 types of ERs with their definitions in a study on types of ERs and its utilities in the library.

Jacobs (2007) has described the proliferation of ERs as a disruptive innovation whereby an innovation leads to the obsolescence of authority or expertise in a specific area or domain. ERs which are freely available on the Internet are breaking the monopoly of libraries in information provision. The basis of Jacobs' (2007) argument is Abbott's (1988) The Systems of Professions which expanded on Parsons' (1956) theory of organisations, with the assumption that professions grow through series of stages known as professionalisation. The library is an organisation and for that matter "a social system oriented to the attainment of a relatively specific type of goal, which contributes to a major function of a more comprehensive system, usually society" (Parsons, 1956, p.63). ERs have made the library adapt and restructure its processes and staffing to cope with the new environment. 


\subsection{Impact of Electronic Resources on Academic Libraries}

Academic libraries reflect the development of colleges and universities of which they are a part, and they tailor their collections and services towards the instructional and research programmes of their parent institution. Their role is central and of critical importance to the instructional and scholarly life of colleges and universities. The development of a student's intellect depends both on classroom interaction and the student's own search for information. Without the existence of good libraries, students would struggle to find relevant and useful information to supplement their course work with further readings (ALA, 1986).

The literature has highlighted how the advent of new technologies and rapid growth of ERs have metamorphosed the role played by academic libraries. Libraries have been reinventing themselves using various techniques. They now serve as hubs for teaching, research, and learning; collaborate with faculty in teaching and research; provide advanced research assistance and user education; and provide access to a wide variety of ERs (Franklin, 2012; Jaguszewski \& Williams, 2013). Research has also revealed the fact that ERs have caused a shift in the role of the library from a content owner to access point. These resources offer library staff and users the opportunity to know the holdings of other libraries through quick searches and also facilitate interlibrary loan. Libraries are able to invest their meagre financial resources on core collections that are relevant to their users while supplementing these with materials from other libraries (Elguindi \& Schmidt, 2012).

Jewell (2001) argued that ERs have also pushed to the forefront license agreements to supplement and sometimes supersede copyright law in defining appropriate use of ERs. Another major impact of the new environment on academic libraries is in the area of workflow, whereby a large number of staff across the various units of libraries are now playing significant roles in the selection, acquisition, support and evaluation of ERs (Chamberlain \& Reece, 2014; Collins, 2009; Elguindi \& Schmidt, 2012; England \& Shipp, 2013). According to ACRL Research Planning and Review Committee's (2014) Top trends in academic libraries, deeper collaboration is the main theme for current trends which provides opportunities for libraries in various areas, including student success initiatives, competency-based learning, digital humanities, and openness in higher education. 
The literature has revealed various opportunities that ERs can provide libraries. However, in the midst of these opportunities for dynamism are various challenges that libraries need to surmount. On a similar note, Higgins (2017) reported that libraries still find it difficult to withdraw their print counterparts of ERs owing to complexities surrounding ERs.

\subsection{Electronic Resource Management (ERM)}

ERM has been defined in various ways by different authors. England \& Miller (2016) define it as the set of systems and operations created to manage ERs in libraries and these operations are intertwined into specific workflows in both libraries and their parent institutions. Bothmann \& Holmberg (2008) define ERM as overseeing all aspects of ERs from pre-selection activities such as trials and initial vendor inquiries to renewal and cancellation decisions, from the perspectives of planning, policy, and workflow issues experienced by many libraries. A similar definition that emphasises content management, systems, and administrative functions is provided by Brown, Nelson, \& Wineburgh-Freed (2005). The definition by Jasper \& Sheble (2005) empasises models for ER budget management. Breeding (2004) identified two aspects of managing ERs which are the front-end functions of delivering contents to library users and back-end staff functions related to acquisition, payment, and licensing. The literature shows that, whereas some authors provide a broader definition, other definitions are narrow in scope.

Bothmann \& Holmberg (2008) reported that little research had taken a holistic view on ERM. However, a review of the literature indicates that there has been a considerable amount of previous research on ERM worldwide. To answer the research questions of this study, literature on the practices of managing ERs in both developed and developing countries are reviewed to understand the phenomenon. What makes reviewing literature on ERs cumbersome is the fact that the literature on ERs in some cases is dispersed across the literature on the traditional functions of the library. Previous research has discussed various issues surrounding the management of ERs. Whereas some studies have investigated the workflow of ERs in academic libraries which includes discovery, selection, acquisition, implementation, evaluation and the challenges of ERM (Kaur \& Walia, 2016; Khan \& Bhatti, 2016; Wadekar \& Nagarkar, 2018), others have studied aspects of managing ERs such as policies for ERs (Mangrum \& Pozzebon, 2012; Johnson et al., 2012), budgeting for ERs (Elguindi \& Schmidt, 2012) and staffing for ERs (Abrams, 2015; Harnett, 2014). 
Branscome (2013) conducted an online survey of academic librarians on electronic serials management in the USA. The study focused on issues surrounding technical services, impact of e-serials on collection development, library staffing and serials management tools. The survey covered considerations of collection development, allocation of responsibilities relating to e-serials management among staff and tools used in managing e-serials. The findings revealed diversity in ERM practices which suggested that, ER workflow was pragmatic and mainly specific to institutional context specific. Gregory's (2006) Selecting and Managing Electronic Resources provides guidelines on policies, acquisition, and processes. Geller (2006) presented guidelines on staffing and workflow of ERs. A special issue of The Acquisitions Librarian edited by $\mathrm{Su}$ (2007) covered major ER related issues such as budgeting, staff reluctance, copyright, and preservation.

Wadekar \& Nagarkar (2018) investigated the management of online databases in university libraries in Maharashtra state of India. Using the descriptive survey method, the study applied the TERMS framework to examine the workflow of ERs including procedures for selection and acquisition of online databases, renewal procedures, and availability of infrastructure facilities as well as the challenges faced in managing online databases of the university libraries investigated. The study revealed that the university librarians were trying to successfully implement ERs. Major challenges identified were unawareness about the life cycle of ERs, lack of standard procedures, lack of collection development and preservation policies, failure to conduct user needs assessment, lack of negotiation skills and lack of competent staff.

Kaur and Walia (2016) conducted a study to examine current practices of ER collection development in Indian management libraries. Using quantitative method (survey), the study discussed the various types of ERs available in management libraries, budget allocation, responsibility and factors of selection, acquisition, authentication and accessibility and challenges faced by libraries in building ER collection. The authors put forward recommendations to address ER related challenges. The findings revealed that responsibility for selection and subscription to ERs rested with the library committee/joint committee/purchase committee made up of experts in different disciplines including director of institution, HODs. Regarding funding, private universities received institutional funding whereas public institutions met library expenses with funding from the Indian government. No external sources of funding were revealed. The findings also revealed that some libraries allocated more than $50 \%$ of their budget to ERs. Various modes of acquisition were indicated, 
and promotional measures included providing links to ERs from library home page, information literacy education for users, email alerts, tutorials, guides, and posters.

These previous studies are important as they provide a frame of reference from which other libraries particularly in developing countries such as Ghana can draw lessons. They also informed the data analysis and discussion in this study. However, what was missing was the fact that these studies did not provide a holistic view of ERs of the library as they investigated only the management of ERs excluding the usage aspect, which could have resulted in better recommendations for practice to encourage high usage of the ERs.

\subsection{Planning for ERs in Libraries}

Without adequate planning, ERs cannot be effectively implemented. Planning involves the coordination of all aspects of the ER lifecycle from selection and acquisition through to maintenance to the final stage which is renewal or withdrawal (Collins, 2009). Despite the significance of planning in ERM, it appears to be hardly adequately practiced in libraries (Bothmann \& Holmberg, 2008; Okogwu \& Ozioko, 2018). Planning for ERs involves policymaking, budgeting, and staffing (Collins, 2009; Shu, 2012; Bothmann \& Holmberg, 2008).

\subsubsection{Policies for ERs}

Collection development policies (CDPs) in libraries are official documents or guides that spell out issues such as scope of collection, the budget, responsibilities, and weeding (Johnson, 2009). They are comparable to a business plan without which libraries cannot function effectively (Johnson, 2009; Mangrum \& Pozzebon, 2012). CDPs cover all procedures for the growth and management of both print and digital collections (Mwilongo, 2017).

Mangrum \& Pozzebon (2012) investigated the use of CDPs in e-collection development. Using content analysis, the authors analysed the content of CDPs of libraries in the USA. Their findings revealed that in almost all the CDPs, traditional components of collection development were adequately addressed whereas e-collections were inadequately addressed. A pivotal contribution of their study is the development of a tool for evaluating CDPs, which could serve as a useful as a guide for academic libraries in the developing countries. Several authors (Jewell et al., 2004; Johnson, et al., 2009; Martin et al., 2009) have emphasised the importance of formulating policies for e-collections to guide library staff and promote consistency in ER 
activities. CDPs for ERs should take into consideration departmental and institutional mission and goals (Mangrum \& Pozzebon, 2012) and should be regularly reviewed or revised to keep up with the constantly changing technological landscape to ensure an alignment between ER policies and practices (David \& Liezl, 2012).

Mwilongo (2017) contends that unlike academic libraries in the developed countries that have revised CDPs to reflect ER services, many academic libraries in developing countries, particularly those in Africa, lack CDPs that take into account changes associated with the electronic environment. The author claims that CDPs are usually developed and shelved. In a survey of sixteen (16) academic libraries in Cuba, Sanchez (2005) found that although library staff were aware of CDPs of the library, only a few implemented the policies. Various researchers have identified challenges of implementing CDPs in libraries. These include inadequate funding (Sasikala et al., 2014), lack of skills to implement hybrid CDPs (Evans, 2004; Neal, 2011) and resistance to change (Mwilongo, 2017). Also, Mangrum \& Pozzebon (2012, p. 109) argued that "CDPs can be too prescriptive or too vague, unresponsive to change, and densely written".

The literature has generally revealed the fact that, the advantages of developing CDPs outweigh the drawbacks. However, research has mainly focused on the availability and implementation of CDPs with less guidelines for developing or assessing policies for ERs, which could assist academic libraries particularly in the developing countries towards effective planning for ERs.

\subsubsection{Budgeting for ERs}

Finance is the bedrock of libraries without which libraries cannot function. For this reason, some authors have provided guidelines on budgeting for ERs in libraries. Conger (2004) who wrote comprehensively on budgeting for ERs indicated that budgeting is a planning process beginning with the library's purpose or values, and past and anticipated demands. She further stated that budgeting should be a learning process, which calls for flexibility to make room for unexpected expenditure. Elguindi \& Schmidt (2012) in sharing a similar view highlighted the need for flexible ER budget allocation models due to the shift from ownership to access, to cover unexpected changes in collection management needs. Budgeting for ERs also involves negotiation through costs and benefits, and pricing models. Conger (2004) indicated various pricing models available in the electronic environment including price per unit, price per user, 
price per use and consortia purchasing. Generally, flexibility of budgets to cover unforeseen expenditure is highlighted in the literature.

\subsubsection{Staffing for ERM}

Staffing determines to a large extent the success of ER implementation (Abrams, 2015). In the early days of ERs, libraries were hesitant in adopting these resources and those who adopted them made no changes to their organisational structure. As ERs expanded and outgrew print documents in libraries during the first decade of the twentieth century, libraries began creating new positions such as ER librarian to handle ER responsibilities. These positions were usually occupied by professionals from the technical and public service units of the library. The role of an ER librarian involves planning, selecting, implementing, and assessing ERs. There have been some initiatives to outline the core competencies of ER librarians (Elguindi \& Schmidt, 2012).

A significant example is the NASIG's Core competencies for electronic resource librarians by Sutton and Davis (2011) which spells out competencies required of ER librarians based on analysis of job advertisements. The competencies include budgeting, acquisition, cataloguing, licensing, database design, usage and staff supervision, which were presented for discussion at the 2012 NASIG Annual Conference (NASIG, 2012). It was subsequently accepted as NASIG policy. The competencies have however received criticisms for broadness due to the fact that, they did not spell out specific task related competencies (Hartnett, 2014). Related studies (Murdock, 2010; Engel \& Robbins, 2008) have also analysed the content of job advertisements to outline required competencies. However, with the rapid growth of ERs, the current trend in ERM has been a collaboration between ER managers and other units of the library (Abrams, 2015; Hartnett, 2014; Wadekar \& Nagarkar, 2018).

In addition, frequent training of ER staff is a defining facet of the new environment (Hartnett, 2014). Albitz (2008) asserted that managing ERs requires a combination of knowledge and skills from the fields of library science, business administration and law as ER staff are involved in negotiating legal contracts, maneuvering the business world of publishers and information providers. In Albitz's view, opportunities for acquiring these skills and knowledge are not widely available. Generally, the literature has shown that in addition to the required technical skills and knowledge in library services, the ER librarian requires leadership, interpersonal and communication skills since they play coordinating and supervisory roles in 
the distributed environment. Furthermore, interdisciplinary knowledge particularly from the fields of law and business is necessary for a successful ERM.

Section 2.5 has reviewed literature on planning for ERs in the library, which comprised policies for ERs, budgeting, and staffing for ERs. The literature on policies for ERs has mainly focused on the availability and implementation of ER policies. Guidelines for budgeting for ERs have been provided and the need for flexibility in allocating financial resources to ERs have been highlighted in the literature. Also, ER staffing challenges and requirements for a successful ERM have been addressed in the literature. However, there is still much more discussion needed within the literature on planning for ERs, particularly on the development and assessment of ER policies, ER staff motivation and strategies for sustainable funding for ERs.

\subsection{Implementing ERs in Libraries}

After adequate planning for ERs, which takes into consideration policies, budgeting and staffing, the next stage is implementation. In implementing ERs, libraries establish workflows throughout the life cycle of ERs after which an ERM approach or model is adopted to facilitate the workflow. The components of ER implementation are presented next.

\subsubsection{ER Workflows/Lifecycle}

ER workflow is an important component of ERM and can be a "cumbersome process" (Anbu, Kataria \& Ram, 2013, p.300). Following the transition of libraries from a print to a hybrid model, efforts have been made to establish systematic practices for managing the life cycle of ERs to break down tasks into manageable pieces for effective ERM. A remarkable effort has been spearheaded by the Digital Library Federation's Electronic Resources Management Initiative (DLF-ERMI). In 2004, ERMI provided a report with the aim of establishing standards and common practices for managing ERs. The report outlined ER lifecycle as consisting of product consideration and trial, acquisition process, implementation, product maintenance and review (Jewell et al., 2004). There have been subsequent reports and projects by DLF-ERMI all aimed at establishing standards for ERM (Jewell, 2008).

Following the ERMI report, many authors have proposed best practices and frameworks for managing ERs. These authors, describing different stages and processes appear to have different views on the components of ER lifecycle which suggests that ER life cycle varies 
from library to library. Smith (2016) in his study on Managing electronic resource workflows using ticketing system software enumerated the workflow of ERs as consisting of trial, acquisition, activation, maintenance and troubleshooting, renewal, and cancellation. Workflow according to Mackinder (2014, p.159) is "a set of overarching directives that allow staff to manage a process, which includes investigating, ordering, licensing, activating, deactivating, or troubleshooting an electronic resource".

Emery \& Stone (2013) proposed the Techniques for Electronic Resource Management (TERMS) framework for managing the lifecycle of ERs. The framework is based on real life experiences of libraries in the USA and UK and comprises six stages which are investigation of new content, acquisition of content, implementation, ongoing evaluation and access, annual review, and cancellation and replacement review. Mangrum \& Pozzebon (2012) listed the stages of ER life cycle as evaluation, negotiation, acquisition, licensing, and implementation. Peshe (2009) provided a comprehensive lifecycle of ERs as consisting of acquisition, access provision, administration, support provision, evaluation, and monitoring. Breeding (2008) gave a detailed description of the workflow of ERs as comprising consideration of resource, trial, negotiation, licensing, procurement, and renewal/de-selection. Joshipura (2008) discussed thoroughly the workflow of ERs from selection, trial, evaluation, licensing, and acquisition and ending with access provision. Boss \& Schmidt (2007) described the ERM process based on the functional model of academic libraries as collections, acquisitions, cataloguing and circulation. Sadeh \& Ellingsen (2005) detailed the ERM lifecycle as consisting of discovery, trial, selection, acquisition, access, and decision to renew/cancel.

Following the establishment of various frameworks for ERs was the introduction of ER management systems (ERMS) to support the management of ER life cycle. An ERMS is a software that manages the various stages of ER lifecycle (McCracken, 2007). Anbu, Kataria \& Ram (2013) provided an overview of the origin of ERMS. Patra \& Jha (2014) analysed and compared sixteen (16) ERMS based on their features, functionalities, and compatibility. ERMS can be proprietary or open source. Proprietary ERMS generally have more features, are relatively expensive and less 'customisable' whereas open source ERMS have generally been found to be more cost effective but require technical expertise for maintenance (Anbu, Kataria \& Ram, 2013). 
Standardising ER workflow across libraries is a great challenge compared to print workflow which is fairly standardised across libraries worldwide (Albitz, 2008; Elguindi \& Schmidt, 2012). Despite the lack of standardisation in the lifecycle of ERs as presented by these authors, there are similarities and common themes of content selection, licensing, acquisition, and access provision. Irrespective of the ERM workflow adopted in libraries, it needs to be reviewed periodically for improvements. For this study, the TERMS framework (Emery \& Stone, 2013) was adopted as the lens for analysing the workflow of ERs in the case institutions. The TERMS framework and justification for this selection are discussed in the next chapter (Chapter Three).

There have also been some studies on the management of digital libraries or institutional repositories (IRs). Liew (2014) in her study towards dynamic and evolving digital libraries developed a conceptual framework. The framework has eight dimensions which highlight issues that should be considered in designing digital libraries and these include content, context, connectivity, consideration, collaboration, construction, confidence, and continuity. CampbellMeier (2011) presented a framework for the development of IRs following case studies of six universities in USA and Canada. The study examined core functions of IR, and development factors. The stages in the proposed framework are founding event, identifying working group, campus needs assessment, development of a project narrative, identification of collections, identification of a project manager/team, project plan, software, content recruitment, assessment, the campus community, and marketing. These studies are important as they recommend best practices for managing digital collections which can be adopted by academic libraries in developing countries such as Ghana.

However, the studies to a large extent lack a holistic view of ERs in academic libraries since the usage of ERs was excluded. For this reason, recommendations put forward may not adequately address challenges associated with ERs in academic libraries. There is therefore the need for a holistic study on the management and usage of ERs for informed practices to attract maximum usage of ERs of the library, which is one of the aims of this study.

\subsubsection{ERM Models/Approaches in Libraries}

Research has revealed some approaches to the management of ERs in libraries. Three basic models of ERM identified in the literature are the integrated or centralised approach, distributed 
support approach and the team approach (Abrams, 2015; Elguindi \& Schmidt, 2012; England \& Shipp, 2013; Higa et al., 2005; Hsiung, 2008; Stackokas, 2009).

\subsubsection{An Integrated or Centralised Approach}

An integrated or centralised ERM approach involves the establishment of an ERM department, usually managed by at least one librarian and one paraprofessional. With this model, tasks associated with ERs are consolidated into an ER department. An advantage of this approach is the fact that it allows librarians to focus their attention solely on ER related responsibilities and not be distracted by unrelated tasks (Elguindi \& Schmidt, 2012). However, not all libraries have adequate staffing that allows for an integrated or centralised ER department (Abrams, 2015; Stachokas, 2009).

Studies have reported that some libraries began ERM with an integrated approach but later had to switch to other models as the responsibilities of ERs departments evolved and became difficult to be handled solely by the ER department. According to Wolverton \& Davidson (2011), a report by Rick Kerns of University of Northern Colorado on Rethinking electronic resources workflows indicated that from 2007 - 2009, the University Library underwent a major reorganisation and subsequently dissolved its integrated approach for a distributed ERM approach due to evolving ER responsibilities and staffing challenges. Kulp \& Rupp-Serrano (2007, p.17) stated that having one or two key personnel or experts in charge of ERs in libraries was a "dangerous game" since in the absence of these personnel, a vacuum would be created which could have adverse consequences on ER services of the library.

\subsubsection{A Distributed Approach}

Inadequate staffing coupled with new and diverse responsibilities led to the adoption of a distributed approach to ERM in libraries. In this approach, duties associated with ERs are incorporated in the existing print-based workflow and processes rather than creating a separate ER department (Elguindi \& Schmidt, 2012). Although ERM becomes an integral part of the work of library staff their titles may not necessarily reflect the added ER responsibilities. Researchers have therefore suggested a revision of job description and titles to reflect hybrid roles played by library staff (England \& Shipp, 2013; Higa et al., 2005; Hsiung, 2008; Jacobs, 2007). An advantage of this approach is that it allows all library staff to familiarise themselves with tasks and responsibilities associated with ERs (Elguindi \& Schmidt, 2012). However, this approach can pose challenges as library staff deal with conventional and ERs concurrently. 
Departmental needs tend to take pre-eminence over duties associated with ERs (Jacobs, 2007). For this approach to be successful, effective communication among all stakeholders is paramount to avoid chaos (Chamberlain \& Reece, 2014; Collins, 2009; Hsiung, 2008; Shu, 2012).

\subsubsection{The Team Approach}

In the team approach, a team or group is formed to oversee all aspects of ERs (England \& Shipp, 2013). Members of the team meet and communicate regularly to discuss workflow. Subsequent groups can be formed out of the original group. For instance, at the University of Maryland of Baltimore County (UMBC), many workflow groups emerged out of the original ERM team and the same staff worked in various groups within the management system. Each functional working group module was kept separate to ensure flexibility (England \& Shipp, 2013).

It appears from the literature that the current trend with regard to ERM approaches in the developed countries is the distributed approach owing to the complexities and inconsistencies associated with ERs (Abrams, 2015; Chamberlain \& Reece, 2014; Geller, 2006; Higa et al., 2005; Hulseberg \& Monson, 2009; Miller, 2008; Pomerantz, 2010; Shu, 2012, West and Millar, 2011). This trend is becoming prevalent irrespective of the existence of ER units in libraries (Abrams, 2015; England \& Shipp, 2013; Hsuing, 2008).

Notwithstanding the current trend of a distributed ERM approach, job postings for ER librarians continue to be announced, especially for larger academic libraries where greater specialisation of duties is common. Larger academic libraries usually have separate units with staff who are tasked solely with the delivery of ERs. As ER functions continue to evolve and spread across the entire workforce, the ER librarian may take up a more managerial and coordination role (Elguindi \& Schmidt, 2012; Hsiung, 2008). Collaboration and effective communication are paramount in coping with the increased demands of the electronic environment.

Whereas studies in the literature on ERM approach paint a picture of the global scene, specifically the developed countries, little has been reported in the literature with regard to the developing world such as African countries including Ghana and Nigeria. There is little, if any, research-based literature that categorically reveals the approaches adopted for ERM in the 
developing countries. However, findings of various studies seem to suggest that all three approaches were adopted in various institutional contexts in Sub-Saharan Africa. In Nigeria, a study conducted by Ugwu \& Onyegiri (2014) on the Management problems of electronic resources at the University of Nigeria, Nusukka appeared to suggest a distributed approach to ERM at the library. The findings revealed that this approach was adopted due to a challenge in the area of skilled staff to manage these resources. An earlier study by Okoye \& Ugwuanyi (2012) suggested an integrated approach adopted by Nigerian Federal University Libraries where ERM responsibilities were centralised within the cataloguing department. The library faced a number of challenges as none of the cataloguers had the requisite expertise to handle licensing negotiations and other technical functions related to ERs.

In Ghana, Adzobu (2014) conducted a study on strategy formulation and implementation at the Main Library of University of Cape Coast and revealed the team approach as being adopted by its Digital Library. A study by Dadzie \& Walt (2015) suggested an integrated approach to implementing digital collections at the University of Ghana. Although the literature seems to portray the ERM approaches adopted in libraries in Africa including Ghana, the evidence is not concrete enough. The current study therefore fills the gap in the literature by exploring the ERM approaches adopted in academic libraries in Ghana, the motivation behind selected models, and their strengths and flaws.

In summary, section 2.6 has reviewed literature on the implementation of ERs in academic libraries which consists of establishing ER workflow and adopting an approach to facilitate the workflow. Recommended best practices for managing digital collections have been put forward which can serve as a point of reference for academic libraries in developing countries such as Ghana. However, as earlier stated, there is the need for a more holistic research on ERs to better inform practices and attract maximum usage, which is one of the aims of this study. The literature has also discussed approaches or models to ERM. That notwithstanding, the focus has predominantly been on the developed country context leaving a gap with regard to the context of developing countries. This research seeks to address this gap by focusing on a developing country context. 


\subsection{Contextual Factors Surrounding ERM in Libraries}

Managing ERs is a challenging function which is exacerbated by their rapid growth. According to many authors, there is a lack of clarity of workflow that is available with print documents. The challenges are in the areas of staffing, time management, and workflow (Bothmann \& Holmberg, 2008; Elguindi \& Schmidt, 2012). Elguindi \& Schmidt (2012) argued that, although technical services units in libraries have experienced dramatic changes over the past three to four decades, their approach to technology has been reactive rather than proactive with associated shortage of staffing in areas that require more technical set of skills.

Several related studies have revealed various factors affecting the management of ERs in libraries. Chawner (2004) in her study on new opportunities and new challenges for free and open source software identified various success factors including organisational culture, technical infrastructure, staff skills, software functionality and extent of available community support. She concludes the study by recommending professional training and development for staff to effectively take on new roles.

In Tanzania, Mwilango (2017) conducted a document review on the $21^{\text {st }}$ century collection development policy in academic library management to determine the factors that affect the implementation of CDPs in managing library resources. He concluded that whereas libraries in developed countries have revised their CDPs to focus more on enhancing ER services and allocating adequate budget to ERs, most libraries in developing countries have no written policies and the few that are available are not frequently revised. Factors affecting policy implementation include inadequate budget, poor library infrastructure and inadequate professional skills.

\subsubsection{Technical Complexities Associated with ERs}

One major factor surrounding the management of ERs as indicated in the literature stems from the nature of these resources. The main challenges in managing ERs are their rapid growth with different packages from various vendors and publishers; and various business models such as bundles, open access and partly open access. All these factors have a bearing on ER collection development in academic libraries (Anbu, Kataria \& Ram, 2013; Bothmann and Holmberg, 2008; Elguindi \& Schmidt, 2012; Jacobs, 2007). 
Instability associated with ERs has been highlighted in the literature as affecting the management of ERs (Abrams, 2015; Yu \& Breivold, 2008; Dadzie \& Walt, 2015; Erb \& Erb, 2015, Ugwu \& Onyegiri, 2014). Technical issues include URL changes, IP authentication, administration of holdings information and the requisite IT skills to ascertain how each journal service works and missing archival coverage.

\subsubsection{Budgeting/Funding}

Reliable and adequate financing are needed to maintain library services to meet the needs of patrons if libraries are to remain successful in this technological environment (Dadzie \& Walt, 2015). Research has revealed that whereas budgeting for ERs in the developed world is high, it has been a major challenge in the developing world. At the University of California San Diego Library, 65\% of library funds were spent on e-resources (University of California San Diego Libraries, n.d.). Generally, funding for academic libraries in Africa is obtained from the budgets of parent institutions which come directly from government subvention (Ubogu \& Okiy, 2011; Okojie, 2010). This funding is usually inadequate (Jan \& Sheikh, 2011; Dadzie \& Walt, 2015; Kwafoa et al., 2014).

\subsubsection{Staffing}

Another factor indicated in the literature as affecting the management of ERs is staffing. Most often, staffing at the library has not kept up with ER staffing needs and responsibilities (Abrams, 2015; Adzobu, 2014; Elguindi \& Schmidt, 2012). Bothmann \& Holmberg (2008) pointed out the inefficiencies that occur when all or most ER related responsibilities are assigned to one or two library personnel. Some libraries, especially in the developing countries, do not have ER librarians or staff with requisite expertise to manage these resources. A survey by Okoye \& Ugwuanyi (2012) on the management of ERs by cataloguers in Nigerian Federal University Libraries revealed that there were no ER librarians, and ER related functions such as licensing, access set-up and link maintenance were either non-existent or at embryonic stages of implementation.

\subsubsection{Collection Development Policies}

Collection development policies is another factor that affects the management of ERs in academic libraries. Collection development policies (CDPs) are necessary as they inform stakeholders about the management of ERs throughout their lifecycle (Gregory \& Hanson, 2006; Johnson, 2009; Mangrum \& Pozzebon, 2012). Despite the importance of e-collection 
policies, it appears it has not received the due recognition in libraries both in the developed and developing countries. Functions of ER lifecycle are usually not guided by CDPs owing to factors such as shrinking budgets and evolving ER workflows, which require flexibility and adjustments (Pickett et al., 2011; Mangrum \& Pozzebon, 2012; Vickery, 2004). Some academic libraries in developing countries such as Nigeria and Ghana are even yet to formulate and integrate ICT policies (Anie \& Achugbue, 2009; Dadzie \& Walt, 2015).

\subsubsection{Attitude of Stakeholders}

The literature has revealed various attitudinal factors that affect the management of ERs (Boamah \& Liew 2017; Cullen \& Chawner, 2009). Cullen \& Chawner (2009) in their study on institutional repositories (IRs) and the role of academic libraries in scholarly communication emphasised that, a major obstacle to developing IRs was getting faculty to submit intellectual contents to the repository. McDowell (2007) in investigating IR deployment in American academe since early 2005 revealed that all respondents in charge of IRs in the US indicated a major obstacle as obtaining contents from academics. This in McDowell's view challenges the purposes of IR as alternative avenues for scholarly publishing. Various strategies have been proposed to resolve reluctance to submit intellectual contents to the repository, such as appointing individuals who have informal leadership roles to lead the collection of contents (Jones, Andrew \& MacColl, 2006). Mandatory deposits have also been advocated (Harnad, 2006; Pinfield, 2005).

Boamah \& Liew (2017) conceptualised the digitisation and preservation of indigenous knowledge focusing on attitude in developing countries and revealed that whereas developed countries were challenged by how to manage enormous collection size, developing countries faced attitudinal hindrances such as fear of loss of heritage among cultural heritage owners, lack of interest in digitisation among stakeholders, and conflicting digitisation ideas among information professionals. Boamah, Dorner \& Oliver (2012) identified attitudinal enablers such as interest in IT and positive cultural attitudes as influencing digital preservation of cultural heritage in Ghana. However, various attitudinal hindrances were identified which included lack of interest in information management, political attitudes, conflicting interests of stakeholders, lack of respect for documentary resources and negative traditional and cultural attitudes. Another negative attitude is resistance to change. Mwilongo (2017) asserted that $21^{\text {st }}$ century CDPs require that librarians acquire ICT skills. However, most librarians in Tanzania had been resistant to change ultimately affecting the implementation of CDPs. These studies are relevant 
to ERs because they reveal potential attitudinal factors that can affect the management of ERs particularly in a developing country context.

The literature has revealed various factors surrounding ERM in academic libraries. However, it fails to conceptualise the ways in which the management of ERs affects its usage to provide better recommendations for practice to encourage high usage. That notwithstanding, the literature served as a basis in identifying potential contextual factors affecting the management of ERs in academic libraries in Ghana. Additional factors from a developing country context were identified based on the research findings. Also, this study fills the gap in the literature by conceptualising the ways in which ERM affect its usage in academic libraries.

\subsection{Usage of ERs in Academic Libraries}

The main function of academic libraries is to create a learning environment in which the academic community is provided with a variety of library resources and, ultimately trained to become competent users (Korobili et al., 2006). Huge financial resources are required in developing and sustaining ER services. For this reason, librarians are concerned about their use. A well-known phenomenon in the literature is the under usage of ERs provided by academic libraries (Ansari, 2010; Malemia, 2014; Korobili et al., 2011; Akussah et al., 2015; Kwadzo, 2015; Kwafoa, et al., 2014). It therefore becomes necessary to examine some of the factors affecting the use of ERs which is the goal of the following sub-section.

\subsubsection{Factors Affecting the Usage of ERs in Academic Libraries}

Various factors have been identified as affecting the usage of ERs. Upon analysis, these factors can be categorised as individual or background characteristics and contextual factors.

\subsubsection{Demographic characteristics}

With this paradigm, researchers focus on individual characteristics or trait variables to explain an individual's propensity to use a new technology. Demographic characteristics identified by researchers include perception, age, gender, educational level or academic rank, and subject discipline. These are discussed next. 


\subsection{Perception of ERs by Academic Researchers}

The literature has revealed that psychological factors, specifically perception play a role in the acceptance of ERs by users (Dukic \& Striskovic, 2015; Ukachi, 2015). Perception of ERs refers to the way in which these resources are regarded, understood, and interpreted by users (Dukic \& Striskovic, 2015). Positive perception about these resources is likely to foster high usage as indicated in some studies (Buchana et al., 2013; Egberongbe, 2011) whereas negative perception is likely to hamper usage (Dzandu \& Boateng, 2013; Ukachi, 2015). Users' perception and expectations of libraries are constantly changing due to other competing information resources on the Web (Liu, 2006). For this reason, academic libraries need to make every effort to discover users' misperceptions about their ERs and put in place measures to promote usage (Dukic \& Striskovic, 2015).

\subsection{Gender}

Gender has been highlighted in the literature as impacting on the use of ERs. However, the findings on gender are mixed. Whereas some researchers have revealed that men are more likely to use ERs (Bassi \& Camble, 2011; Tella \& Mutala, 2008; Tury, Robinson \& Bawden, 2015), other studies have reported a higher use among females than men (Steinerová \& Šušol, 2007). A third group of researchers found that the gender gap in the use of ERs was not significant (Makori, 2015; Malemia, 2014; Tahir et al., 2010). The literature on gender as an influencing factor is therefore inconclusive.

\subsection{Subject Discipline or Field of Study}

Studies have revealed subject discipline as affecting the uptake of ERs in academic libraries. Some researchers have indicated the fact that humanities scholars are low users of ERs (Barret, 2005; Stanton \& Liew, 2011; Sukovic, 2008; Tahir et al., 2010). On the contrary, Toms \& O'Brien (2008) saw a significant change in findings from studies that observed reticence among humanists to use ERs. Other studies have rather reported high usage of ERs among social science academic researchers (Negahban \& Talawar, 2009). Conversely, some studies have indicated academic researchers in the sciences as the highest adopters of ERs (Dukic \& Striskovic, 2015; Nwagwu et al., 2009; Sheeja, 2010). A study by Malemia (2014) identified no association between subject discipline and use of electronic journals. These studies are important in discussing how the findings of the current research relates with the larger literature. 


\subsection{Age}

According to the literature, the usage of ERs can be affected by the age group of users. It is a generally held view that younger users are more comfortable with ERs. For this reason, younger academic researchers make more use of ERs than their older counterparts (Makori, 2015). On the contrary, some studies have revealed that, all things being equal, age has little or no influence on the uptake of ERs. Malemia (2014) found no relationship between age and usage of electronic journals although older staff valued printed sources more.

\subsection{Educational Level}

Researchers have revealed that the higher the educational level of users, the more likely they are to use the ERs of libraries because they would have become more familiar with them (Dukic \& Striskovic, 2015). Undergraduate students tend to use less ERs compared to graduate students and faculty (Liu, 2006) and usually consult the Web as their primary source of information with little regard to quality of information (Dadzie, 2005). However, some studies have found no relationship between academic status and usage of electronic journals (Malemia, 2014; Das \& Achary, 2014).

\subsubsection{Contextual Factors Affecting Usage of ERs}

Students and faculty now have access to a wide range of electronic information through a variety of channels including library websites, search engines, research publication archives, specific websites of research institutions, and subject gateways. The attributes of these services and other contextual factors greatly affect information seeking, access and use patterns (Gardiner, McMenemy \& Chowdhury, 2006).

\subsection{Awareness of ERs}

Research has indicated lack of awareness as one of the main reasons for the under usage of ERs: it is impossible for users to make use of a service of which they are unaware. Services that would have otherwise been under-used or unused could be highly used if awareness level were high. High levels of awareness positively impact on the usage of ERs in libraries (Dhanavandan, Esmail \& Nagarajan, 2012; Owolabi et al., 2012) whereas low awareness levels negatively impact on usage (Ansari, 2010; Campbell-Meier, 2015; Damilola, 2013; Das \& Achary, 2014; Nisha \& Ali, 2013, Stanton \& Liew, 2011). Alsalmi, Liew \& Chawner (2014) conducted a study on contextual factors that affect the adoption and development of Electronic 
Theses and Dissertations (ETD) programmes in the Arab Gulf States and found that inadequate promotional activities affected the adoption of ETD programmes.

In Ghana, Kwafoa et al., (2014); Akussah et al., (2015); Dadzie \& Walt, (2015) and Kwadzo, (2015) revealed low usage levels of ERs in academic libraries due to lack of awareness. However, some studies have indicated that high awareness levels may not necessarily translate into usage (Asefeh \& Nosrat, 2007; Baro et al., 2011, Kwadzo, 2015) due to interest/relevance and familiarity (Swain, 2010) or perception of users about these resources (Dukic \& Striskovic, 2015; Ukachi, 2015). Nevertheless, the pre-eminence of awareness creation of services or marketing of library collections cannot be overemphasised and should form an important component of implementing ERs in academic libraries (Emery \& Stone, 2013; Hosburgh, 2014; Velasquez \& Campbell-Meier, 2018).

\subsection{Searching Skills}

Searching skills, next to awareness is an important pre-requisite in accessing ERs in libraries. Although students and faculty may be computer literates, they would require some searching skills to access the ERs of their respective libraries. Inadequate ERs searching skills is likely to impede the use of ERs (Adeyoyin, Idowu \& sowole, 2016; Buchanan et al., 2013; Das \& Achary, 2014; Damilola, 2013; Ukachi, 2015, Malemia, 2014) or at best, result in usage by trial and error (Ansari, 2010; Ndinoshiho, 2010). Required searching skills include a knowledge of the structure of online databases and their instructions (Okello-Obura, 2010). The implementation of digital literacy programmes in academic institutions would go a long way to influence the use of ERs of the library.

\subsection{Access to ICT Infrastructure}

ICT infrastructural challenges such as inadequate computers, lack of off-campus access or power cuts can hinder the use of ERs in academic institutions. This appears to be a significant factor in the developing world especially in African countries (Akussah et al., 2015; Dadzie \& Walt, 2015; Damilola, 2013; Das \& Achary, 2014; Kwadzo, 2015; Malemia, 2014; Okorie \& Agboola, 2012). It is not uncommon to find students queuing at ICT centres or various computer laboratories on campuses waiting for their turn to use a computer to access ERs. Networking challenges also hinder the use of ERs in academic libraries (Ansari, 2010; OkelloObura, 2010). This is not surprising since developing countries usually face financial and infrastructural challenges making it difficult to provide the state-of-the-art ICT infrastructure. 
Consequently, users turn to other available options such as print documents or freely available electronic information via private Internet cafés (Malemia, 2014).

\subsection{Lack of Relevant Materials / Local Content}

Relevance is the main impetus for the use of ERs. If users perceive these resources as irrelevant to their information needs, it will result in non-usage. Various studies have revealed irrelevant contents and lack of local contents as contributing to the low usage of ERs of academic libraries (Cameron \& Siddall, 2015; Malemia, 2014; Sheeja, 2010; Tahir et al., 2010). This points towards inadequate assessment of the information needs of users by the library. A survey of 16 academic libraries in Cuba by Sanchez (2005) revealed that libraries did not adequately conduct user survey to ascertain user information needs. Academic libraries can only cater to the needs of users when they have a proper understanding of their needs (Calvert \& Neo, 2012). The literature calls for the inclusion of users in the selection of ERs and conducting user information needs analysis to ensure that relevant resources are made available to them (Emery \& Stone, 2013).

\subsection{Social Factors}

Social factors have been identified in the literature as affecting the usage of ERs in academic institutions. However, these factors have not received equal attention in the literature compared to demographics and other contextual factors earlier presented in this review. Social factors include recommendations by superiors and colleagues, duties and responsibilities of users and affinity to alternative sources of information.

The influence of superiors and colleagues within the user community can encourage or hinder the use of ERs in academic libraries. Faculty can influence their colleagues and students towards using ERs of the library. Studies have revealed the role played by faculty in the usage of ERs of the library by students (Mbabu et al., 2013; Chirra \& Madhusudhan, 2009). Alsalmi, Liew \& Chawner (2014) examined the influence of contextual factors on the adoption of Electronic Thesis and Dissertation (ETD) programmes in the Arab Gulf States. Using semistructured interviews, the findings revealed contextual, institutional, and personal factors as affecting the adoption of ETD programmes. The findings highlighted the significance of social factors in influencing the adoption and development of ETD programmes. The demands of institutional curricula and faculty can contribute to the usage of ERs by students. Teaching methodologies and curricula in some academic institutions in Africa appear not encourage 
students to conduct research using the ERs of the library as students are usually expected to reproduce teaching materials or notes from faculty during examinations and other assessments (Korobili et al., 2011).

A study conducted by Kim (2010) on motivations and barriers to faculty self-archiving showed that concerns about copyright, the effort and time it took to submit a content was a barrier. In Nigeria, Malemia (2014) revealed that an increase in demand for teaching due to large class sizes, and assessment responsibilities such as examination, invigilation and marking of scripts hindered the use of ERs of the library by faculty as they had less time for research that would encourage usage of these resources Similarly, Damilola (2013) revealed that excessive academic workload prevented students from using ERs of the library. However, other studies have revealed that some students simply prefer rival available and easily accessible information resources on the Internet to those of their institutional library (Albitz, 2008; Lamothe, 2013).

Section 2.8 has reviewed literature on the usage of ERs in academic libraries. Various factors have been identified as affecting the usage of ERs, which are categorised as demographic characteristics of users and contextual factors. Comparatively, the literature showed that conversations surrounding demographic factors as impacting on the usage of ERs are inconclusive. The review also revealed that social factors affecting the usage of ERs had not received equal attention compared to other contextual factors. Building on the literature, this study investigates the demographic and contextual factors affecting the usage of ERs of the library within the Ghanaian context.

\subsection{Chapter Summary}

Bearing in mind the research questions and main concepts of the study, this chapter has reviewed literature on the concept of ERs, impact of ERs on academic libraries, ERM, planning for ERs, implementing ERs, factors affecting ERM, usage of ERs and factors affecting the usage of ERs in academic libraries. The literature showed that the definition of ERs has evolved from a narrow to a more widened scope to include content, systems and programmes. The impact of ERs on academic libraries has also been highlighted. The literature established that libraries have had to adapt and restructure their processes and staffing to cope with the new environment. Deeper collaboration and frequent staff training have been a defining facet of the ER environment. 
Regarding planning for ERs, the literature reviewed on policies for ERs has mainly focused on the availability and implementation of ER policies. Guidelines for budgeting for ERs have been provided and the need for flexibility in allocating financial resources to ERs has been highlighted. Also, ER staffing challenges and requirements for a successful ERM have been addressed in the literature. However, there is still much discussion needed in the literature on planning for ERs, particularly on the development and assessment of ER policies, ER staff motivation and strategies for sustainable funding for ERs.

The study also reviewed literature on the implementation of ERs in academic libraries, which consists of establishing ER workflow and adopting an approach to facilitate the workflow. Recommended best practices for managing digital collections have been put forward which can serve as a point of reference for academic libraries in developing countries such as Ghana. That notwithstanding, there is a lack of research that takes a holistic view of ERs in academic libraries. There is the need for a more holistic research on ERs by investigating together the concepts of management and usage of ERs to better inform practices and attract maximum usage as recommendations made by previous studies have not adequately addressed surrounding challenges. Furthermore, the literature on ERM approach or model adopted by libraries has focused predominantly on the developed country context leaving a gap regarding the developing country context. Finally, various factors have been identified as affecting the management and usage of ERs in academic libraries. Some of the factors are inconclusive whereas others have received less attention in the literature. This study therefore builds on the literature by identifying additional factors of ERM and usage, and fills the gaps by studying the concepts of management and usage of ERs in the context of a developing country. 


\section{Chapter Three \\ Theoretical Foundations}

\subsection{Introduction}

This chapter introduces the theories that underpin this study. Various authors have presented a number of ways in which a study employs theories such as an initial guide to support data collection and data analysis, or the product of a study (Creswell, 2012; Gregor, 2006; Walsham, 2006). After considering several theories that can guide the study, two theoretical frameworks were found to be particularly pertinent. These are the Techniques for Electronic Resource Management (TERMS) framework (Emery \& Stone, 2013) and the Unified Theory of Acceptance and Use of Technology (UTAUT) (Venkatesh, Morris, Davis \& Davis, 2003). These theories provided conceptual lenses to guide data collection to answer the questions the study seeks to address.

The chapter begins by providing a justification for choosing the selected theoretical frameworks, followed by a presentation of the frameworks. Finally, it presents a new preliminary conceptual model of factors developed from ideas from the literature and selected frameworks which served as the basis of data collection, analysis and discussion in this research.

\subsection{Justification for Choosing the Selected Theories}

The problem that informed this study was that, few researchers have studied both concepts of management and usage of ERs in a single study to reveal how they are related. In addition, the literature on the management of ERs in libraries has predominantly focused on developed countries leaving a gap in the context of developing countries. This research therefore fills the gap by studying both concepts with a focus on a developing country context. Furthermore, there is evidence (Adzobu, 2014; Dadzie \& Walt, 2015) suggesting that academic libraries in Ghana are ineffective in managing ERs, which could explain the observed low usage of ERs. There is therefore a lack of understanding on how ERs are managed, as well as the contextual factors surrounding the management and usage of these resources in Ghanaian universities. This necessitated an exploratory investigation to understand these issues and factors in order to recommend strategies for addressing them. 
To address the research problem, the following research questions are raised: "How are ERs managed and used in academic libraries in Ghana?"; "What are the contextual factors surrounding the management and usage of ERs in academic libraries in Ghana?"; "In what ways do these contextual factors affect the management and usage of ERs in academic libraries in Ghana?" and "In what ways does the management of ERs affect its usage and vice versa"?

In this study, the management of ERs is considered as a complex iterative process as indicated in the literature (Bothmann \& Holmberg, 2008; Elguindi \& Schmidt, 2012; Mangrum \& Pozzebon, 2012) and, in order to understand this phenomenon in the Ghanaian setting, a framework that would help investigate the process of managing the various stages or lifecycle of ERs was required. In addition, to understand and identify the factors surrounding the planning, implementation, and usage of ERs, a framework that facilitated exploration of context was required. Due to the multi-faceted nature of the research problem that the study seeks to investigate, it was deemed insufficient to use a single theory. More than one theoretical framework was therefore required. The TERMS framework was deemed appropriate and therefore adopted to investigate the management of ERs in the case institutions, and an initial conceptual model based on factors from the literature and UTAUT provided a lens for investigating and understanding the factors surrounding the management and usage of ERs in academic libraries in Ghana. These theoretical foundations are explained in the following subsection.

\subsection{Techniques for Electronic Resource Management (TERMS)}

TERMS is a project initiated by Jill Emery of Portland State University and Graham Stone of University of Huddersfield in 2008. The framework emerged as a result of the authors' quest to find a solution to inconsistencies in the practices of managing ERs in libraries. TERMs seek to spell out the lifecycle of ERs and proposes best practices for managing the lifecycle of these resources (Emery \& Stone, 2013).

\subsubsection{Stages of TERMS}

TERMS details a checklist outlining the workflow across the ER lifecycle. It defines six stages in the iterative lifecycle of ERs which are investigation of new content, acquisition of new content, implementation, ongoing evaluation and access, annual review, and cancellation and 
replacement review (Emery \& Stone, 2013; Hosburgh, 2014). Figure 3.1 depicts the TERMS framework showing the stages. An explanation of each stage in the framework then follows.

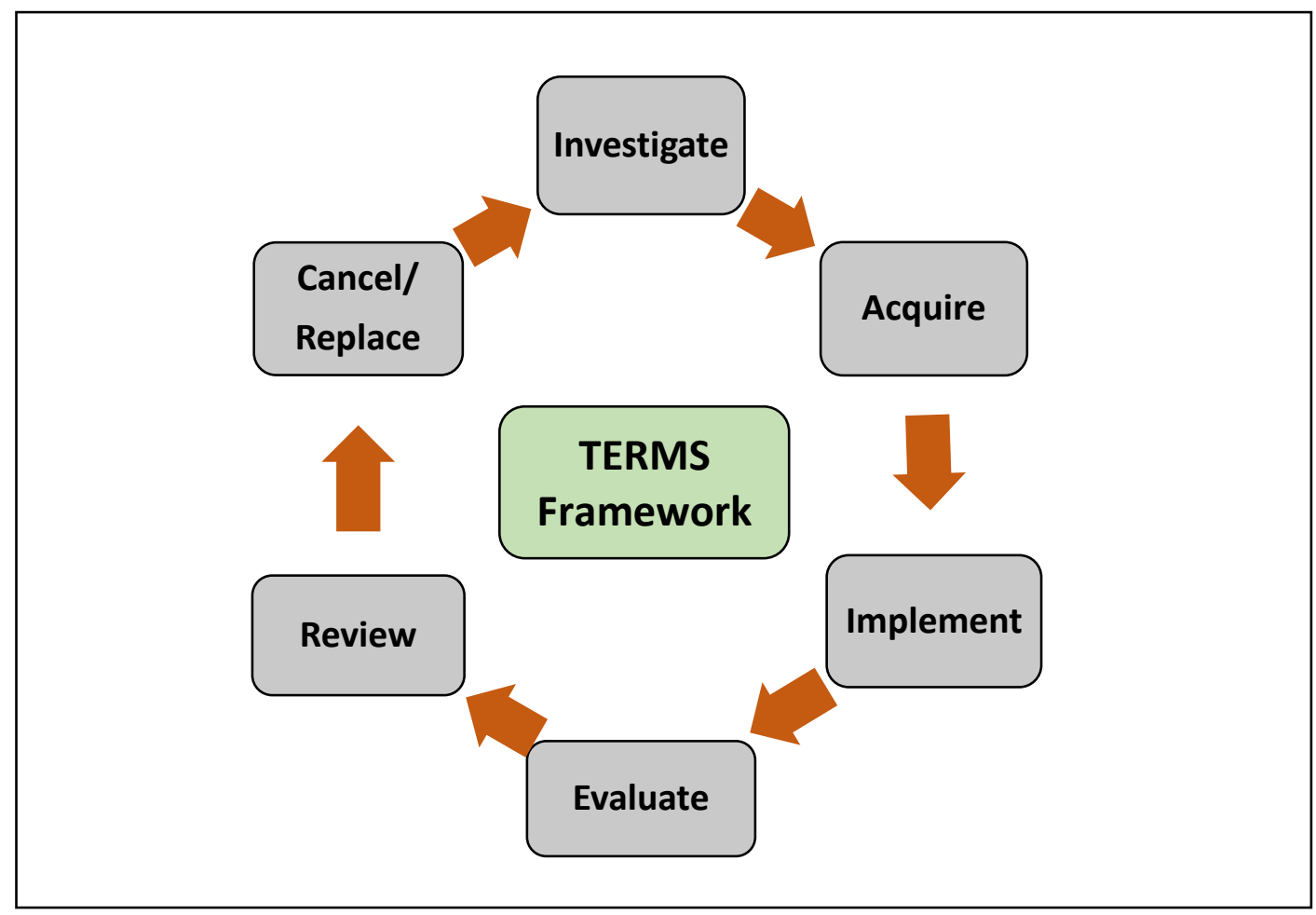

Figure 3. 1. The TERMS framework (Emery \& Stone, 2013)

\subsubsection{Stage One: Investigating New Content for Purchase or Addition}

This stage involves evaluating new content using established criteria based on existing collection development policies (CDPs). According to the TERMS guidelines, content is paramount. Evaluation criteria mainly cover relevance and attributes of ERs. The framework proposes focusing on exact needs, documenting specifications, building a team of experts, market review, trial set up, discussing with vendors/suppliers and selection of content. A documentation of purchase or rejection decision then follows (Emery \& Stone, 2013).

\subsubsection{Stage Two: Acquiring New Content}

The next stage after selecting the resource is acquisition. The nature of the selected contents determines largely how complicated or straightforward this stage will be. At this stage, TERMS specifies the need for librarians to negotiate with publishers over terms of payment and /or contract. Top factors to consider are definition of site, definition of authorised users, remote access, IP authentication, access and connectivity, indemnification, privacy clauses, usage statistics, content transfer, third-party discovery tools, loss of funding out clause, application 
of venue to location and institutional guidelines, perpetual access, and price cap allowance. Signing and documenting licensing agreement then follows (Emery \& Stone, 2013).

\subsubsection{Stage Three: Implementation}

After acquisition, contents need to be implemented to facilitate exploitation. This stage may be complicated or simple depending on how small or large the ER is. TERMS prescribes various steps in this stage including testing of resource, marketing, training \& documentation, soft launch, feedback assessment and full launch. The product is first tested to ensure satisfactory performance after which ERs are marketed to target users and stakeholders to create awareness. A marketing plan and matrix, which outline target user groups, actions, responsibilities, and timing, should be developed. Training and user documentation are provided to users to facilitate usage (Emery \& Stone, 2013).

\subsubsection{Stage Four: Ongoing Evaluation and Access}

TERMS posits that acquired ERs take about a year to gain familiarity among users. For this reason, the best assessment occurs within three to five years. This stage involves assessing user behaviour and usage data mostly quantitatively; obtaining formal or informal feedback on the ERs from users; and tracking downtime and availability. It also involves checking various access points, and regularly communicating feedback from users with ER vendors/providers. Ongoing evaluation ensures that access is enabled, and everything is smoothly ongoing. This may be scheduled monthly, quarterly, or annually (Emery \& Stone, 2013).

\subsubsection{Stage Five: Annual Review}

This stage ensures that all resources are providing value for money. It mainly involves reviewing cost per download, usage statistics, new licenses and making it available to stakeholders for their input regarding renewal or cancellation decisions (Emery \& Stone, 2013).

\subsubsection{Stage Six: Cancellation and Replacement Review}

Ultimately, a decision is made regarding the retention, renegotiation or cancelling of each resource. Relevance and level of usage do not remain constant. ERs need to be cancelled for various reasons such as changing academic programs, a decrease in the usage of these resources, cuts to budget and changes in platform. This stage also involves noting the final decision taken in the ERM system and accounting system (Emery \& Stone, 2013). 
Chapters Five and Seven present data analysis and discussion on the process of ERM in academic libraries in Ghana.

\subsubsection{Applications of the TERMS Framework}

The Techniques for Electronic Resources Management (TERMS) framework has gained considerable recognition since its inception. It has provided a theoretical perspective to guide a number of studies providing insight into the workflow of ER life cycle; and integrated into a number of projects and curricula in librarianship. Fry (2013) in her study outlined the principles for creating a hybrid workflow for ER usage statistics, using the experience of Bowling Green State University's Jerome Library as a case study. The TERMS framework was applied in developing a hybrid statistic workflow framework. The framework integrated statistics workflow into all the stages of TERMS. Similarly, Wadekar \& Nagarkar (2018) investigated the management of online databases in university libraries in Maharashtra state of India. Using the descriptive survey method, the study applied the TERMS framework to examine the workflow of ERs including procedures for selection and acquisition of online databases, renewal procedures, and availability of infrastructure facilities as well as the challenges faced in managing online databases of the university libraries investigated.

In addition to providing a theoretical lens in various studies, TERMS has provided practical support to guide the workflow of ERs in academic libraries. TERMS was adopted as part of the framework for ER workflow for the library at Baruch College, City University of New York (Hamlett, 2016). Hosburgh (2014) developed a concise checklist for managing ERs based on the TERMS framework. He recommended the TERMS framework as a detailed checklist and valuable tool that can assist new ER librarians in managing the lifecycle of ERs.

In 2011, TERMS was used as a teaching aid at the School of Library and Information Studies, University of Wisconsin - Madison to establish a key framework for its ERM class. Similarly, Erb (2015) in a study on The impact of reorganisation of staff using the core competencies as a framework for staff training and development indicated that TERMS was used as a teaching tool during staff training at the Colorado State University Libraries. The techniques have been successfully applied to ERM workflow at the University of Maryland University College Library (England \& Miller, 2016). In 2012, TERMS was endorsed by the Knowledge Base+ project in the United Kingdom, a project of JISC Collections made up of a set of workflow management tools related to the selection, review, renewal, and cancellation of publications. It 
has also received recognition from GOKb (Global Open Knowledge base) managed by Kuali OLE (Open Library Environment) which is a community of nine research libraries working together to build an open-source system designed by and for academic and research libraries to manage and deliver intellectual information (Emery \& Stone, 2013).

Nevertheless, the TERMS framework has received some criticisms from researchers and practitioners. Fry (2013) pointed out the fact that, even though the framework provides advice on the collection and reporting of usage statistics at stages three to five, it failed to outline a workflow for gathering and reporting usage statistics. Also, after receiving comments and suggestions from stakeholders, it was realised that an important function or component of ERs had not been covered in the framework - Preservation. Preservation is key to provide long term access to ERs. Consequently, the TERMS team is working to transform the original TERMS version into TERMS Version 2.0 which would alter the sixth heading to include a section on "Preservation of Electronic Resource Content" while merging two of the existing components - "Ongoing Evaluation and Access" and "Annual Review” sections (TERMS Facebook Group, 2017; Emery \& Stone, 2013; Hosburgh, 2014). It is important to emphasise at this point that, this was not available at the time the study was being conducted and therefore not used in this study.

\subsubsection{Relevance of TERMS to this Study}

Despite the criticisms the TERMS framework has received as earlier mentioned in section 3.3.2, it has been referenced as a valuable source for best practices in managing ERs (Hosburgh, 2014; Rathmel, Currie \& Enoch (2015). Furthermore, it has a strong empirical basis since it is based on real life experiences and practices from the UK and USA (Emery and Stone, 2013). Due to its relevance and wide application, the study used TERMS as a lens to investigate and understand how ERs are managed in academic libraries in Ghana. Interview guides for selected library staff were developed based on the concepts in TERMS in addition to those identified in the literature. The study revealed the extent to which ERM processes in academic libraries in Ghana compare with the TERMS framework revealing what was missing in the Ghanaian context as well as what could be added to a new or revised framework. TERMS has been applied to libraries in the developed world such as USA, UK, and Canada. The usefulness of the framework to libraries in developing countries particularly in Africa is largely unexplored. One of the contributions of the study therefore is to apply the framework to an African context and fill the knowledge gap in the literature. 


\subsection{The Unified Theory of Acceptance and Use of Technology (UTAUT)}

The acceptance and use of technology as a component of implementing ERs/information systems has received extensive attention in research. Low adoption of technology in organisations and institutions in the 1970s (Rogers, 1995; Swanson, 1988) attracted the attention of researchers and practitioners to expend research efforts on the predictors of technology use. Consequently, various theoretical frameworks and models have been propounded to assist in the explanation and prediction of the acceptance of new technologies by users. These include the Technology Acceptance Model (TAM) (Davis, 1989); Theory of Reasoned Action (TRA) (Fishbein \& Ajzen, 1975); Theory of Planned Behaviour (TPB) (Taylor \& Todd, 1995b); Innovation Diffusion Theory (IDT) (Moore \& Benbasat, 1991; Rogers, 1995) and the Unified Theory of Acceptance and Use of Technology (UTAUT) (Venkatesh et al., 2003). Some of these theories/models share similar constructs although different terminologies are adopted.

The UTAUT theory consolidates eight models/theories to the acceptance of technology into a unified model. These eight models are the TRA (Fishbein \& Ajzen, 1975); TAM (Davis, 1989); the Motivational Model (MM) (Davis et al., 1992); the Theory of Planned Behaviour (TPB) (Ajzen, 1991); a model which combines TAM and the TPB (Taylor \& Todd, 1995b), the model of PC Utilisation (MPCU) (Thompson et al., 1991), the Innovation Diffusion Theory (Moore \& Benbasat, 1991; Rogers, 1995) and the Social Cognitive Theory (Compeau \& Higgins, 1995). The unified model was tested based on data from four organisations over six months at three different sessions and further confirmed using two different organisations all of which provide a strong empirical basis for the model (Venkatesh et al., 2003). A comparison of these individual theories/models projects the UTAUT model which integrates all these theories as being the most robust in investigating and predicting use and acceptance of technology (Venkatesh et al., 2003). Also, other theories such as Uses and Gratification Theory (UGT) were considered in this study. However, the variables of UGT appeared not clearly defined and therefore deemed unsuitable for the study. For this reason, the UTAUT model was adopted as a lens in this study to examine the individual and contextual factors surrounding the management and usage of ERs in academic libraries in Ghana. 


\subsubsection{Factors in the UTAUT Theory}

The core of UTAUT model lies in the assumption that, four major constructs that determine intention to use technology and usage behaviour are performance expectancy, effort expectancy, social influence, and facilitating conditions. The model also comprises four moderating factors which are gender, age, experience, and voluntariness to use. Figure 3.2 illustrates the factors in the UTAUT model.

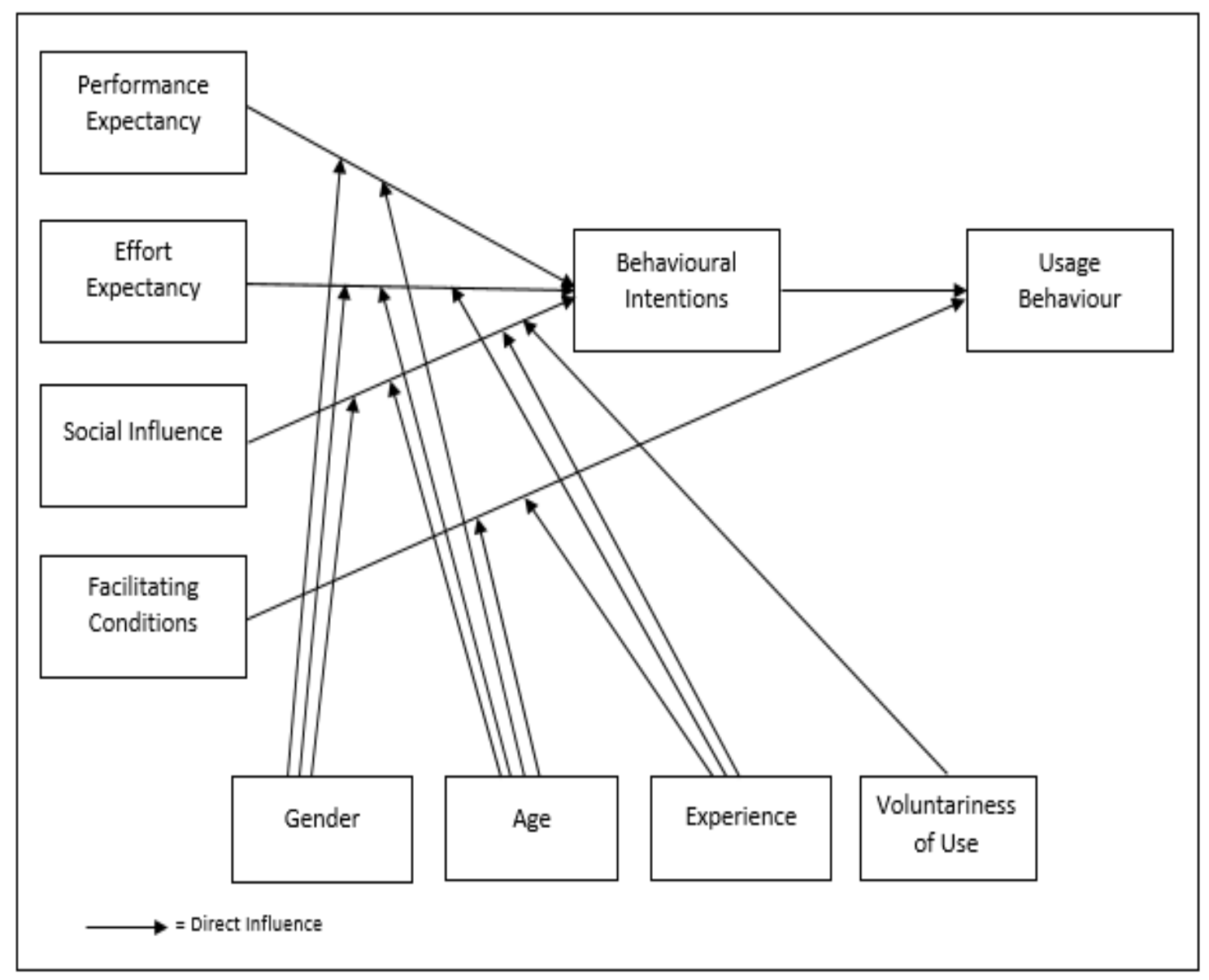

Figure 3. 2. The UTAUT model (Venkatesh, Morris, Davis \& Davis 2003)

\subsubsection{Performance Expectancy}

According to Venkatesh et al., (2003, p.447), performance expectancy is "the degree to which an individual believes that using a system will help him or her attain gains in job performance". This determinant is synonymous with constructs in other theories/models such as "perceived usefulness" (TAM/TAM2 and C-TAM-TPB), “extrinsic motivation” (MM), “job-fit” (MPCU), "relative advantage" (DOI), and "outcome expectations" (SCT). According to Venkatesh et al., this construct is the strongest predictor of intentions in both voluntary and mandatory settings. 
The authors also found that the association between performance expectancy and behavioural intention was moderated by gender and age.

\subsubsection{Effort Expectancy}

Venkatesh et al., (2003, p.450) define effort expectancy as the "degree of ease associated with the use of the system". This concept is similar to constructs in other models such as "perceived ease of use" (TAM/TAM2), "complexity" (MPCU), and "ease of use" (DOI). The authors found this construct to be significant in both voluntary and mandatory usage contexts. However, it is significant only in the initial stage of adoption and becomes less significant over prolonged and repeated usage. The model assumes that, the association between effort expectancy and behavioural intention to use a technology is moderated by gender, age, and experience.

\subsubsection{Social Influence}

Social influence is "the degree to which an individual perceives that important others believe he or she should use the new system" (Venkatesh et al., 2003, p. 451). This means that, an individual's intention to use a new system is based on the opinion of people they consider important to them. This construct is similar to those in related models such as "subjective norm" (TRA, TAM2, TPB/DTPB and C-TAM-TPB), "social factors" (MPCU) and "image" (DOI). The UTAUT model assumes that, this determinant has a direct effect in the context of mandatory usage whereas in voluntary contexts, social influence constructs are insignificant (Venkatesh et al., 2003). The authors further suggest that, social influence appeared significant only in the initial stages of a user's experience with the technology and becomes insignificant over time. The association between social influence and intention to use the system is moderated by gender, age, voluntariness, and experience.

\subsubsection{Facilitating Conditions}

Facilitating conditions is defined as "the degree to which an individual believes that an organisational and technical infrastructure exists to support the use of the system" (Venkatesh et al., 2003, p. 453). In other words, the use of system or technology depends on the available enabling environment. This determinant appears as concepts in related models such as "perceived behavioural control" (TPB/DTPB, C-TAM-TPB), "facilitating conditions" (MPCU), and "compatibility" (DOI). The authors further added that, facilitating conditions will become insignificant in predicting behavioural intention when performance expectancy 
and effort expectancy constructs are present. However, the model assumes that, facilitating conditions have a direct effect on usage (Venkatesh et al., 2003)

Concerning the moderators, the model assumes that gender has moderating effects on 'performance expectancy (PE) and behavioural intention (BI)'; 'effort expectancy (EE) and behavioural intention'; 'social influence (SI) and behavioural intention'. Also, age has moderating effects on 'PE and BI'; 'EE and BI'; 'social influence (SI) and BI' and 'facilitating conditions and use behaviour (U)'. Again, experience has moderating effects on EE and BI, SI and BI, FC and U. Voluntariness is assumed to have a moderating effect on SI and BI.

Venkatesh et al., (2003) further suggest three indirect determinants of behavioural intention which are attitude toward using technology, self-efficacy, and anxiety in addition to the four direct determinants of user acceptance and usage. These however do not have a significant effect on intention.

\subsubsection{Applications of the UTAUT Model}

The literature reveals a wide application of the UTAUT model to investigate user acceptance and use of technologies in different disciplines/fields and in various contexts while employing qualitative and or quantitative research techniques. Whereas some studies have fully applied the UTAUT and validated it (Arif \& Rafiq, 2016; Awwad \& Al-Majali, 2015), others have extended the model in different contexts (Oh \& Yoon, 2014). Yet still other studies (Padhi, 2018) have partially used the model as a theoretical lens for their research. Wiliams, Rana, Dwivedi, \& Lal (2011) conducted a systematic review on the application of the UTAUT model in research. Based on their findings, application of the model was grouped into four broad categories which were citations with no use of UTAUT, citations with use of UTAUT with different research methods, citations with partial use of UTAUT and citations with complete use of the UTAUT model.

Awwad \& Al-Majali (2015) studied electronic library services acceptance and use in public Jordanian universities. The study examined the determinants of use behaviour of electronic library services and moderating effects of gender, age, experience, educational level, and academic discipline. Employing the survey research design, the findings indicated that, students' use intention was dependent on performance expectancy, effort expectancy and social influence while use behaviour was dependent on intention to use and facilitating conditions. In 
addition, the findings revealed that the effect of performance expectancy on intention was significant for younger, undergraduate, and social science discipline students, whereas impact of effort expectancy on intention was significant for older and applied discipline students. In Pakistan, Arif \& Rafiq (2016) applied the UTAUT model in investigating the factors affecting student use of web-based services in the Pakistani context. Using the quantitative research method, the hypotheses tested revealed that performance expectancy, effort expectancy and social influence were significant predictors of intention to use Allama Iqbal Open University's (AIOU) web-based services. Facilitating conditions and behavioural intention affected the actual use of AIOU's web-based services. The effects of moderating variables with regard to gender, age and experience were insignificant according to the study's findings.

In Korea, Oh \& Yoon (2014) conducted a study on predicting the use of online information services based on a modified UTAUT model. The aim of the study was to modify the UTAUT model to provide a better understanding of Internet services user behaviour. The findings of the study revealed that the four main determinants of the model had significant impact on intention and actual use of Internet services.

In India, Padhi (2018) adapted the UTAUT model to investigate the acceptance and usability of open educational resources (OER) among faculty in Indian Higher Education. Using the survey method and focusing only on the four main determinants while excluding the moderators of the model, the study findings supported only two of the main determinants of the model, which are performance expectancy and effort expectancy. Other studies have applied the UTAUT model to investigate e-learning and related phenomena (Decman, 2015; Olasina, 2018).

\subsubsection{Relevance of the UTAUT Model to this Study}

Researchers employ theoretical frameworks in various ways as earlier mentioned. One strategy is to partially adopt a theoretical model in a study. Following the study by Padhi (2018), this study did not adopt the complete UTAUT model as the study's theoretical framework. However, it made a partial use of UTAUT by adopting the main determinants of the study to assist in interpreting the research findings. Drawing on the four main determinants of UTAUT as depicted in Figure 3.3, the study explored the possible factors surrounding the usage of ERs in academic libraries in Ghana. 
However, it is noted that the UTAUT model has received some criticisms since its development. The theory has been criticised for involving too many independent variables as predictors of behavioural intention and usage behaviour (Bogozzi, 2007); and being less parsimonious (Van Raaij \& Schepers, 2008). Another criticism or possible limitation of the model is that, emphasis is placed more on factors at the individual level rather than contextual or external factors (Oye, Lahad \& Robin, 2011; Oye, Noorminshah \& NorZairah, 2011). Despite the criticisms and possible limitations, the model is considered robust (Venkatesh et al., 2003) and has received a wide application. It was partially adopted for this study to investigate the perception and usage of ERs among faculty and postgraduate students in the case institutions.

\subsection{The Initial Conceptual Framework of Factors Affecting ERM and Usage}

An objective of the study is to identify the contextual factors affecting the management and usage of ERs in academic libraries in Ghana and to explain how these factors affect management and usage. Chapter Two of this thesis provides a review of the literature that discusses various factors that facilitate or hinder effective management and usage of ERs of the library. In this section, an initial conceptual framework of factors to guide the exploration and understanding of factors surrounding the management and usage of ERs is developed based on factors from the literature and the UTAUT model. The initial framework provided a lens for analysis of data obtained from the interviews and surveys. That notwithstanding, the study was open to new factors that could emerge from the research findings. The initial conceptual framework was revised after analysis of the findings from the interviews and surveys (See Chapter Eight). Figure 3.3 depicts the factors derived from the literature and theory to guide the exploration of ERM and usage factors in Ghana. 


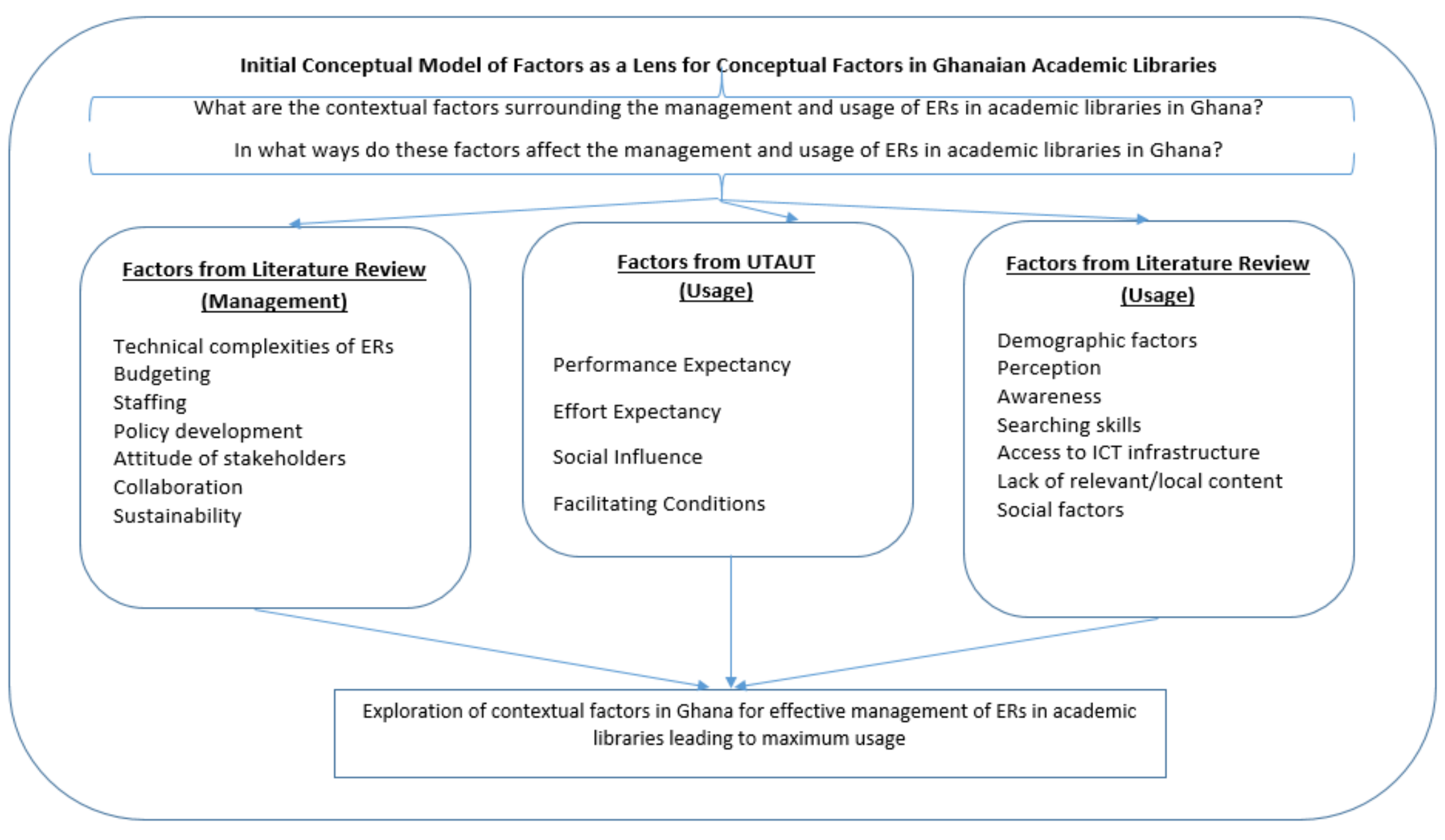

Figure 3. 3. Initial conceptual model of factors that guided exploration of ERM and usage factors 
Based on a combination of factors from the literature and UTAUT, several factors were identified that could facilitate or hinder the management and usage of ERs in academic libraries in Ghana. Although the initial conceptual framework shows separate factors from the literature on management, usage and UTAUT, these factors are combined in a logical manner and explained below.

\subsubsection{Perception of ERs of the Library}

The literature has indicated that the way in which ERs are regarded by users can affect how they use the resources. Performance expectancy and effort expectancy are strong determinants of users' acceptance and usage of technology (Venkatesh et al., 2003). Research has established that when faculty and postgraduate students have a positive perception regarding the usefulness of ERs of the library it is likely to foster usage (Buchana et al., 2013), whereas usage will be hampered when users have a negative perception about these resources (Dzandu \& Boateng, 2013; Ukachi, 2015). Users' perceptions and expectations of libraries are constantly changing. For this reason, it is necessary to periodically investigate the perception of users. Combining performance expectancy and effort expectancy from UTAUT and perception from the literature, this study was interested in the perception of faculty and postgraduate students on ERs of the library in the case institutions to understand its usage.

\subsubsection{Social Influence}

The literature has highlighted social influence as playing a role in the usage of ERs of the library. When users are encouraged by respectable people or people in their social circle to use a system, they are likely to use it (Venkatesh et al., 2003). The influence of colleagues and/or faculty over the usage of ERs has been highlighted in the literature (Mbabu et al., 2013; Chirra \& Madhusudhan, 2009). Combining social influence from UTAUT and social factors identified in the literature, this research was interested in investigating the impact of social influence on the usage of ERs of the library in the case institutions.

\subsubsection{Demographics of Users}

Studies have indicated the impact of demographic profile of users on the uptake of ERs. Whereas some researchers have indicated demographic profile as moderating factors (Venkatesh et al., 2003), others have indicated demographic factors such as gender (Tury, Robinson \& Bawden, 2015); age (Makori, 2015); subject discipline (Dukic \& Striskovic, 2015; 
Tahir et al., 2010) and educational level (Dukic \& Strisckovic, 2015; Liu, 2006) as direct determinant of usage of ERs. The study was interested in exploring the effects of demographic profile on the usage of ERs of the library among faculty and postgraduate students in the case institutions.

\subsubsection{Facilitating Conditions}

Organisational and technical infrastructure that exist to support the use of technology can impact on the level of usage of ERs (Venkatesh et al., 2003). The literature has highlighted various activities and infrastructural related issues that facilitate or hinder the use of ERs of the library. These include promotional efforts such as awareness creation (Das \& Achary, 2014; Olawabi et al., 2012); user training/equipping users with searching skills (Adeyoyin, Idowu \& Sowole, 2016; Ukachi, 2015); access to ICT infrastructure (Das \& Achary, 2014; Malemia, 2014) and technical complexities associated with ERs (Anku, Kataria \& Ram, 2013; Elguindi $\&$ Schmidt, 2012). Facilitating conditions provided a guide in understanding conditions within the case institutions that affected the management and usage of ERs of the library.

\subsubsection{Policy Development for ERs}

Studies have pointed out the importance of policies for ERs as they inform stakeholders about the management of ERs throughout the ER lifecycle. (Johnson, 2009; Mangrum \& Pozzebon, 2012). The literature has raised concerns about poor ER policy development in both developed and developing countries which contributes to adverse consequences such as inconsistent ERM practices. This study was interested in investigating ER policy development in the case institutions to understand its impact on ERM.

\subsubsection{Budgeting for ERs}

Finance is an important resource without which libraries cannot function effectively particularly regarding planning for ERs. Budgeting for ERs has been indicated in the literature as a major challenge particularly for the developing world (Dadzie \& Walt, 2015; Kaur \& Walia, 2016). This study aimed to understand how ERs of the library were budgeted for in the case institutions.

\subsubsection{Staffing for ERs}

Research has highlighted the key role of staffing in ERM. Staffing to a large extent determines the success of ER implementation (Abrams, 2015). As ERs continue to expand and outgrow 
conventional materials in libraries, libraries are creating ER positions and defining ER responsibilities. The role of ER librarian highlighted in the literature include planning, selecting, implementing, and assessing ERs (Elguindi \& Schmidt, 2012). This research was interested in investigating the staff in charge of ERs, the role they played and capacity building in both public and private case institutions.

\subsubsection{Collaboration}

Studies have revealed collaboration as a current trend in ERM. Increased demands of the technological environment compel libraries to adopt collaborative efforts in managing ERs (Delaney \& Bates, 2015; Massis, 2016). Collaborative ventures include internal collaboration within the library (Elguindi \& Schmidt, 2012; Hsiung, 2008) or external collaboration through a consortium (Kaur \& Walia, 2016). The study was interested in understanding the impact of collaboration on ERM in the case institutions.

\subsubsection{Sustainability}

As indicated in the literature, effective ERM practices to ensure adequate ER services require planning for sustainability. In this way, ER services are likely to attract maximum usage by users. Sustainability concerns planning for infrastructural maintenance and upgrade, continual ER subscription, and continuous professional development. The literature has revealed challenges of managing ERs, such as inability to meet subscription deadlines and staff training challenges, all of which point towards inadequate planning for sustainability (Okogwu \& Ozioko, 2018). This study was interested in investigating the sustainability of ERs/ services in the institutions investigated.

These initial factors provided a guide for exploring the contextual factors of the management and usage of ERs in academic libraries in Ghana. A revised model is presented in Chapter Seven which highlights changes in the model.

\subsection{Chapter Summary}

This chapter of the thesis has outlined the theoretical foundations of the study. Firstly, the TERMS framework was adopted as the theoretical lens to investigate the management of ERs in academic libraries in Ghana. Secondly, based on components of the UTAUT model and literature review, an initial conceptual model of factors affecting the management and usage of 
ERs was developed to guide data collection and analysis to answer the research questions. The next chapter (Chapter Four) presents the research design and methodology adopted in the study. 



\section{Chapter Four \\ Research Methodology}

\subsection{Introduction}

This chapter discusses the methodology employed for this study. Research methodology is a systematic way that is adopted in solving a research problem (Creswell, 2012; Pickard, 2013). The chapter covers the research paradigm, research methodology and approach, unit of analysis, case selection, the research process, data collection tools and procedures, methods of data analysis, limitations of the study and ethical considerations. The chapter concludes with a summary.

\subsection{Research Paradigm}

A paradigm in research refers to a set of viewpoints that influences an action (Lincoln \& Guba, 1994). All research begins with assumptions about the nature of the world, which guide the approach, and direction of research activities as well as the nature of research outputs (Pickard, 2013; Lincoln \& Guba, 1998). Although every discipline has a dominant paradigm, there is no dominant paradigm in Information Science due to its diverse nature (Pickard, 2013). Three major research paradigms in Information Science are positivism, post-positivism and interpretivism (Pickard, 2013). A research paradigm is defined by ontology, epistemology, and methodology. Ontology refers to the nature of reality; epistemology refers to the relationship between the knower and the known. Methodology refers to how knowledge is acquired (Pickard, 2013, p.14).

\subsubsection{Post-positive Paradigm}

After considering the main paradigms in Information Science, the post-positivism paradigm was found most suitable and therefore adopted for the study. Post-positivism emerged to address the short comings of positivism although they share similar ontological and epistemological beliefs (Pickard, 2007). In this paradigm, researchers rely on facts as well as the context within which the facts occur to obtain a holistic picture (Ryan, 2006). A postpositive paradigm is critical realism, whereby ontological realism posits that reality is independent, external to humans and associated with uncertainty and probability. It also assumes that cause and effect relationships exist but can hardly be explored to its logical conclusion (Pickard, 2013). In terms of epistemology, this paradigm argues that knowledge is 
constructed through interpretation, however the onus lies on the researcher to remain objective in the research process through external validity (Pickard, 2013). Post-positivism seeks to learn from rather than test reality (Ryan, 2006) which fits the main aim of this study. Concerning methodology, the post-positivist paradigm allows for "critical multiplism" which is similar to triangulation (Guba \& Lincoln, 1994, p. 110). It therefore facilitates a combination of qualitative and quantitative data collection methods (Pickard, 2013). To explore and understand how ERs are managed and used, the contextual factors surrounding these activities in academic libraries in Ghana, and how the concepts of ER management and usage are related, the research adopted qualitative and quantitative methods. Furthermore, the post-positivist paradigm was deemed suitable for this study as it facilitates an in-depth study of a phenomenon within a specific context based on components of existing theory. Academic libraries in Ghana formed the context of the study and a priori factors from the literature, TERMS framework and UTAUT model underpinned this study. In summary, the post positivist paradigm supports the focus of the study and the methodology that was followed in answering the research questions.

\subsection{Mixed Methods Research Methodology}

Research methodology refers to the overall research activity and there are two basic types which are qualitative and quantitative research methodologies. Quantitative methodology asks questions regarding how many, how often, or when whereas qualitative methodology asks questions relating to why, how, or personal experiences (Pickard, 2013). Research design should be flexible enough to allow questions to be addressed using the most appropriate method without inhibiting discovery and innovation (Pickard, 2013; Yin, 2014). Creswell (2012) also argues that, combining both quantitative and qualitative methods provides a better understanding of the research problem rather than employing either of the two by itself. Vohra (2014) asserted that case studies employ various data collection methods such as interviews, questionnaires, documents, and observation to generate qualitative and or quantitative data.

This study therefore adopted mixed methods which facilitates the gathering of both qualitative and quantitative data in a study (Pickard, 2013). This allowed the study to employ suitable data collection methods and procedures to arrive at conclusions. There are various types of mixed methods designs. These include the convergent parallel, explanatory sequential, exploratory sequential, embedded, transformative, and multiphase designs (Creswell \& Plano-Clark, 2007). Creswell (2003) provided guidelines for choosing a mixed methods design and these guidelines 
revolve around implementation sequence of the quantitative and qualitative data, priority, integration stage, and the use of an overall theoretical perspective (e.g., gender, race/ethnicity, lifestyle, and class).

Implementation refers to whether the researcher collects both the qualitative and quantitative data in phases (sequentially) or simultaneously (concurrently). The researcher also has to decide on priority, whether to give equal weight to both qualitative and quantitative, or prioritise one over the other (Creswell, 2003). Also, in mixed methods design qualitative and quantitative data can be integrated at various stages in the research process which are data collection, analysis, interpretation, or a combination of them. The final factor to consider is whether the entire design is guided by a theoretical perspective which would operate irrespective of the implementation, priority, and integrative features of the adopted strategy.

Based on the guidelines provided by Creswell (2003), the convergent parallel design was selected for this study. This type of mixed methods design allows the researcher to gather qualitative and quantitative simultaneously, analyse them separately but merge the two sets of findings to assess how they converge and diverge, in order to develop a complete understanding of the phenomenon (Creswell \& Plano-Clark, 2007). The study collected qualitative and quantitative data concurrently. However, based on the focus and interests of the study, more weighting was given to the qualitative aspect of the research. The quantitative data therefore served to support the qualitative data which could be annotated by QUAL + quan indicating a qualitatively oriented concurrent parallel design. Prioritising one type of data collection method and analysis over the other is well suited for research undertaken by graduate students (Creswell, 2003). Qualitative and quantitative data were integrated at the data interpretation stage. The study was also guided by theoretical perspectives as discussed in Chapter Three of this research. Figure 4.1 depicts the convergent parallel design adopted in the study. 


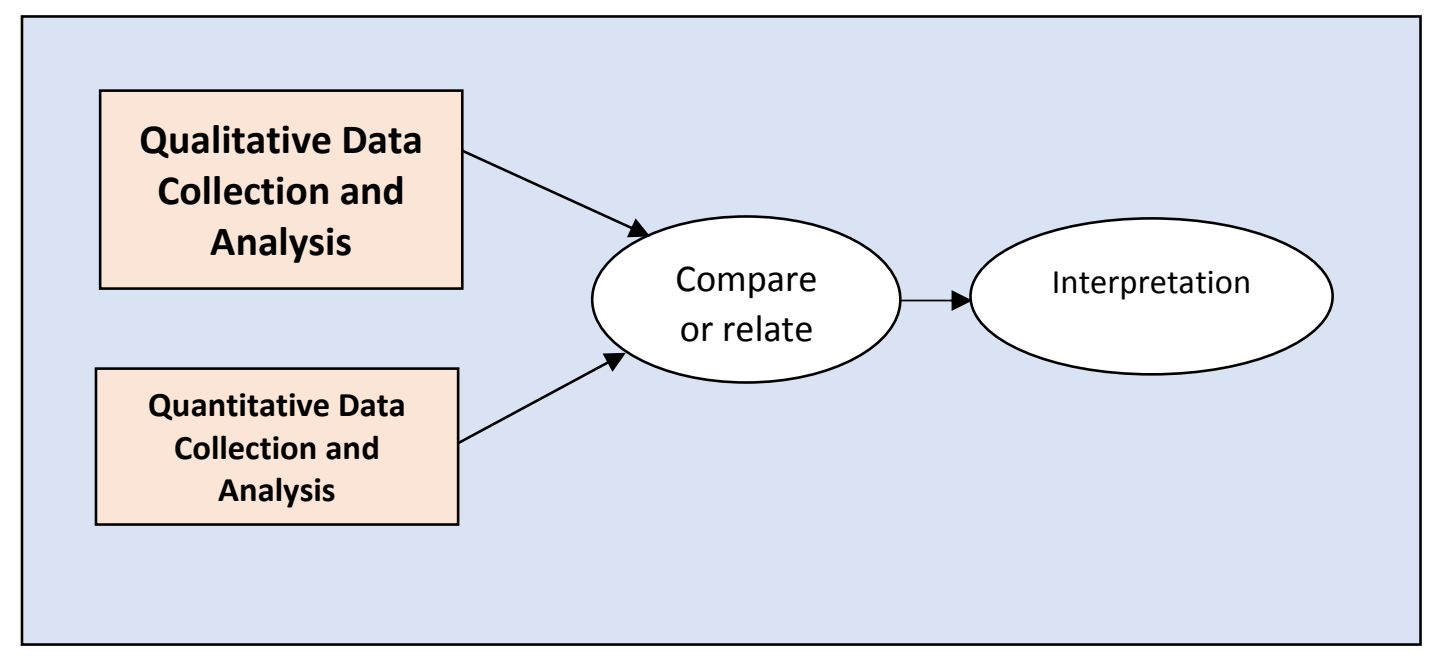

Figure 4. 1. The convergent parallel design (Adapted from Creswell \& Plano-Clark, 2007)

\subsection{Research Approach}

The choice of a research method or approach is influenced by "research questions, the extent of control a researcher has over actual behavioural events, and the degree of focus on contemporary as opposed to entirely historical events" (Yin, 2014. p. 9). Considering these three factors, this study adopted the case study approach. A case study is "an empirical inquiry that investigates a contemporary phenomenon in-depth and within its real-world context, especially when the boundaries between phenomenon and context are not clearly evident" (Yin, 2014. p. 16). It focuses on an in-depth study of a case, which can be individual(s), events, an institution, a programme, activities or a process (Creswell, 2012). It is appropriate when answering "how" research questions, investigating a contemporary phenomenon and when the researcher has little or no control over something or when behaviours cannot be manipulated (Yin, 2014). The case study approach is one of the most common approaches in the field of information systems (Orlikowski \& Baroudi, 1991; Liu \& Myers, 2011).

This study seeks to understand how ERs are managed and used in academic libraries in Ghana and the researcher believes that understanding this contemporary phenomenon would involve pertinent contextual factors thereby making the case study method suitable. Case study approach has however received some criticisms including lack of rigour, bias, time commitment and generalisability of findings. According to Yin (2014), some authors argue that case study researchers do not follow systematic procedures and therefore the method is not 
rigorous enough. In addition, bias may occur more frequently. Another concern is inability to generalise from case study findings. However, findings can allow for analytic generalisations or generalising to theoretical propositions (Yin, 2014).

\subsection{The Type of Case Study Research}

Case study research basically investigates either a single case or multiple cases. Yin (2014) described four major types of case study design based on single or multiple units of analysis. These are single-case holistic, single-case embedded, multiple-case holistic, and multiple-case embedded designs. Case studies can also be classified as exploratory, descriptive, or explanatory. Single cases facilitate in-depth study of a phenomenon by generating rich description and insight (Walsham, 1995b). However, researchers have highlighted limitations of the single case research regarding analytical generalisation (Lee, 1989). To address this drawback, multiple cases can be included in a study to strengthen the results and make the study more robust through repetition of patterns (Yin, 1994). Multiple case designs are appropriate when the research seeks provide a description, build, or test a theory. Yin (2003) posits that, multiple cases may be adopted to predict similar or contrasting findings. This strategy facilitates cross-case analysis of a phenomenon in various settings and produces more general findings thereby enhancing external validity (Benbasat, Goldstein \& Mead, 1987).

Yin (1994) pointed out that, multiple case designs are desirable if a study seeks to build a theoretical framework and explore its implications in diverse settings. This study aims to explore how ERs are managed and used in academic libraries in Ghana to develop frameworks that can be applied to libraries similar or diverse contexts. This exploratory study therefore adopted the multiple-case holistic approach as illustrated in Figure 4.2 with coloured broken lines. 


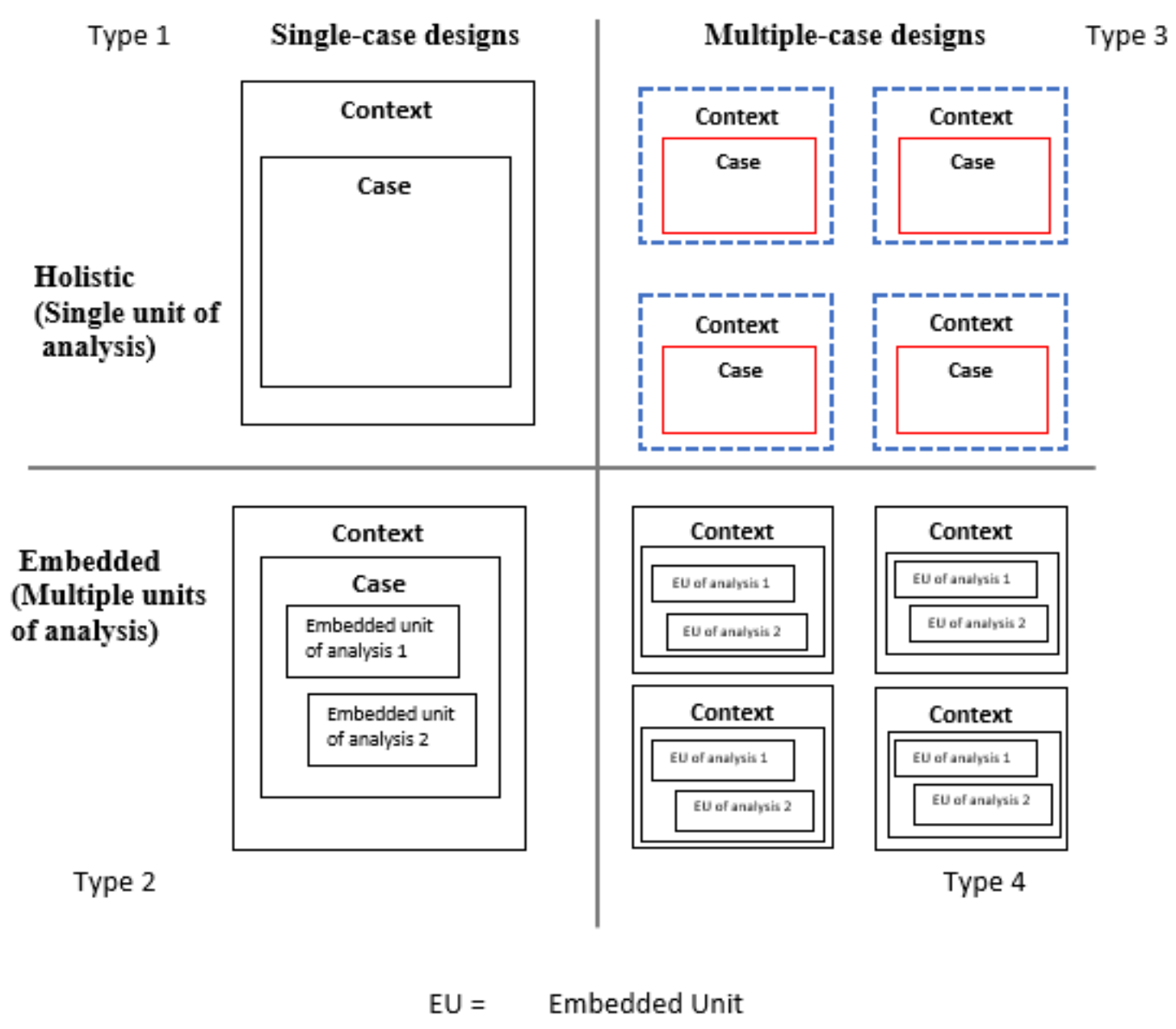

Figure 4. 2. Basic types of case study design (Adapted from Yin, 2014, p. 50)

\subsection{Unit of Analysis (The Case)}

Prior to choosing study sites, it is necessary for the researcher to determine the case or most suitable unit of analysis for the research (Benbasat, Goldstein \& Mead, 1987). The 'case' in a case study may be an individual, a group, a programme, an organisation, nation, events, or activities (Creswell, 2012; Yin, 2014). Research questions determine the appropriate case or unit of analysis, which sets a boundary for the phenomenon of interest in a study (Miles \& Huberman, 1994).

The main research questions of the study are how are ERs managed and used in academic libraries? What are the contextual factors surrounding the management and usage of ERs? and In what ways does the management of ERs affect its usage and vice versa? Considering the research questions of the study, an appropriate unit of analysis is the academic library at 
the institutional level to facilitate cross-case analysis of ERM practices and ER usage in the selected academic libraries, and the contextual factors surrounding these activities in the institutions.

\subsection{Case Selection}

In selecting cases for a study, it is important to select cases that can provide detailed insights on the phenomenon and help answer research questions (Pickard, 2013; Yin, 2014). Yin (2014) provides guidelines for selecting cases: when eligible candidates exceed twelve, there is the need for a two-stage screening procedure to select the most suitable. The first criterion is the selection of cases where similar results are predictable. The second criterion is to select cases whereby contradictory results could be predicted (Yin, 2014). In this study, eligible cases exceeded twelve for which reason the guidelines provided by Yin (2014) were followed.

For this study, the first criterion used in screening eligible candidates is membership of the Consortium of Academic and Research Libraries and Ghana (CARLIGH) to ensure that similar results were predictable (Yin, 2014). To ensure that contradictory results could be predicted as further recommended by Yin, the second set of criteria consists of age, resources, size, and accessibility for researcher. Cases selected are the University of Ghana (UG) and University of Cape Coast (UCC), which are public universities; and Central University (CU) and Wisconsin International University College (WIUC), which are private universities. The selection of these four universities is justified by the fact that they have a similar structure, they are accessible to the researcher which made data collection feasible and are all members of CARLIGH. They have access to over ninety thousand journals of various subjects that CARLIGH offers its members. However, they are dissimilar in terms of age, size, resources, and the fact that two are public (UG and UCC) and the other two (CU and WIUC) are private institutions.

UG is the oldest public university, largest and well-endowed in terms of ICT infrastructure and other resources whereas UCC is a comparatively less endowed public university. CU is the largest and well-endowed private university whereas WIUC is relatively new, less endowed in terms of resources, and smaller in size. These similarities and differences were meant to facilitate a cross-case analysis and to discover prevailing contextual factors in these diverse settings. Table 4.1 provides an overview of the selected cases. 
Table 4. 1: An Overview of the Selected Cases

\begin{tabular}{lcccc}
\hline \multirow{2}{*}{ Name of University } & $\begin{array}{c}\text { Year } \\
\text { Established }\end{array}$ & Library Staff & Faculty & $\begin{array}{c}\text { Postgraduate } \\
\text { Students }\end{array}$ \\
\cline { 3 - 5 } & 1948 & 183 & 1,179 & 4,820 \\
\hline $\begin{array}{l}\text { University of Ghana } \\
\text { (Public) }\end{array}$ & 1962 & 210 & 680 & 2,680 \\
$\begin{array}{l}\text { University of Cape Coast } \\
\text { (Public) }\end{array}$ & 1988 & 34 & 330 & 820 \\
$\begin{array}{l}\text { Central University } \\
\text { (Private) }\end{array}$ & 2000 & 15 & 157 & 210 \\
$\begin{array}{l}\text { Wisconsin International } \\
\text { Univ. College (Private) }\end{array}$ & - & 442 & 2346 & 8530 \\
\hline Total & & & & \\
\hline
\end{tabular}

\subsection{The Research Process}

The study followed a research process developed by Dubé and Paré (2003) to enhance the rigour of case study research in Information Systems. Their guidelines address the various phases of the research process which are research design, data collection and data analysis.

Phase One of the study involved engaging with the literature to identify the research gap and questions of the study as presented in Chapters One and Two. Theoretical models/frameworks were then identified and an initial conceptual framework of factors affecting ERM and usage was developed to guide the research design, data collection and analysis. This was followed by the selection of a suitable research approach to address the research question.

Phase Two covered the research design and in order to select appropriate cases for the study, the context was taken into consideration and insights obtained on the diverse settings that served as candidate cases. Cases were selected based on both similarities and differences. Then taking into consideration the research questions, interview protocols and schedules, questionnaires and document analysis instruments were developed.

Stage Three consisted of a pre-test and then full data collection. The instruments were pretested using two institutions and this facilitated a review, assessment, and refinement of the research instruments prior to full data collection. Full data collection comprised 27 semistructured interviews with twenty-four (24) library staff from the four selected cases, and three (3) members of the governing council of CARLIGH. Data were also collected from surveys of 
faculty and postgraduate students, and documents identified as relevant were obtained from the selected cases.

Stage Four covered data analysis and discussion. Qualitative data obtained from the interviews and relevant documents were analysed. A within-case thematic analysis was presented followed by a cross-case analysis. Quantitative data obtained from the surveys were also analysed. Finally, the findings were interpreted and discussed, and the initial conceptual models or frameworks were revised to reflect how ERs were managed and used in academic libraries in Ghana as well as the surrounding contextual factors. Figure 4.3 summarises the research process.

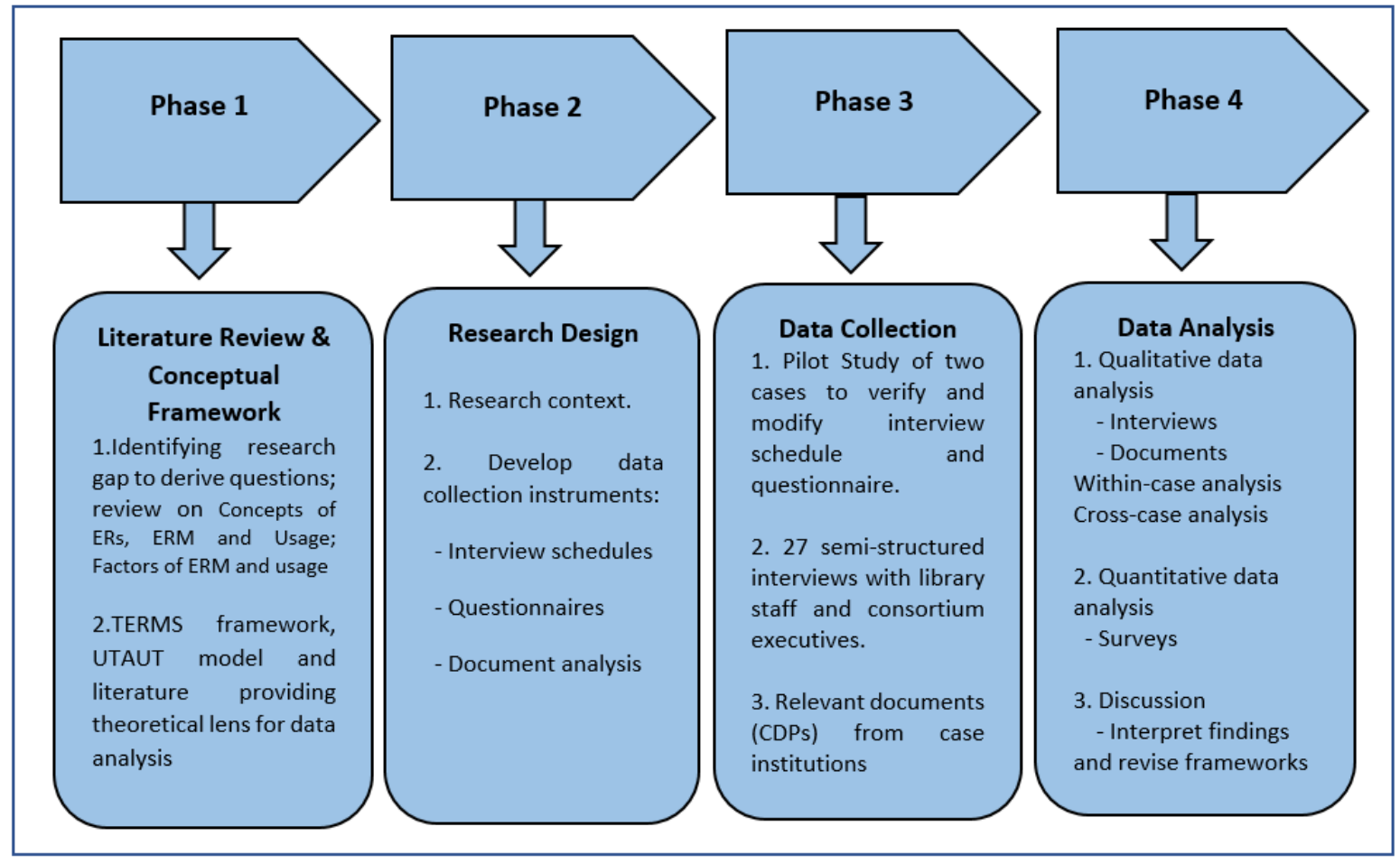

Figure 4. 3. A summary of the research process

\subsection{Data Collection Tools and Procedures}

Case research studies typically employ multiple data collection methods to facilitate triangulation which is also supported by post positivist research paradigm (Benbasat, Goldstein \& Mead, 1987; Pickard, 2013). Yin (2014) outlines various sources that can be used to gather data in a case study which are interviews, direct observation, participant observation, documentation, archival records, and physical artefacts. However, Pickard (2007) argues that it is not appropriate to presume that a certain approach dictates a certain strategy. Having 
obtained approval from the VUW Human Ethics Committee (HEC), this study adopted qualitative and quantitative data collection methods to obtain information needed to answer the research questions. Semi-structured interviews and questionnaires were employed, and collection development policies (CDPs) were obtained from the case institutions, all of which facilitated triangulation and verification of data.

\subsubsection{Interviews}

This study employed semi-structured interviews to obtain information directly from library staff and consortium executives. It consisted of a checklist of topics or questions without predetermined answers (Creswell, 2012; Pickard, 2013). This generated rich, contextual description of issues to facilitate understanding of the management, usage, and contextual factors of ERs in academic libraries in Ghana. Semi-structured interview allows the researcher to take "control over the line of questioning" by employing a schedule of questions (Creswell, 2012, p. 186). Following the recommendation by Yin (2003), the interview protocol or guide (see Appendix C) was developed based on the research questions, theoretical framework, and factors from the literature.

The interview process began by contacting interviewees from New Zealand via email explaining the research project. Upon informal agreement and arrival in Ghana, personal contacts with interviewees were made to formally explain the aims and objectives of the study to obtain formal consent, distribute hard copies of information sheet and consent form (see appendices A and B), and schedule the interviews. All 27 interviews took place in the offices of interviewees. Data collection spanned a period of five months (September 2017 - January 2018). Three of the case institutions (UG, CU, WIUC) as well as CARLIGH were in the country's capital and the remaining institution (UCC) was in the central region of Ghana. Challenges were faced in scheduling meetings with interviewees and traveling back and forth to their institutions, which slowed down the data collection process. Some sessions had to be rescheduled a few times as interviewees had unexpected changes in their schedules and were therefore unavailable for the interview.

Each interview session lasted between 40 minutes to 1 hour. The introductory stage of the interview sought to provide an overview of the interview process and build trust in interviewees as well as obtain background information about interviewees. The main part of the interview covered specific questions relating to the process of managing ERs and the enabling and 
hindering factors surrounding these activities. In order not to divert from the topic, the responses of interviewees were guided by the interview schedule. My familiarity with the Ghanaian context and the culture of the people enabled me to observe non-verbal cues during the interview session. At the final stage of the interview, a summary of interviewees comments was presented for confirmation. Opportunity was also given them to provide additional information. The interviews were recorded with the permission of interviewees alongside notetaking.

\subsubsection{Study Participants}

Interviewees of the study involved library staff and consortium executives. Library staff were deemed very important to this study, as they are responsible for managing ERs of the library and could provide the needed information to answer the research questions. As indicated in Table 4.1, the library staff populations for the four universities are as follows: UG (183), UCC (210), CU (34) and WIUC (15) giving a total of 442 library staff. However, interviewees were key stakeholders who played a role related to ERs of the library or were knowledgeable about the ERs. University librarians (library directors), heads of ERs, heads of digital repositories and the heads of the various units of case libraries were considered. It was considered that the library directors or university librarians would be able to provide information on planning for ERs particularly policy and budgetary concerns. The heads of ERs and institutional repositories were deemed able to provide relevant information on the development and management of ERs in their respective libraries. Furthermore, since the literature indicated a common trend of distributing ERs duties across units of the library, heads of various units were included in the study to explore the role they played in ERM practices of the library to reveal the ERM approach(es) adopted by these libraries. In addition, it was considered necessary to include members of the consortium CARLIGH due to the significant role they played in the management of ERs of case libraries.

\subsubsection{Selection of Interviewees}

To investigate the management of ERs in the four case institutions, this study employed the purposive sampling technique. In the view of Patton (2002), "the logic of purposeful sampling lies in selecting information-rich cases for study in depth. Information-rich cases are those from which one can learn a great deal about issues of central importance to the purpose of the research" (p.169). Pickard (2007) highlighted two approaches to purposive sampling which are a priori sampling which establishes a sampling frame prior to sampling; and snowball sampling 
which adopts an inductive approach in selecting the sample. This research adopted the a priori purposive sampling by identifying stakeholders and making a deliberate selection of library staff who played a role in the ERs of the library and senior managers of the library in the four case institutions who had the ability to provide information on ERs of the library. Also, members of the governing council of CARLIGH who played a role regarding ERs of the consortium and therefore had the ability to provide rich information for in-depth study of the phenomenon were included in the research. (Creswell, 2012; Patton, 2002; Pickard, 2013).

For the public case institutions (UG and UCC), eight (8) interviewees were selected at UG which included the university librarian (library director), head of ERs, head(s) of other units of the library and one other staff from the ER unit. Similarly, interviewees from UCC included the university librarian (library director), head of ERs, head(s) of other units of the library and two staff from the ER unit giving a total of eight (8). Regarding the private case institutions, six (6) interviewees comprising the system librarian and head(s) of units and campuses were selected from CU. At WIUC, two (2) interviewees consisting of the university librarian (library director) and head of ERs were included in the study. In addition, three (3) members of the governing council of CARLIGH were selected. These were the chair/director, ER chair and treasurer of CARLIGH. A total of twenty-seven (27) interviewees were included in the research. Table 4.2 illustrates the number of interviewees from the selected cases who were recruited in the study. Further details about interviewees are provided in Chapter Five section 5.3 .

Table 4. 2: Number of Study Interviewees

\begin{tabular}{ccccc}
\hline \multicolumn{2}{c}{ Public Academic Library } & \multicolumn{2}{c}{ Private Academic Library } & CARLIGH \\
\hline Institution & Interviewees & Institution & Interviewees & Interviewees \\
\hline UG & 8 & CU & 6 & 3 \\
UCC & 8 & WIUC & 2 & \\
\hline
\end{tabular}

\subsubsection{Pre-testing of Interview Guide}

A pre-test is necessary to refine data collection plan and procedures (Creswell, 2012; Pickard, 2013; Yin, 2014). Prior to the pre-test, the interview guide was reviewed by two academics who were knowledgeable in LIS research and qualitative research. For this study, the interview questions were tested at Ghana Institute of Management and Public Administration (GIMPA) 
which is a public university and Methodist University College (MUC) which is a private university. These sites were selected based on geographic proximity and presumed accessibility. Gaining access to the former site was quite challenging unlike the latter as unexpected bureaucratic procedures had to be followed. Despite this challenge, in-depth information was provided by interviewees in both pilot institutions once full access was granted.

Interviews were conducted with the university librarian, head of ERs and a head of unit in the two institutions. Findings from the pre-test revealed a number of issues revolving around the selection of interviewees and interview questions. In respect of the interviewees, it was revealed that some ERs duties was carried out by CARLIGH which reflected the situation in the actual case institutions. For this reason, it was needful to include members of the governing council of CARLIGH who were involved with ERs. In respect of the questions, it became apparent that some were too long and not straightforward and thus required rephrasing for easy understanding. These questions were rephrased accordingly. It was also pointed out that, certain interview questions for head of ERs such as consortia matters would be better answered by the university librarian. These questions were added to the interview guide for the university librarian. Finally, it was established that certain questions in the interview guides for ER librarian would be better answered if directed to CARLIGH officials or representatives. This suggestion was therefore taken into consideration. Generally, responses from pilot interviewees assisted in improving upon the interview questions and process.

\subsubsection{Surveys}

Quantitative methodology asks questions regarding how many, how often, and when (Pickard, 2013). Myers (1997) outlined quantitative research methods including surveys and numerical techniques such as mathematical modelling and laboratory experiments. Considering the research questions on the usage of ERs, the study adopted the survey design to obtain information from users of ERs of the library in the institutions investigated. Pickard (2007) pointed out two common types of descriptive surveys which are exploratory and explanatory. Whereas descriptive or exploratory survey seeks to establish trends and patterns within a sample that can be generalised to a population, explanatory survey seeks to discover causal relationships between variables, thereby making use of hypotheses. This study largely employed descriptive survey as it sought to answer research questions rather than test hypotheses. 
Using survey as a data collection tool, data was obtained from faculty and postgraduate students of the four case institutions. A survey entails using a written list of questions which are ideally clear and easy to understand to which respondents provide answers (Kumar, 2005). The use of survey as a tool for data collection has advantages such as, it is appropriate for literate respondents and allows the collection of large volumes of data over a relatively short period. It is also easier to quantify and treat statistically. However, it precludes personal contact with respondents and sometimes accuracy of responses is compromised as well as possible low response rate (Kumekpor, 1999). Using survey is also practical particularly in the case where the researcher requires uncontroversial, relatively brief, and straightforward information (Denscombe, 2007). The study adopted a combination of structured and unstructured questionnaire designed by the researcher based on the research questions and initial conceptual framework. The structured aspect of the questionnaire provided multiple answers which respondents were expected to tick one or as many as applicable. The unstructured aspect of the questionnaire gave respondents the freedom to express themselves without any restraint. Two sets of questionnaires were developed and administered to faculty and postgraduate students respectively.

The surveys for faculty and postgraduate students consisted of 46 and 45 questions respectively both under seven sections $(A-G)$. These covered demographic data, awareness of ERs, usage, training, perception, challenges, and suggestions for improvement of ER services. The questionnaire also used Likert scale questions which allowed respondents to select responses that best stated their views relative to a list of statements (Pickard, 2007). The scale for each item was 1 = strongly disagree, $2=$ disagree, $3=$ neutral, $4=$ agree and $5=$ strongly agree. However, neutral $=3$ could have resulted in misinterpretation by respondents (see Appendix D). Various methods can be adopted in administering questionnaire which include face-to-face questionnaires, postal questionnaires, telephone questionnaires, and online questionnaire (Pickard, 2007). Initially, this study adopted online questionnaire. However, due to infrastructural challenges such as unstable Internet connectivity, respondents found it challenging completing the online survey. For this reason, hard copies of the questionnaires were made available and administered face-to-face to both faculty and postgraduate respondents. The average time required to complete the questionnaire was 25 minutes. The data collection period was between September 2017 to January 2018. No online surveys were completed and included in data collection. 
With the help of course representatives, library staff and receptionists at graduate hostels, questionnaires were administered to postgraduate students at three strategic points in the case institutions which were the lecture halls, libraries, and graduate hostels. Course representatives, library staff and receptionists at the hostels served as focal points for the collection of completed questionnaires. For the faculty, the questionnaires were administered to them in their offices and respondents were given 5 days due to time constraints to complete and return the questionnaires. After the fifth day, the researcher assisted by the assistants went back to their offices to collect the completed questionnaires. The survey findings were used to ascertain the extent the views of users supported, contrasted, or complemented those from interviews with library staff.

Some hindrances were encountered in administering the questionnaire. For example, getting faculty to agree to participate in the study and obtaining completed questionnaires was a challenge due to their busy schedules. Also, some incidences that had taken place in the country whereby past reports by investigative journalists had exposed compromising positions of many reputable figures in certain institutions and organisations (Nettey, 2019) led to the hesitation of some professors in partaking in the study The researcher was met with suspicion as some faculty thought she was an undercover foreign investigative journalist who had investigatory intent rather than academic study, even after showing an introductory letter from the School of Information Management (VUW), supporting documents and speaking in a local dialect as a proof of nationality. However, these faculty were finally excluded from the study.

\subsubsection{Survey Population}

A population refers to the entire community under investigation (Pickard, 2013). The survey had two different categories of population. These are faculty and postgraduate students in the identified universities. The decision to include faculty is justified by the fact that, their responsibilities include teaching and imparting knowledge to students. Also, they are expected to frequently engage in research publication to rise in academia. For these reasons, ERs are relevant to them. The population sizes of faculty in the four universities are as follows: UG (1,179), UCC (680), CU (330) and WIUC (157) giving a total of 2,346 as indicated in Table 4.3. The decision to focus on postgraduate students and not all students in this study is justified by the fact that the library, and for that matter ERs are more relevant to postgraduate students than undergraduate students due to the research-oriented nature of their programmes. The 
postgraduate student populations for the four universities are as follows: UG $(4,820)$, UCC (2,680), CU (820) and WIUC (210) giving a total of 8,530 as depicted in Table 4.3.

\subsubsection{Survey Sampling}

Sampling is the process of selecting study units from the target population in order to carry out empirical study (Pickard, 2013) as a complete study of the entire population is usually extremely difficult, and whereby studying the entire population may be unnecessary.

The total of the postgraduate students and faculty in the four universities are 8,530 and 2,346 respectively. Neuman (2007) posits that for smaller populations under 1000, a sample size of $30 \%$ is acceptable and for a moderately large population over 1000 a sample size of $10 \%$ is acceptable. However, for this study, in respecting resource constraints such as limited time and finance, a sample size of $5 \%$ of populations of the postgraduate students and faculty was selected giving sample sizes of 426 postgraduate students and 118 faculty.

Due to the sharp variation in the population of faculty and postgraduate students in the case universities, using proportionate sampling would result in small sample sizes for CU and WIUC which would not provide adequate representation in the study. For this reason, disproportionate sampling technique was adopted. Disproportionate stratified sampling is "a stratified sampling procedure in which the number of elements sampled from each stratum is not proportional to their representation in the total population" (Daniel, 2012, p.134). Daniel (2012) posits that, sometimes disproportionate stratified sampling may yield adequate sample sizes to facilitate detailed analysis within a relatively small stratum. For this reason, disproportionate stratified sampling may be a better option. The drawback of this technique however is that, the characteristic of the overrepresented group can skew the findings. For the postgraduate students, 107 (2.2\%), 107 (3.9\%), $106(12.9 \%)$ and $106(50.5 \%)$ were selected from the population of UG, UCC, CUC and WIUC respectively. For the faculty, 30 (2.5\%), 30 (4.4\%), 29 (8.8\%) and 29 (18.5\%) were selected from the population of UG, UCC, CU and WIUC respectively (See Table 4.3). 
Table 4. 3 Population and Sample Sizes of Respondents

\begin{tabular}{lcccc}
\hline \multirow{2}{*}{ Institution } & \multicolumn{2}{c}{ Faculty } & \multicolumn{2}{c}{ Postgraduate Students } \\
\cline { 2 - 5 } & Population & Sample & Population & Sample \\
\cline { 2 - 5 } UG & 1,179 & 30 & 4,820 & 107 \\
UCC & 680 & 30 & 2,680 & 107 \\
CU & 330 & 29 & 820 & 106 \\
WIUC & 157 & 29 & 210 & 106 \\
\hline Total & 2346 & 118 & 8530 & 426 \\
\hline
\end{tabular}

\subsubsection{Sampling Technique for Survey Respondents}

For both postgraduate students and faculty, disproportionate stratified sampling was used due to the various schools and faculties to which they belong. By so doing, a representation of the various schools and faculties was obtained. The various schools and faculties were categorised to form three strata: humanities, social sciences, and the sciences (Daniel, 2012). For each stratum in both categories of population, convenience/voluntary sampling technique was applied. An ideal sampling strategy for both faculty and postgraduate students would be a stratified random sampling since it offers every member of the population an equal chance to be selected in the sample. However, this method was not be feasible owing to time constraints. Stratified random sampling is time consuming and makes use of a sampling frame (a complete list); thereby requiring that one selects specific individuals (Creswell, 2012; Pickard, 2013) who may not even be available or willing to participate in the study. Consequently, stratified convenience/voluntary sampling was used in each university for collecting data from faculty and postgraduate students.

\subsubsection{Pre-testing of Surveys}

The surveys were pre-tested using fifty postgraduate students and twenty faculty in both pilot case institutions to obtain feedback from respondents on its clarity, comprehension and structure, particularly perceived time-cost of answering the questionnaire, perceived difficulty, and also to uncover any flaws in the design or specific questions. Prior to the pre-test, the questionnaires were reviewed by three academics familiar with LIS research and quantitative research methods, and useful feedback was obtained. For example, the reviewers proposed amendment to one of the questions taking into consideration the Ghanaian context. It was also suggested that, there should be an indication whenever necessary to skip questions based on the responses to avoid confusion. Finally, there were concerns about the length of the questionnaire. However, all questions were relevant to the research questions and were 
therefore left as such. Findings from the pre-test suggested that the questions were easy to understand and not ambiguous, as the majority of respondents indicated that the questions and instructions were clear. Generally, the questionnaires were modified accordingly based on the pre-test findings.

\subsubsection{Documentary Evidence}

Documents can provide detailed information to supplement information from other sources (Yin, 2014). In this study, relevant documents gathered for analysis include collection development policies (CDPs) of case libraries, strategic plan, and constitution of CARLIGH. The CDPs of UCC, CU and WIUC libraries were obtained and analysed. This provided a clearer picture on the extent to which ERs were addressed in the CDPs of the library. UG, according to the data obtained did not have CDPs at the time the research was being conducted.

CDPs of the case libraries were analysed using an evaluation tool developed by Mangrum \& Pozzebon (2012). Each document was read twice, first time for an overall understanding and a second time to note the elements covered. To establish inter-coder reliability, the researcher and a colleague coded one of the CDPs. Coding strategies were discussed beforehand using the criteria outlined by the authors as codebook. The criteria are cost, consortia, responsible parties, content, access, usability, assessment, licensing (user perspective), and licensing (library management). The researchers attained an agreement rate of $83 \%$ which was above the recommended 80\% agreement rate (Lombard et al.,2010). Data from documentary evidence was integrated with data from the interviews with library staff.

\subsection{Method of Data Analysis}

Data analysis is the method of organising and reducing research data to make it meaningful (Miles, Huberman \& Saldana, 2014). Since the study gathered both qualitative and quantitative data, different methods of data analysis were employed in the study. Using multiple data collection methods provides opportunity for triangulation which greatly supports the researcher's conclusions (Benbasat, Goldstein \& Mead, 1987). This section covers analysis of qualitative data gathered in this study followed by quantitative data analysis. 


\subsubsection{Qualitative Data Analysis}

Prior to data analysis, the audio recordings of interviews were transcribed to refine them into text to facilitate data analysis (Miles, Huberman \& Saldana, 2014). All 27 interviews were transcribed by the researcher. Transcriptions were organised and stored according to case institutions. A folder was allocated to each case institution where audio files, transcripts, contact information and relevant documents were stored. Transcripts were uploaded to the qualitative data analysis tool NVivo version 12. Selecting appropriate strategies and tools for qualitative data analysis was an important task in this study. Miles \& Huberman (1994) outlined components of qualitative data analysis: data gathering, data reduction, data display and conclusion drawing. This model was adapted for qualitative data analysis for the study. Figure 4.4 depicts data analysis procedures of the study.

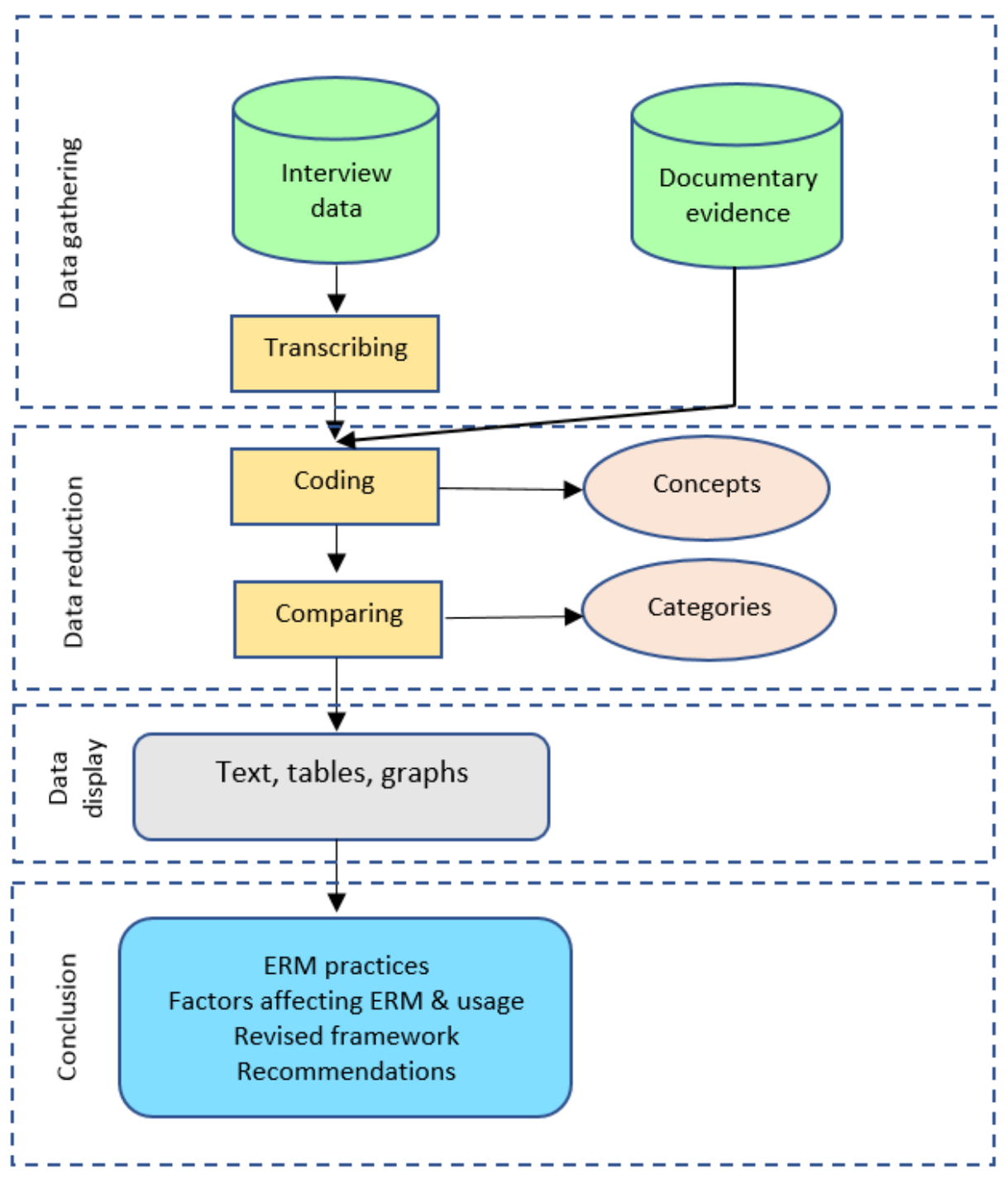

Figure 4. 4. Qualitative data analysis procedures (Adapted from Miles \& Huberman, 1994) 
Following data gathering is data reduction. Data reduction approach specified by Miles \& Huberman (1994) was followed in this study. This involved selecting, focusing and simplifying, abstracting and transforming fieldnotes and transcriptions. The stage involving coding of data. The qualitative data from the interviews was coded by selecting segments of the data and grouping them into categories to form concepts that provide insight, facilitate comparison and develop theory (Kaplan \& Maxwell, 2005). In alignment with the postpositivist paradigm which allows research to commence with established theory but make room for new themes to emerge (Creswell, 2003), the study adopted both inductive and deductive approaches to analysis of the interview findings. In deductive analysis, the researcher commences data analysis with a coding scheme based on the research questions and conceptual framework (Creswell, 2003). In contrast, the aim of inductive analysis is to allow themes to freely emerge from data without any limitation. This allows the researcher to make sense and identify multiple realities from the data (Lincoln \& Guba, 1985) and requires the researcher to work iteratively or back and forth to arrive at a set of themes (Creswell, 2012). Based on this technique for the qualitative data gathered, concepts and categories were derived to modify the initial conceptual framework.

For the documentary evidence, a deductive approach was used for data analysis. The CDPs of UCC, CU and WIUC libraries were analysed using an evaluation tool developed by Mangrum \& Pozzebon (2012). The evaluation tool listed nine criteria for ER collection development which are cost, consortia, responsible parties, content, access, usability, assessment, licensing (user perspective), and licensing (library management). These criteria are based on literature on policy development, definitions of components of ERM from the Digital Library Federation's Electronic Resource Management report (Jewell, et al., 2004). For this reason, the evaluation tool was deemed reliable and therefore adopted for the study although the authors conceded that, the tool did not allow the recording of depth of coverage but rather a more inclusive coverage (Mangrum \& Pozzebon, 2012). The evaluation tool and data analysis are presented in Chapter Five of this study.

Researchers have recommended that when analysing multiple case studies, "a typical format is to first provide a detailed description of each case and themes within the case, called a withincase case analysis" (Creswell, 1998, p. 63). Following this is a cross-case analysis or crosscase synthesis based on themes (Creswell, 1998; Yin, 2003). Adopting this approach, a within- 
case analysis was provided for the case institutions, after which the findings were synthesised in a cross-case analysis (see Chapter Five).

In conducting the within-case analysis, the researcher searched for themes that emerged as relevant to the description of the events (Daly, Kellehear \& Gliksman, 1997). It began by providing a description of individual cases regarding ERs and ICT infrastructure, then the planning and implementation of ERs followed. The cross-case analysis facilitated the comparison of similarities and differences in the activities and processes in the case institutions by comparing and contrasting or combining data from all cases to enhance robustness, generalisability, and applicability of results in other context. This process also deepens understanding and explanation (Miles, Huberman \& Saldana, 2014). Miles, Huberman \& Saldana proposed two approaches to cross-case analysis which are variable-oriented and caseoriented. A variable-oriented strategy looks for themes that cuts across-cases whereas a caseoriented suggests a replication strategy where cases are examined to see whether there are common patterns. It is usually helpful to combine both strategies for a more robust analysis (Miles, Huberman \& Saldana, 2014). For this reason, the study adopted both strategies for the cross-case analysis of the findings. This supported the stance of post-positivism which recommends a combination of strategies to maintain rigour (Ryan, 2006). Also, in interpreting the findings, cases were clustered in some instances using three criteria which are type of institution (public verses private institutions), size (large verses small) and resources (wellendowed verses less endowed).

The within-case and cross-case analyses were based on the initial conceptual frameworks. Upon completion of the analysis, the findings were compared with the literature to establish how the findings relates to the literature. Based on the discussion of findings, the TERMS framework and initial conceptual model of factors of ERM and usage were revised to reflect the findings.

\subsubsection{Quantitative Data Analysis}

The survey was largely descriptive or exploratory and therefore did not test hypothesis. The Statistical Package for the Social Sciences (SPSS) software was used for analysis of data. SPSS facilitates data management, display, retrieval and provides a means of quick data analysis (Pickard, 2007). After the questionnaires administered to faculty and postgraduate students were retrieved, a coding manual was developed, and questionnaires were translated into SPSS 
to facilitate analysis of data. The study employed descriptive statistics and inferential statistics. Descriptive statistics were used to analyse response rates, awareness, usage, training, perception, and challenges of using ERs. Chi-square test of association was used to examine the association of various factors with the usage of ERs. Results are presented in Chapter Six of this study.

\subsection{Evaluating Qualitative Research}

In evaluating qualitative research, trustworthiness and authenticity are mostly used by researchers (Creswell, 2005). The researcher used these two criteria to assess the quality of the research.

\subsubsection{Trustworthiness}

Trustworthiness refers to the criteria applied to enhance the value of research findings with regard to the methodology used. Establishing trustworthiness include credibility, transferability, dependability, and confirmability (Pickard, 2013). Credibility questions how one can establish confidence in the truth of the findings or how believable the results of the study are (Lincoln \& Guba, 1985). One main way to establish credibility is by adopting triangulation (Pickard, 2013). This study made use of both qualitative and quantitative data collection techniques to increase credibility. Combining multiple data collection techniques helps to address the limitations of techniques (Pickard, 2013) and ensures accurate information (Creswell, 2005). The use of interviews, surveys and documentary evidence assisted in verifying and complementing the data to increase credibility.

Transferability refers to the applicability of the conclusions of a study beyond its context. Qualitative studies allow for the transferability of findings rather than generalisation to a population. Transferability is usually facilitated by rich description (Pickard, 2013). In this study, detailed and rich description of data were provided on the cases regarding the management of ERs and contextual factors.

Dependability refers to whether the study's process is "consistent, reasonably stable over time and across researchers and methods" (Miles \& Huberman, 1994, p. 278). Theoretical frameworks were adopted to guide the study, and data collection protocols were developed for consistency in procedures. After data collection, the researcher emailed a report to supervisors 
for verification and feedback. Also, research procedures have been described in-depth to enhance dependability.

Confirmability seeks to ascertain relative neutrality and considerable freedom from unacknowledged researcher bias (Miles \& Huberman, 1994). Key interviewees were contacted to check the findings and claims, and conclusions were supported by interview excerpts. Confirmability can also be achieved by triangulation (Lincoln \& Guba, 1985). Triangulation was applied in this study as earlier mentioned.

\subsubsection{Authenticity}

Guba \& Lincoln (2005) outlined a number of criteria for ensuring authenticity of qualitative research which are fairness, educative authenticity, catalytic authenticity and tactical authenticity. Fairness refers to a fair representation of different viewpoints meaning each interviewee should have an equal chance to be included in the research. In this study, all viewpoints of interviewees were represented. Education authenticity entails ensuring that interviewees are informed about other interviewees' perspectives of their social setting. The study would accomplish this by publishing the findings in peer review journals. Also, interviewees were provided with summary of research findings to create awareness of contemporary issues surrounding the management and usage of ERs of their library as well as other libraries. Catalytic authenticity involves stimulating and motivating stakeholders towards required action. It is hoped that the findings of the research would stimulate stakeholders to take the necessary actions towards effective ERM practices for maximum patronage. Tactile authenticity refers to empowering stakeholders in the study to carry out necessary actions. The study provides practical recommendations to empower all stakeholders with requisite knowledge for effective management and usage of ERs in the institutions.

\subsection{Evaluating Quantitative Research}

In evaluating quantitative research, the common criteria used are validity and reliability.

\subsubsection{Validity}

Validity in quantitative study mainly refers to the validity of the instrument. It entails ensuring that questions measure the concepts they intend to measure. One strategy to test for clarity of questionnaire is by allowing a different set of respondents to assess the items on the 
questionnaire (Cavana et al., 2001). This research pre-tested the questionnaires in two different academic institutions as earlier presented in section 4.9.2.1. Also, scales from previous research were used to measure the constructs for the fact that their validity had already been determined. Further details on construct validity are presented in section 4.9.12 and Table 4.5. Again, external validity or generalisability is used to test validity in quantitative research (Creswell \& Plano Clark, 2011). This entails selecting a representative sample from the population (Pickard, 2007). However, since this study adopted convenience sampling technique, the resulting sample was not a probability one, as further discussed under section 4.13 (limitations of the study). That notwithstanding, the high response rates (88.1\% and 85.2\%), which equals 104 and 363 faculty and postgraduate students respectively, provided the possibility for the findings to be generalised to other settings in Ghana.

\subsubsection{Reliability}

Reliability refers to the accuracy, consistency, precision and predictability of the instrument. It is the extent to which a construct is measured by its indicators. Findings may not be reliable if the instrument is not assessed for reliability (Pickard, 2007). Reliability is widely calculated using the Cronbach's coefficient alpha (Pallant, 2001) which was adopted in this study. Ideally, the Cronbach's coefficient alpha should be above 0.7 and indicators below a value of 0.4 should be removed from the model (De Vellis, 2003; Hair et al., 2014). Existing scales from previous research (Venkatesh et al., 2003) were used to measure each construct since their reliability had already been established. However, to suit the context of the study minor changes were made to the wording of these existing scales. Reliability levels of all the indicators were above the recommended minimum value (0.7) as depicted by the Cronbach alpha values in Table 4.4. Each construct was measured using multiple indicators. 
Table 4. 4: Item Loadings

\begin{tabular}{|c|c|c|c|}
\hline Construct & & Measurement Item & Ld. \\
\hline \multirow[t]{4}{*}{$\begin{array}{l}\text { Performance } \\
\text { expectancy }\end{array}$} & PE 1 & $\begin{array}{l}\text { ERs of the library are more useful than alternative resources } \\
\text { freely available on the Web. }\end{array}$ & 0.88 \\
\hline & PE 2 & $\begin{array}{l}\text { My academic performance/outputs have improved as a result of } \\
\text { using ERs of the library. }\end{array}$ & 0.74 \\
\hline & PE 3 & Using the ERs of the library simplifies finding information. & 0.81 \\
\hline & PE 4 & $\begin{array}{l}\text { Using the ERs of the library reduces the time required for finding } \\
\text { information compared to alternative resources on the Web. }\end{array}$ & 0.80 \\
\hline \multirow[t]{4}{*}{$\begin{array}{l}\text { Effort } \\
\text { expectancy }\end{array}$} & EE 1 & $\begin{array}{l}\text { It takes a lot of effort to become skillful at using the ERs of the } \\
\text { library. }\end{array}$ & 0.75 \\
\hline & EE 2 & It is easy to get relevant information using ERs of the library. & 0.83 \\
\hline & EE 3 & Overall, it is easy to use the ERs of the library. & 0.89 \\
\hline & EE 4 & I am familiar with the ERs of the library and find it easy to use. & 0.84 \\
\hline \multirow{4}{*}{$\begin{array}{l}\text { Social } \\
\text { influence }\end{array}$} & SI 1 & I am encouraged by library staff to use ERs of the library. & 0.83 \\
\hline & SI 2 & $\begin{array}{l}\text { I am encouraged by lecturers/supervisors to use ERs of the } \\
\text { library. }\end{array}$ & 0.72 \\
\hline & SI 3 & I am encouraged by colleagues to use the ERs of the library. & 0.84 \\
\hline & SI 4 & $\begin{array}{l}\text { Assignments and recommendations by lecturers influence my } \\
\text { decision to use ERs of the library. }\end{array}$ & 0.82 \\
\hline \multirow[t]{8}{*}{$\begin{array}{l}\text { Facilitating } \\
\text { conditions }\end{array}$} & FC 1 & $\begin{array}{l}\text { I have easy access to the required facilities to use ERs of the } \\
\text { library. }\end{array}$ & 0.84 \\
\hline & FC 2 & $\begin{array}{l}\text { The training I received from the library has enabled my ability } \\
\text { to use the ERs. }\end{array}$ & 0.78 \\
\hline & FC 3 & I can access the ERs of the library whenever I want. & 0.84 \\
\hline & FC 4 & $\begin{array}{l}\text { Academic workload prevents me from making time to use the } \\
\text { ERs of the library. }\end{array}$ & 0.80 \\
\hline & FC 5 & I am able to retrieve relevant information in e-format. & 0.84 \\
\hline & FC 6 & I am confident using ERs of the library. & 0.80 \\
\hline & FC 7 & I am proficient in the use of the library's ERs. & 0.84 \\
\hline & FC 8 & $\begin{array}{l}\text { I possess the necessary knowledge and skills to use the ERs of } \\
\text { the library. }\end{array}$ & 0.81 \\
\hline \multirow[t]{2}{*}{ Attitude } & ATUT 1 & $\begin{array}{l}\text { I use alternative resources on the Internet rather than ERs of the } \\
\text { library. }\end{array}$ & 0.74 \\
\hline & ATUT 2 & I am satisfied with the library's ER services. & 0.72 \\
\hline
\end{tabular}

Note. $\mathrm{N}=140$

Convergent validity seeks to analyse the extent to which indicators explain a construct whereas discriminant or divergent validity tests whether constructs or measurements that are not supposed to be related are, in fact, unrelated (Fornell \& Larcker, 1981; Gefen \& Straub, 2005). Constructs were modelled using reflective indicators. All internal consistency reliabilities (ICRs) were above 7.0, which is the generally acceptable level (De Vellis, 2003; Hair et al., 
2014). The square roots of the shared variance between the constructs and their measurements were greater than the correlations across constructs thereby supporting convergent and discriminant validity (Fornell \& Larcker, 1981; De Vellis, 2003; Hair et al., 2014) as depicted in Table 4.5 .

Table 4. 5: Overview of Constructs and Measurement Model

\begin{tabular}{lcccccccc}
\hline & ICR & Mean & S Dev & PE & EE & ATUT & SI & FC \\
\hline PE & .92 & 5.12 & 1.13 & .94 & & & & \\
EE & .91 & 4.56 & 1.40 & $.31^{* * *}$ & .91 & & & \\
ATUT & .84 & 4.82 & 1.16 & $.29^{* * *}$ & $.21^{* *}$ & .86 & & \\
SI & .88 & 4.40 & 1.04 & $.30^{* * *}$ & $-.16^{*}$ & $.21^{* *}$ & .88 & \\
FC & .87 & 4.17 & 1.02 & $.18^{*}$ & $.31^{* * *}$ & $.17^{*}$ & $.33^{* * *}$ & .89 \\
\hline
\end{tabular}

Note. $1 . \mathrm{N}=140$

2. ICR: Internal Consistency Reliability

3. Diagonal elements are the square root of the shared variance between the constructs and their measures; off-diagonal elements are correlations between constructs.

4. PE: Performance Expectancy; EE: Effort Expectancy; ATUT: Attitude Toward Using Technology; SI: Social Influence; FC: Facilitating Condition.

It is worth mentioning again that the quantitative aspect of this study was largely exploratory with no hypothesis tested. For this reason, descriptive statistics were mostly employed in the study. Also, the Likert scale questions were treated individually.

\subsection{Limitations of the Study}

Like every other research, this study has a number of limitations. The limitations were related to both the research design/approach and context of the study. Firstly, the data collection was carried out within a limited period (September 2017 - January 2018). Also, due to the primarily qualitative and interpretive nature of this research, the findings could have other interpretations as remarked by Bryman (2004). However, various strategies were adopted to make the findings more valid and accurate as earlier discussed in this chapter. In addition, due to the convenience and disproportionate sampling techniques adopted, and the small sample sizes (5\%) used in the study, the findings may not be generalisable to other universities. Again, the findings are specific to Ghana and may not be generalisable to other developing countries. 
The findings also revealed that many interviewees had limited understanding of the management of ERs of the library which could have influenced their responses to the interview questions and the depth of discussion. Other stakeholders such as institutional leaders in the private case institutions could have contributed to the research since they were responsible for acquiring individual library subscriptions, as well as undergraduate students. Their perspectives could have added another dimension to the findings. However, owing to limited time and resources these groups were excluded from the study. Another limitation of this study is the fact that ERs are discussed as a whole rather than a variety of tools and interfaces which could have provided further depth to the findings.

\subsection{Ethical Considerations}

Research involving human subjects or affecting people's privacy are subject to Human Ethics Committee guidelines according to the Human Ethics Policy of Victoria University of Wellington. Since the research involved human subjects, the researcher obtained approval from the School of Information Management Human Ethics Committee (HEC) before commencing data collection. Consent was sought from interviewees by providing them with information sheets and requiring them to sign consent forms (see Appendices A and B). The rights of privacy and confidentiality of interviewees were respected by assigning pseudonyms to all interviewees. Also, all sources were acknowledged, and the researcher abided by the Victoria University of Wellington's code of conduct. Relevant documents are included in the appendices.

\subsection{Chapter Summary}

The main purpose of this study is to explore the management and usage of ERs in academic libraries in Ghana to unveil surrounding contextual factors and also how these two concepts are related. This chapter has presented the methodology employed to answer the research questions of the study. The choice of research paradigm and justification have been provided. The research design, methodology, research approach, type of case research, case selection and the research process have been discussed. Also, data collection tools and procedures, limitations of the study and ethical considerations have been presented. The next chapter presents analysis of qualitative data obtained from interviews and document analysis. 


\section{Chapter Five \\ Findings on the Management of ERs}

\subsection{Introduction}

The overarching aim of the study is to investigate how electronic resources (ERs) are managed and used; and to explore the ways in which the management of ERs in academic libraries affect their usage and vice versa. The study also seeks to understand the contextual factors surrounding these activities within the Ghanaian context. This chapter presents analysis of data obtained on the management of ERs. It includes findings from interviews conducted with stakeholders, and analysis of collection development policies (CDPs) of case institutions both aimed at answering the research questions that focus on the management aspect of the study:

1. How are ERs managed (and used) in academic libraries in Ghana?

2. a. What are the contextual factors surrounding the management (and usage) of ERs in academic libraries in Ghana?

b. In what ways do the contextual factors affect the management (and usage) of

ERs in academic libraries in Ghana?

The chapter begins with a brief profile of case institutions and a description of interviewees after which findings from the interviews and analysis of CDPs are presented. When employing multiple cases, "a typical format is to first provide a detailed description of each case and themes within the case, called a within-case analysis" (Creswell, 1998, p.63). After presenting a within case analysis, a thematic analysis across-cases known as cross-case analysis (Creswell, 1998; Yin, 2003) is presented. This chapter therefore presents a within-case analysis followed by a cross-case analysis of the findings.

\subsection{Case Institutions}

Interviewees of the study represent two main types of academic institutions, which are public and private universities. The study considers a public university as a university that is mostly funded by public means through national government. A private university on the hand is considered as a university that is not provincially or federally assisted but relies on private funding, tuition, and fees. The University of Ghana (UG) and University of Cape Coast (UCC) were the two public universities selected for the study. I interviewed eight (8) library staff from the Balme Library (UG) and eight (8) library staff from Sam Jonah Library (UCC). Central 
University (CU) and Wisconsin International University College (WIUC) were the two private universities selected for the study. I interviewed six (6) library staff from CU library and two (2) library staff from WIUC library. Also, the study found it necessary to include the Consortium of Academic and Research Libraries in Ghana (CARLIGH) due to the significant role it played in the ER services of the case institutions. Three (3) executives of CARLIGH were interviewed in this study.

\subsection{Description of Interviewees}

The study sought the views of key stakeholders of ERs in the institutions included in the study. The institutions were selected based on the criteria specified in the methodology chapter of this thesis. Adopting a semi-structured interview method and purposive sampling technique, a total of twenty-seven (27) interviewees were included in the study. In accordance with the research questions, selection criteria involved identifying interviewees who were deemed knowledgeable or were involved in the management of ERs of the library. These included university librarians (library directors), heads of ERs, heads of institutional repository (IR), heads of unit(s), selected para-professionals of ERs units all from the academic libraries; and three members of the governing council of the Consortium of Academic and Research Libraries in Ghana (CARLIGH). All 27 interviews were conducted in English.

Ethical considerations for the interviews stipulated that neither the thesis nor resulting publications would include any information that could be used to identify interviewees. For this reason, pseudonyms have been assigned to all interviewees to ensure confidentiality. The pseudonyms are Ghanaian local names chosen to replace the real names of interviewees. Table 5.1 depicts interviewees from various categories of institution and their pseudonyms.

Table 5. 1: Pseudonyms of Study Interviewees

\begin{tabular}{lllll}
\hline \multicolumn{2}{l}{ Public University Interviewees } & \multicolumn{2}{l}{ Private University Interviewees } & CARLIGH \\
UG & UCC & CU & WIUC & Interviewees \\
\hline Acheampong & Abeeku & Aboagye & Akyere & Ampah \\
Addae & Abrafi & Aboraa & Dufie & Agyeman \\
Adutwumwaa & Danquah & Achiaa & & Basiwa \\
Afriyie & Danso & Afia & & \\
Akuba & Esaaba & Akosua & & \\
Badu & Kyeiwaa & Yoofi & & \\
Maame & Kwamena & & & \\
Owusuwaa & Nyamekye & & & \\
& & & & \\
\hline
\end{tabular}


Interviewees of the study had a range of educational qualifications. Four (4) had $\mathrm{PhD}$, eleven (11) had MPhil degrees, seven (7) had MA, two (2) had MSc and three (3) had BA degrees. One senior member and para-professional from one public case institution were pursuing online programmes towards a $\mathrm{PhD}$ and MA degrees respectively. Similarly, two (2) senior members from the private universities had enrolled in an online $\mathrm{PhD}$ programme at the time the study was being conducted. This demonstrates that most of the interviewees were professionals who could provide the needed information to answer the research questions of this study. The following section presents a within-case analysis of findings from the case institutions.

\subsection{ERs/ Services and ICT Infrastructure in the Case Institutions}

In order to understand how ERs are managed, it is first necessary to identify the ERs and ICT infrastructure available in the case institutions. This section presents a within-case analysis of findings on the ERs/services and ICT infrastructure available in each case institution beginning with the two public institutions followed by the two private institutions and CARLIGH.

\subsubsection{ERs/Services and ICT Infrastructure at The Balme Library (UG)}

The Balme Library of UG is a public academic library and the findings revealed a range of ERs and services provided by the library. The library acquired and made available various online databases, e-journals, e-books to the user community mainly through consortium-based subscription and individual library subscription. Afriyie and Adutwumwaa pointed out that through the library's membership of CARLIGH, the library had access to eleven (11) databases. In addition, the library solely subscribed to other contents such as Elsevier databases which included ScienceDirect and Scopus. Furthermore, the library had established an institutional repository (IR) which made available the intellectual output of the institution including theses, dissertations, past examination questions, and digitised local and rare collections of the library.

Access to the ERs was both on and off-campus via the library website. In addition, the library provided ER services such as Article Request and live chat with a librarian, which assisted users in accessing and using the ERs. The Article Request service enabled users to request for the acquisition of titles which were not in the library's existing databases. The Integrated Library System (ILS) and repository software used by the library were Sierra and DSpace 
respectively. The institution had also acquired anti-plagiarism software - Turnitin and learning management software - Sakai.

Concerning infrastructure, the Balme Library had a total of two hundred and fifty-four (254) computers distributed across three commons being Faculty Commons (FC) (12), Research Commons (RC) for postgraduate students (191) and Knowledge Commons (KC) for undergraduate students (151) computers. The institution also had available Wi-Fi connectivity on campus which allowed users to connect to the Internet using personal devices. These findings point towards efforts of the library to provide adequate ERs/services to the user community.

\subsubsection{ERs/Services and ICT Infrastructure at The Sam Jonah Library (UCC)}

Findings from UCC main library, which is also a public academic library revealed that, the library acquired and made available online databases and e-journals to its user community only through CARLIGH. However, there were efforts by the library to make available other types of ERs to users. For example, Abrafi pointed out that the library had planned to establish a CD library with the existing CD-ROM books of the library. This collection was deemed relevant to some users. The library also had an IR which made available the intellectual outputs of the university including dissertations, theses, university publications and past examination questions.

Access to ERs of the library at the time of data collection was only on-campus via the library webpage. This was because the library had experienced infrastructural and technical challenges that delayed off-campus access. This meant that geographical location was a barrier to accessing the ERs as access was only feasible on-campus. However, Abeiku reported all efforts being made to provide off-campus access within the shortest time possible. The ILS and repository software used by the library were Koha and DSpace respectively. Regarding infrastructure in the library, key interviewees (Kyeiwaa, Abrafi and Kwamena) revealed the current state indicating that the library had a computer lab with about fifty (50) computers some of which had broken down. Inadequate infrastructure was highlighted as a challenge. However, the institution had Wi-Fi connectivity available on campus which allowed for connection to the Internet to access the ERs using personal devices. Generally, the findings showed that ERs and ICT infrastructural developments were not without challenges at UCC. 


\subsubsection{ERs/Services and ICT Infrastructure at CU Library}

Findings from CU library, which is a private academic library showed that, the library made available consortium based ERs to users. In addition, Yoofi indicated that the institution had solely acquired 488 e-books. Access to ERs of the library was both on and off-campus via the library webpage. The ILS and repository software used by the library were Destiny Library Manager and DSpace respectively. Regarding infrastructure, interviewees revealed inadequate infrastructure as a major challenge being faced by the CU library. With a total of twenty-four (24) computers for students some of which were dysfunctional, many interviewees such as Achiaa expressed concern over this obstacle:

If people can come in and help us being a third world country, we would be much grateful because actually their technology is a bit higher than us so may be used computers and other things, we would be much grateful to use at our end being a third world country.

Achiaa's comment above showed that the challenge was a dire situation which was linked to inadequate finance. In her opinion, receiving donations of used or discarded computers from advanced countries was a better option than total lack of computers. Yoofi and Aboraa however indicated the availability of Wi-Fi connectivity on campus which allowed users to access the ERs using personal devices. However, this was not without challenges as will be presented under section 5.8 of this chapter of the study.

\subsubsection{ERs/Services and ICT Infrastructure at WIUC Library}

Interview findings from WIUC library which is a private academic library revealed that the library acquired and made available online databases and e-journals through consortium-based subscription only. Also, access to the ERs was on-campus only via the library webpage. Furthermore, the library was yet to have a fully functional IR although a repository software (DSpace) had been installed. Regarding infrastructure, the library was faced with acute infrastructural constraints as there were only eight (8) functional computers at the ER unit of the library. However, the institution had wi-fi connectivity available on campus which meant that students could have access to the ERs using personal devices. The findings generally pointed towards major challenges being faced by the library in providing ERs and services to users.

\subsubsection{ERs of the Consortium - CARLIGH}

Interviews with members of the governing council of CARLIGH revealed that the consortium provided subscription to a standard list of eleven (11) electronic databases. The consortium 
afforded its members highly subsidised rates to access these resources. In addition, there were donor-funded resources that were accessible to CARLIGH members such as Research4Life databases, which comprised Hinari, AGORA, OARE, ARDI and GOALI. The consortium also discovered and made available open access information sources to members. The findings revealed the pivotal role played by CARLIGH in the ER services provided by the case institutions. Almost all interviewees reiterated the immense benefits of the consortium, which included cost-sharing, pre-financing ERs to cover payment delays by members, training opportunities and technical support. For example, as contained in the following statements by Akyere (WIUC), being part of the consortium was perceived as indispensable to the ERs and services provided by the library:

In fact, if we were not members of CARLIGH, we would not have been able to provide ERs because ERs are very expensive. Being members of CARLIGH makes it possible for us to provide ERs, have training for our staff and sometimes even have training for our users. Recently in collaboration with TEEAL, we organised a training programme, it was supposed to be for staff, but we also did another one for students. We got to know about TEEAL because of our membership with CARLIGH so it's not only the resources we pay directly for but just by being members you get the opportunity to know about other resources and other things that are available, so cooperation and partnership for me is the best way to go.

Generally, the findings revealed that the role of CARLIGH brought a level of uniformity and standardisation in the ERs provided by both public and private case institutions, endowed and the less endowed case academic libraries. This ensured adequate ER services even by the less endowed libraries.

\subsubsection{Cross-case Analysis of ERs and ICT Infrastructure}

The findings established that the impetus for the provision of ERs in both public and private case institutions was the core values of librarianship which seek to make available timely and relevant information in all formats to users. There was a commonality in the ERs provided in both public and private institutions by virtue of their membership of CARLIGH. In clustering the cases based on type of institution, public case universities (UG and UCC) appeared better endowed than their private case counterparts (CU and WIUC). In clustering the cases based on endowment and size, UG and $\mathrm{CU}$ which were larger and comparatively better endowed provided both on and off-campus access to the ERs. In addition to consortium-based subscription, there were institutional subscription to other resources. In contrast, the small and less endowed (UCC and WIUC) provided only on-campus access to ERs at the time of the data collection and relied solely on consortia subscription in addition to open access information sources. This meant whereas geographical distance was not a barrier to accessing ERs at UG 
and CU, it was a hindrance to accessing ERs of the libraries at UCC and WIUC. The findings also revealed varying levels of development of IR in the institutions, with comparatively betterestablished IRs at the public case institutions.

Concerning ICT infrastructure, the findings revealed infrastructural challenges in all case institutions. Inadequate computers and slow Internet connectivity were some of the low points from all four institutions. However, situations were worse in the private universities (CU and WIUC) compared to their public counterparts (UG and UCC). This was attributed to acute financial challenges in the private case institutions. These challenges impeded access and usage of the ERs of the library contributing to the observed low usage. The availability of wireless connection in all four universities was perceived to be a partial solution to inadequate infrastructure since users who owned laptops could connect to the WI-FI and access these resources. However, the typical student in a developing country such as Ghana may not be able to afford a laptop which could in the long run affect the usage of ERs of these libraries. ER services and ICT infrastructure available in the case universities are summarised in Table 5.2.

Table 5. 2: ER Services and ICT Infrastructure in the case libraries

\begin{tabular}{|c|c|c|c|c|c|}
\hline \multicolumn{2}{|c|}{ Institution } & ERs/Services & ER Acquisition & ICT Infrastructure & ER Access \\
\hline \multirow{2}{*}{ 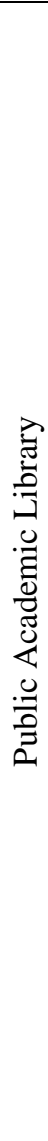 } & UG & $\begin{array}{l}\text { ERs: } \\
\text { Donor funded databases (5) } \\
\text { Free e-books (4) } \\
\text { Free open access journals (12) } \\
\text { Institutional Repository } \\
\text { Subscribed databases (63) } \\
\text { Open access journals (8) } \\
\text { Reference sources (4) } \\
\text { ER Services: } \\
\text { Article Request } \\
\text { Live chat with a librarian } \\
\text { Research Guides } \\
\text { Software installation request }\end{array}$ & $\begin{array}{l}\text { Consortium } \\
\text { Library subscription }\end{array}$ & $\begin{array}{c}\text { 254 Computers } \\
\text { Wi-Fi connectivity } \\
\text { Proxy server } \\
\text { Sierra } \\
\text { DSpace }\end{array}$ & $\begin{array}{l}\text { On-campus } \\
\text { Off-campus }\end{array}$ \\
\hline & UCC & $\begin{array}{l}\text { ERs: } \\
\text { CD-ROM } \\
\text { Donor funded databases (5) } \\
\text { Free e-books (8) } \\
\text { Free open access journals } \\
\text { (18) } \\
\text { Open access journals (7) } \\
\text { Subscribed databases (11) } \\
\text { Institutional Repository } \\
\text { ER Service: } \\
\text { User support }\end{array}$ & Consortium & $\begin{array}{c}\text { <50 Computers } \\
\text { Wi-Fi } \\
\text { Koha } \\
\text { DSpace }\end{array}$ & On-campus \\
\hline
\end{tabular}




\begin{tabular}{|c|c|c|c|c|c|}
\hline 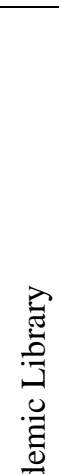 & $\mathrm{CU}$ & $\begin{array}{l}\text { ERs: } \\
\text { Donor funded databases (5) } \\
\text { E-books (488) } \\
\text { Free online databases (12) } \\
\text { Institutional Repository } \\
\text { Open access journals (3) } \\
\text { Subscribed databases (11) } \\
\text { ER Service: } \\
\text { User support }\end{array}$ & $\begin{array}{c}\text { Consortium } \\
\text { Institutional/library } \\
\text { subscription }\end{array}$ & $\begin{array}{c}<24 \text { Computers } \\
\text { Wi-Fi } \\
\text { Proxy server } \\
\text { Destiny } \\
\text { DSpace }\end{array}$ & $\begin{array}{l}\text { On-campus } \\
\text { Off-campus }\end{array}$ \\
\hline 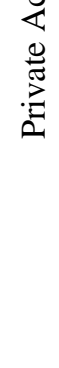 & WIUC & $\begin{array}{l}\text { Donor funded databases (5) } \\
\text { Free online databases (10) } \\
\text { Open access journals (7) } \\
\text { Free reference source (1) } \\
\text { Subscribed databases (11) } \\
\text { ER Service: } \\
\text { User support }\end{array}$ & Consortium & $\begin{array}{c}8 \text { Computers } \\
\text { Wi-Fi } \\
\text { Koha } \\
\text { DSpace }\end{array}$ & On-campus \\
\hline
\end{tabular}

Generally, the Balme Library (UG) provided the widest range of ERs and services compared to its case counterparts. It was also the best endowed among the institutions investigated in terms of ICT infrastructure.

\subsection{Planning for Electronic Resources}

Planning as outlined in the literature involves policy development, budgeting, and staffing. In order to get a sense of where the case institutions stood in terms of planning for ERs, key interviewees from each institution were asked questions on policy development, budgeting, and staffing for ERs. Responses revealed varying levels of planning for ERs in the institutions. This section presents a within-case analysis of findings after which a cross-case analysis is presented.

\subsubsection{Planning for ERs at the Balme Library (UG)}

As earlier indicated, UG is a large, public, and well-endowed university. Responses from key interviewees revealed lack of policies for the ERs although there was an IR policy which was still at the draft stage. Adutwumwaa revealed that responsibility for developing policies and procedures lay with heads of units, and the various policies were not co-located. In the absence policies for ERs, it appeared that ERM practices in the library were guided by professional experience which were not documented. 
Regarding staffing for ERs, the library had an ER unit made up of professionals and paraprofessionals with a total strength of about six (6) staff. The unit also received support from heads of other units who assisted in awareness creation, orientation, and user training. Staff designated as head of ERs were mostly from the public services and technical units of the library with a minimum of a second degree. The job title was "Head of Electronic Resources" and the position was on rotational basis. This meant that, periodically, the head of ERs was replaced. Owing to the dynamic nature of the technological environment, which calls for continuous staff training, key interviewees were asked how the training needs of ER staff were met. Afriyie and Adutwumwaa revealed that CARLIGH organised frequent "training of trainers" sessions for the head of ERs who in turn was supposed to impart to other library staff and users. One challenge highlighted by Adutwumwaa was understaffing. This was mainly as a result of suspension of recruitment in the institution following a directive by the government of Ghana.

Finally, the study sought to investigate how ERs of the Balme library had been budgeted for. Adutwumwaa revealed that, the library obtained internal funding from the institution but was uncertain about specifics regarding the percentage of the institutional budget allocated annually to the library. Over $50 \%$ of the library's budget was allocated to ERs. A challenge highlighted by key interviewees was inadequate finance which had implications on the ERs and services provided by the library. Afriyie highlighted some of the consequences of inadequate budget for ERs:

It is never enough so sometimes we start subscription and then we would have to cease subscription because of payment. I don't know if it is right but they are always using the usage statistics, so we end up punishing those who are using it because many people are not using it. The same thing happened with NVivo, we just had to stop subscription and the few who were using it were all over the place. Some people had their documents locked up in there. We never get half enough. Sometimes we wish we would have given our users more but because of the financial constraints.

The institution received subvention from the government which was inadequate and contributed to the financial constraints. However, other interviewees such as Acheampong had contrasting views on the contributing factors of inadequate funding:

It's not just about lack of budget but the commitment to give, seeing the need and working at it, knowing that the ERs are not for the library but the general user community because when we see it in that light, then pushing funds to acquire these things will be easy, there will be willingness to invest. 
In the view of Acheampong, there would be adequate allocation of funding for ERs if institutional leaders perceived the value of these resources and were committed to investing in them. Generally, the findings revealed that ERs were not adequately planned for at the Balme Library (UG) which manifested in lack of policies for ERs, understaffing and insufficient budget for ERs all of which negatively impacted on the ER services provided by the library.

\subsubsection{Planning for ERs at the Sam Jonah Library (UCC)}

UCC is a public university just like UG. However, it is comparatively smaller and less endowed. To understand where the UCC library stood regarding planning for ERs, key interviewees were asked questions revolving around policies, staffing, and budgeting for ERs of the library. The library had Collection Development Policies (CDPs) to guide collection development. Concerning policies for ERs of the library, responses from interviewees mainly portrayed a lack of awareness of policies for ERs of the library. For instance, Abrafi had this to say when asked about policies for ERs:

Honestly, I can't say yes or I can't say no because I haven't seen but I know even if there is a policy they are not written but the University has a policy but not the library, there's no written policy but we try as much as possible to manage everything but I haven't seen any policy.

Analysis of the CDPs of the library revealed a section on e-collection, which provided guidelines on ER content selection and evaluation. However, the polices were incomplete as presented in the document analysis section in this chapter. The library also had an IR policy. Findings revealed that, responsibility for developing CDPs lay with the head of acquisitions and university librarian (library director) and the policies made provision for ERs of the library. With the lack of awareness of ER policies among key interviewees, it suggested that ER activities were not guided by documented policies. It even appeared that the significance of ER policies was trivialised due to the role of CARLIGH in the ER services provided by the library, as reflected in a comment by Kyeiwaa:

Well we don't have any formal policy but what it is, is that, at the end of the year CARLIGH has some ERs that they are interested in and then we select those databases that are relevant to our users.

Such a viewpoint by interviewees does not bode well for effective ERM as there could be inconsistencies in ERM practices leading to poor ER services and ultimately resulting in low usage of the resources. 
Concerning staffing, the findings revealed that the library had five (5) staff working at the ER section with support from a few staff from other units of the library. Similar to the findings from UG, the head of ERs was mostly from public services and technical units of the library with a minimum of second degree in Information Studies or a related field. The job title was "Head of Electronic Resources" and the position was on rotational basis whereby heads of units of the library were periodically shifted to other units. This was to promote professional development and eliminate boredom associated with monotonous or routine functions. In response to how the training needs of ER personnel were met, Abrafi and Kyeiwaa pointed out that CARLIGH regularly organised "training of trainers" sessions for the head of ERs who was to impart acquired knowledge to other staff and users. A staffing challenge revealed by Abrafi was low staff strength, which was attributed to suspension of recruitment in public tertiary institutions following the directive by government. This led to the overburdening of staff of the ER section. For example, Kyeiwaa pointed out that, in some instances, ER staff were unable to go on lunch breaks due to low staff strength and demands from students.

Concerning budgeting, the library had a separate budget; however, interviewees were uncertain about specifics regarding the percentage of the institutional budget allocated annually to the library as reflected in Abrafi's comment for example:

The annual budget allocated to the library is not specific. Every year it changes. Originally, we were getting 5\% of the University's annual budget but last year we had less than $1 \%$ so I can't even give you an exact figure of how much we get or got last year. This academic year they have just started paying in some monies and we don't even know the percentage.

About $20 \%$ of the library's budget was allocated annually to ERs. The findings revealed that the library was financially challenged. Various views were expressed regarding the reasons for financial constraints. Maame for instance attributed this to an institution-wide issue of inadequate funds:

It is not because the university does not want to support the library but because it is a whole university wide problem. Otherwise I always say we kind of get our fair share of the cake.

UCC, like UG, being a public academic institution received funding form government subvention which was perceived as inadequate. Financial constraints hindered the acquisition of ERs to adequately satisfy the information needs of users. The library however made efforts towards sustainable funding by generating incomes from student library fee, commercial services such as photocopying, printing and bindery services which went directly into the institutional coffers. That notwithstanding, funding for the library was not enough to support 
adequate ERs for the user community. Taken together, it can be observed that ERs were not adequately planned for at UCC, which manifested in lack of awareness of ER policies, incomplete ER policies, inadequate budget, and low ER staff strength.

\subsubsection{Planning for ERs at CU Library}

$\mathrm{CU}$ is a large, private, and well-endowed university. Interviewees from CU library were asked questions revolving around policies, staffing and budgeting for ERs at the CU library. Yoofi and Aboraa indicated the availability of a draft CDP which had not yet been ratified. Analysis of the CDP revealed a brief section stating the obligation of the library to provide access to the Internet, online resources and training students on the use of online resources. The incomplete nature of the policies on ERs suggested that ERM practices in the library were not guided by documented policies and procedures. This was confirmed by Yoofi who pointed out that the management of ERs of the library was by "voluntary methods". Other interviewees such as Afia who played an ER-related role had this to say concerning the availability of ER policies: "For me I don't know, I am not in charge of policy formulation". This indicated the lack of awareness of policies in the library. Responsibility for CDPs which included a section on ERs lay with the system librarian and library director as revealed by Yoofi and Aboraa. Generally, ER activities were based on undocumented professional experience.

Low staff strength was a major challenge being faced by the library. For about a decade, only a single professional oversaw the implementation of both the subscription based ERs and IR until the recent recruitment of an assistant. The job title of the head of ERs was "Systems Librarian". However, there was an ERs Group made up of heads of units to assist in providing user support, awareness creation of ERs and training. Concerning budgeting for ERs, the library did not have a separate library budget. This was because the institution operated a centralised management structure whereby activities were directly controlled by institutional leaders. Aboraa revealed that the library obtained invoices and forwarded them to institutional leaders for approval subject to availability of funds. Inadequate funds as a challenge for the library was expressed by Achiaa, Yoofi and Aboraa. A comment by Achiaa for example highlighted the impact of financial constraints on the acquisition of ERs, ICT infrastructure and sustainability of ER services:

Usually the computers and things that we need, management are finding it hard to release money for it. The reason being they don't see how important the library is, they don't liaise or understand that academics cannot function without the library, so the logistics are not there for the students to use. That's the problem. 
The comment above shows that, inadequate funding was perceived as a result of lack of recognition of the role of the library which led to low institutional commitment and unwillingness to invest in ERs of the library. Generally, the findings indicated that ERs were not adequately planned for at the CU library manifesting in lack of complete ER policies, inadequate staffing and financial constraints all of which negatively affected the ER services provided by the library contributing to the observed underused ERs.

\subsubsection{Planning for ERs at WIUC Library}

WIUC, as earlier mentioned is a smaller, private and less endowed university. Findings from WIUC library revealed that, CDPs of the library included a section on ERs providing guidelines on the kinds of ERs to be acquired by the library. The head of ERs and university librarian (library director) were responsible for developing the CDPs of the library. The data obtained revealed infrequent renewal of the policies. No justification was provided for this however Dufie advised that the policies were soon to be revised. Regarding implementation of the policies, Akyere made the following comments:

Sometimes it's a little difficult. You put things on paper but following them is another thing so I wouldn't say that we follow very closely but to a very large extent we try to do that...Sometimes for instance when it comes to copyright issues, it's a little difficult, a student may sit behind a machine and may download things and you cannot determine what the student downloads and how they use it. It's a little difficult to do that.

The above comment suggests that ERM practices were not aligned with documented policies which could lead to inconsistencies in ERM activities. It could mean that due to the incomplete nature of the policies as revealed in the document analysis (presented later in the chapter), the policies did not provide adequate guidelines to support ERM practices. Regarding staffing for ERs, the library had one professional librarian in charge of the ERs whose job title was "Head of Electronic Resources". Training needs of ER staff were met through frequent "training of trainers" sessions organised by CARLIGH. Interviewees highlighted understaffing as a major challenge. This was accounted for by reasons beyond the control of the library including high library staff turnover and suspension of recruitment by the institution. This resulted in overburdening of ER personnel and the closing of the ER unit earlier than expected by users as there was no staff for evening shifts.

Concerning budgeting for ERs, Akyere pointed out that the library did not have a separate budget and described how the needs of the library were met: 
You know, over here, we do not have a specific amount of money or budget allocated to the library...but basically when we need things, we take an invoice and it gets paid subject to the availability of funds, so we are not told that " 5 cedis (a specific amount) has been allocated to you and so this is your portion of the budget". We have not been told that and funding is not adequate because it is not all the things that we send that gets paid or that gets fully paid for.

Inadequate funding affected the purchasing power of the library. For example, Akyere pointed out that renewal of ER subscriptions had been a hurdle and some required resources including antiplagiarism software had not been acquired due to financial constraints. Generally, the findings indicated inadequate planning for ERs at the WIUC library which manifested in inadequate development and implementation of ER policies, inadequate budgeting for ERs and low ER staff strength.

\subsubsection{Planning for ERs at the Consortium Level}

Due to the immense role played by CARLIGH in the ER services provided by the case institutions, it was deemed necessary to investigate the planning for ERs at the consortium level. Members of the governing council of CARLIGH were asked questions revolving around policies, staffing, and budgeting for ERs to support member libraries. The findings showed that, the consortium had a constitution approved by founding members and a five-year strategic plan to guide the provision of ERs to members. These policies were adequately implemented to ensure effective operations of CARLIGH.

Regarding staffing, the findings revealed that the consortium had an ER working group headed by the Chair of ERs. The responsibilities of the group included negotiating and licensing ERS, monitoring and assessing the usage of ERs, and discovering and making available open access information sources to member institutions. In consistent with data obtained from both public and private case institutions, Agyeman and Ampah revealed that the consortium organised frequent training workshops and seminars for members. As part of consortium membership package, participation in workshops and seminars was free for two persons from each member institution. This was to ensure equal capacity building of ER staff in member institutions to promote effective and standardised ERM practices.

Concerning sources of funding for the consortium, Agyeman pointed out that, the consortium obtained funding from annual membership fee, ER subscription fee, proceeds from workshops, seminars, and conferences as well as support from international bodies such as INASP. These 
sources of funding enabled CARLIGH to make up-front payments for ERs to cover payment delays from member institutions.

\subsubsection{Cross-case Analysis of Planning for ERs}

This sub-section presents a cross-case analysis of planning for ERs in the four case institutions to reveal similarities and differences. Regarding policies for ERs, two clusters emerged among the four case institutions. One cluster consisting of UCC, CU and WIUC had sections on ERs in their CDPs. A commonality in the findings from these three institutions was the fact that, ERM practices particularly for subscription based ERs were not adequately guided by policies. Also, interviewees generally lacked awareness of the availability of the policies. The other cluster comprising UG had no policies for subscription based ERs, but an IR policy had been drafted according to the findings of the study. The findings generally suggested that ERM practices in all case institutions were to a large extent discretionary and based on experience.

Responsibility for developing ER policies varied from institution to institution. For example, at UG, it was the duty of the head of ERs as various sectional heads were responsible for developing policies and procedures for their unit. At UCC, the head of acquisitions and university librarian (library director) were responsible for developing CDPs which included ERs. Regarding the private case institutions (CU and WIUC), a similar pattern was revealed where the systems librarian/head of ERs and library directors were responsible for developing CDPs which covered ERs of the library. However, ratification of policies in all four institutions was the responsibility of a committee made up of top-level management, university librarian (library director), head of ERs or systems librarian and acquisitions. The process in all selected cases was typically perceived as bureaucratic leading to delays in ratification of policies.

Taken together, the findings revealed that ERM practices in both public and private institutions were to a large extent discretionary and not guided by documented policies. This could hinder prioritisation and consistency in ERM activities which would ultimately lead to low usage of these resources. A major consequence of undocumented procedures was that, it led to a lack of clarity on ER duties and responsibilities, which also affected the depth of information obtained from the interviews as some questions were not adequately answered particularly by interviewees who were relatively new in their position in both public and private case institutions. Regarding staffing for ERs, the public case libraries had ER units made up of a minimum of a single professional and a few paraprofessionals. In the private academic 
libraries, a single professional oversaw the ERs of the library. Staff designated as head of ERs in the four institutions were mostly from the public services and technical units of the library who had a minimum of second degree in Information Studies or a related field. In the public case institutions, the position of head of ERs was on a rotational basis unlike in the private case counterparts. In UG, UCC and WIUC, the job title was for staff overseeing the ERs was "Head of Electronic Resources" whereas in CU the job title was "Systems Librarian". However, responsibilities were fundamentally similar in all the four institutions.

A common challenge revealed in both public and private case universities was understaffing which was accounted for by various reasons. In the public institutions, low staff strength was as a result of a directive by the government to suspend recruitment in tertiary institutions. In the private case institutions, understaffing was caused by suspension of recruitment by institutional management in their bid cut down institutional expenditure, and high staff turnover as revealed at WIUC. Comparatively, understaffing appeared more pronounced in the private universities as these institutions had very low staff strengths and a single professional was in charge of ERs of the library. However, in all four case institutions, understaffing was partly addressed by assigning information literacy education to staff from other units of the library. Also, all four libraries relied on the ICT directorate of their institution for technical support.

Concerning capacity building of ER personnel, there was a commonality in the strategies adopted by both public and private case institutions. "Training of trainers" sessions were organised at least twice in a semester by the consortium for two ER staff from member institutions as part of consortium membership package. Interviewees perceived this strategy as cost effective, a convenient way of building the capacity of ER personnel and promoting standardisation of practices. Member libraries that required training for more than two personnel incurred extra cost. Key interviewees from all case institutions expressed similar views on required competencies and skills for managing ERs. These skills and competencies revolved around ICT or technical skills, interpersonal skills (communication, advocacy, and teaching skills), management skills (systems management and ERM skills) and professional knowledge (library services).

Regarding budgeting for ERs, the findings revealed that both public and private academic case libraries received only internal funding from their institution. Public institutions obtained grants from the government whereas the private case institutions were not eligible for 
government funding and relied solely on internally generated funds from student fees. Also, public case universities (UG and UCC) had a separate library budget and a budget for ERs. This was because these institutions operated a decentralised management structure which allowed various units of the institution a level of autonomy in their operations. In contrast, private case libraries (CU and WIUC) did not have a separate library budget as these institutions operated a fundamentally centralised management structure whereby operations were mainly controlled by institutional leaders with the library being less autonomous. These libraries forwarded invoices or requests to institutional leaders for approval subject to availability of funds.

Inadequate funding as a challenge was revealed in both public and private case institutions and this hindered acquisition and sustainability of ERs and services. Interviewees had varying perceptions on the factors accounting for inadequate funding. While some believed it was an institution-wide challenge, others attributed the problem to a lack of institutional commitment to the needs of the library. Financial constraints were however more prevalent in the private case universities than their public counterparts as the former did not receive any government subvention unlike their public case counterparts and struggled to even maintain subscriptions to ERs.

In summary, findings from the case institutions revealed varying levels of planning for ERs. Responses from interviewees in both public and private case institutions generally pointed towards inadequate planning which manifested in lack of policies and incomplete policies for managing ERs, low staff strength, and inadequate budgeting for ERs, with situations being more pronounced in the private case universities. Planning for ERs in the case institutions have been summarised in Table 5.3. 
Table 5. 3: Planning for ERs in the Case Institutions

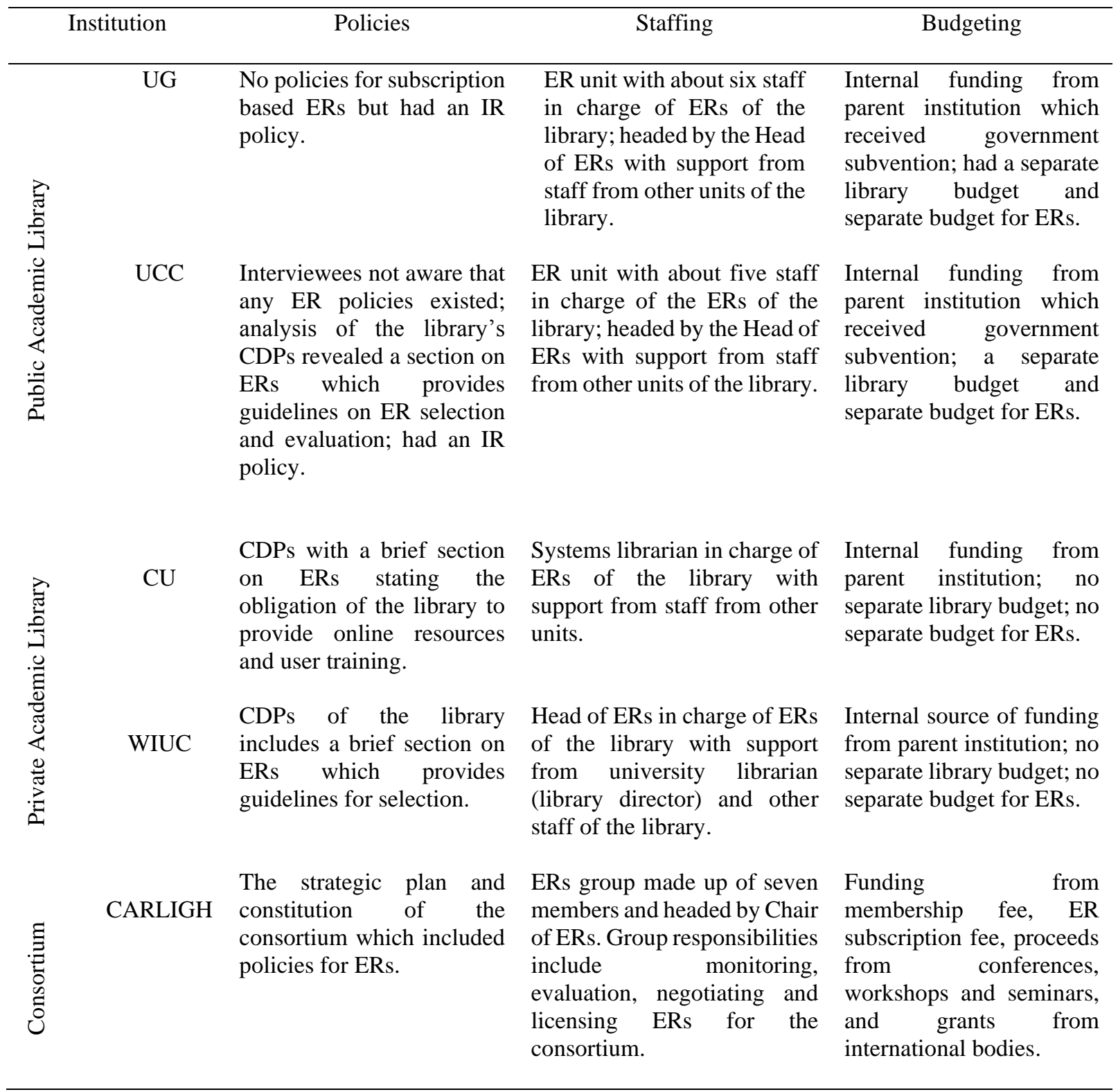

\subsection{Implementing Electronic Resources}

After planning for ERs in terms of policy development, budgeting and staffing, the next phase is implementation. In this phase, libraries develop a workflow throughout the lifecycle of ERs and adopt an approach or model to facilitate the workflow. This study investigated how ERs were implemented in the institutions and findings are presented in the structure of a withincase analysis followed by cross-case analysis. 


\subsubsection{Workflow of ERs in the Case Libraries}

Using Emery and Stone's (2013) TERMS framework as a lens, the workflow of ERs particularly subscription based, in the case institutions was investigated. TERMS defines six stages in the iterative lifecycle of ERs which are: (1) Investigation of new content; (2) Acquisition (3) Implementation; (4) Ongoing evaluation and access; (5) Annual review; and (6) Cancellation and replacement review. Findings from the case institutions are presented in the following sub-sections.

\subsubsection{Workflow of ERs at the Balme Library (UG)}

Bearing in mind the stages of TERMS, key interviewees were asked questions on the discovery of new contents and the findings revealed that contents were discovered through the list of online databases that CARLIGH made available to members every year for selection, renewal or cancellation decisions. Other modes of discovery indicated by Afriyie were market scouts, proposals from publishers and requests from users through the article request service, and request option on the library webpage. These modes of discovery encouraged user input in the selection of ER contents which bodes well in providing ER services that are tailored towards the information needs of users.

Owusuwaa revealed that individual titles requested by users via the article request service were acquired within four (4) working days through British Library Document Supply Service (BLDSS). Discovery of contents through CARLIGH, market scouts or publishers was followed by a trial session which usually lasted up to three months during which faculty were alerted to use contents on trial. Usage statistics were gathered during the trial period and feedback through random emails, face-to-face contacts or phone calls were obtained from faculty all of which demonstrated the library's efforts in assessing user information needs. Following satisfactory usage statistics and feedback from faculty, recommendations were made to CARLIGH for negotiation, licensing and procurement on behalf of the library. For contents that were acquired outside consortia subscription, the head of ERs who had obtained training on negotiation and licensing of ERs spearheaded its acquisition.

The next stage after acquisition was implementation. At this stage, the IP range of the institution was sent to providers and links to the databases were obtained and embedded in the webpage of the library. This was followed by URL checks, off-campus/authentication and access checks. According to Afriyie and Acheampong, the choice of IP based access to ERs 
over password protected resources was informed by convenience and assurance of user authentication. For off-campus access, the library registered users using email address and password. Once access to the ERs was provided and various checks carried out, the next stage was promotion of the resources. Various channels for awareness creation were adopted by the library which included orientation, library website, brochures usually distributed at workshops, quarterly email reminders to faculty and students, and publicity during graduate students' week. Regarding training for users quarterly workshops were organised for faculty, and training sessions were organised at the beginning of each semester for students. The findings revealed efforts by the library to attract user attendance to ER training sessions. For example, to encourage faculty attendance to training, providers and vendors were sometimes invited to spearhead training sessions. Faculty were also encouraged by the library to request for training for students.

In evaluating ERs of the library, the library relied on annual usage statistics from providers although the head of ERs had administrative rights to some databases to generate monthly inhouse usage reports. Renewal/cancellation decisions were informed by usage level and budget. Challenges highlighted by interviewees as affecting the implementation of ERs of the library included institutional commitment, inadequate finance, infrastructural challenges such as lack of training labs, unstable Internet connectivity and power outage, low usage, inadequate promotion, inadequate staff training and information literacy problem among users. These factors will be presented in detail in section 5.8 of this chapter. The findings generally revealed efforts by the Balme Library to follow standard procedures in implementing ER workflow.

\subsubsection{Workflow of ERs at UCC Library}

Regarding discovery of new contents, the interview findings revealed limited modes of discovery at the UCC library. Kyeiwaa described how new ER contents were selected by the library:

We get the list from CARLIGH then we select those that are relevant to the programmes that are being ran here and then from time to time we go back to see those that people really use because some of the databases even though they are relevant, it turns out that people don't use them so then there would be no point.

The above comment shows that, contents were discovered solely through the consortium. Also, perceived relevance to institutional programmes by library staff mainly informed the selection 
of contents which suggested minimal input from the user community. This was confirmed by a statement from Esaaba revealing minimal input from the user community:

I know head librarians go and then they choose the resources but then if it could come down to maybe the users, we find out from users what they want because currently we give what we think they would need which could not be, so if we could kind of trickle those things down and then bring more inclusiveness in the management I think it's going to increase the usage.

The implication of minimal input from users in the selection of contents is that, acquired ERs may not be relevant enough to adequately satisfy user information needs which could contribute to the observed underusage of ERs of the library. Kyeiwaa however revealed that, following the discovery of new contents was a trial session during which random feedback was obtained from faculty through email and informal contacts. Consortium subscription was the main mode of acquiring ERs for the library; and CARLIGH was responsible for negotiating, licensing and procuring ERs on behalf of the library. IP addresses were then sent to providers, and links to databases were obtained to be embedded in the webpage of the library. Danquah pointed out that the decision to use IP based access was due to convenience and prevention of unauthorised access associated with password protected resources.

Upon access provision, the library promoted the ERs through various channels including orientation, radio announcements, emails, and open days. Regarding user training, Kyeiwaa revealed that training workshops were organised occasionally for faculty, and annually for postgraduate students. For first year undergraduate students, training on ERs was incorporated in the Information Literacy course as part of the institutional curriculum. This in Kyeiwaa's view encouraged high usage of the ERs among undergraduates compared to postgraduate students and faculty. In evaluating these resources, the library obtained usage statistics from providers at the end of the academic year. This was followed by cancellation/renewal decisions informed by usage level and cost. Some of the challenges revealed by key interviewees as affecting the implementation of ERs included financial constraints, understaffing, low usage and inadequate promotion which are presented in detail in section 5.8 of this chapter. Generally, the findings showed lapses in the workflow of ERs at the UCC library. For example, there was minimal user input in the selection of contents and inadequate training for faculty and postgraduate students. 


\subsubsection{Workflow of ERs at CU Library}

At the CU library, new contents were discovered mainly through the consortium and requests from users, particularly faculty. The main criterion for selecting new contents was relevance to institutional programmes. Following the discovery of contents was a trial session which lasted for about three months after which feedback was obtained from faculty through informal contacts and email. CARLIGH was responsible for negotiation, licensing, and procurement on behalf of the library. Aside consortia subscription, the institution solely acquired contents (Ebooks) and Yoofi described the acquisition process for these contents:

I wasn't actually involved in the selection and acquisition. They (institutional leaders) wrote to the various lecturers, deans and faculties to bring out their list. I didn't negotiate the license. I wasn't involved in the negotiation.

This goes to show that, the library had no direct control over the acquisition of ERs of the library as CARLIGH oversaw acquisition of consortia subscription while institutional leaders spearheaded the acquisition of individual library subscriptions. For consortium-based subscription, IP addresses were sent to publishers via CARLIGH and links to the databases were obtained and embedded in the webpage of the library. URL checks, off-campus/other authentication and access checks were then carried out. For off-campus access, the library registered users using their email address and password. Channels for awareness creation included banners, emails and SMSs, and publicity by word-of-mouth.

Generally, the findings revealed inadequate promotional efforts by the library. However, responses from key interviewees showed readiness to improve marketing strategies for increased awareness of ERs of the library. For example, Afia (CU) highlighted the need for increased promotion:

I think we should go all out. May be take a week, make some noise about it, do fliers promote it (the ERs) throughout all the campuses that we have, sensitise them because most students are not even aware, apart from telling them at the orientation. I think we have to take a week or two and make a lot of noise to sensitise the students and staff, create awareness about its existence and usage.

Training was organised once in a year for students but occasionally for faculty. Afia further highlighted the low turnout of students for ER training organised annually by the library. Yoofi reported that to equip students with requisite skills, Information Literacy course was soon to be incorporated in the institutional curriculum for first year undergraduate students. At the end of the academic year, the library obtained usage statistics from providers through the consortium. Cancellation/renewal decisions were informed by usage levels and 
cost/availability of funding. Other challenges revealed by key interviewees were communication gap among library staff, inadequate promotion, infrastructural challenges and low usage of ERs which are presented in detail under section 5.8 of this chapter. Generally, the findings indicated that some components of the ER workflow were absent at the CU library which manifested in inadequate awareness creation and user training, communication gaps among library staff and inadequate infrastructure to promote usage of the resources.

\subsubsection{Workflow of ERs at WIUC Library}

The findings from WIUC revealed that, new contents were mainly discovered through the list of ERs provided annually by the consortium. Dufie described how new contents were selected by the library upon receiving the list from CARLIGH:

If there is an area that we think we should go in for or if there is an electronic database, we think will be useful to our users, we have to subscribe to it so that our users can have access. We saw that this database, Lexis Nexis is good for them and we went out of our way to subscribe to it.

Contents were deemed relevant to users when library staff perceived alignment of these contents with institutional programmes. Selection was mainly based on perceived relevance by library staff rather than on actual user needs identified through user surveys. This could have led to the selection of irrelevant contents resulting in the observed underused ERs. Concerning acquisition of ERs of the library, CARLIGH was responsible for negotiation, licensing and procurement of the ERs. Links to the databases were embedded in the webpages of the library and various tests were carried out including URL and access checks. Channels for awareness creation included orientation, fliers and library handbook. Generally, the findings revealed low awareness creation efforts by the library. Training sessions were scheduled for users only when new contents were acquired by the library. This suggested that, the library had no refresher training sessions which could negatively affect the searching skills of users and ultimately the usage of these resources. Dufie described the kind of training provided for faculty when new contents were acquired by the library:

I do a one-on-one training for them because getting them together is very difficult. It's difficult to bring them together based on their schedules. One is lecturing, the other is busy so if it gets to that point then I go to their office, it's a one-on-one training. I sit them down and take them through the ERs and then it's encouraging.

Regarding evaluation of ERs of the library, the library obtained usage statistics from providers through the consortium. The head of ERs also had administrative rights to some databases to generate monthly usage reports. Cancellation or renewal decisions were informed by demand 
and cost or availability of funding. Some of the challenges the library faced in implementing ERs included inadequate infrastructure, inadequate finance, understaffing, information literacy problem and low usage. These are presented in detail in section 5.8 of this chapter. The findings generally revealed lapses in the workflow of ERs at the WIUC library manifesting in minimal user involvement in ER selection, inadequate promotional activities by the library and inadequate infrastructure to access these resources.

Due to the major role CARLIGH played in the ERs provided by the case institutions, the study sought to investigate the workflow of ERs at the consortium level. Findings are presented in the next sub-section.

\subsubsection{Workflow of ERs at the Consortium Level}

Interviewees from CARLIGH indicated that new contents were mostly discovered through proposals from publishers, database providers and sometimes recommendations from faculty. The consortium had dedicated publishers and database providers including EBSCO, Emerald, Wiley and Blackwell whose contents were subject to automatic selection. The consortium assured adequate input from member libraries by sending a list of databases to members for selection, renewal or cancellation. In negotiating, licensing and procuring the selected databases, factors such as cost, content relevance, functionality, demand, terms and conditions of use were taken into consideration by CARLIGH.

CARLIGH had responsibility to member libraries in the areas of selection of ERs, acquisition, access provision, evaluation, capacity building and technical support. The findings revealed pros and cons of joining the consortium. Key interviewees from both public and private case institutions emphasised the immense benefits of joining CARLIGH which included reduced costs in terms of cost sharing among members and the ability of the Licensing and Negotiation Committee under the auspices of INASP and EIFL to negotiate for discounted prices. Akyere (WIUC) highlighted some of the benefits of joining CARLIGH:

In fact, if we were not members of CARLIGH, we would not have been able to provide ERs because they are very expensive. The databases are very expensive so going solo is not the idea. The idea is to partner with others and I think that CARLIGH is the best way to go so being members of CARLIGH makes it possible for us to provide ERs, makes it possible for us to have training for our staff and sometimes even makes it possible for us to have training for our users. 
The data gathered also revealed a timely acquisition and renewal of ERs for both public and private case institutions through the efforts of CARLIGH, as the consortium was able to prefinance payments of ER subscriptions to make up for delayed payments by members. The role of CARLIGH led to a standardisation of ER implementation in both public and private case institutions. For example, a standard list of eleven (11) online databases provided by the consortium, and donor funded ERs such as Research4Life databases were common to both public and private case institutions. There was also a level of standardisation of capacity development in both public and private case institutions as CARLIGH frequently organised training workshops for two ER staff of member libraries as part of the consortium package. Furthermore, the consortium handling a chunk of the ER workflow in the case institutions eased the burden on the understaffed ER units in both public and private case institutions.

Albeit the above-mentioned benefits reaped by all case institutions by virtue of their membership of CARLIGH, it was observed that the role of CARLIGH contributed to a lack of clarity on some aspects of managing ERs particularly those aspects solely overseen by the consortium. This observation was confirmed by a comment from Maame (UCC):

I think with CARLIGH managing, it used to be centralised and they are now decentralising it which is good. I think a further decentralisation of the management will help because although I play a role related to ERs of the library, I don't have answers to some of the questions you have asked.

Key interviewees from both public and private case institutions lacked clarity on aspects of the ER workflow which consequently affected the depth of responses to some of the interview questions. Concerning challenges that the consortium faced with regard to ERs, interviewees from the governing council of CARLIGH highlighted various obstacles which included low commitment of members, disparity and cost sharing, communication challenges, low usage among users, ER rising costs and package contents. These factors have been presented in detail in section 5.8 of this chapter of the thesis.

\subsubsection{Cross-case Analysis of workflow of ERs}

This sub-section presents a cross-case analysis of findings from the case institutions by revealing similarities and differences in the workflow of ERs. Regarding discovery of new contents, the findings revealed two clusters of institutions. The first cluster of institutions (UCC and WIUC) discovered new contents only through the consortium. The second cluster of institutions (UG and CU) adopted other modes of discovery in addition to discovery through 
the consortium. At CU, e-books were acquired based on recommendations from faculty. At $\mathrm{UG}$, recommendations from users through the request option on the library webpage and Article Request service, market scouts and proposals from publishers were the various modes of discovering new contents. The library subscribed to databases such as ScienceDirect based on requests from faculty. The various modes of discovery and allowance for user input suggested that ER services UG and CU libraries were more likely to satisfy user information needs better than their counterpart libraries (UCC and WIUC) where user input was very minimal.

Regarding acquisition of ERs of the library, two clusters of institutions emerged from the findings. The first cluster of institutions (UCC and WIUC) solely relied on consortium-based subscriptions and depended on CARLIGH for negotiation, licensing, and procurement of ERs on behalf of the library. For this reason, the acquisition stage was missing in the ER workflow of the library or institution. The second cluster of institutions (UG and CU) acquired other contents aside consortia purchasing through individual library subscriptions. The acquisition stage of the workflow was therefore present in the institution. However, the type of university determined which unit was responsible for this stage. For the public university, the library spearheaded by the head of ERs oversaw the acquisition of contents as revealed in the findings from the Balme Library (UG). For the private university, institutional leaders spearheaded the acquisition of individual library contents with minimal or no input from the library as observed in the findings from CU. It can be concluded that for institutions that acquired ERs outside consortia purchasing, the type of university determined the responsibility for the acquisition stage of the ER workflow.

Concerning implementation of ERs which involved access provision, promotion and training, the public case institutions (UG and UCC) provided only IP based access to ERs whereas the private case institutions (CU and WIUC) provided both IP based, and password protected access to ERs of the library. Regarding off-campus access, UG and CU which were larger and more endowed than UCC and WIUC provided remote access to ERs of the library whereas the latter had not yet made available remote access to the ERs at the time the study was being conducted. This was due to lack of funding to acquire a proxy server at WIUC and technical and infrastructural challenges at UCC. Geographical location was therefore a barrier to accessing ERs at UCC and WIUC which could negatively affect the usage of the resources. Regarding the marketing of ERs of the library, the findings revealed low promotional efforts 
particularly at UCC, CU and WIUC. However, key interviewees from these institutions indicated readiness to improve the publicity of ERs for increased awareness. Awareness creation was perceived as critical to promoting effective usage of ERs of the library and this positive attitude bodes well for effective ERM going forward.

The findings revealed similar evaluation methods across the case institutions. All four case libraries relied on annual usage statistics from providers. Furthermore, the head of ERs had administrative rights to some of the databases to generate monthly in-house usage reports. Usage statistics from publishers covered hits, downloads, and searches. There was a consensus among key participants that usage statistics from providers were reliable.

All four case libraries adopted subscription-based model and package pricing for online databases. The main criteria which informed cancellation and renewal decisions were usage, library budget and cost. Prior to renewal or cancellation decisions, findings from all four case libraries revealed that special training on underused contents were organised after which usage was analysed and decisions made. Common themes that emerged from findings from all case institutions included understaffing, low usage, infrastructural constraints which manifested in inadequate computers and slow and unstable Internet connectivity. However, situations were more pronounced in the private case universities than in the public case counterparts.

Section 5.6.1 sought to analyse the workflow of ERs in the case institutions with the ultimate aim of establishing the extent to which it followed the TERMS framework as presented in the discussion chapter of this thesis. The findings revealed similarities and differences in the ER workflow in both public and private institutions. Similarities to a large extent were as a result of the role played by CARLIGH in the management of ERs in the case institutions. The findings generally revealed that, the workflow of ERs was affected by the type of institution (public or private), size and the resources (endowment) of the institution. Table 5.4 provides a summary of the ER workflow in the case institutions and CARLIGH. 
Table 5. 4: A Summary of the Workflow of ERs in the Case Institutions and CARLIGH

\begin{tabular}{|c|c|c|c|c|c|c|c|}
\hline & \multirow[t]{2}{*}{ Institution } & \multicolumn{6}{|c|}{ Workflow of ERs in the Case Institutions } \\
\hline & & $\begin{array}{l}\text { Investigation of } \mathrm{New} \\
\text { Content }\end{array}$ & Acquisition & Implementation & $\begin{array}{c}\text { Ongoing } \\
\text { Evaluation and } \\
\text { Access }\end{array}$ & Annual Review & $\begin{array}{c}\text { Cancellation } \\
\text { /Renewal Review }\end{array}$ \\
\hline \multirow[b]{2}{*}{ 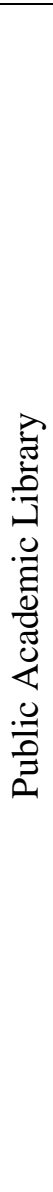 } & UG & 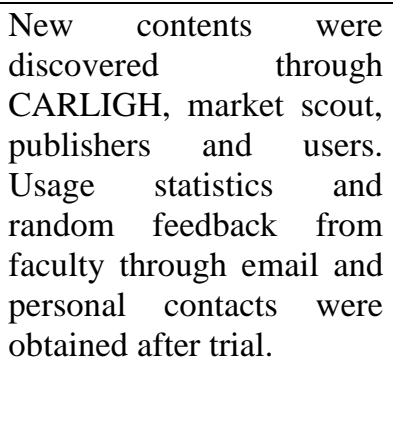 & $\begin{array}{lr}\text { CARLIGH negotiated, } \\
\text { licensed and procured } \\
\text { subscription based ERs. } \\
\text { Head of } \\
\text { spearheaded }\end{array}$ & $\begin{array}{l}\text { URL checks, off- } \\
\text { campus/authentication } \\
\text { and access checks. } \\
\text { Promotion of ERs } \\
\text { through orientation, } \\
\text { email, brochures and } \\
\text { graduate student week. } \\
\text { Quarterly workshops for } \\
\text { faculty and once a } \\
\text { semester training for } \\
\text { students. }\end{array}$ & $\begin{array}{lr}\text { Access } & \text { checks, } \\
\text { Annual } & \text { usage } \\
\text { statistics } & \text { from } \\
\text { providers; } & \\
\text { administrative } \\
\text { rights to some } \\
\text { databases ro } \\
\text { generate monthly } \\
\text { in-house reports. }\end{array}$ & $\begin{array}{lr}\text { Annual } & \text { usage } \\
\text { statistics } & \text { from } \\
\text { providers. } & \\
\end{array}$ & $\begin{array}{l}\text { Renewal/cancellation } \\
\text { decisions informed by } \\
\text { usage level and } \\
\text { budget. }\end{array}$ \\
\hline & $\mathrm{UCC}$ & $\begin{array}{l}\text { New contents discovered } \\
\text { solely through CARLIGH } \\
\text { and selected based on } \\
\text { perceived relevance to } \\
\text { institutional programs. } \\
\text { Random feedback through } \\
\text { email and informal } \\
\text { contacts obtained from } \\
\text { faculty after trial of } \\
\text { contents. }\end{array}$ & $\begin{array}{l}\text { Negotiation, licensing } \\
\text { and procurement of } \\
\text { contents by CARLIGH } \\
\text { on behalf of the library. }\end{array}$ & 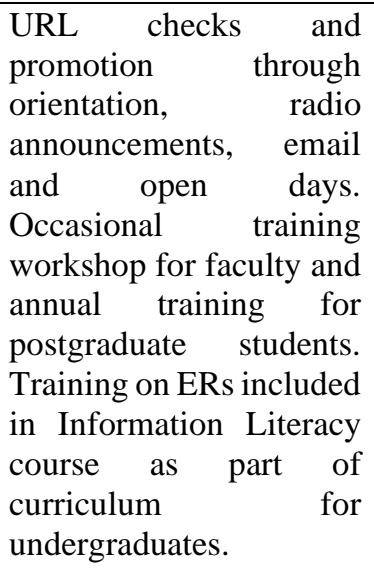 & $\begin{array}{l}\text { Annual } \\
\text { statistics } \\
\text { providers; } \\
\text { administrative } \\
\text { rights to some } \\
\text { databases } r \text { to } \\
\text { generate in-house } \\
\text { reports. }\end{array}$ & $\begin{array}{lr}\text { Annual } & \text { usage } \\
\text { statistics } & \text { from } \\
\text { providers. } & \\
\end{array}$ & $\begin{array}{l}\text { Cancellation/renewal } \\
\text { decisions informed by } \\
\text { usage level and } \\
\text { budget. }\end{array}$ \\
\hline
\end{tabular}




\begin{tabular}{|c|c|c|c|c|c|c|c|c|}
\hline 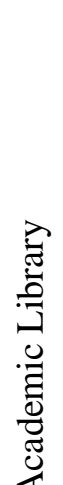 & $\mathrm{CU}$ & $\begin{array}{l}\text { New contents } \begin{array}{r}\text { were } \\
\text { discovered } \\
\text { CARLIGH and faculty } \\
\text { recommendation. }\end{array}\end{array}$ & $\begin{array}{l}\text { Negotiation, licensing } \\
\text { and procurement of } \\
\text { consortium-based } \\
\text { contents by CARLIGH } \\
\text { on behalf of the library. } \\
\text { Individual library } \\
\text { subscriptions were } \\
\text { acquired by institutional } \\
\text { leaders. }\end{array}$ & $\begin{array}{l}\text { URL checks, off- } \\
\text { campus/other } \\
\text { authentication and access } \\
\text { checks. Channels of } \\
\text { awareness creation } \\
\text { included banners, email, } \\
\text { SMSs and mouth-to- } \\
\text { mouth. Occasional } \\
\text { training workshop for } \\
\text { faculty and annual } \\
\text { training for postgraduate } \\
\text { students. }\end{array}$ & $\begin{array}{l}\text { Annual usage } \\
\text { statistics from } \\
\text { providers; } \\
\text { administrative } \\
\text { rights to some } \\
\text { databases ro } \\
\text { generate in-house } \\
\text { reports. Access } \\
\text { checks. }\end{array}$ & $\begin{array}{l}\text { Annual } \\
\text { statistics } \\
\text { providers. }\end{array}$ & $\begin{array}{l}\text { usage } \\
\text { from }\end{array}$ & $\begin{array}{l}\text { Cancellation/renewal } \\
\text { decisions informed by } \\
\text { demand, } \\
\text { cost/availability of } \\
\text { funding. }\end{array}$ \\
\hline 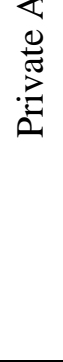 & WIUC & $\begin{array}{l}\text { New contents were } \\
\text { discovered solely through } \\
\text { CARLIGH and selection } \\
\text { based on perceived } \\
\text { relevance to institutional } \\
\text { programme. }\end{array}$ & $\begin{array}{l}\text { Negotiation, licensing } \\
\text { and procurement of } \\
\text { contents by CARLIGH } \\
\text { on behalf of the library. }\end{array}$ & $\begin{array}{l}\text { URL and other access } \\
\text { checks. Awareness } \\
\text { creation through } \\
\text { orientation, fliers and } \\
\text { library handbook. } \\
\text { Training of users } \\
\begin{array}{l}\text { occasionally (only upon } \\
\text { acquisition of new } \\
\text { contents). }\end{array}\end{array}$ & $\begin{array}{lr}\text { Annual } & \text { usage } \\
\text { statistics } & \text { from } \\
\text { providers; } & \\
\text { administrative } \\
\text { rights to some } \\
\text { databases ro } \\
\text { generate in-house } \\
\text { reports. Access } \\
\text { checks. }\end{array}$ & $\begin{array}{l}\text { Annual } \\
\text { statistics } \\
\text { providers. }\end{array}$ & $\begin{array}{l}\text { usage } \\
\text { from }\end{array}$ & $\begin{array}{l}\text { Cancellation/renewal } \\
\text { of contents based on } \\
\text { usage level and } \\
\text { availability } \\
\text { funding }\end{array}$ \\
\hline 导 & CARLIGH & $\begin{array}{l}\text { Contents discovered } \\
\text { mainly through publishers, } \\
\text { member libraries and } \\
\text { individual faculty } \\
\text { recommendation. } \\
\text { Selection of contents based } \\
\text { on cost, content relevance, } \\
\text { demand, functionality, } \\
\text { terms and usage } \\
\text { conditions. }\end{array}$ & $\begin{array}{l}\text { Negotiation, licensing } \\
\text { and procurement of ERs } \\
\text { carried out by the } \\
\text { Licensing and } \\
\text { Negotiation committee } \\
\text { with support from } \\
\text { INASP and EIFL. }\end{array}$ & $\begin{array}{l}\text { Access provision and } \\
\text { technical support to } \\
\text { member libraries. } \\
\text { Advocacy and capacity } \\
\text { building of member } \\
\text { libraries through training } \\
\text { workshops. }\end{array}$ & $\begin{array}{l}\text { Annual } \\
\text { statistics } \\
\text { providers. }\end{array}$ & $\begin{array}{l}\text { Annual } \\
\text { statistics } \\
\text { providers. }\end{array}$ & $\begin{array}{l}\text { usage } \\
\text { from }\end{array}$ & $\begin{array}{l}\text { Cancellation/renewal } \\
\text { of contents based on } \\
\text { demand by member } \\
\text { libraries. }\end{array}$ \\
\hline
\end{tabular}




\subsubsection{ERM Model/Approach Adopted by Case Libraries}

After establishing the workflow of ERs, libraries adopt an approach in undertaking the various activities in the workflow of ERs. The basic models of ERM identified in the literature are the integrated approach, distributed approach, team approach and a single person approach. The study therefore sought to investigate the ERM approach(es) adopted by the case institutions. Determinations about the approach adopted by the case libraries were made based on staffing for ERs and services of the library. Library staff who played a role related to the ERs, and the unit(s) to which they belonged were considered in determining the ERM approach or model adopted by each case library.

At the Balme Library (UG), the ERs unit which oversaw the Faculty Commons, Research Commons and the Knowledge Commons; and headed by the head of ERs was responsible for ER subscriptions, access provision, marketing, and training sessions. Staff of the IR/digitisation unit were responsible for the IR. However, the interview findings revealed that, staff from other units of the library such as Student Reference, Acquisitions, Cataloguing and Africana Library assisted in information literacy training aspects of implementing ERs of the library. Similarly, at UCC, the main library had an ERs section headed by the head of ERs and was responsible for ER subscriptions, access provision, marketing, and training. However, staff from other units of the library including Cataloguing department, IR/Digitisation unit and Acquisitions department participated in ER implementation activities including information literacy training, maintaining correspondence with publishers and providers, and responding to queries from users, particularly faculty.

At CU, the systems librarian was mainly in charge of the ERs of the library including the IR. In practice however, the systems librarian oversaw subscription to consortium based ERs, access provision, marketing, user training and activities of the IR. Institutional leaders spearheaded negotiation and licensing of subscriptions to e-books which were acquired aside consortia subscription. In addition, there was an ERs support group consisting of heads from other sections of the library who assisted with orientation, awareness creation and user training. At WIUC, the head of ERs oversaw ER subscriptions, access provision, marketing, and training in principle. 
However, the university librarian (library director) and other staff of the library assisted in providing training and user support respectively.

Taken together, the findings revealed similar patterns within the case public academic libraries as both UG and UCC adopted an integrated approach in principle but a distributed approach in practice. For the private case academic libraries, both CU and WIUC had a single person approach in principle but adopted a distributed approach in practice whereby ER tasks were assigned to staff from other units. Findings from case institutions suggested that the approach to practice in all four case libraries was motivated by understaffing and evolving nature of ER workflow. A summary of the ERM approach or model adopted in the case institutions is provided in Table 5.5.

Table 5. 5: A summary of the ERM Approach/Model Adopted in the Case Institutions

Case Library ERM Approach /Model Conclusion

\begin{tabular}{|c|c|c|c|}
\hline 苞 & $\begin{array}{l}\text { UG } \\
\text { Library }\end{array}$ & $\begin{array}{l}\text { ER unit responsible for subscription based } \\
\text { ERs of the library. Staff of IR/Digitisation } \\
\text { unit were responsible for the IR. However, } \\
\text { staff from other units of the library assisted } \\
\text { in information literacy training. }\end{array}$ & $\begin{array}{l}\text { A centralised approach } \\
\text { adopted in principle but } \\
\text { distributed approach in } \\
\text { practice. }\end{array}$ \\
\hline 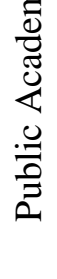 & UCC Main library & $\begin{array}{l}\text { ER section responsible for the ERs of the } \\
\text { library. Staff of IR/Digitisation unit were } \\
\text { responsible for the IR However, staff from } \\
\text { other units of the library assisted in } \\
\text { information literacy training, } \\
\text { correspondence with providers and users. }\end{array}$ & $\begin{array}{l}\text { A centralised approach } \\
\text { adopted in principle but a } \\
\text { distributed approach in } \\
\text { practice. }\end{array}$ \\
\hline 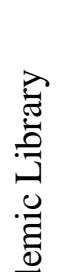 & CU Library & $\begin{array}{l}\text { System librarian in charge of both the IR } \\
\text { and other ERs of the library. However } \\
\text { institutional leaders licensed and negotiated } \\
\text { non-consortium based ERs and staff from } \\
\text { other units (ERs support group) assisted in } \\
\text { information literacy training }\end{array}$ & $\begin{array}{l}\text { A single-person approach } \\
\text { adopted in principle but } \\
\text { distributed approach in } \\
\text { practice. }\end{array}$ \\
\hline 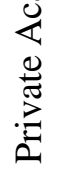 & WIUC Library & $\begin{array}{l}\text { Head of ERs responsible for the ERs of the } \\
\text { library and IR (yet to be functional). } \\
\text { However, all staff of the library assisted in } \\
\text { user support or training. }\end{array}$ & $\begin{array}{l}\text { A single-person approach } \\
\text { adopted in principle but } \\
\text { distributed approach in } \\
\text { practice. }\end{array}$ \\
\hline
\end{tabular}




\subsection{Analysis of Collection Development Policies of Case Institutions}

Management of ERs entails developing policies for ERs as part of the planning process. To examine the extent to which the CDPs of case libraries covered the ERs in their collections, contents of their CDPs were analysed. Three case libraries (UCC, CU and WIUC) made available their CDPs for analysis. The study employed the evaluation tool developed by Mangrum \& Pozzebon (2012) for evaluating CDPs. The authors developed the tool based on their experience with collection development in the electronic environment, previous research and ERM specifications by the Digital Library Federation's Electronic Resource Management Initiative (Mangrum \& Pozzebon, 2012). The tool comprises nine (9) major categories which are as follows:

1. Cost,

2. Consortia,

3. Responsible parties,

4. Content,

5. Access,

6. Usability,

7. Assessment,

8. Licensing (user perspective), and

9. Licensing (library management).

Each criterion consists of four elements making a total of thirty-six (36) items. All 36 elements have been defined to ensure uniformity in coding. In applying the tool, CDPs that mentioned any of the items were ticked and rewarded one point after which the percentage was calculated, whereas no point was awarded in the instance of no mention. Table 5.6 provides an overview of the CDP evaluation tool developed by Mangrum \& Pozzebon (2012) which was adopted in the study whereas Table 5.7 depicts the results of analysis of the CDPs of UCC, CU and WIUC libraries. A within-case analysis is presented whereby each CDP is analysed separately. This is followed by a cross-case analysis which looks at similarities and differences in the CDPs. Finally, an overall case analysis is presented. 
Table 5. 6: CDP Evaluation Tool (Mangrum \& Pozzebon, 2012)

\begin{tabular}{|c|c|c|}
\hline Criteria & Criteria details & Definitions/Examples/Notes \\
\hline Cost & $\begin{array}{l}\text { Brief mention } \\
\text { Pricing model } \\
\text { Justification } \\
\text { Hidden costs }\end{array}$ & $\begin{array}{l}\text { Any brief mention of the cost } \\
\text { Is the product purchased as a subscription, one-time, etc? } \\
\text { How will pricing increases be handled? How will funds be re-allocated to cover costs? } \\
\text { Incidental costs, service fees, software, etc. }\end{array}$ \\
\hline Consortia & $\begin{array}{l}\text { Brief mention } \\
\text { Consortia participation }\end{array}$ & $\begin{array}{l}\text { Any brief mention of the consortia } \\
\text { How is the selection and assessment of materials accomplished? }\end{array}$ \\
\hline & $\begin{array}{l}\text { Consortia maintenance } \\
\text { Consortia cost negotiation }\end{array}$ & $\begin{array}{l}\text { How are statistics gathered? How is maintenance work divided and communicated? } \\
\text { What is the structure for negotiation with vendors? }\end{array}$ \\
\hline Responsible parties & $\begin{array}{l}\text { Who evaluates? } \\
\text { Who acquires? } \\
\text { Who implements? } \\
\text { Who assesses? }\end{array}$ & $\begin{array}{l}\text { For selection purposes, sets up trials, etc? } \\
\text { Including negotiation and licensing } \\
\text { Who sets up access, maintains access? } \\
\text { Manages statistics, reporting, and gathering feedback? }\end{array}$ \\
\hline Content & $\begin{array}{l}\text { Current and authoritative } \\
\text { Academic need } \\
\text { Scope/depth } \\
\text { Overlap with print }\end{array}$ & $\begin{array}{l}\text { Accurate, from a trusted source } \\
\text { Who is the collection for? } \\
\text { Is the level of the product addressed? Are materials purchased for specialty areas? } \\
\text { Discuss how overlap is handled as a selection or weeding issue }\end{array}$ \\
\hline Access & $\begin{array}{l}\text { Brief mention/site license } \\
\text { Interoperability } \\
\text { Software/plug-ins } \\
\text { MARC record availability }\end{array}$ & $\begin{array}{l}\text { Any mention of access to electronic materials or mention of IP range, site licensee, etc. } \\
\text { Can communicate with other open URL discovery resources } \\
\text { Any mention of special add-ons needed for access } \\
\text { Any mention of how material is made available through the library's catalogue }\end{array}$ \\
\hline Usability & $\begin{array}{l}\text { Interface } \\
\text { Tutorials/training } \\
\text { Search tools/metadata } \\
\text { Vendor }\end{array}$ & $\begin{array}{l}\text { Is the product easy to use, manoeuvre between screens; display non-text? } \\
\text { How much training is needed? Is tech. support available? Tutorials/help screen available? } \\
\text { Quality of the search engine, reliable metadata that produces useful results } \\
\text { Does the vendor have a reputation of being reliable? }\end{array}$ \\
\hline Assessment & $\begin{array}{l}\text { Trial period } \\
\text { Feedback from users } \\
\text { Statistics } \\
\text { Renewal decisions }\end{array}$ & $\begin{array}{l}\text { Is there any emphasis of testing or gathering feedback before purchase? } \\
\text { Does the policy mention gather feedback from any users during the trial or for renewal } \\
\text { Any mention of gathering statistical data to evaluate usage, renewal, etc. } \\
\text { How are renewal decisions made, is there any criteria for renewal or protocol? }\end{array}$ \\
\hline Licensing (User perspective) & $\begin{array}{l}\text { Brief mention } \\
\text { Interlibrary loan } \\
\text { Perpetual access/archival copy } \\
\text { Authorised users }\end{array}$ & $\begin{array}{l}\text { Any mention of licensing or protecting users from unreasonable restrictions? } \\
\text { Any mention of addressing interlibrary loan rights concerning electronic resources } \\
\text { Any mention of obtaining perpetual access or the ability to create an archival copy } \\
\text { Defining who has access to electronic resources, students, public use, alumni use, etc }\end{array}$ \\
\hline Licensing (Library management) & $\begin{array}{l}\text { Duration } \\
\text { Fair use } \\
\text { Liability } \\
\text { Termination rights }\end{array}$ & $\begin{array}{l}\text { License dates, automatic renewals, multi-year licenses } \\
\text { Fair use of DRM is addressed in any way } \\
\text { Indemnification or liability issues are addressed } \\
\text { How can the library terminate the contract? }\end{array}$ \\
\hline
\end{tabular}


Table 5. 7: Analysis of CDPs of UCC, CU and WIUC libraries

\begin{tabular}{|c|c|c|c|c|c|c|}
\hline \multirow[t]{2}{*}{ Criteria } & \multirow[t]{2}{*}{ Criteria details } & \multicolumn{3}{|c|}{ CDPs of Case Institutions } & \multicolumn{2}{|c|}{ Total } \\
\hline & & UCC & $\mathrm{CU}$ & WIUC & $\mathrm{N}$ & (\%) \\
\hline \multirow[t]{4}{*}{ Cost } & Brief mention & $\checkmark$ & & $\checkmark$ & 2 & 66.7 \\
\hline & Pricing model & $\checkmark$ & & $\checkmark$ & 2 & 66.7 \\
\hline & Justification & & & & 0 & 0.0 \\
\hline & Hidden costs & & & & 0 & 0.0 \\
\hline \multirow[t]{4}{*}{ Consortia } & Brief mention & $\checkmark$ & & & 1 & 33.3 \\
\hline & Consortia participation & $\checkmark$ & & & 1 & 33.3 \\
\hline & Consortia maintenance & & & & 0 & 0.0 \\
\hline & Consortia cost negotiation & & & & 0 & 0.0 \\
\hline \multirow[t]{4}{*}{ Responsible parties } & Who evaluates? & & & & 0 & 0.0 \\
\hline & Who acquires? & & & & 0 & 0.0 \\
\hline & Who implements? & & & & 0 & 0.0 \\
\hline & Who assesses? & & & & 0 & 0.0 \\
\hline \multirow[t]{4}{*}{ Content } & Current and authoritative & $\checkmark$ & & & 1 & 33.3 \\
\hline & Academic need & $\checkmark$ & $\checkmark$ & $\checkmark$ & 3 & 100.0 \\
\hline & Scope/depth & $\checkmark$ & & $\checkmark$ & 2 & 66.7 \\
\hline & Overlap with print & & & $\checkmark$ & 1 & 33.3 \\
\hline \multirow[t]{4}{*}{ Access } & Brief mention/site license & & $\checkmark$ & $\checkmark$ & 2 & 66.7 \\
\hline & Interoperability & & & & 0 & 0.0 \\
\hline & Software/plug-ins & & & & 0 & 0.0 \\
\hline & MARC record availability & $\checkmark$ & $\checkmark$ & & 2 & 66.7 \\
\hline \multirow[t]{4}{*}{ Usability } & Interface & $\checkmark$ & & & 1 & 33.3 \\
\hline & Tutorials/training & & $\checkmark$ & & 1 & 33.3 \\
\hline & Search tools/metadata & & $\checkmark$ & & 1 & 33.3 \\
\hline & Vendor & $\checkmark$ & & & 1 & 33.3 \\
\hline \multirow[t]{4}{*}{ Assessment } & Trial period & & & & 0 & 0.0 \\
\hline & Feedback from users & & & & 0 & 0.0 \\
\hline & Statistics & $\checkmark$ & & & 1 & 33.3 \\
\hline & Renewal decisions & $\checkmark$ & & & 1 & 33.3 \\
\hline \multirow[t]{4}{*}{ Licensing (user perspective) } & Brief mention & $\checkmark$ & & & 1 & 33.3 \\
\hline & Interlibrary loan & & & & 0 & 0.0 \\
\hline & Perpetual access/archival copy & & & & 0 & 0.0 \\
\hline & Authorised users & $\checkmark$ & $\checkmark$ & $\checkmark$ & 3 & 100.0 \\
\hline \multirow[t]{4}{*}{ Licensing (Library management) } & Duration & & & & & 0.0 \\
\hline & Fair use & & & & & 0.0 \\
\hline & Liability & & & & & 0.0 \\
\hline & Termination rights & & & & & 0.0 \\
\hline Overall N (\%) & & $14(38.9)$ & $6(16.7)$ & $7(19.4)$ & 27 & (25.0) \\
\hline
\end{tabular}


As shown in Table 5.7, the findings revealed that the CDPs of UCC library covered 14 (38.9\%) out of 36 items detailed in the evaluation tool. The CDPs mainly addressed the content of ERs (75\%) which covered currency and authoritativeness, academic need and scope or depth. Whereas access which focuses on MARC record availability was minimally addressed (25\%), no mention was made of responsible parties and licensing (library management). For CU, the CDPs of the library covered $6(16.7 \%)$ out of the 36 items in the evaluation too. The CDPs moderately addressed access (50\%) which highlighted site license and usability (50\%) which highlighted training and search tools. There was no mention of cost, consortia, responsible parties, assessment and licensing (library management). In the case of WIUC, the CDPs of the library covered 7 (19.4\%) out of the 36 items in the tool. The CDPs largely focused on content (scope/depth, and overlap with print) (75\%) while consortia, responsible parties, usability, accessment and licensing (library management) were not addressed in the CDPs.

The findings revealed some similarities and differences in the CDPs that were analysed. Regarding content, all three CDPs emphasised 'academic need' as highlighted in Table 5.7. This was consistent with findings from the interviews with library staff which revealed perceived relevance to academic programmes as one of the main criteria for selecting ERs for the library. Also, concerning licensing (user perspective), 'authorised users' was addressed by all three CDPs as highlighted. For cost, the findings indicated similar items (brief mention and pricing model) specified by the CDPs of UCC and WIUC libraries.

Although CDPs of UCC and WIUC libraries largely addressed content, whereas the policies of UCC library mentioned currency and authoritativeness, those from WIUC did not make any such mention. Again, whereas the policies of WIUC library addressed overlap with print, those of UCC library did not make any such mention. Comparatively, CDPs of UCC library had the highest scoring completeness (38.9\%) of the specified criteria. This was followed by WIUC library (19.4\%) with the least coverage by CU library (16.7\%). The average completeness of these policies was $25 \%$. This meant that, the CDPs covered a quarter of the criteria details on the average, indicating that they were incomplete and lacked vital components.

Overall, the findings as illustrated in Table 5.7 showed that the case libraries mainly addressed content of ERs in their CDPs as 3(100\%) highlighted academic need of content and $2(66.7 \%)$ addressed scope and depth of content. Figure 5.1 provides an overall average occurrence of the nine criteria details. Content which is the top criterion was addressed by over half $(58.3 \%)$ of 
the policies with about a third of the policies addressing access, cost, licensing (user perspective) and usability. At the end of the spectrum, none of the policies mentioned licensing (library management) and responsible parties whereas assessment and consortia had very low average occurrence ( $16.7 \%$ each respectively).

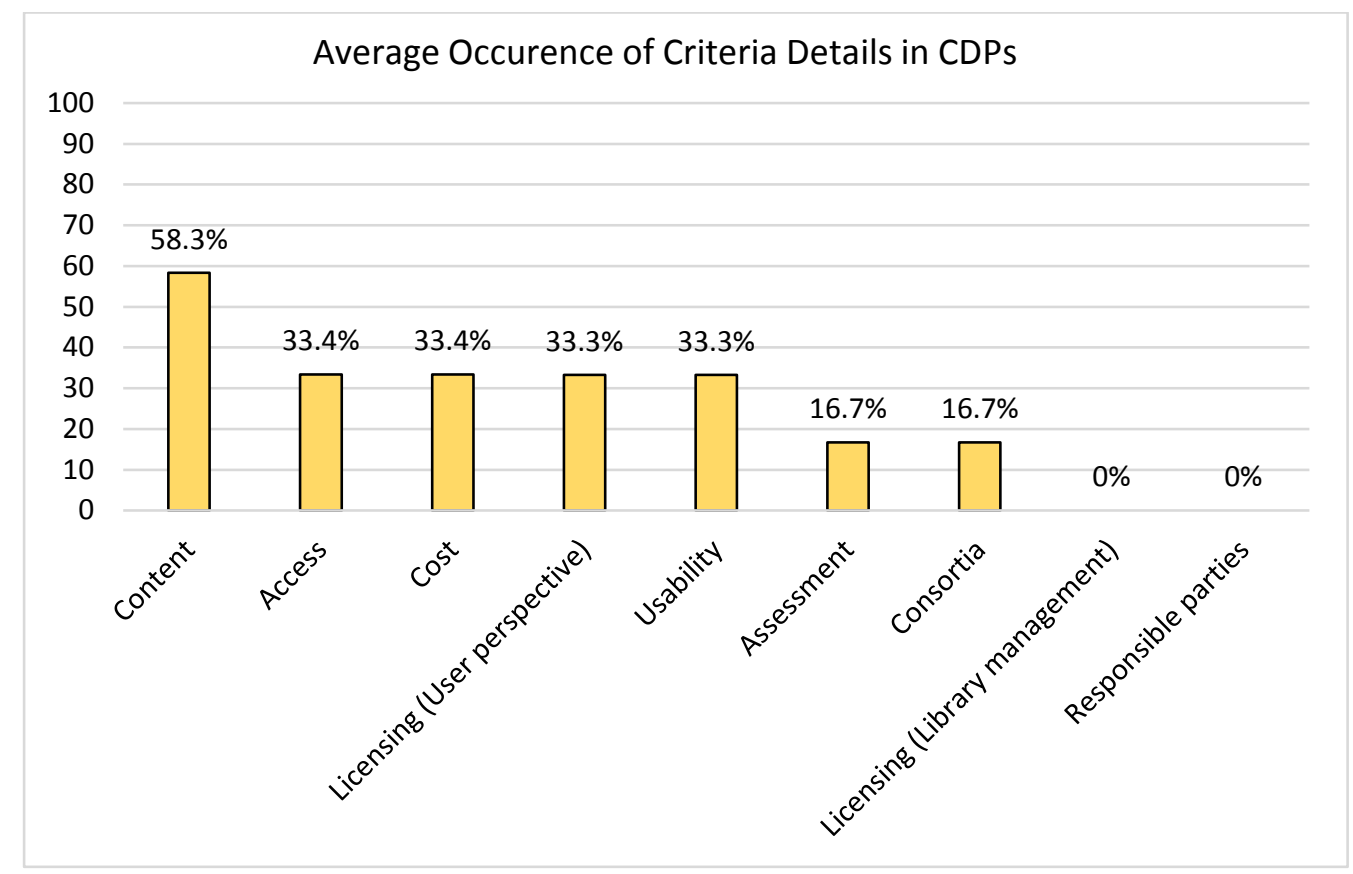

Figure 5. 1:Average occurrence of criteria details in CDPs of case institutions

The findings therefore illustrate that, access provision, cost related factors, licensing matters (on both usage and management), assessment, consortia and responsible parties were not given the due recognition in the CDPs by the case libraries. Inadequate knowledge and lack of clarity on ERM practices could have contributed to the absence of these components in the CDPs of these libraries. 


\subsection{Factors Affecting the Management of Electronic Resources}

One of the main aims of this study is to identify the factors affecting the management of ERs in the case institution. Findings from the interviews revealed various factors and these have been grouped into governmental, organisational and individual factors. The factors are presented in the following sub-sections.

\subsubsection{Governmental Factors}

The findings revealed governmental factors as affecting ERM in the case institutions particularly the public institutions. These concerned policies and decisions by the government which served as obstacles to the availability of human and non-human resources required for effective ERM. Recruitment of employees in the public case institutions had been suspended due to a directive by Government. This followed a decision by the government of Ghana in 2010 to manage the public wage bill and stabilise the economy by clearing ghost names from payrolls. Consequently, new staff could not be employed to replace retired or resigned staff and to complement existing staff which affected staffing for ERs in the public case institutions. Adutwumwaa (UG) and Abrafi (UCC) highlighted the effects of government directives on staffing for ERs:

In general, we are understaffed. Virtually every department is understaffed on campus. When a staff retires, we are not able to fill the position immediately because they always need government clearance. Once you don't have government clearance you cannot hire anybody. So, somebody leaves and their position is vacant and people will have to manage other people's job. So we do have staff challenges everywhere (Adutwumwaa).

For a very long time there has not been employment, so people have retired and there hasn't been any replacement and people have upgraded themselves, they have moved from one level to the other and we are just managing (Abrafi).

Due to the suspension of recruitment in the public case institutions, the few ER staff available had to take on extra ER related duties to make up for the low staff strength although less technical tasks were assigned to non-ER staff. The implication is that staff were overburdened which could negatively impact on staff productivity as staff could easily be overwhelmed by the additional work they had to do.

Another governmental or national factor which affected the management of ERs in the case institutions was power rationing resulting in frequent power outage. This crisis referred to as "dumsor" (on-and-off) in Ghanaian parlance was a directive by the government for which reason, the former president was nicknamed “Mr Dumsor" (BBC News, 2015). Early 2019, 
severe power rationing was re-introduced which brought a new term "dumsaa" (indefinite off). This affected ERM activities. For instance, ER training programmes were sometimes cancelled and access to the resources was hindered which affected usage of ERs of the library.

The third government factor revealed in the findings was related to funding. Public case institutions received government subvention which was generally perceived by interviewees as inadequate. Private case institutions on the other hand were not eligible for any such support from the government. Inadequate funding hindered the purchasing power of case institutions which affected acquisition and sustainability of ERs and services of the library. Taken together, the government played a hindering role in the management and usage of ERs in the case institutions through unfavourable regulations and inadequate funding.

\subsubsection{Organisational Factors}

Findings from the interviews revealed various organisational factors surrounding the management of ERs in the institutions investigated. The factors included collaboration with stakeholders, institutional support, communication, advocacy, institutional management structure, infrastructure, sustainability, and staffing. These are presented in the following subsections.

\subsubsection{Collaboration with Stakeholders}

The findings from both public and private case institutions revealed collaboration as playing a major role in facilitating the management of ERs in the case institutions. Collaboration was identified at three levels being local, national, and international levels. These have been presented in the following sub-sections.

\subsection{Collaboration at the Local Level}

The findings revealed collaboration at the local level between ER units and non-ER units which facilitated ERM in both public and private case institutions. For example, in the public institutions, staff of other units of the library assisted in information literacy education for users and some administrative functions. Comments from Acheampong (UG) and Danquah (UCC) who were non-ER staff revealed some of the role they played related to ERs of the library:

I am part of a team made up of library senior members who assist in running trainings on the available resources especially ERs and how faculty and students can access them. We create awareness on the ERs and other tools available for research like EndNote, Mendeley and other resources; and provide training on how to access them (Acheampong, UG). 
I manage the SAGE ERs that come over here. Whenever there is any issue, they (providers) contact me because I am part of their contact list. Some also send me their new publications which I share on the senior members platform so that lecturers could have access to them. Again, regarding IP addresses which facilitate access, you know we have to send our proxy addresses to them (providers) and I have to update those records. In addition, sometimes lecturers are not able to access contents and they get to me and I contact the technical support (unit) to find out what the problem is (Danquah, UCC).

Similar findings pertained in the private case institutions where staff of other units of the library assisted the ER unit in carrying out information literacy education and providing user support:

We have an ER group made of the various heads of the library and other paraprofessionals of the library. Each one organises training for staff to acquaint them with the ERs that the library has and equip them with ER skills so that they in turn assist students and provide them with better services (Yoofi, CU).

From time to time we organise training programmes for all staff members because we don't want a situation whereby if the head of ERs is not there, they will not be able to serve clients. We try to train them, and they are doing it. Right now, one of the staff at the front desk is attending to clients at the ERs corner so that it should not be head of ERs alone. Every staff should know how to do almost everything in the library (Dufie, WIUC).

Collaboration between the ER unit and non-ER units of the library eased the burden on understaffed ER units by relieving them of less technical tasks to focus more attention on the technical aspects of ERM.

The findings also revealed cooperation between ER units/staff and the user community at UG, CU and WIUC in the areas of ER promotion, training provision and evaluation of ERs. These three case libraries collaborated with faculty by encouraging them to create awareness of the ERs among students and to request training for students. Students were also encouraged to schedule training sessions which boosted attendance as reported by Afia (CU). At CU also, there was a collaboration with faculty in assessing students' usage of ERs of the library as pointed out by Aboagye:

I have contacts with the lecturers so I asked them to let us know the level of usage of ERs of the library by students as in how they answer questions in terms of research assignments but the feedback we received was they (the lecturers) had realised that they used one source of information, that is Wikipedia and all the answers they usually gave came from one source, only Wikipedia and Google, that is all that they know. They don't even know about Google Scholar or any database. They don't know anything.

Collaboration with the user community informed promotional activities by the library which boosted awareness of ERs of the library, attendance to training and increased usage of the resources. For example, the Balme Library (UG) observed an increase in the usage of ERs 
which was attributed to collaborating with users in creating awareness and scheduling training sessions.

\subsection{Collaboration at the National Level (The Consortium)}

The findings revealed collaboration at the national level through consortium building as greatly facilitating ERM in the case institutions. Almost all interviewees from both public and private case institutions acknowledged the immense role played by CARLIGH in the acquisition of ERs, capacity building and advocacy for the library. For example, Afriyie (UG) mentioned cost reduction and cost sharing as the major benefits of joining CARLIGH. In the same vein, Abrafi (UCC) highlighted the benefits of joining CARLIGH:

It has really helped otherwise we couldn't have afforded because the ERs are very expensive but thanks to CARLIGH, when we come together, we are able to share the cost. Even that is not easy but at least it's been very manageable with CARLIGH.

Similarly, key interviewees from the private case institutions were also appreciative of the role CARLIGH played. Yoofi (CU) highlighted cost reduction and capacity building as the major benefits of joining the consortium. Advantages of joining the consortium were also highlighted in the findings from WIUC:

In fact, if we were not members of CARLIGH, we would not have been able to provide ERs because they are very expensive. The databases are very expensive so going solo is not the idea. The idea is to partner with others, and I think that CARLIGH is the best way to go. Being members of CARLIGH makes it possible for us to provide ERs, provide training for our staff and sometimes for our users (Akyere).

The role played by CARLIGH resulted in a level of uniformity in the ERs provided by both the endowed and less endowed institutions such as UG and WIUC respectively. The consortium pre-financed ER subscriptions to make up for payment delays by member institutions. Capacity building as indicated by all case institutions was also a hallmark of the consortium as it organised periodic training workshops for ER staff of member libraries. In addition, CARLIGH played an advocacy role by assisting member libraries to obtain the necessary institutional support to facilitate the management of ERs:

The difficulty that some of them, especially the smaller universities face is that, against the rate they pay and the usage, the usage statistics have not been good, so they (institutional leaders) continue to complain "why do we have to pay for this?" but without taking into consideration that it's been highly subsidised and that is where CARLIGH will now go in to discuss with various management that, this is highly subsidised and you need to take advantage of it (Agyeman, CARLIGH). 
This support from CARLIGH gave member libraries a collective bargaining power to lobby institutional leaders for the cause of the library. Overall, the consortium was instrumental in cost reduction and sharing, sustainability of ER services, capacity development and advocacy for case libraries, all of which promoted ER services in the institutions.

\subsection{Collaboration at the International Level}

Analysis of the interview findings showed that collaboration at the international level was an enabler to ERM in the case institutions. With CARLIGH playing an intermediary role, international bodies including International Network for the Availability of Scientific Publication (INASP) and Electronic Information for Libraries (EIFL) supported the case institutions in the areas of acquisition of ERs and capacity building. For example, all four case institutions had access to donor funded resources such as Research4Life databases which comprised HINARI, AGORA, OARE, ARDI and GOALI. Also, INASP and EIFL had for a long time assisted the consortium in negotiating and licensing ERs and obtaining discounted prices for members. Support from international bodies reduced the financial burden on case institutions and allowed libraries to channel available limited funding to other priority areas such as ICT infrastructure. Furthermore, international bodies played a remarkable role in capacity building in both public and private case libraries through the consortium. For instance, Akyere (WIUC), Afriyie (UG) and Basiwa (CARLIGH) pointed out that they had participated in local and international training sessions on licensing and negotiation organised by INASP. Ampah (CARLIGH) highlighted capacity building efforts of these international bodies:

INASP and EIFL have tried as much as possible to develop our capacity to manage these resources on our own. Actually, some of the projects we are involved with them are ending next year March, so we have to now ensure that we have the capacity to continue with the projects, but we have had a lot of training and a lot of support from INASP and EIFL.

Capacity building through these international bodies aimed to equip the libraries with requisite skills for managing ERs effectively.

Generally, collaboration at the local level sought to enhance ER services in the case institutions to promote effective usage of the ERs, ease the burden on staff of ER unit, and ensure adequate ER services. Collaboration at the national and international levels facilitated acquisition and sustainability of ERs and capacity building of ER staff. 


\subsubsection{Staffing Challenges}

Staffing to a large extent determines the success of an ER system or implementation (Abrams, 2015). The findings revealed various staffing challenges which served as obstacles to the management of ERs in the case institutions. These revolved around staff strength, skills, and motivation.

\subsection{Low Staff Strength}

Low staff strength was a theme that ran across all four case institutions. Factors accounting for low staff strength varied according to the type of institution. In the public case institutions (UG and UCC), understaffing was as a result of suspension of recruitment following a directive by the government of Ghana, which was exacerbated by an institutional policy of compulsory staff annual leave. Suspension of recruitment in the public tertiary institutions was to enable the government to manage its public wage bill. Also, public university employees were compelled to go on compulsory annual leave within a period in the academic year with the aim of promoting the well-being of university staff. This followed a high record of stress-related illnesses among university staff. Various comments were made by interviewees to emphasise the staffing challenges being faced by the library:

Staffing is an issue, the pressure on the Digitisation/IR unit is so high that intermittently, other works come in. For instance, we are working on past questions now. We are trying to convert the print format into the digital format. So, for the past one month that is what we are doing, and we have held on with the IR works so the workflow is sometimes interjected due to understaffing depending on the needs of students (Addae, UG).

There are staffing challenges. We have staff for the ERs section and so it means that when somebody is on leave for instance, then it means that they have to make do with what they have there and so just recently staff were compelled to go on leave because of some policies and so just two-three people were running the place and it's really a challenge. So, they run more hours than they normally would (Kyeiwaa, UCC).

The above comments from the public case institutions showed that understaffing greatly affected ER services of the library. A similar pattern prevailed in the private institutions (CU and WIUC) where understaffing was accounted for by suspension of recruitment by the institution to cut down budget and high attrition rate as highlighted by interviewees:

We have staffing challenges. Last few months, the library has lost three of its permanent staff and these are people who come, they get trained, you get them to know how to do things, but they get other opportunities elsewhere and they need to go (Akyere, WIUC).

The big challenge is that this one comes in the morning and goes, so in the afternoon who handles the students' complaints and all that?" (Akosua, CU). 
The consequences of low staff strength included inability of ER staff to go on lunch breaks, take full annual leave, the ER section closing earlier than required by users and increased workload and responsibilities of ER staff. Aboagye (CU) for instance had to work extra hours from $8 \mathrm{am}$ to $9 \mathrm{pm}$ being the only ER personnel at his section. However, the findings indicated efforts by all four case libraries to alleviate this challenge by assigning promotional activities such as awareness creation and training, and other ER tasks to staff of other units of the library.

\subsection{Inadequate Skills}

Another staffing factor perceived to be a hindrance to ERM in both public and private case institutions was inadequate skills. Interviewees perceived ICT and ERM skills as lacking among library staff. Various reasons were provided as accounting for this:

If you ask me, knowledge and skills are very important because even we as librarians who are managing these resources, not many people have the skills. These things were not taught when we were in the library school. I am still not sure whether they are teaching them enough of the digital content even as at now. So, skills of both sides because skills of we who are managing those resources and skills of the users to be able to use these things very well (Ampah, CARLIGH).

The idea of ERs and services in my opinion calls for rethinking of library staffing because if you are continuously employing people based on Information Science education, that will not be bad but if you ensure that they have enough ICT skills by the time of completion, then they fit in well so what it means is that staffing should not just be looking at people with information science background. It should be a blend (Badu, UG).

In the view of Ampah (CALIGH) and Badu (UG), gaps in LIS education in Ghana contributed to the lack of ICT skills among library staff. Responses from other interviewees pointed towards lack of training as accounting for inadequate ICT skills among library staff, particularly ER staff.

Actually, we don't usually do that (training) here. Nothing usually comes up (Achiaa, CU).

The training needs of the staff, hmm is a problem. I think any training that is being organised by CARLIGH, Quansah is assigned to attend and then he would in turn teach the other staff who are responsible for the ERs (Aboraa, CU).

Hardly do I attend training workshops, most of the time we are excluded from training programmes and workshops. It's only staff of the Research Commons that get frequent training opportunities. Whatever goes on we are not included or informed because they think this section (Knowledge Commons) is only for undergraduate students, so we don't need training programmes and workshops but it's not the best (Akuba, UG). 
By implication, not all ER staff had the opportunity to attend training programmes and those who participated in "training of trainers" sessions failed to impart acquired skills and knowledge to other staff of the library. For this reason, it appeared some staff were better equipped than others in terms of ICT skills. However, a comment by Afriyie (UG) seemed to provide a justification for unequal training opportunities among ER staff as earlier pointed out by Akuba (UG):

ER staff at the Research Commons mostly get opportunities to travel outside the country. Some of them have been to India, South Africa, and when there are training programmes here, they also attend but the Knowledge Commons deals with undergraduates so that pressure is not really there.

Lack of training opportunities leading to inadequate ICT skills among ER staff affected the ER services provided by the case libraries as some staff were unable to provide adequate user support. In such instances, staff usually referred users to the head of ERs for assistance which only added to their workload. Many interviewees from both public and private case institutions indicated the need to build the capacity of all library staff to equip them with the requisite skills needed to survive in the technological environment. This notwithstanding, a few of the interviewees had contrasting views on participation in ER training:

Well, in fact, I have been in this profession for almost 29 years and so the number of workshops that I have been to, I can't count them. In fact, frankly now I don't go for workshops. I think that others will have to get those opportunities (Danquah, UCC).

This view could hinder effective management of ERs as technology is constantly evolving which makes frequent re-training paramount.

Analysis of the interview findings also indicated lack of clarity on ERM practices. ERM appeared to be a relatively new concept that both public and private case libraries were grappling with. In addition, other factors were revealed as contributing to the lack of clarity on ERM practices in the case libraries. These were lack of documented policies, inadequate succession planning and the role of the consortium. Both public and private case libraries followed undocumented policies and procedures in managing ERs of the library which made it a challenge particularly for new library staff to have any precedence to follow. This challenge was pronounced in the public case libraries where the position of head of ERs was on a rotational basis coupled with inadequate succession planning. Some interviewees had been at post for barely over a year and were still in the process of getting a grasp of ER responsibilities, while a few others had just shifted from the ER unit to other units of the library. ER job rotation 
was also echoed by members of the governing council of CARLIGH as being a threat to consortium activities as the consortium had to deal with new heads of ERs of member libraries periodically. This posed challenges especially in the case where there had not been adequate succession planning to facilitate continuity of ER activities. On the other hand, the findings also revealed the consortium as contributing to the lack of clarity on ER workflow in the case institutions. This was particularly so for case institutions such as UCC and WIUC that solely relied on consortium subscription in acquiring ERs. It appeared that, because the consortium handled a chunk of the ER workflow, ER personnel in the case institutions lacked clarity on those aspects of the workflow that were carried out by the consortium:

I think with CARLIGH managing, it used to be centralised and they are now decentralising it which is good. I think a further decentralisation of the management will help because although I play a role related to ERs of the library, I don't have answers to some of the questions you have asked (Maame, UCC).

Maame (UCC) was of the view that a further decentralisation of ER functions by the consortium would equip ER staff of institutions such as UCC which solely relied on consortium-based subscription, with adequate ERM skills and knowledge particularly in the areas of negotiation, licensing and evaluation of ERs.

Generally, inadequate ICT skills among library staff hindered ER services in both public and private case institutions as staff lacked the requisite skills to provide adequate user support which also lowered their confidence level as revealed in the findings from WIUC, for instance. Lack of clarity on ER workflow affected the implementation of these resources and also impacted on the depth of information obtained from the interviews as some questions posed to interviewees did not yield required responses. For instance, questions regarding the availability of tools or ERM systems (ERMS) for managing the workflow of ERs yielded responses such as the following:

We have an ERMS, but I think there's a little problem with that one but otherwise I don't know if this one also is part of what you are asking for. Students have EndNote, the reference management software.

These are databases so if you need an article, for article download, it does not normally require any tool or software, only Internet connectivity

The above statements suggested that ERM was a relatively new concept that ER staff in the case institutions were yet to come to terms with. 


\subsection{Low Motivation of ER Staff}

Findings particularly from the private institutions revealed low motivation of ER staff due to lack of incentives which could impact on ER services provided by the case libraries. It appeared some aspects of implementing ERs were perceived as extra duties for which reason ER staff believed they were entitled to incentives. Yoofi (CU) for instance highlighted the need for providing incentives to ER staff:

I think there should be some kind of motivation for ER staff. For instance, you organise training workshops and you expect that you would be given some kind of allowance to boost your morale because it is actually for the university. It is a unit under the library which is offering this service. I am imparting my skills and expertise. That is my heartfelt wish.

The above comment appeared to be linked to the lack of clarity on ERM for which reason some aspects of implementing ERs were regarded as outside the responsibilities of ER staff. Consequently, staff were de-motivated in carrying out those duties. Lack of incentives lowered the morale and job satisfaction of ER staff which could negatively impact on their level of commitment and productivity.

\subsubsection{Communication Gaps}

Effective communication is paramount for a successful ERM (Elguindi \& Schmidt, 2012; Hsiung, 2008). Findings from the interviews revealed communication gaps at the individual library and consortium levels which affected the management of ERs in the institutions investigated. At the local level, the findings revealed communication gaps between ER units and other units of the library which affected the ERs services provided by the library. For example, Akosua (CU) mentioned some of the communication challenges:

Some of them [students] begin to ask questions "Ah if you said this is electronic why don't we register?" I heard they have forms with their pictures and all sort of things, there's no clue, you don't even know what it is. So many times, students bring issues like that then I direct them because it looks as if we don't really know what is happening. These are the forms students are given and I don't know what they are used for, they don't tell me anything but students will bring them with their picture, so some of them ask "ah what is this for?", meanwhile they don't engage us. They have to involve us so we can help students.

Communication gaps led to lack of awareness and clarity on ER workflow among library staff which negatively affected ER services as some staff were not well informed to effectively provide user support. To avoid the semblance of incompetence, such staff usually referred users to the head of ERs which only increased the burden on them. 
At the consortium level, Agyeman (CARLIGH) highlighted some of the communication challenges which affected the smooth operations of the consortium:

One of the challenges CARLIGH faces is members not responding quickly to mails that are sent to them. I mean letters are sent and you want a quick response, but you don't see the response and you don't know whether they have received it. And sometimes when members attend meetings, we expect that decisions that are taken will be sent back to their institutions. It's not sent back and then members will complain that CARLIGH management is not responsive. On the management committee, we have a representative for the various categories of institutions, and it is expected that they would also meet to discuss issues that pertain to their institution but at that level also there is a communication gap.

Poor communication led to delays in implementing decisions at the consortium level which ultimately impacted on ER activities.

\subsubsection{Consortium Cost Sharing Model Concerns}

The findings revealed a lack of consensus between CARLIGH and members over the cost sharing model adopted for ERs which affected the activities of the consortium. CARLIGH executives revealed that the disparity and cost sharing model adopted by the consortium was met with resistance from members:

We do the flat rate equal price, so we all pay the same thing and that's what people are having problems with now. So, for the resources we have about eleven which are common to all of us. We pay the same price and the smaller ones are now complaining "if you look at the usage statistics, you see that "University A" and others are using more than others so why do we pay the same rate"? Others are saying that "usage doesn't depend on the size of the institution. There are some universities that are small, but the usage is high" (Ampah, CARLIGH).

The price per use model (flat rate equal pricing) adopted by CARLIGH for cost sharing among member institutions was not welcomed by some members and this led to payment delays and lack of interest in the consortium all of which negatively affected ERM activities. As a way forward for the consortium, Ampah (CARLIGH) pointed out that a committee had been established to investigate the various cost sharing models used by consortia in other African countries to assist CARLIGH in reaching a fair decision.

\subsubsection{Impact of Institutional Management Structure}

It was observed through analysis of the interview findings that the management structure adopted in an institution impacted on how ERs of the library were managed. The public case institutions (UG and UCC) operated a decentralised management structure whereas the private case institutions (CU and WIUC) adopted a fundamentally centralised management structure. These had implications on the span of control of the library in terms of managing the ERs 
particularly regarding individual library subscriptions. For instance, at UG, the library/head of ERs spearheaded the acquisition of contents that were acquired outside consortia subscription, whereas at $\mathrm{CU}$ e-books were acquired by institutional leaders with little to no input from the library. This intercepted the workflow of ERs within the library and compounded the lack of clarity on ER workflow as key interviewees were less informed about the acquisition of individual library subscriptions.

\subsubsection{Low Institutional Commitment}

Responses from interviewees from both public and private case institutions indicated a perceived low commitment on the part of institutional leaders to the needs of the library which negatively affected the management of ERs. Many interviewees opined that low institutional commitment caused the institutional leaders' unwillingness to invest in the library:

Actually, the logistics to work with. We have a systems librarian who is in charge but usually the computers and the things that we need, management are finding it hard to release money for it. Reason being they (institutional leaders) don't see how important the library is, so the logistics are not there for students to use. That's the problem (Achiaa, CU).

With regard to infrastructure for instance computers and all, we have requested for computers. We haven't received them yet. We have been promised that these would come, and we keep following up on it, so we are hoping to receive them (Akyere, WIUC).

It's not just about the lack of budget but the commitment to give, seeing the need and working at it, knowing that the ERs are not for the library but for the general community because when we see it in that light, there will be willingness to invest (Acheampong, UG).

Key interviewees from these three institutions were of the view that institutional leaders did not prioritise the needs of the library which resulted in delays in supporting the library and allocation of inadequate resources. Consequently, the purchasing power of these libraries was affected which hindered acquisition and sustainability of ERs and ICT infrastructure.

\subsubsection{Low User Involvement in ER Services}

To provide ER services that fully satisfy user information needs, it is necessary to involve the user community in the implementation process particularly in the selection and evaluation of contents (Emery \& Stone, 2013). Although the ER unit in the case institutions cooperated with the user community in ER promotion, training and sometimes evaluation, minimal input from users particularly in the selection of contents was observed in some of the case institutions. Analysis of the data unveiled two clusters of institutions. Findings from the first cluster (UG and $\mathrm{CU}$ ) revealed a comparatively higher user input in the selection of ER contents than the 
second cluster of institutions (UCC and WIUC). At UG and CU, faculty recommendation informed acquisition of contents. For example, the Balme Library (UG) subscribed to ScienceDirect database following suggestions from faculty. Also, the Article Request service allowed users to make direct input in the selection and acquisition of titles. Similarly, at CU, faculty recommendations informed the acquisition of E-books by the institution.

In contrast, the findings from UCC and WIUC revealed a very minimal user input in the selection of ERs. Selection of contents appeared to be based mainly on perceived relevance by the library. Determination of relevance of ER contents was based on prejudice informed by institutional programmes. The issue of inadequate assessment of contents prior to selection was also observed. Findings particularly from UCC, CU and WIUC generally indicated low feedback from users after ER trial sessions prior to acquisition as random feedback was obtained from a few faculty through personal contacts. On the other hand, findings from UG painted a better picture as the library gathered usage statistics and obtained both formal and informal feedback from faculty through email and personal contacts after the trial of new contents. Minimal user input in the discovery and selection of ERs could result in the library acquiring irrelevant contents which would contribute to low usage of ERs of the library.

\subsubsection{Low Usage of ERs}

Low usage of ERs was of great concern to most interviewees as it negatively affected ERM activities in both public and private case institutions. For example, Akyere (WIUC) expressed her concern about low usage of the ERs:

Most of the time we speak to them and they go like "wow and we didn't know this" and yet at the end of the day, they still do not come and use it. You go talk to them and they get very interested right there and then, you see a lot of interest but afterwards they don't come. I don't know how it can be handled.

Similar findings were obtained from UG, UCC and CU although UG observed a comparatively increased usage of ERs over the years. Ampah (CARLIGH) also expressed concern over the low usage of ERs as it affected the activities of CARLIGH:

I am not impressed about the use of the ERs. I have access to the usage statistics and sometimes I get disturbed about the low usage because we pay so much for these resources and the usage is very low. I see the challenge as one to do with first of all the people not having the skills to access them (Ampah, CARLIGH).

Factors perceived by interviewees as contributing to the low usage of these resources included users' preferences and inadequate searching skills. Most interviewees believed that some users 
still preferred print information resources to ERs. This echoed a personal experience during the administration of the survey questionnaire where some faculty objected to participating in the study due to their preference for only print information resources. They believed ERs were more relevant to and friendlier towards younger faculty. Also, lack of interest in ERs of the library which manifested in low attendance to training programmes was perceived as affecting the usage of ERs. For example, Adutwumwaa (UG) expressed concern over the attitude of users towards training sessions organised by the library:

We are doing well except that the response is not too great. Yesterday we had Author Aid workshop. Next week we are having Scopus training. Even though 100 people have signed up when it comes for the time for people to show up, then we don't know where those people are.

Similarly, at UCC Kyeiwaa and Akyere commented on the low response of faculty to training programmes organised by the library. Interviewees believed low attendance to training sessions ultimately affected the usage of ERs, as users did not have the requisite skills to access the ERs of the library. This paralleled the views of interviewees from CARLIGH who perceived lack of searching skills as contributing greatly to the low usage of ERs.

Usage of ERs of the library had implications on ERM activities particularly regarding budget allocation as institutional leaders were not willing to invest in ERs that were underused. Acheampong (UG) narrated some of the implications of low usage of ERs: "We have had instances where the University was seriously asking that some databases that were not in high use be cancelled". Usage therefore informed budgeting which led to the cancellation of resources that some users perceived as useful. For example, at UG subscription to NVivo was cancelled due to low usage and the few who found it useful for their research were left frustrated as they had their organised files locked up in the software. In summary, usage of ERs affected ERM with regard to budgeting for the acquisition and sustainability of ERs.

\subsubsection{Inadequate publicity}

The findings revealed issues regarding publicity of ERs in the case institutions. Responses from interviewees indicated lack of awareness of ERs among both library staff and users. Some library staff were not fully aware of the ERs of the library although they performed ER related tasks. For example, at CU Afia, Akosua and Aboraa were not aware of the e-books that had been acquired by the institution although they were involved in user training, orientation and promotion of ERs. Lack of awareness among library staff trickled down to the user community. 
Many interviewees from all case institutions including CARLIGH highlighted inadequate marketing of ERs to users and expressed the need for increased publicity. Interviewees highlighted the implications of lack of awareness of ERs. For example, based on his interactions with faculty, Aboagye (CU) pointed out the consequences of lack of awareness and low usage of the ERs: "All they know is Wikipedia, Google, that is it. So, we have realised that they don't do proper research when it comes to information". The need to intensify publicity to increase awareness levels among staff and users to promote effective ER orientation, training and usage was expressed by many interviewees.

In summary, organisational factors identified as affecting the management of ERs in the case institutions were cooperation, staffing challenges, low motivation of staff, communication gaps, consortium cost sharing model concerns, impact of institutional management structure, low institutional commitment, low user input in ER services, low usage and inadequate publicity.

\subsubsection{Lack of Policies for ERs}

Analysis of the interviews brought to light policy-related factors which affected the management of ERs in the case institutions. Findings from UG revealed lack of ER policies whereas at UCC, CU and WIUC, the collection development policies (CDPs) of the library incorporated a section on ERs. However, many of the interviewees from these three institutions were unaware of them despite the ER-related role they played. For example, Afia (CU) responded when asked by saying, "For me I don't know. I am not in charge of policy formulation". Similarly, at UCC, the findings revealed a lack of awareness and seeming trivialisation of the value of policies for ERs as revealed in the responses of some interviewees: "Well I'm not aware of any formal policy but what it is, is that, at the end of the year CARLIGH has some ERs that they are interested in and then we select those databases that are relevant to our users" (Kyeiwaa, UCC).

Analysis of the CDPs of UCC, CU and WIUC libraries revealed that the sections on ERs were generally incomplete. The total average completeness as earlier indicated in section 5.7 was $25 \%$. However, key interviewees including Yoofi (CU) indicated efforts by the library to revise ER policies: 
When we did our collection development policy, frankly we didn't emphasise the digital or econtent but fortunately we are revising the policy now and it's one of the things we are considering. You know we have realised that there is not much in the policy so the current one we are formulating we are factoring that into it.

Since policies on ERs were not adequately developed, professional experience which Yoofi (CU) termed as "voluntary methods" was adopted in managing ERs of the library. Dufie (WIUC) also pointed out the incompleteness of the CDPs of the library and efforts to revise the policies:

Renewal of the CDPs is supposed to be five years or so but it doesn't really happen. It will happen but as and when, if there is a need we can sit up and say this is what we think we should do, this is what we think we should change, so as and when there is a need we are able to adjust.

Dufie's comment similarly suggested that ERM practices in the library were not guided by the policies. Akyere (WIUC) however explained the challenges of implementing ER policies, highlighting the need for flexibility.

Another factor which emerged from the findings was related to the process of policy development. Policy making was perceived to be cumbersome and required several processes prior to ratification. Aboraa (CU) explained policy development in her institution:

We have a committee and they are supposed to develop policies for the library. Normally I am asked to bring a proposal for us to discuss so the committee is the corporate group responsible for policy formulation but what I normally do is that we have a library management committee. We come together and look at what we want to review, it comes to me and I clear it and forward it to the committee for approval and finally it goes to the academic board before it is accepted as a policy so the policy decisions go through a lot of processes.

The cumbersome nature of policy development in the case institutions discouraged libraries from developing appropriate policies to guide ERM. The cumbersome process also appeared to have accounted for other policy-related issues earlier presented such as infrequent renewal of ER policies and lack of interest and trivialisation of policy development. However, at the consortium level, the findings revealed that policies on ERs had been developed and incorporated in the CARLIGH Strategic Plan and the Constitution to guide activities related to ERs. The strategic plan was developed to "enable the consortium follow a clear roadmap and be highly self-sustainable" (CARLIGH Strategic Plan for 2016-2020:2). It highlights strategies for good governance, effective access to information by member institutions, capacity building, sustainability, partnerships and collaboration, and positioning the consortium in the national and global agenda. 
In summary, lack of ER policies, incomprehensive policies, lack of awareness of ER policies, infrequent renewal, cumbersome processes of policy development and inadequate implementation of available policies were identified as roadblocks to effective ERM in the case institutions. The cumbersome nature of policy development appeared to have played a connecting role to most of the other policy-related factors identified in the findings.

\subsubsection{Resource-Related Factors as a Hindrance to ERM}

Resources are fundamental to effective management of ERs in libraries. Resource-related factors were revealed as negatively affecting ERM in the institutions investigated. These factors revolved around the complexities associated with ERs, inadequate finance and inadequate infrastructure which are presented in the following sub-sections.

\subsection{Complexities Associated with ERs}

Complexities associated with ERs were perceived as obstacles to the implementation of ERs. This had to do with technical issues, rising costs, content relevance, and terms and conditions of usage. Technical issues indicated by key interviewees from all four universities included the unstable nature of ERs which manifested in changes in URL and IP authentication challenges. Danquah (UCC) commented on some of the technical challenges:

Sometimes there are technical challenges in the sense that you expect to be able to access a particular site and it says cannot be reached either there might be a problem with configuration, the IP or your proxy address has been entered wrongly or sometimes especially when we were using passwords. You give out a password and you don't know where, who would give it to whom, and when the providers realise that the passwords that they have given to a particular institution are being used from a different place, then they will either cancel the subscription or cut you off and that's a challenge here.

Also, the findings revealed challenges associated with the development of IRs as recounted by Abeeku (UCC):

Currently we have issues with some of the contents of CDs going bad, and situations where wrong contents were copied onto CDs. Other cases, they cellotape the magnetic field of the CDs and we can't use them. In these instances, we have to do direct digitising with our photo scanner and sometimes we end up getting huge files which are not very good for our repository because it shouldn't be too big if they don't have much pictures on them. So, these are the two challenges I can talk about.

The volatile nature of ERs sometimes hindered IR activities. However, this could be linked to lack of knowledge and skills in managing the resources as CD-ROMs do not have any magnetic field as supposed in the above comment. These challenges resulted in delays in the upload of 
contents onto the IR platform as print versions of damaged CDs had to be scanned and uploaded.

Also, the yearly escalating costs of ERs was a cause for concern among key interviewees as libraries were already in financial crisis. This put a strain on their purchasing power and therefore fewer resources were acquired to stay within budget. Another issue was related to contents of package subscription as highlighted by Ampah (CARLIGH):

You see because it's a package, some of the materials are not relevant to you (the institution) but you are forced to take them. It is also an issue. The content is an issue, we have several journals that even though we say we have over 50000 or 30000 e-journals, for all you know just a few will be relevant to users yet we are paying for the rest so it's also an issue. There is also this issue about having that collaboration or that engagement with the publishers to also look at the African content. People are complaining that most of the things that come are of foreign content but it's not the publishers' making. We are not publishing, that's all.

Ampah and Basiwa both from CARLIGH added that, irrelevant contents included in package subscription led to complaints from users and ultimately resulted in the low usage of the ERs. Ampah pointed out further challenges associated with the various types of ERs. For example, e-books had various restrictive access and usage conditions whereas e-journals usually had multiple simultaneous access terms.

Generally, technical challenges, content relevance and unfavourable terms and conditions of usage hindered the smooth provision of ER services in the case institutions and resulted in interruption of ER services and low usage.

\subsection{Inadequate Finance}

The findings revealed that all four libraries investigated received internal funding from their institution which was largely inadequate. Inadequate finance affected the acquisition and sustainability of ERs and ICT infrastructure. However, inadequate finance was more pronounced in the private universities compared to the public ones because the former was not federally assisted and depended solely on private funding, tuition, and fees unlike the public case institutions which were federally assisted. Consequently, private case institutions struggled to maintain annual subscriptions to ERs. Various strategies were adopted in attempts to alleviate this challenge which included joining CARLIGH, ER content replacement, and charging library usage fee in the public universities. Inadequate finance faced by the case institutions also had implications on the operations of CARLIGH as indicated by Agyeman: 
We are able to put aside some monies so even before the members pay, we would have paid upfront but this year it looks like, last year some members didn't pay so we are having a bit of a challenge. That is the challenge we are facing.

The operations of CARLIGH were affected due to delayed payments by members as the consortium had to make upfront payments to cover such delays. CARLIGH however made efforts towards sustainable funding through conference fees, membership fees and support from external organisations including INASP and EIFL.

\subsection{Inadequate Infrastructure}

Infrastructure to a large extent determines the quality of ER services provided to the user community. The findings revealed that all four institutions were challenged in the area of infrastructure which manifested in inadequate computers and training facilities, poor Internet connectivity and other access-related issues. Situations appeared worse in the private universities due to acute financial constraints as earlier explained. Inadequate infrastructural maintenance was also revealed, as many of the computers in the libraries of UCC, CU and WIUC had broken down for a long time. However, findings from the Balme Library suggested provision for annual infrastructural maintenance. Related to inadequate computers was lack of training facilities which affected training sessions organised by all case libraries as indicated by key interviewees such as Afriyie (UG):

One major thing is, we do not have a training lab. The library itself does not have a training lab so we depend on Information Access Centre (IAC) but IAC is for anybody at all who wants to use the place so it's open to anybody to book and use at a fee so you can only do your training as and when the lab is available. Very few departments have complete Internet computing lab or well-equipped computer lab that you can use so that's the major problem.

Lack of training facilities affected the frequency and timing of training sessions as training sessions could only be scheduled based on availability of space. Another major infrastructural challenge revealed in all four institutions was poor Internet connectivity. This was supported by evidence during the data collection when the researcher experienced Internet interruptions at UG. Network challenges were of great concern to interviewees from all case institutions and various comments were made to indicate the severity of this challenge:

There are instances when the university system is so slow, and it's worse when it's the weekend because people will be at home using off-campus access account and normally it's not working, and staff are not around. There is also the need for standby power sources because sometimes the power goes off on weekends or Sundays when there is no staff around. Then it means that no researcher can work because the servers are down (Acheampong, UG). 
We have a lot of problems with our network. Sometimes two (2) to four (4) days it's not working. Sometimes you come in the morning, it's working. In the afternoon it's very slow. It's a major challenge but the university is working on it. At least since school reopened, it's better than it used to be. It's not the best but it's getting better (Abrafi, UCC).

From time to time we have this Internet interruption. Like the Business Library, for almost one month the Internet was not working. When you call them, they would tell you, they are working on it (Aboraa, CU).

Findings from WIUC were no better. Network challenges generally hindered training programmes and usage of ERs. For example, at CU, training sessions were sometimes cancelled due to network instability. Another challenge which was revealed in the findings were frequent power outage. Erratic power supply was perceived by interviewees as affecting ER services in the institutions. Power cuts nicknamed or popularly referred to as "Dumsor" (On-and-Off) in Ghanaian parlance had until recently been a major issue as Government had issued a directive for load shedding across the country due to infrastructural constraints. Even after the directive had been revoked, many areas of the country continue to experience erratic power supply (Ghana Web, 2018).

The findings revealed other factors which hindered the implementation of ERs in the institutions investigated. For example, Afriyie (UG) highlighted some required logistics that were not available which affected the smooth management of ERs:

.... and then, transportation because we need to visit sister campuses like Atomic, we went there once, and we had to use a colleague's vehicle and his own fuel, so mobility is an issue. Other research stations such as the Kporng research station, Kede I am sure if we introduce them to all these resources and train them the usage statistics will go up and people will benefit from the resources that we have.

Taken together, resource-related factors revealed in the findings were complexities associated with ERs, inadequate finance and inadequate infrastructure. Complexities of ERs included technical issues, content issues, and terms and conditions of usage. Inadequate finance affected acquisition and sustainability of ER services. Infrastructural challenges included inadequate computers, lack of training facilities, poor Internet connectivity, power outage and the lack of other required logistics.

Section 5.8.2 has presented findings on organisational factors affecting the management and usage of ERs in the case institutions. Organisational factors included collaboration with stakeholders, staffing challenges, communication gaps, consortium cost sharing model concerns, impact of institutional management structure, low institutional commitment, low 
user involvement in ER services, low usage of ERs, inadequate publicity, lack of policies for ERs, and resource-related factors. There were more orgnisational hindrances than enablers and the factors had varying levels of impact on the management and usage of ERs.

\subsubsection{Individual Factors}

Analysis of the interview findings unveiled individual factors as affecting the management of ERs in the case institutions. These are attitudinal, socio-cultural, and religious factors.

\subsubsection{Attitudinal Factors}

Responses from interviewees indicated attitudinal factors as affecting ERM in the case institutions. Positive attitude which encouraged effective management of ERs included the desire among library staff to improve upon their ER services, desire to keep up with technology and the desire of non-ER staff to participate in ER functions. Key interviewees from all case institutions indicated the need for improved ER services for which reason various efforts were being made to provide adequate ER services amidst challenging circumstances. For example, Afriyie (UCC) who was greatly concerned about usage of the ERs highlighted some of the promotional efforts being made by the library to promote increased usage:

The only problem is that people are not using them because if you look at the usage statistics sometimes it's quite disturbing. We have started our own selective dissemination of information just to let them know about it. We have written to all colleges and departments and they have given us their research needs, we have nominated people to be in charge of various colleges and we are just hoping that with these efforts, people will start using the ERs. We have sent out fliers, made announcements on ATL FM just to let them know what we have and I think that it is helping because we cannot just be sitting down, the resources are expensive and should be used.

Similar efforts were indicated by interviewees from UG whereby various channels of ER awareness creation had been adopted for increased publicity. Another positive outlook revealed in the findings from both public and private universities was the desire to keep up with technology. The importance of keeping abreast with the constantly changing technology was expressed by key interviewees which encouraged various efforts towards mentorship, professional developments, and upgrade of technology:

Now, all the other staff are also forced to learn more IT because I tell them that when you sit behind your desk, you have Internet, go online, get busy. Study the trend, get to know what is happening, emerging technologies and how they are impacting on the library (Dufie, WIUC) 
A lot of training goes on both locally and internationally, so they try to keep up to the recent developments taking place all over the world. From time to time they migrate. Our providers alert us, like Science Direct when they added an 's' to 'http' that's a security feature to their link, they made us aware so the Technical Service our support unit immediately migrated from the one without the 's' to the 's' so we are constantly informed and we try to move along with whatever innovations or new things they are coming up with (Afriyie, UG).

This positive attitude led to various efforts aimed at providing adequate ER services to encourage maximum use of the resources. Another positive attitude which facilitated ERM was the interest some non-ER staff had in the ER services of the library which led to proactive participation in ER functions. For example, Acheampong (UG) who was a non-ER staff, recounted how he sometimes contacted service providers on behalf of the ER unit to resolve technical issues. Similarly, Danquah (UCC) maintained correspondence with publishers, database providers and users on behalf of the ER section. At WIUC, Dufie revealed that all library staff were involved in providing ER services. Also at CU, Akosua indicated her desire to be involved in ER functions: "I wish, in fact to me, all the library staff should be involved in ER functions so that at every point in time it looks like we are on top of issues when students come then we will just respond to their queries".

The interest and participation of non-ER staff in ER functions eased the burden on the staff of ER unit while providing them with a greater understanding of the complexities of managing ERs. This could prevent any sabotage from other units of the library that would hinder effective management of these resources.

\subsubsection{Socio-cultural Factors}

Socio-cultural factors consist of values, customs and lifestyles that are typical to a society. Observation through the analysis of interview findings revealed socio-cultural values as affecting the management of ERs in the institutions investigated. Identified factors revolved around information culture and power distance which are presented next.

\subsection{Socio-cultural Factors as an Enabler}

A socio-cultural factor which served as an enabler to ERM in both public and private case institutions is information culture of the Ghanaian society. From the findings, oral culture which is mainly informal appeared to play a complementary role to formal means of ERM particularly in the areas of selection and evaluation of ERs. For example, Aboagye (CU) explained how he evaluated the usage of online databases among students through word of 
mouth by finding out from faculty the quality of and references to assignments and research projects submitted by students. The information he obtained informed awareness creation efforts and training sessions for students. At UG, Acheampong indicated how phone calls were made to some faculty for feedback on ERs of the library. Oral information culture provided a quicker means of obtaining feedback on ER services from users.

\subsection{Socio-cultural Factors as a Hindrance}

Notwithstanding the fact that oral information culture served to facilitate ERM, the findings also revealed negative effects on some aspects of ERM in the case institutions. This was particularly in the area of documentation and communication. A close analysis of the interview findings revealed inadequate documentation habits as a result of the influence of oral culture. This translated into lack of documented ER policies, ER administrative activities and infrequent renewal of policies in the case institutions as obtaining information by word of mouth appeared to be the preferred option. Inadequate documentation had various consequences including lack of clarity on ER workflow and inadequate succession planning which could result in lack of prioritisation and inconsistencies in ER activities. It also impacted on the depth of information obtained from interviewees. For example, Afriyie (UG) indicated the need to contact others to be able to address some of the interview questions: "I will have to find out".

Related to inadequate documentation habits was poor writing culture leading to communication challenges particularly between CARLIGH and member representatives which manifested in delayed or no response to mails from the consortium. This could be attributed to the predominance of oral culture, which made responding to written communication not a second nature to some library staff. Delayed correspondence as emphasised by Agyeman (CARLIGH) hindered the planning and implementation of ERs of the consortium.

Also, the findings reflected the impact of the Ghanaian culture particularly power distance on the management of ERs in the institutions. In the findings, power distance manifested in the form of fear of speaking against authority or the decisions made by institutional leaders. Many interviewees were careful not to voice anything that could go against the image of authorities. For example, a comment by Afia (CU) hinted fear of offending authorities "It is not because the university does not want to support the library but because it (inadequate funding) is a whole university-wide problem. Otherwise I always say we kind of get our fair share of the 
cake". Similarly, a comment by Afriyie (UG) suggested respect for and fear of speaking against authorities: "I don't know if it is right but they are always using the usage statistics, so we end up punishing those who are using it because many people are not using it".

A major consequence of power distance causing fear of speaking against authority is that, it lowered the bargaining power of library staff which hindered them from lobbying institutional leaders and other stakeholders to advocate for the cause of the library to promote effective management of the ERs. This factor could also have impacted on the information obtained in the study, as some responses were moderated by socio-cultural factors and may not paint a true picture.

\subsubsection{Religious Beliefs}

An observation made from the interview findings from both public and private case institutions revealed that religious beliefs of library staff played a role in the management of ERs of the library. Responses from interviewees showed that some library staff applied religious beliefs at the workplace which served as an enabler to the management of ERs. For example, Yoofi (CU) acknowledged God for making it possible to integrate Information Literacy course into the institutional curriculum:

We need to do more of the marketing, orientation and awareness creation. We are trying our best. By the Grace of God, Information Literacy has been integrated into the curriculum which we are going to teach as a course, and I believe that would help alleviate some of the challenges.

Similarly, at UCC, a comment by Abrafi indicated a belief in God for a timely launch of the library's Online Public Access Catalogue (OPAC). Religious beliefs of library staff facilitated ERM in the case libraries as it enabled them to maintain a positive perspective in the midst of operational challenges.

In summary, individual factors identified from the findings as positively and negatively affecting the management and usage of ERs were attitudinal factors, socio-cultural factors and religious beliefs.

\subsection{Summary of Key Findings on the Management of ERs}

This chapter has presented findings on the management of ERs in the case institutions. Findings from interviews and document analysis have been presented with the aim of investigating how ERs are managed in academic libraries and identifying the contextual factors surrounding these 
activities with the Ghanaian context in focus. Generally, the findings revealed that the type of institution, size and resources affected the management of ERs in the case institutions. There was a commonality in the ERs provided in both public and private institutions by virtue of their membership of CARLIGH. The findings revealed that UG and CU provided both on and offcampus access whereas UCC and WIUC provided only on-campus at the time of the data collection. Infrastructural challenges were indicated by all case institutions as an impediment to accessing and using ERs of the library. Inadequate computers and poor Internet connectivity were some of the low points from all four institutions. However, situations were more pronounced in the private case universities (CU and WIUC) compared to the public counterparts (UG and UCC). These challenges contributed to the observed low usage of ERs of the library.

Regarding planning for ERs which entailed policy making, staffing, and budgeting, the findings showed varying levels of planning for ERs in the case institutions. ERM in both public and private institutions were to a large extent discretionary and based on experience rather than documented policies and procedures. This led to a lack of clarity on ER duties and responsibilities which also affected the depth of information obtained from the interviews as some interviewees were relatively new in their position and were unable to adequately address the interview questions. Analysis of the CDPs of UCC, CU and WIUC libraries indicated a total average completeness of $25 \%$ which revealed missing important components.

All case libraries had ER units/heads that spearheaded ER activities in the library. The findings reflected a common challenge of understanding in both public and private case institutions which was accounted for by various reasons. In the public institutions, low staff strength mainly followed a directive by government to suspend recruitment in tertiary institutions. In the private case institutions, understaffing was caused by suspension of recruitment by institutional leaders and staff turnover. All case institutions addressed understaffing by assigning information literacy education and less technical tasks to staff from other units of the library. A common strategy adopted by both public and private case institutions for capacity building was participation in "training of trainers" sessions organised periodically by CARLIGH for members. Interviewees perceived this strategy as a cost effective and convenient way of building the capacity of ER staff. 
Concerning budgeting, both public and private case academic libraries obtained only internal funding from their institution. However, whereas the public case universities (UG and UCC) had a separate library budget and therefore could budget for ERs, private case institutions did not have a separate library budget. Inadequate funding in both public and private case institutions negatively affected the acquisition and sustainability of ERs and services. Financial constraints were however more prevalent in the private case universities than their public counterparts as the former did not receive government subvention and had greater challenges in the acquisition and sustainability of ERs.

Regarding the workflow of ERs, findings from the case institutions revealed similarities and differences. Similarities to a large extent were as a result of the role played by CARLIGH in the management of ERs in the case institutions. Concerning the discovery of new contents, the data indicated two clusters of institutions. The first cluster (UCC and WIUC) discovered new contents only through the consortium. The second cluster (UG and CU) had other modes of ER discovery in addition to the consortium. Also, in terms of acquisition of ERs, two clusters of institutions emerged from the findings. One cluster (UCC and WIUC) solely relied on consortium-based purchasing or subscription. For this reason, the acquisition stage was missing in the ER workflow in those institutions. The second cluster (UG and CU) acquired other ER contents in addition to consortium-based subscription. The acquisition stage was therefore present within the institutional workflow. However, the type of university determined responsibility for this stage of the ER workflow. For the public university, the library spearheaded by the head of ERs oversaw the acquisition of individual library subscriptions as pertained at the Balme Library (UG). For the private university, institutional leaders spearheaded the acquisition of individual library e-contents with minimal or no input from the library as observed in the findings from CU.

Concerning implementation of ERs which involved access provision, promotion and training, the findings indicated low promotional efforts of the library particularly at UCC, CU and WIUC. Also, similar evaluation methods were revealed across the case institutions. All four case libraries relied on annual usage statistics from providers for renewal or cancellation decisions and the usage statistics from providers were perceived as reliable. The main criteria which informed cancellation and renewal decisions in both public and private case institutions were usage and budget/cost. In addition, the findings showed similar ERM approaches or models adopted in the public academic libraries as both UG and UCC fundamentally adopted 
an integrated approach but took on a distributed model in practice. For the private academic libraries, both CU and WIUC basically had a single person approach but adopted a distributed model in practice. The findings suggested that the distributed approach to practice in all four case libraries was motivated by understaffing and the evolving nature of ER workflow.

Various factors were revealed as affecting the management of ERs in the case institutions and these were at the governmental, organisational, and individual levels. Governmental factors impeded the availability of human and non-human resources required for effective ERM. Several organisational factors were revealed as affecting the management of ERs in the case institutions. These factors generally revolved around organisational structures, various activities, availability of resources and logistics needed to facilitate ERM. Individual factors identified from the findings were attitudinal, socio-cultural, and religious factors. All these factors had varying levels of impact on ERM in the case institutions. 



\section{Chapter Six \\ Findings on the Usage of ERs}

\subsection{Introduction}

This chapter presents findings from surveys of faculty and postgraduate students on the usage of ERs in the case institutions. Due to infrastructural challenges faced in completing the survey online, paper questionnaire was made available to respondents in the four case institutions. The chapter is aimed at answering the following research questions of the study:

1. How are ERs (managed) and used in academic libraries in Ghana?

2. a. What are the contextual factors surrounding the (management) and usage of ERs in academic libraries in Ghana?

b. In what ways do these contextual factors affect the management and usage of ERs in academic libraries in Ghana?

Using the UTAUT model (Venkatesh et al., 2003) as a guide and supported by factors from the literature as presented in Chapter Three, the study explored various factors that may affect the usage of ERs of the library. The assumption of the UTAUT model is that, performance expectancy, effort expectancy, social influence and facilitating conditions are the four main determinants of acceptance and usage of IT. The model further identifies key moderators of the usage of IT being gender, age, voluntariness, and experience (Venkatesh et al., 2003). The study adapted UTAUT focusing on its four main determinants to explore the factors affecting the usage of ERs of the library.

Findings from the surveys established how the views of users of ERs of the library compared with, contrasted or complemented findings from interviews with managers of the ERs as presented in Chapter Five of the study. A copy of the survey questionnaire can be found in Appendix D.

\subsection{Responses from Case Institutions}

The survey targeted faculty and postgraduate students in the case institutions. The overall response rates for faculty and postgraduate students were $88.1 \%$ (104 out of 118 ) and $85.2 \%$ (363 out of 426) respectively. Specific response rates obtained from the case institutions are 
presented in Table 6.1. A total of twenty-one (21) partially completed questionnaires were discarded prior to data analysis.

Table 6. 1: Responses from Case Institutions

\begin{tabular}{lcccccc}
\hline University & \multicolumn{3}{c}{ No. of Faculty } & \multicolumn{3}{c}{ No. of Students } \\
\cline { 2 - 7 } & $\begin{array}{l}\text { Sample } \\
\text { drawn }\end{array}$ & $\begin{array}{c}\text { Response } \\
(\mathrm{N})\end{array}$ & $\begin{array}{c}\text { Response } \\
(\%)\end{array}$ & $\begin{array}{c}\text { Sample } \\
\text { drawn }\end{array}$ & $\begin{array}{c}\text { Response } \\
(\mathrm{N})\end{array}$ & $\begin{array}{c}\text { Response } \\
(\%)\end{array}$ \\
\hline UG - Public & 30 & 27 & 90.0 & 107 & 89 & 83.2 \\
UCC - Public & 30 & 28 & 93.3 & 107 & 91 & 85.0 \\
CU - Private & 29 & 23 & 79.3 & 106 & 95 & 89.6 \\
WIUC-Private & 29 & 26 & 86.7 & 106 & 88 & 83.0 \\
\hline Total & 118 & 104 & 88.1 & 426 & 363 & 85.2 \\
\hline
\end{tabular}

As revealed in Table 6.1, the highest faculty response rate was from a public university (UCC) and the lowest response rate was from a private university (CU). Both highest and lowest postgraduate response rates were from private universities (CU and WIUC respectively).

\subsection{Demographic Profile of Respondents}

The aim of gathering, information on the demographics of respondents was to determine the characteristics of the respondents and investigate any association these variables had with the usage of ERs in the case institutions. Demographic profile obtained from respondents includes gender, age, discipline, and academic rank.

\subsubsection{Gender Distribution of Respondents}

Figure 6.1 depicts the gender distribution of the faculty and postgraduate respondents from the universities investigated. 


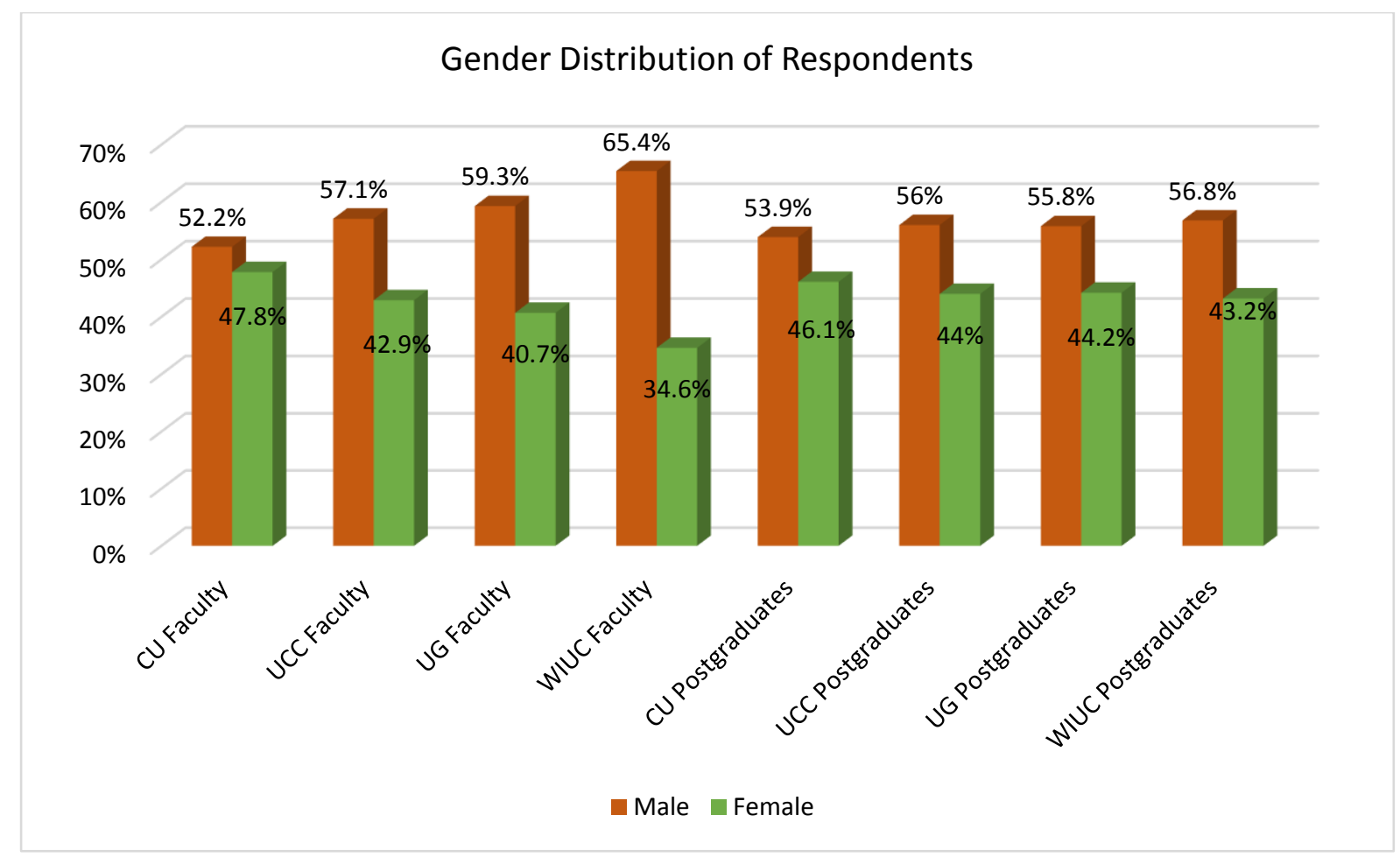

Figure 6. 1. Gender distribution of faculty and postgraduate respondents

The results as illustrated in Figure 6.2 show that most respondents in this study are men as the dominant gender among both faculty and postgraduate respondents from all case institutions was male. This probably provided a true reflection of the gender distribution of faculty and students in the case institutions.

\subsubsection{Age Distribution of Respondents from Case Institutions}

The survey asked respondents to indicate their age group. Age groups of faculty and postgraduate respondents are presented in separate tables for clarity (See Tables 6.2a and 6.2b respectively). 
Table 6. 2a: Age Distribution of Faculty Respondents

\begin{tabular}{|c|c|c|c|c|c|c|c|c|c|}
\hline \multirow[t]{3}{*}{ Age of Faculty } & \multicolumn{8}{|c|}{ University } & \multirow{3}{*}{$\begin{array}{c}\text { Total } \\
\mathrm{N}\end{array}$} \\
\hline & \multicolumn{2}{|c|}{ CU } & \multicolumn{2}{|c|}{ UCC } & \multicolumn{2}{|c|}{ UG } & \multicolumn{2}{|c|}{ WIUC } & \\
\hline & $\mathrm{N}$ & $(\%)$ & $\mathrm{N}$ & $(\%)$ & $\mathrm{N}$ & $(\%)$ & $\mathrm{N}$ & $(\%)$ & \\
\hline $20-29$ & 2 & 8.7 & 0 & 0.0 & 0 & 0.0 & 1 & 3.9 & 3 \\
\hline $30-39$ & 8 & 34.8 & 9 & 32.1 & 6 & 22.2 & 9 & 34.6 & 32 \\
\hline $40-49$ & 7 & 30.4 & 11 & 39.3 & 10 & 37.1 & 11 & 42.3 & 39 \\
\hline $50-59$ & 4 & 17.4 & 5 & 17.9 & 7 & 25.9 & 2 & 7.7 & 18 \\
\hline 60 or older & 2 & 8.7 & 3 & 10.7 & 4 & 14.8 & 3 & 11.5 & 12 \\
\hline Total & 23 & 100 & 28 & 100 & 27 & 100 & 26 & 100 & 104 \\
\hline
\end{tabular}

Table 6. 2b: Age Distribution of Postgraduate Respondents

\begin{tabular}{|c|c|c|c|c|c|c|c|c|c|}
\hline \multirow{3}{*}{$\begin{array}{l}\text { Age of } \\
\text { Postgraduates }\end{array}$} & \multicolumn{8}{|c|}{ University } & \multirow{3}{*}{$\begin{array}{c}\text { Total } \\
\text { N }\end{array}$} \\
\hline & \multicolumn{2}{|c|}{ CU } & \multicolumn{2}{|c|}{ UCC } & \multicolumn{2}{|c|}{ UG } & \multicolumn{2}{|c|}{ WIUC } & \\
\hline & $\mathrm{N}$ & $(\%)$ & $\mathrm{N}$ & $(\%)$ & $\mathrm{N}$ & $(\%)$ & $\mathrm{N}$ & $(\%)$ & \\
\hline $20-29$ & 41 & 46.1 & 34 & 37.3 & 37 & 39.0 & 43 & 48.9 & 155 \\
\hline $30-39$ & 36 & 40.4 & 37 & 40.7 & 33 & 34.7 & 35 & 39.8 & 141 \\
\hline $40-49$ & 12 & 13.5 & 16 & 17.6 & 19 & 20.0 & 10 & 11.3 & 57 \\
\hline $50-59$ & 0 & 0.0 & 4 & 4.4 & 6 & 6.3 & 0 & 0.0 & 10 \\
\hline 60 or older & 0 & 0.0 & 0 & 0.0 & 0 & 0.0 & 0 & 0.0 & 0 \\
\hline Total & 89 & 100 & 91 & 100 & 95 & 100 & 88 & 100 & 363 \\
\hline
\end{tabular}

As revealed in Table 6.2a, the age group 20 - 29 years was not represented among faculty respondents from the public universities (UCC and UG). The median age group of faculty respondents was 40 - 49 years in all four institutions. Regarding postgraduate respondents (see Table 6.2b), the age group 50 - 59 years was not represented among respondents from the private institutions (CU and WIUC). The median age group of postgraduate respondents from the public universities (UCC and UG) was 30 - 39 years whereas that of respondents from the private universities was $20-29$ years. Generally, there were more older students among postgraduate respondents from the public institutions than the private institutions.

\subsubsection{Discipline Distribution of Respondents in the Case Institutions}

Figure 6.2 depicts the discipline distribution of faculty and postgraduate respondents from the case institutions. 


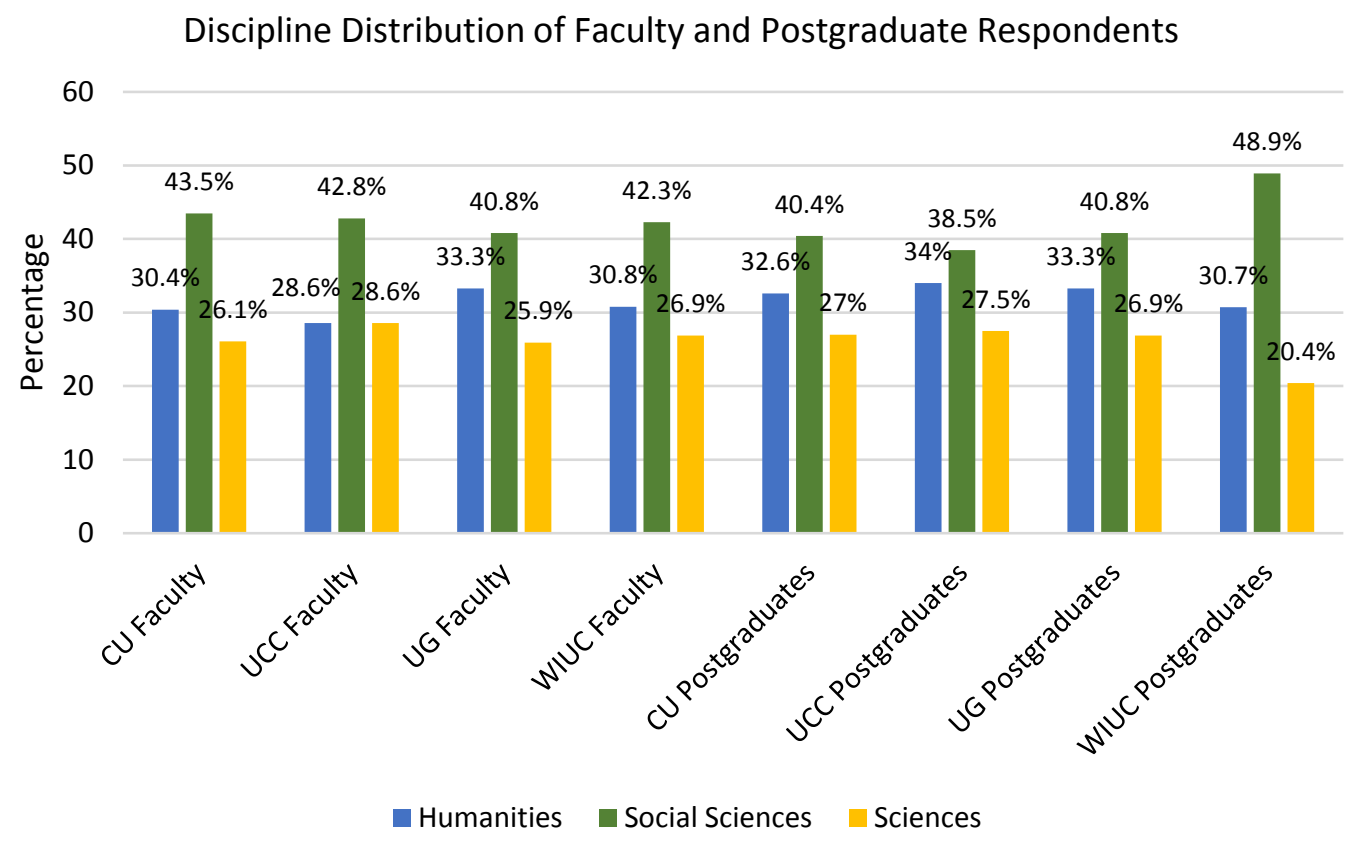

Figure 6. 2. Discipline distribution of respondents in the case institutions

As illustrated in Figure 6.2, the highest represented discipline among both faculty and postgraduate respondents from all four universities was the Social Sciences. This is not surprising as Social Sciences is usually the largest group of programmes in most Ghanaian universities thereby recording larger numbers of students and faculty.

\subsubsection{Academic Rank of Faculty Respondents}

Figure 6.3 shows the distribution of the rank of faculty respondents from all the case institutions. 


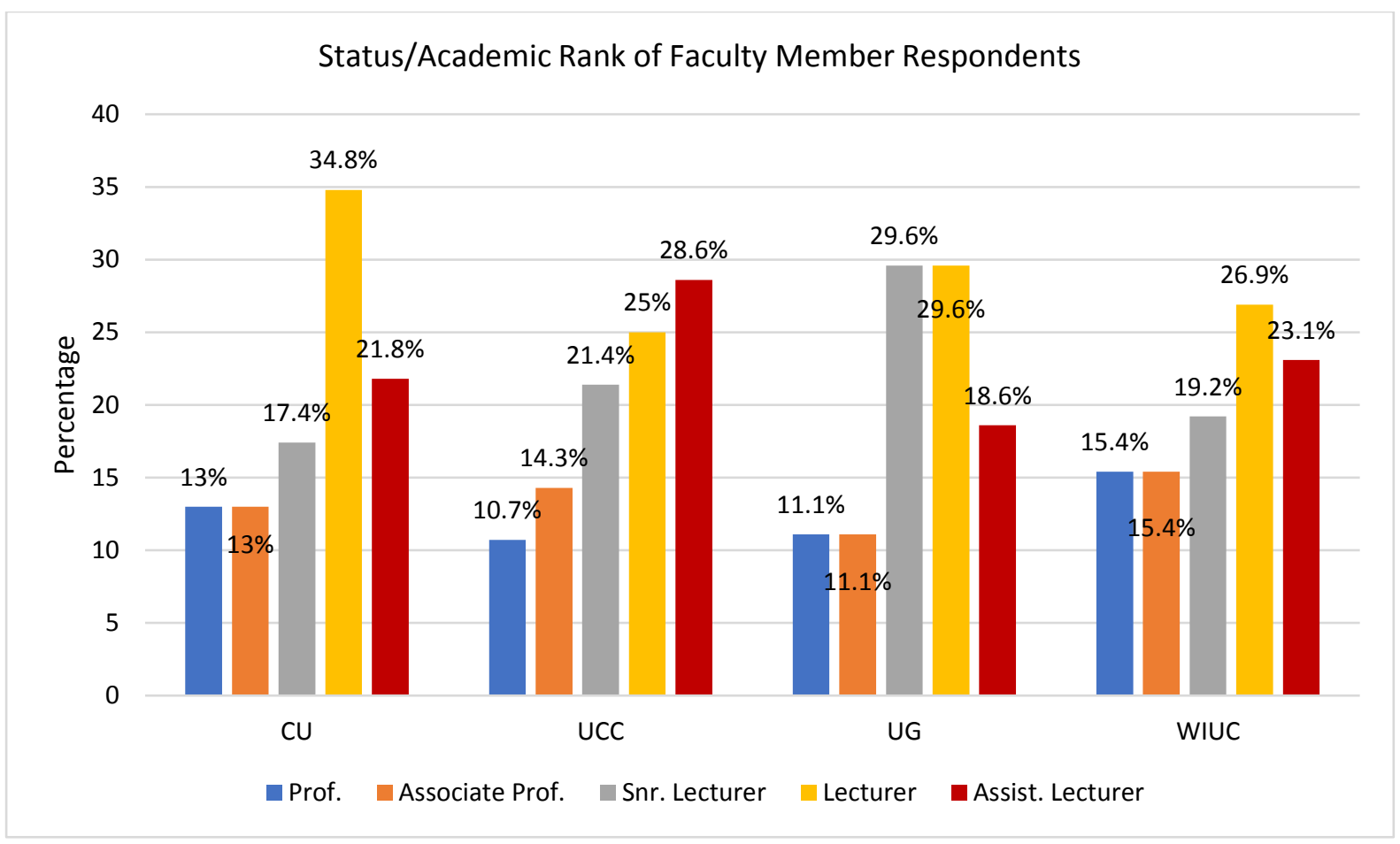

Figure 6. 3. Academic rank of faculty respondents from the case institutions

As depicted in Figure 6.3, the most frequent rank among faculty respondents from both private universities (CU and WIUC) was "Lecturer". For the public universities, the most frequent rank among UCC respondents was "Assistant lecturer" whereas at UG, "Senior lecturers" and "Lecturers" were the most frequent ranks. Low percentages were obtained for "Professors" and "Associate Professors" in all case institutions; and this was because many of them indicated their inability to participate in the study owing to busy schedule.

In summary, section 6.3 has presented the demographic characteristics of faculty and postgraduate respondents of the study. The findings revealed that males dominated both faculty and postgraduate respondents from all case institutions. The age groups $20-29$ years and 50 - 59 years were not represented among public university faculty respondents and private university postgraduate respondents respectively. All academic ranks in the case institutions were involved in the study. 


\subsection{Awareness of ERs of the Library Among Respondents}

Faculty and postgraduate students were asked to indicate their awareness of the various ERs available via their respective university library. Respondents were allowed as many options as applicable. Findings are presented in Tables 6.3a and 6.3b.

Table 6. 3a: Awareness of ERs Among Faculty Respondents

\begin{tabular}{|c|c|c|c|c|c|c|c|c|c|c|}
\hline \multirow{3}{*}{$\begin{array}{l}\text { Awareness of } \\
\text { ERs/Services }\end{array}$} & \multicolumn{10}{|c|}{ University } \\
\hline & \multicolumn{2}{|c|}{$\mathrm{CU}$} & \multicolumn{2}{|c|}{ UCC } & \multicolumn{2}{|c|}{ UG } & \multicolumn{2}{|c|}{ WIUC } & \multicolumn{2}{|c|}{ Total } \\
\hline & $\mathrm{N}$ & $(\%)$ & $\mathrm{N}$ & $(\%)$ & $\mathrm{N}$ & $(\%)$ & $\mathrm{N}$ & $(\%)$ & $\mathrm{N}$ & $(\%)$ \\
\hline Online databases & 17 & 73.9 & 19 & 67.9 & 23 & 85.2 & 17 & 65.4 & 76 & 34.5 \\
\hline CD-ROM & - & - & 7 & 25.0 & - & - & - & - & 7 & 3.2 \\
\hline E-book & 13 & 56.5 & - & - & - & - & - & - & 13 & 5.9 \\
\hline E-Journal & 16 & 69.6 & 23 & 82.1 & 26 & 96.3 & 21 & 80.8 & 86 & 39.1 \\
\hline IR & 8 & 34.8 & 14 & 50.0 & 16 & 59.3 & - & - & 38 & 17.3 \\
\hline Total & 54 & 24.6 & 63 & 28.6 & 65 & 29.5 & 38 & 17.3 & 220 & 100 \\
\hline
\end{tabular}

Table 6. 3b: Awareness of ERs Among Postgraduate Respondents

\begin{tabular}{|c|c|c|c|c|c|c|c|c|c|c|}
\hline \multirow{3}{*}{$\begin{array}{l}\text { Awareness of } \\
\text { ERs/Services }\end{array}$} & \multicolumn{10}{|c|}{ University } \\
\hline & \multicolumn{2}{|c|}{$\mathrm{CU}$} & \multicolumn{2}{|c|}{ UCC } & \multicolumn{2}{|c|}{ UG } & \multicolumn{2}{|c|}{ WIUC } & \multicolumn{2}{|c|}{ Total } \\
\hline & $\mathrm{N}$ & $(\%)$ & $\mathrm{N}$ & $(\%)$ & $\mathrm{N}$ & $(\%)$ & $\mathrm{N}$ & $(\%)$ & $\mathrm{N}$ & $(\%)$ \\
\hline Online databases & 30 & 33.7 & 42 & 46.2 & 65 & 68.4 & 46 & 52.3 & 183 & 39.4 \\
\hline CD-ROM & - & - & 10 & 11.0 & - & - & - & - & 10 & 2.2 \\
\hline E-book & 39 & 43.8 & - & - & - & - & - & - & 39 & 8.4 \\
\hline E-journal & 29 & 32.6 & 56 & 61.5 & 62 & 65.3 & 32 & 36.4 & 179 & 38.6 \\
\hline IR & 8 & 9.0 & 21 & 23.1 & 24 & 25.3 & - & - & 53 & 11.4 \\
\hline Total & 106 & 22.9 & 129 & 27.8 & 151 & 32.5 & 78 & 16.8 & 464 & 100 \\
\hline
\end{tabular}

From Tables $6.3 \mathrm{a}$ and $6.3 \mathrm{~b}$, it can be observed that faculty respondents were generally more aware of the various ERs of the library than the postgraduate respondents in all four institutions. This paralleled the interview findings which revealed that efforts in creating awareness of ERs of the library were more targeted towards faculty than students. At UCC, CU and WIUC, ERs of the library were mainly promoted to students during annual orientation programmes for first year students whereas emails on e-contents were periodically sent to faculty. Many of the interviewees were of the view that targeting faculty in their awareness creation efforts will eventually "trickle down" to students as faculty will then become ambassadors of the ERs of the library. At the Balme Library (UG) on the other hand, there appeared to be equal awareness creation efforts for both faculty and students as quarterly emails on available ERs were sent to both groups. That notwithstanding, the level of awareness of the ERs was higher among faculty than postgraduate respondents from UG. Concerning all postgraduate respondents, awareness of the various ERs of the library was higher in the public universities than the private 
universities. The frequencies and percentages indicated as ' -' constituted resources which were not yet available at the time the study was being conducted.

\subsubsection{Channel/Mode of Awareness of ERs Among Respondents}

The study was interested in the channels through which faculty and postgraduate respondents became aware of the ERs of the library. Respondents were to select as many as applicable. Results are presented in Tables 6.4a and 6.4b.

Table 6. 4a: Channels of Awareness of ERs Among Faculty Respondents

\begin{tabular}{|c|c|c|c|c|c|c|c|c|c|c|}
\hline \multirow[t]{3}{*}{ Channel } & \multicolumn{10}{|c|}{ University } \\
\hline & \multicolumn{2}{|c|}{$\mathrm{CU}$} & \multicolumn{2}{|c|}{ UCC } & \multicolumn{2}{|c|}{ UG } & \multicolumn{2}{|c|}{ WIUC } & \multicolumn{2}{|c|}{ Total } \\
\hline & $\mathrm{N}$ & $(\%)$ & $\mathrm{N}$ & $(\%)$ & $\mathrm{N}$ & $(\%)$ & $\mathrm{N}$ & $(\%)$ & $\mathrm{N}$ & $(\%)$ \\
\hline Orientation & 11 & 47.8 & 12 & 42.9 & 13 & 48.1 & 11 & 42.3 & 47 & 21.9 \\
\hline Notices & 10 & 43.5 & 9 & 32.1 & 13 & 48.1 & 7 & 26.9 & 39 & 18.1 \\
\hline Colleagues & 16 & 69.1 & 14 & 50.0 & 15 & 55.5 & 10 & 38.4 & 55 & 25.6 \\
\hline Newsletters & 2 & 8.7 & 3 & 10.7 & 4 & 14.8 & 0 & 0.0 & 9 & 4.2 \\
\hline Library website & 10 & 43.5 & 6 & 21.4 & 13 & 48.1 & 6 & 23.1 & 35 & 16.2 \\
\hline This survey & 0 & 0.0 & 0 & 0.0 & 0 & 0.0 & 0 & 0.0 & 0 & 0 \\
\hline Library training & 6 & 26.1 & 7 & 25.0 & 7 & 25.9 & 7 & 26.9 & 27 & 12.6 \\
\hline Graduate studies & 0 & 0.0 & 0 & 0.0 & 3 & 11.1 & 0 & 0.0 & 3 & 1.4 \\
\hline Lecturers/tutors & 0 & 0.0 & 0 & 0.0 & 0 & 0.0 & 0 & 0.0 & 0 & 0 \\
\hline Total & 55 & 25.6 & 51 & 23.7 & 68 & 31.6 & 41 & 19.1 & 215 & 100 \\
\hline
\end{tabular}

Table 6. 4b: Channels of Awareness of ERs Among Postgraduate Respondents

\begin{tabular}{|c|c|c|c|c|c|c|c|c|c|c|}
\hline \multirow[t]{3}{*}{ Channel } & \multicolumn{8}{|c|}{ University } & \multirow{3}{*}{$\begin{array}{c}\text { Total } \\
\mathrm{N}\end{array}$} & \multirow[b]{3}{*}{$(\%)$} \\
\hline & \multicolumn{2}{|c|}{$\mathrm{CU}$} & \multicolumn{2}{|c|}{ UCC } & \multicolumn{2}{|c|}{ UG } & \multicolumn{2}{|c|}{ WIUC } & & \\
\hline & $\mathrm{N}$ & $(\%)$ & $\mathrm{N}$ & $(\%)$ & $\mathrm{N}$ & $(\%)$ & $\mathrm{N}$ & $(\%)$ & & \\
\hline Orientation & 34 & 38.6 & 36 & 39.6 & 53 & 55.8 & 20 & 22.7 & 143 & 23.1 \\
\hline Notices & 16 & 18.2 & 9 & 9.9 & 20 & 21.1 & 17 & 19.3 & 62 & 10 \\
\hline Colleagues & 35 & 39.7 & 50 & 55.0 & 58 & 61.1 & 50 & 56.8 & 193 & 31.1 \\
\hline Newsletters & 4 & 4.5 & 10 & 11.0 & 12 & 12.6 & 3 & 3.4 & 29 & 4.6 \\
\hline Library website & 11 & 12.5 & 14 & 15.4 & 28 & 29.5 & 15 & 17 & 68 & 11 \\
\hline This survey & 4 & 4.5 & 0 & 0.0 & 3 & 3.2 & 4 & 4.5 & 11 & 1.8 \\
\hline Library training & 0 & 0.0 & 0 & 0.0 & 0 & 0.0 & 0 & 0.0 & 0 & 0 \\
\hline Graduate studies & 0 & 0.0 & 0 & 0.0 & 0 & 0.0 & 0 & 0.0 & 0 & 0 \\
\hline Lecturers/tutors & 16 & 18.2 & 28 & 30.8 & 52 & 54.7 & 18 & 20.5 & 114 & 18.4 \\
\hline Total & 120 & 19.3 & 147 & 23.7 & 226 & 36.5 & 127 & 20.5 & 620 & 100 \\
\hline
\end{tabular}

As indicated in Table 6.4a, "colleagues" was the most popular channel of awareness of ERs of the library among faculty respondents from CU, UCC and UG whereas at WIUC the most popular channel of awareness creation was orientation (42.3\%). Similar findings were obtained 
from the postgraduate respondents as the most popular channel of awareness was "colleagues" in all case institutions (See Table 6.4b).

Overall, the findings revealed similar channels of awareness among faculty and postgraduate respondents in all case institutions and "colleagues" was the pre-dominant mode of awareness of the ERs of the library. It could explain why the various ERs of the library had varying levels of awareness among respondents as users could only promote what they were aware of. This corroborated findings from the interviews with library staff in the case institutions, which revealed minimal awareness creation efforts by the library. The results however revealed the role faculty and students played in facilitating the implementation of ERs of the library by creating awareness among their peers.

\subsection{Usage of ERs/Services of the Library}

Respondents were asked to indicate whether or not they used the ERs of the library. Results are displayed in Figure 6.4.

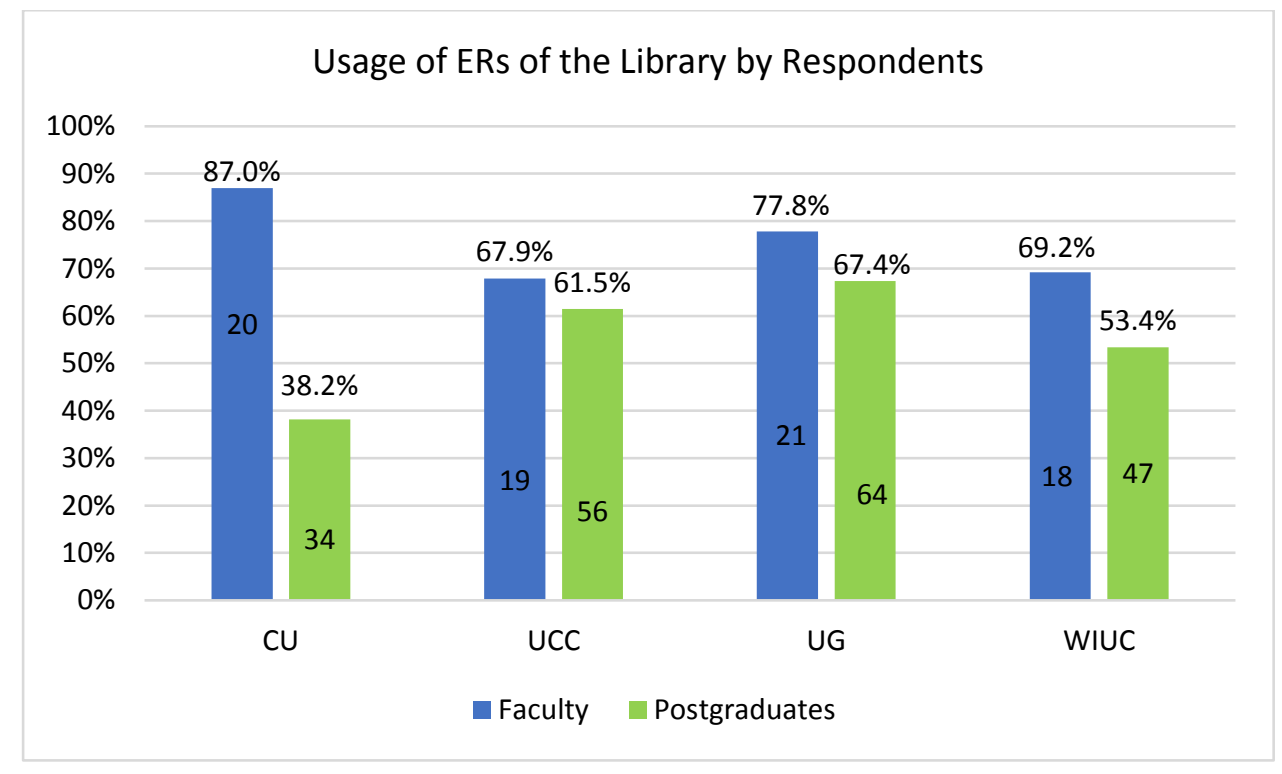

Figure 6. 4. Usage of ERs of the library by respondents

Among the faculty respondents, the highest and lowest usage were recorded in the private case universities (CU and WIUC respectively). Regarding postgraduate respondents, usage was comparatively higher in the public universities than their private case counterparts and this may have been accounted for by the acute infrastructural challenges in the private case institutions 
which hindered usage ERs of the library by students as revealed in the interview findings. Usage was generally higher among faculty than postgraduate students in both public and private case institutions.

\subsubsection{Types of ERs/Services Used in the Case Institutions}

Respondents were asked to indicate the kind(s) of ERs/services of the library that they made use of (See Tables 6.5a and 6.5b).

Table 6. 5a: Usage of the Various ERs/Services by Faculty Respondents

\begin{tabular}{|c|c|c|c|c|c|c|c|c|c|c|}
\hline \multirow{3}{*}{$\begin{array}{c}\text { Usage of } \\
\text { ERs/Services }\end{array}$} & \multicolumn{10}{|c|}{ University } \\
\hline & \multicolumn{2}{|c|}{ CU } & \multicolumn{2}{|c|}{ UCC } & \multicolumn{2}{|c|}{ UG } & \multicolumn{2}{|c|}{ WIUC } & \multicolumn{2}{|c|}{ Total } \\
\hline & $\mathrm{N}$ & $(\%)$ & $\mathrm{N}$ & $(\%)$ & $\mathrm{N}$ & $(\%)$ & $\mathrm{N}$ & $(\%)$ & $\mathrm{N}$ & $(\%)$ \\
\hline Online databases & 12 & 52.2 & 12 & 42.9 & 17 & 63.0 & 11 & 42.3 & 52 & 37.7 \\
\hline CD-ROM & - & - & 1 & 3.6 & - & - & - & - & 1 & 0.7 \\
\hline E-book & 8 & 34.8 & - & - & - & - & - & - & 8 & 5.8 \\
\hline E-journal & 14 & 60.9 & 13 & 46.4 & 20 & 74.0 & 13 & 50.0 & 60 & 43.5 \\
\hline IR & 5 & 21.7 & 6 & 21.4 & 6 & 22.2 & - & - & 17 & 12.3 \\
\hline Total & 39 & 28.3 & 32 & 23.2 & 43 & 31.1 & 24 & 17.4 & 138 & 100 \\
\hline
\end{tabular}

Table 6. 5b: Usage of the Various ERs/Services by Postgraduate Respondents

\begin{tabular}{|c|c|c|c|c|c|c|c|c|c|c|}
\hline \multirow{3}{*}{$\begin{array}{c}\text { Usage of } \\
\text { ERs/Services }\end{array}$} & \multicolumn{10}{|c|}{ University } \\
\hline & \multicolumn{2}{|c|}{ CU } & \multicolumn{2}{|c|}{ UCC } & \multicolumn{2}{|c|}{ UG } & \multicolumn{2}{|c|}{ WIUC } & \multirow{2}{*}{$\begin{array}{c}\text { Total } \\
\mathrm{N}\end{array}$} & \multirow[b]{2}{*}{$(\%)$} \\
\hline & $\mathrm{N}$ & $(\%)$ & $\mathrm{N}$ & $(\%)$ & $\mathrm{N}$ & $(\%)$ & $\mathrm{N}$ & $(\%)$ & & \\
\hline Online databases & 16 & 18.0 & 29 & 31.9 & 40 & 42.1 & 27 & 30.7 & 112 & 41.8 \\
\hline CD-ROM & - & - & 5 & 5.5 & - & - & - & - & 5 & 1.9 \\
\hline E-book & 21 & 23.6 & - & - & - & - & - & - & 21 & 7.8 \\
\hline E-journal & 15 & 16.9 & 33 & 36.3 & 36 & 37.9 & 14 & 15.9 & 98 & 36.6 \\
\hline IR & 3 & 3.4 & 15 & 16.5 & 14 & 14.4 & - & - & 32 & 11.9 \\
\hline Total & 55 & 20.5 & 82 & 30.6 & 90 & 33.6 & 41 & 15.3 & 268 & 100 \\
\hline
\end{tabular}

The findings revealed similarities in the various ERs/services used by faculty and postgraduate respondents in the public and private case institutions. The frequencies and percentages indicated as ' - ' constituted resources which were not yet available via the library at the time the research was being conducted. Overall, online databases and E-journals were the most widely used in the case institutions. These findings are expected since online databases and Ejournals had higher awareness levels as presented in Tables 6.3a and 6.3b. 


\subsubsection{Time Spent in Using the ERs of the Library}

Time spent in using the ERs of the library can assist in assessing the usefulness of these resources. Respondents who used the ERs of the library were therefore asked to indicate how much time they averagely spent in using the ERs (See Tables 6.6a and 6.6b).

Table 6. 6a: Hours Spent by Faculty Respondents in Using ERs of the Library

\begin{tabular}{lcccccccccc}
\hline \multirow{2}{*}{$\begin{array}{l}\text { Time Spent Using ERs } \\
\text { of the Library }\end{array}$} & \multicolumn{1}{c}{ CU } & \multicolumn{1}{c}{ UCC } & UG & \multicolumn{2}{c}{ WIUC } & \multirow{2}{*}{ Total } \\
\cline { 2 - 10 } & $\mathrm{N}$ & $(\%)$ & $\mathrm{N}$ & $(\%)$ & $\mathrm{N}$ & $(\%)$ & $\mathrm{N}$ & $(\%)$ & $\mathrm{N}$ & $(\%)$ \\
\hline 2 to 4 Hours in a day & 4 & 20.0 & 9 & 47.3 & 4 & 19.0 & 6 & 33.3 & 23 & 29.5 \\
Up to 2 Hours in a day & 5 & 25.0 & 5 & 26.2 & 4 & 19.0 & 7 & 38.9 & 21 & 26.9 \\
2 to 4 Hours in a week & 1 & 5.0 & 1 & 5.3 & 1 & 4.8 & 0 & 0.0 & 3 & 3.8 \\
Up to 2 hours in a week & 3 & 15.0 & 1 & 5.3 & 2 & 9.6 & 2 & 11.1 & 8 & 10.3 \\
2 to 4 Hours in a month & 2 & 10.0 & 1 & 5.3 & 3 & 14.3 & 1 & 5.6 & 7 & 9 \\
Up to 2 Hours in a month & 2 & 10.0 & 1 & 5.3 & 4 & 19.0 & 2 & 11.1 & 9 & 11.5 \\
Up to 4 Hours a semester & 1 & 5.0 & 1 & 5.3 & 0 & 0.0 & 0 & 0.0 & 2 & 2.6 \\
As and when necessary & 2 & 10.0 & 0 & 0.0 & 3 & 14.3 & 0 & 0.0 & 5 & 6.4 \\
\hline Total & 20 & 25.6 & 19 & 24.4 & 21 & 26.9 & 18 & 23.1 & 78 & 100 \\
\hline
\end{tabular}

Table 6. 6b: Hours Spent by Postgraduate Respondents in Using ERs of the Library

\begin{tabular}{lcccccccccc}
\hline \multirow{2}{*}{ Time Spent in Using } & \multicolumn{1}{c}{ University } & \multicolumn{1}{c}{} & \multicolumn{2}{c}{ Total } \\
\cline { 2 - 9 } ERs of the Library & $\mathrm{N}$ & $(\%)$ & $\mathrm{N}$ & $(\%)$ & $\mathrm{N}$ & $(\%)$ & $\mathrm{N}$ & $(\%)$ & $\mathrm{N}$ & $(\%)$ \\
\hline 2 to 4 Hours in a day & 18 & 52.9 & 17 & 30.4 & 23 & 35.9 & 8 & 17 & 66 & 32.8 \\
Up to 2 Hours in a day & 6 & 17.7 & 14 & 25.0 & 14 & 21.9 & 21 & 44.7 & 55 & 27.3 \\
2 to 4 Hours in a week & 1 & 2.9 & 7 & 12.5 & 7 & 10.9 & 0 & 0.0 & 15 & 7.5 \\
Up to 2 hours in a week & 4 & 11.8 & 8 & 14.2 & 14 & 21.9 & 5 & 10.6 & 31 & 15.4 \\
2 to 4 Hours in a month & 0 & 0.0 & 1 & 1.8 & 0 & 0.0 & 2 & 4.3 & 3 & 1.5 \\
Up to 2 Hours in a month & 4 & 11.8 & 5 & 8.9 & 2 & 3.1 & 0 & 0.0 & 11 & 5.5 \\
Up to 4 Hours a semester & 1 & 2.9 & 3 & 5.4 & 0 & 0.0 & 1 & 2.1 & 5 & 2.5 \\
As and when necessary & 0 & 0.0 & 1 & 1.8 & 4 & 6.3 & 10 & 21.3 & 15 & 7.5 \\
\hline Total & 34 & 16.9 & 56 & 27.9 & 64 & 31.8 & 47 & 23.4 & 201 & 100 \\
\hline
\end{tabular}

The most frequent number of hours indicated by both faculty and postgraduate respondents in all case institutions (as revealed in Tables 6.6a and 6.6b) were "2 to 4 hours in a day" and "Up to 2 hours in a day". Among faculty respondents, the median response for time spent in using the ERs of the library were CU (Up to 2 hours a week); UCC (Up to 2 hours a week); UG (2 to 4 hours a week) and WIUC ( 2 to 4 hours a day). It can be observed that WIUC faculty respondents spent more hours using the ERs of the library than faculty from their counterpart case institutions. This may have been accounted for by the one-on-one training sessions provided by the library to faculty which encouraged the faculty of WIUC to spend more time 
using the ERs of the library. Findings from postgraduate respondents revealed a similar pattern across all case institutions as the median response for time spent in using the ERs was "2 to 4 hours a day" in both public and private case universities. Looking at the median response, the results show that although usage of the ERs was higher among faculty than postgraduate respondents in terms of the number of respondents who used the ERs of the library (see Figure 6.4), postgraduate respondents who used the ERs particularly at CU, UCC and UG, spent much more time using the ERs of the library than faculty.

\subsubsection{Location/Device for Accessing the ERs of the Library}

The location/device for accessing the ERs of the library was of interest to the study as this would help in better understanding the challenges encountered while using these resources. Tables $6.7 \mathrm{a}$ and $6.7 \mathrm{~b}$ present the various locations from where respondents accessed the ERs of the library.

Table 6. 7a: Location/Device for Accessing the ERs of the Library by Faculty Respondents

\begin{tabular}{lcccc|cccccc}
\hline \multirow{2}{*}{$\begin{array}{l}\text { Location } \\
\text { Access }\end{array}$} & \multicolumn{1}{c}{ for } & \multicolumn{1}{c}{ CU } & \multicolumn{2}{c}{ UCC } & \multicolumn{2}{c}{ UG } & \multicolumn{2}{c}{ WIUC } & Total & \\
\cline { 2 - 9 } & $\mathrm{N}$ & $(\%)$ & $\mathrm{N}$ & $(\%)$ & $\mathrm{N}$ & $(\%)$ & $\mathrm{N}$ & $(\%)$ & $\mathrm{N}$ & $(\%)$ \\
\hline Office & 15 & 75.0 & 12 & 63.2 & 21 & 100 & 15 & 83.3 & 63 & 55.3 \\
Library & 5 & 25.0 & 9 & 47.4 & 6 & 28.6 & 5 & 27.8 & 25 & 21.9 \\
Cybercafé & 2 & 10.0 & - & - & 0 & 0.0 & - & - & 2 & 1.8 \\
Home Computer & 8 & 40.0 & - & - & 4 & 19.0 & - & - & 12 & 10.5 \\
Mobile Phone & 4 & 20.0 & 3 & 15.8 & 4 & 19.0 & 1 & 5.6 & 12 & 10.5 \\
\hline Total & 34 & 29.8 & 24 & 21.1 & 35 & 30.7 & 21 & 18.4 & 114 & 100 \\
\hline
\end{tabular}

Table 6. 7b: Location/Device for Accessing the ERs of the Library by Postgraduates

\begin{tabular}{|c|c|c|c|c|c|c|c|c|c|c|}
\hline \multicolumn{11}{|c|}{ University } \\
\hline \multirow{2}{*}{$\begin{array}{l}\text { Location } \\
\text { Access }\end{array}$} & \multicolumn{2}{|c|}{$\mathrm{CU}$} & \multicolumn{2}{|c|}{$\mathrm{UCC}$} & \multicolumn{2}{|c|}{ UG } & \multicolumn{2}{|c|}{ WIUC } & \multicolumn{2}{|c|}{ Total } \\
\hline & $\mathrm{N}$ & $(\%)$ & $\mathrm{N}$ & $(\%)$ & $\mathrm{N}$ & $(\%)$ & $\mathrm{N}$ & $(\%)$ & $\mathrm{N}$ & $(\%)$ \\
\hline Office & 4 & 11.8 & 12 & 21.4 & 7 & 10.9 & 2 & 4.3 & 25 & 8.5 \\
\hline Library & 24 & 70.6 & 43 & 76.8 & 47 & 73.4 & 43 & 91.5 & 157 & 53.2 \\
\hline Cybercafé & 1 & 2.9 & - & - & 5 & 7.8 & - & - & 6 & 2.0 \\
\hline Home Computer & 7 & 20.6 & - & - & 19 & 29.7 & - & - & 26 & 8.8 \\
\hline Mobile Phone & 17 & 50.0 & 16 & 28.5 & 33 & 51.6 & 15 & 31.9 & 81 & 27.5 \\
\hline Total & 53 & 18.0 & 71 & 24.1 & 111 & 37.6 & 60 & 20.3 & 295 & 100 \\
\hline
\end{tabular}

As revealed in Table $6.7 \mathrm{a}$, faculty respondents from both public and private case institutions mostly accessed the ERs of the library from their offices. This is expected as faculty usually have individual or shared offices with networked computers. For postgraduate respondents, 
Table $6.7 \mathrm{~b}$, reveals that the library was the most popular location for accessing the ERs of the library. Considering inadequate infrastructure revealed in the interview findings, particularly in the private universities, this is likely to hinder the usage of ERs of the library among students thereby contributing to the observed low usage of these resources. However, the findings further revealed that the second most frequent point/device for accessing ERs of the library among postgraduate respondents in both public and private universities was via "mobile phone" which reflected the role of mobile devices in complementing the infrastructure of the library in accessing the ERs. The ' - ' count obtained for "cybercafe" and "home computer" at UCC and WIUC supported the interview findings which revealed that their libraries did not have off-campus access to ERs of the library at the time the study was being conducted.

\subsubsection{Information Search Strategies of Respondents}

To better understand how faculty and postgraduate respondents made use of ERs of the library, it was necessary to investigate their first port of call when they needed scholarly information. Respondents were asked to indicate where they typically began their search for information. Findings are revealed in Figure 6.5.

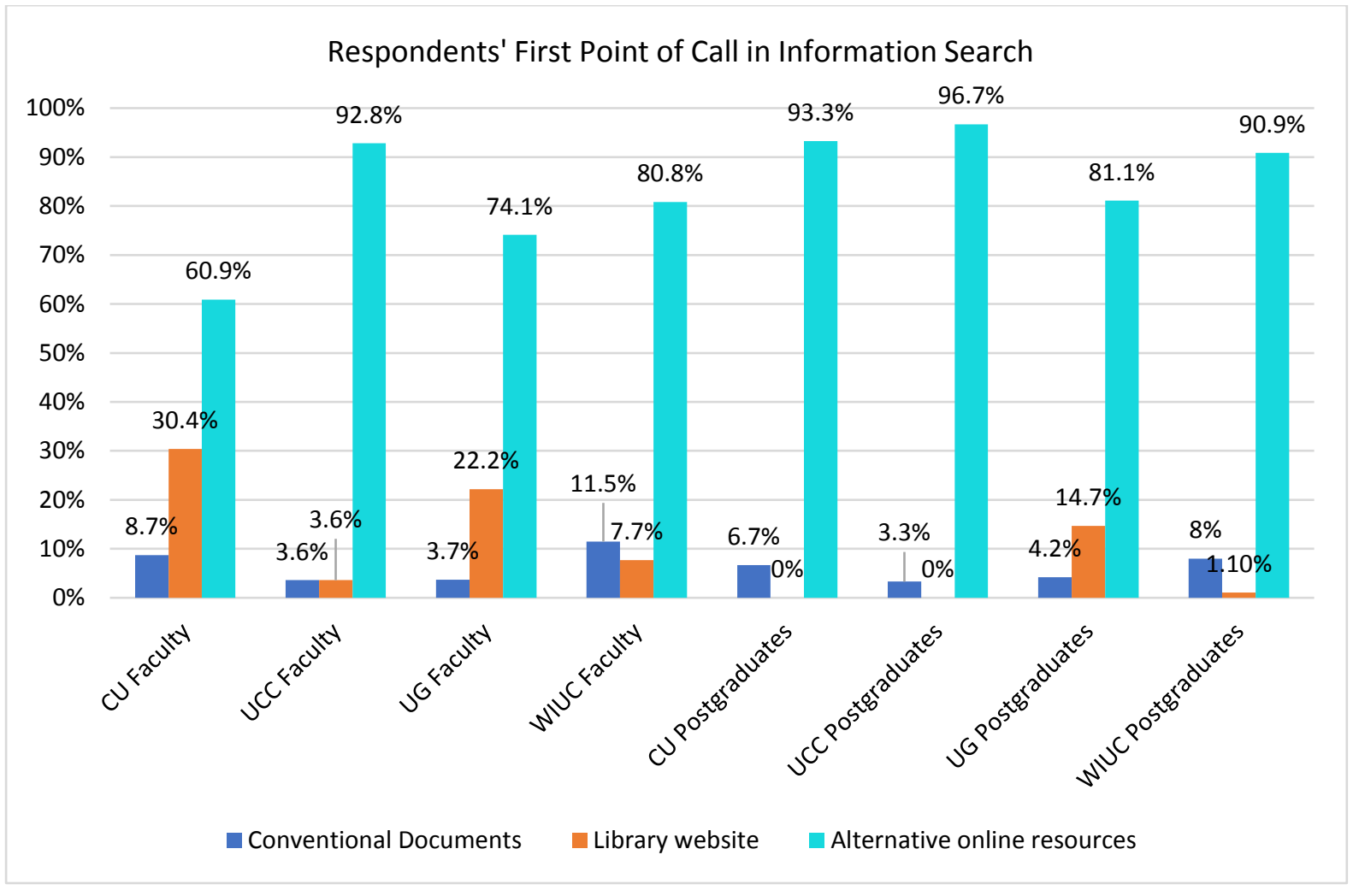

Figure 6. 5. Information search strategies of respondents in case institutions 
As depicted in Figure 6.5, alternative online resources were the first port of call for most faculty and postgraduate respondents in the public and private case institutions. These respondents indicated high recall of search outputs, quick response, and ease of access as the main reasons for selecting alternative online resources as the first port of call. For respondents who indicated the library website as the first point of call, the ERs of the library were perceived as providing high precision and reliable information compared to freely available online information resources. Generally, most respondents perceived the ERs of the library as not easy to use and not providing adequate search results. These reasons provided by respondents pointed towards lack of searching skills resulting from inadequate user training, and inadequate user needs analysis by the library which may have contributed to the observed low usage of ERs of the library. Respondents who used the ERs of the library were further asked to indicate how they had learned to use these resources.

\subsubsection{Mode of learning to how to use the library's ERs}

Figure 6.6. presents the results on how faculty and postgraduate respondents had learned to use the ERs of the library.

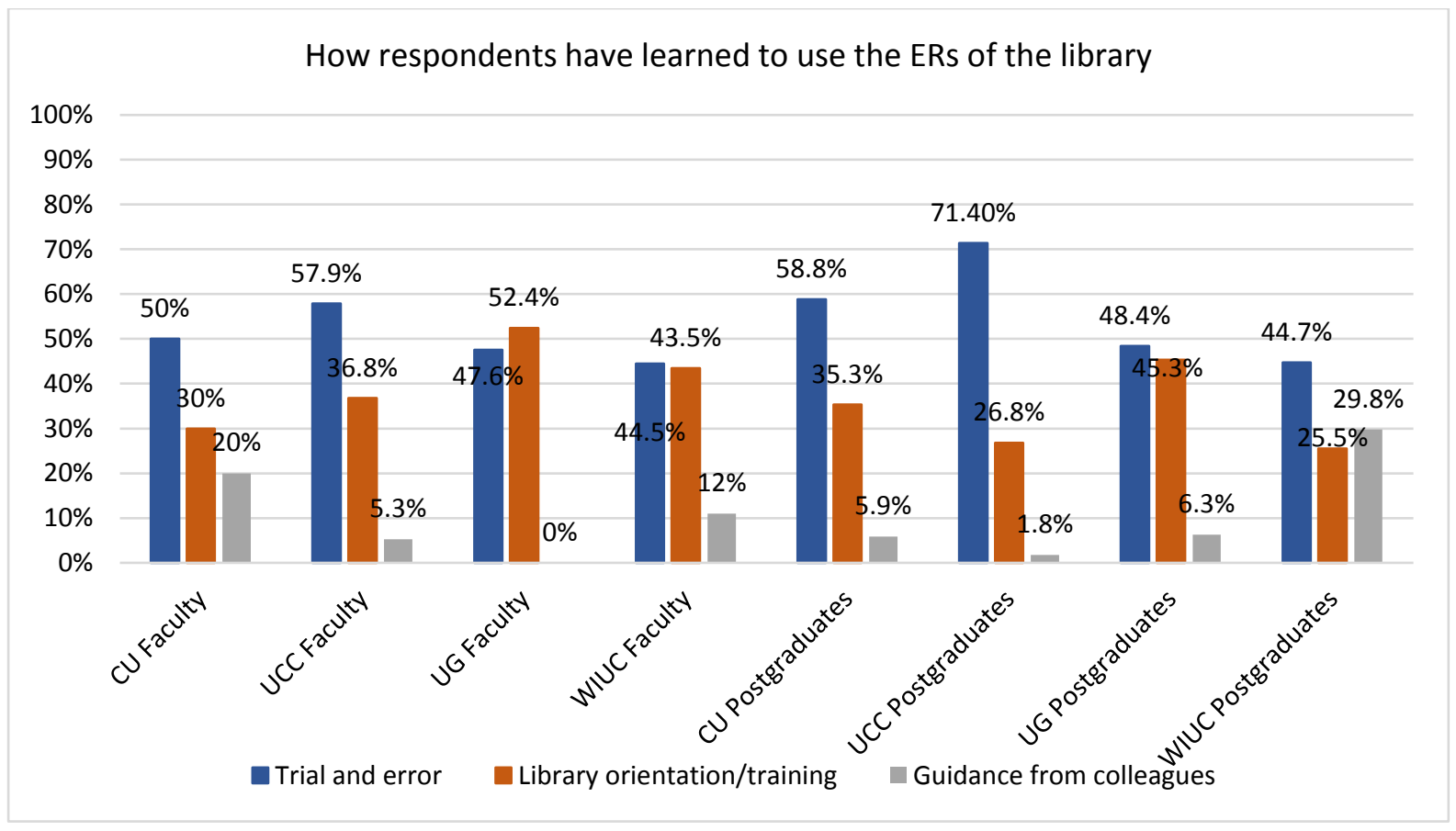

Figure 6. 6. Mode of learning how to use the ERs of the library

Figure 6.6 reveals that over half of UG faculty respondents indicated library orientation/training as the mode of learning to use the ERs of the library. This finding was 
consistent with the interview findings which revealed efforts by the Balme Library in providing adequate training for faculty. For UCC, CU and WIUC, 'trial and error' was the main mode of learning how to use the ERs of the library among faculty respondents. Similar results were obtained from postgraduate respondents from all case institutions as 'trial and error' was the main mode of learning how to use ERs of the library.

Overall, 'trial and error' was the main mode of learning how to use the ERs of the library among faculty and postgraduate respondents in both public and private case institutions which suggested minimal participation of respondents in ER training. The survey examined the participation of respondents in ER training programmes organised by the library.

\subsubsection{Training in the Use of the ERs of the library}

Faculty and students can be motivated to use the ERs of the library when they are equipped with the requisite skills for searching the resources through training programmes. Figure 6.7 presents findings on the participation of respondents in training programmes on ERs of the library.

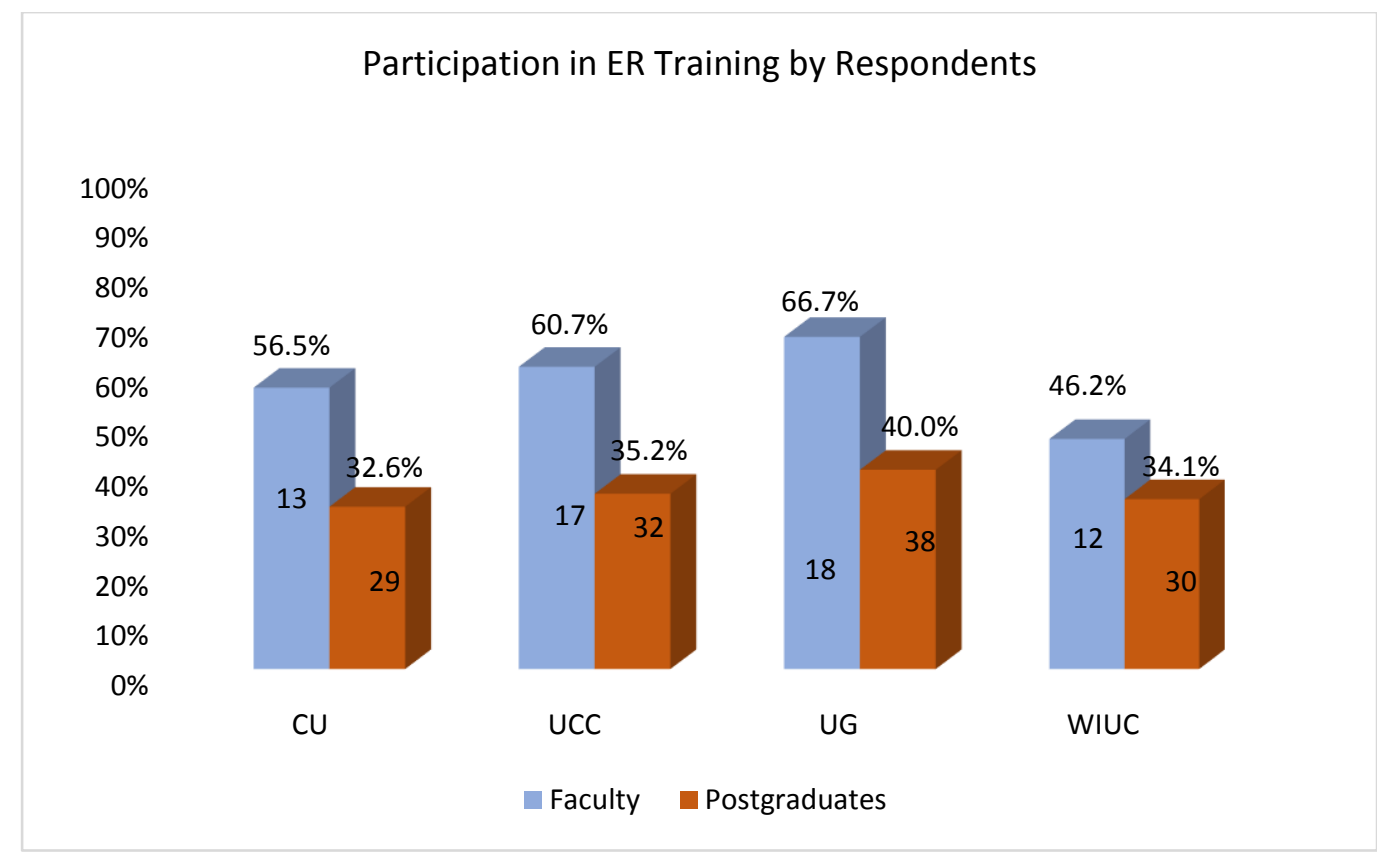

Figure 6. 7. Participation in training on ERs of the library

As shown in Figure 6.7, participation in ER training organised by the library was generally low among faculty and postgraduate respondents in all case universities. This complements 
findings from the interviews which revealed infrequent ER training sessions particularly at CU, UCC and WIUC; and also, the low turn-out to ER training sessions organised by the case libraries. This may explain why the most popular mode of learning to use the ERs of the library in the case universities which was by 'trial and error' (see section 6.5.5). Overall, participation in ER training was higher in the public case institutions than their private counterparts, and higher among faculty than postgraduate respondents in both public and private case institutions.

Views on training obtained from the library were sought and most faculty and postgraduate respondents from both public and private institutions perceived the training they had received as not adequate enough to equip them with skills for searching the ERs of the library. Various suggestions were provided including frequent training, customised or discipline-specific training and alternative modes of training such as ER usage manuals, online training and ER usage demonstration on library website. Respondents who had never participated in any ER training organised by the library indicated lack of awareness and unsuitable training time as the main reasons for not participating in training programmes. Lack of awareness of ER training revealed inadequate publicity of training programmes by the library. Also, unsuitable training time as indicated suggested inadequate planning of training schedules. This may have contributed to the low turn-out to ER training sessions organised by the library in both public and private case universities as revealed in the interview findings. In addition, inadequate training pointed out by the respondents paralleled findings from the interviews which revealed occasional training particularly for faculty at UCC, CU and WIUC all of which ultimately hindered the usage of ERs of the library.

\subsection{Perception and Behaviour of Respondents Towards the ERs of the Library}

The survey posed questions to reveal the perception and behaviour of respondents towards the ERs of the library. Tables $6.8 \mathrm{a}$ and $6.8 \mathrm{~b}$ Illustrate the perception and behaviour of faculty and postgraduate respondents towards the ERs of the library. These have been ranked from the highest to the least based on the mean value. 
Table 6. 8a: Perception and Behaviour of Faculty Towards ERs of the Library

\begin{tabular}{|c|c|c|c|}
\hline Rank & Perception/Behaviour & M & SD \\
\hline 1. & I use alternative resources on the Internet rather than the electronic resources of the library. & 3.91 & 1.183 \\
\hline 2. & I possess the necessary knowledge and skills to use the electronic resources of the library. & 3.70 & .934 \\
\hline 3. & It is easy to get relevant information using the electronic resources of the library. & 3.54 & .835 \\
\hline 3. & My academic outputs have improved as a result of using the electronic resources of the library. & 3.54 & .835 \\
\hline 4. & Using the electronic resources of the library simplifies finding information. & 3.39 & .980 \\
\hline 4. & Overall, it is easy to use the library's electronic resources. & 3.39 & .897 \\
\hline 5. & I am familiar with the electronic resources of the library and find it easy to use. & 3.34 & 1.076 \\
\hline 5. & I am satisfied with the library’s electronic resource services. & 3.34 & .961 \\
\hline 6. & It takes a lot of effort to become skillful at using the electronic resources of the library. & 3.17 & .961 \\
\hline 7. & $\begin{array}{l}\text { Using the electronic resources of the library reduces the time required for finding information compared to alternative } \\
\text { resources on the Web. }\end{array}$ & 3.16 & 1.006 \\
\hline 8. & Electronic resources of the library are more useful than alternative resources freely available on the Web. & 3.12 & .988 \\
\hline
\end{tabular}

Table 6. 8b: Perception and Behaviour of Postgraduates Towards ERs of the Library

\begin{tabular}{|c|c|c|c|}
\hline Rank & Perception/Behaviour & M & SD \\
\hline 1. & I use alternative resources on the Internet rather than the electronic resources of the library. & 4.21 & 9.21 \\
\hline 2. & I possess the necessary knowledge and skills to use the electronic resources of the library. & 3.34 & 1.025 \\
\hline 3. & Overall, it is easy to use the library's electronic resources. & 3.24 & .885 \\
\hline 4. & It is easy to get relevant information using the electronic resources of the library. & 3.23 & .910 \\
\hline 5. & Using the electronic resources of the library simplifies finding information. & 3.17 & .955 \\
\hline 6. & I am familiar with the electronic resources of the library and find it easy to use. & 3.15 & 1.936 \\
\hline 7. & It takes a lot of effort to become skillful at using the electronic resources of the library. & 3.09 & .956 \\
\hline 8. & My academic outputs have improved as a result of using the electronic resources of the library. & 3.08 & 1.005 \\
\hline 9. & I am satisfied with the library’s electronic resource services. & 2.97 & 1.028 \\
\hline 10. & $\begin{array}{l}\text { Using the electronic resources of the library reduces the time required for finding information compared to alternative } \\
\text { resources on the Web. }\end{array}$ & 2.85 & 1.038 \\
\hline 11. & Electronic resources of the library are more useful than alternative resources freely available on the Web. & 2.79 & 1.050 \\
\hline
\end{tabular}


As revealed in Tables 6.8a and 6.8b, there were similarities and differences in the perception and behaviour of faculty and postgraduates towards the ERs of the library. Both faculty and postgraduate respondents used alternative resources on the Internet rather than the ERs of the library. Also, both groups perceived themselves as possessing the necessary knowledge and skills to use ERs of the library. Considering low mean values obtained, it can be inferred that both faculty and postgraduate respondents perceived ERs of the library as not more useful than alternative resources freely available on the web. Again, both groups considered using the ERs of the library as not reducing the time for finding information compared to alternative resources. These findings probably explain why both faculty and postgraduate students relied heavily on other resources on the Internet as a first port of call rather than ERs of the library when searching for information as depicted in section 6.5.4.

However, it can be inferred from the findings that whereas faculty respondents believed their academic outputs had improved as a result of using ERs of the library, postgraduate respondents who used the ERs of the library did not perceive as much improvement in their academic performance. Also, faculty were more satisfied with the ERs of the library than postgraduate respondents. Comparatively, while faculty perceived using ERs of the library as reducing information search time, postgraduate students did not perceive using ERs of the library as reducing information search as much. This may have been accounted for by the fact that, more faculty had participated in ER training programmes organised by the library than postgraduate students and were therefore better equipped with the requisite skills for searching the ERs. Again, the results could partly explain why usage of ERs of the library was higher among faculty than postgraduate students in both public and private case institutions. The findings are revelatory and can assist case libraries in identifying opportunities for improvement in their ER services to attract maximum usage.

\subsection{Respondents' Participation in the Implementation of ERs}

To provide effective ERs and services that meet the information needs of users, it is necessary for libraries to involve the user community in the implementation of ER services (Emery and Stone, 2013). Input from faculty and students in the selection and evaluation of ERs is necessary if these resources are to be relevant to them. This study therefore sought to investigate the input made by faculty and postgraduates in the implementation of ERs in their institution. Findings are presented in Tables 6.9a and 6.9b. 
Table 6. 9a: Participation of Faculty Respondents in ER Implementation

\begin{tabular}{lcccccccccc}
\hline \multirow{2}{*}{ ER implementation } & \multicolumn{9}{c}{ Participation of faculty in implementing ERs } & \multicolumn{2}{c}{ Total } & \\
\cline { 2 - 9 } Activity & $\mathrm{CU}$ & $(\%)$ & $\mathrm{N}$ & $(\%)$ & $\mathrm{N}$ & $(\%)$ & $\mathrm{N}$ & $(\%)$ & $\mathrm{N}$ & $(\%)$ \\
\hline Recommending ERs & 7 & 30.4 & 8 & 28.6 & 2 & 7.4 & 7 & 26.9 & 24 & 28.6 \\
Participating in trial & 6 & 26.1 & 7 & 25.0 & 5 & 18.5 & 8 & 30.8 & 26 & 31.0 \\
Providing feedback & 5 & 21.7 & 3 & 10.7 & 6 & 22.2 & 4 & 15.4 & 18 & 21.4 \\
Assessment survey & 5 & 21.7 & 3 & 10.7 & 4 & 14.8 & 4 & 15.4 & 16 & 19.0 \\
\hline Total & 23 & 27.4 & 21 & 25.0 & 17 & 20.2 & 23 & 27.4 & 84 & 100 \\
\hline
\end{tabular}

Table 6. 9b: Participation of Postgraduate Respondents in ER Implementation

\begin{tabular}{|c|c|c|c|c|c|c|c|c|c|c|}
\hline \multirow{3}{*}{$\begin{array}{l}\text { ER implementation } \\
\text { activity }\end{array}$} & \multicolumn{10}{|c|}{ Participation of Postgraduates in implementing ERs } \\
\hline & \multicolumn{2}{|c|}{$\mathrm{CU}$} & \multicolumn{2}{|c|}{ UCC } & \multicolumn{2}{|c|}{$\mathrm{UG}$} & \multicolumn{2}{|c|}{ WIUC } & \multicolumn{2}{|c|}{ Total } \\
\hline & $\mathrm{N}$ & $(\%)$ & $\mathrm{N}$ & $(\%)$ & $\mathrm{N}$ & $(\%)$ & $\mathrm{N}$ & $(\%)$ & $\mathrm{N}$ & $(\%)$ \\
\hline Recommending ERs & 11 & 12.4 & 14 & 15.4 & 16 & 16.8 & 9 & 10.2 & 50 & 32.5 \\
\hline Participating in trial & 8 & 9.0 & 15 & 16.5 & 12 & 12.6 & 10 & 11.4 & 45 & 29.2 \\
\hline Providing feedback & 8 & 9.0 & 5 & 5.5 & 8 & 8.4 & 7 & 8.0 & 28 & 18.2 \\
\hline Assessment survey & 7 & 7.9 & 5 & 5.5 & 14 & 14.7 & 5 & 5.7 & 31 & 20.1 \\
\hline Total & 34 & 22.1 & 39 & 25.3 & 50 & 32.5 & 31 & 20.1 & 154 & 100 \\
\hline
\end{tabular}

Comparatively, the findings illustrated in Tables $6.9 \mathrm{a}$ and $6.9 \mathrm{~b}$ reveal that more faculty than postgraduate students from both public and private case institutions had ever participated in the implementation of ERs of the library. However, the findings generally revealed minimal involvement of faculty and postgraduate respondents in the ERs of the library, as less than a third of faculty and postgraduate students in both public and private case institutions had ever recommended ER contents, participated in ER trial, provided feedback on the ERs of the library or participated in ER assessment surveys. These results corroborated the findings from the interviews with library staff which revealed low user input in the implementation of the ERs of the library particularly in the selection and assessment of ERs.

\subsection{Promotion of ERs by Faculty in the Case Institutions}

To examine the role of faculty in promoting the ERs of the library, respondents were asked to indicate how often they referred students to the ERs of the library. Findings are presented in Figure 6.8. 


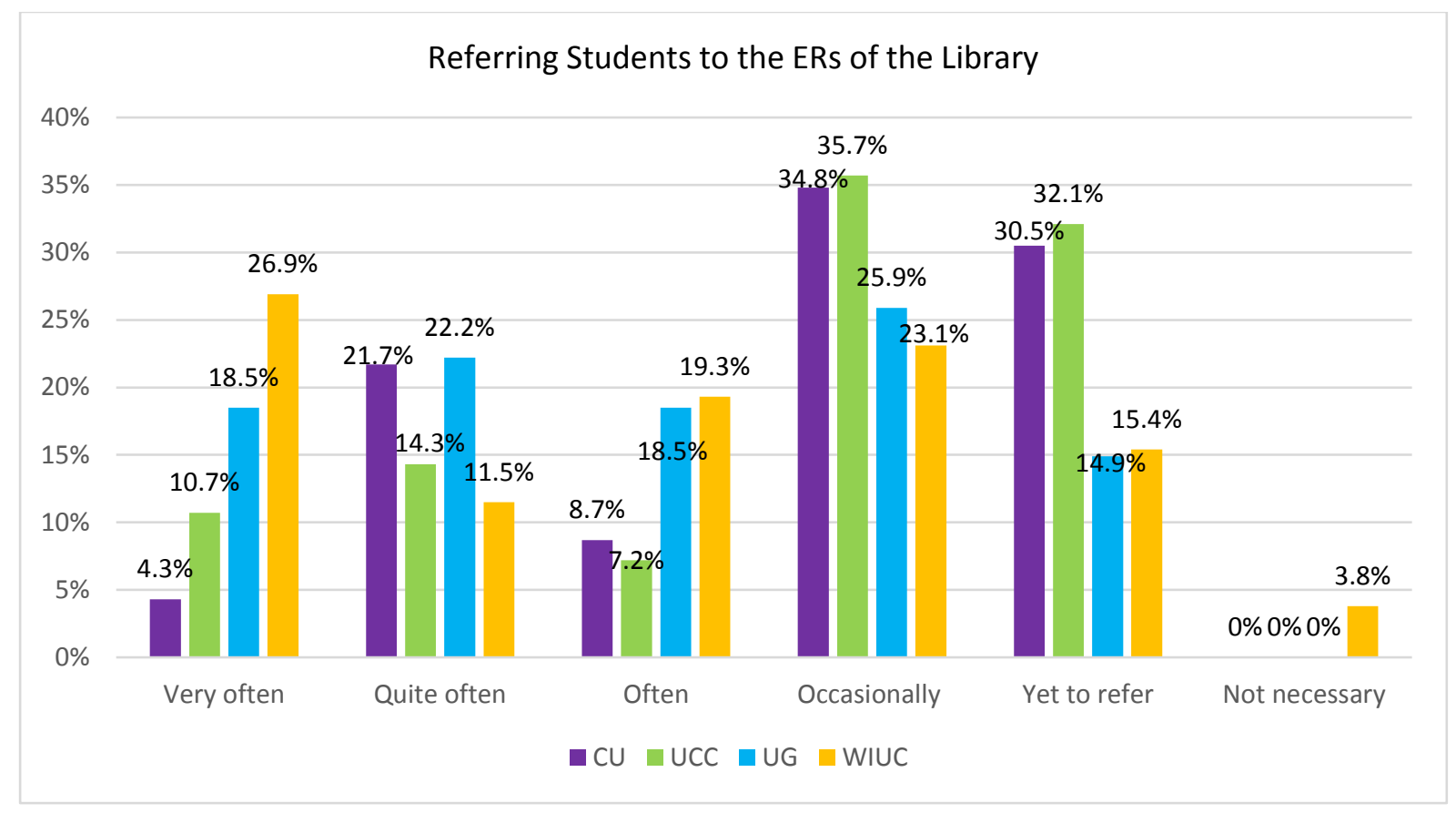

Figure 6. 8. Promotion of ERs of the library by faculty respondents

As illustrated in Figure 6.8, the findings generally revealed low referral of students to ERs of the library by faculty in both public and private case universities. The highest referral $(59.2 \%)$ was recorded at a public university (UG) where faculty referred students very often, quite often, or often to the ERs of the library. Some respondents from UG explained that they had not referred students to ERs of the library because they accessed the resources themselves and made available hard copies to students. For this reason, referral of students to the ERs of the library was deemed unnecessary. This view does not promote awareness of ERs of the library and could in the long run contribute to underusage of the ERs among students. The lowest level of referral (32.2\%) was also recorded at a public university (UCC) where faculty referred students to the ERs very often, quite often or often. Low referral by faculty does not encourage awareness and usage of these resources among students.

\subsection{Challenges of Using the ERs of the Library}

Respondents were asked to indicate the challenges they faced in accessing and using the ERs of the library. Various challenges were indicated, and these have been grouped into four categories namely national (governmental) factor, institutional (organisational) factors, factors related to the nature of ERs, and individual (personal) factor. These have been presented in the following sub-headings. 


\subsubsection{A National Factor as a Challenge of Using ERs of the Library}

An obstacle indicated by faculty and postgraduate respondents as hindering access to ERs of the library was frequent power cuts. Findings are depicted in Figure 6.9.

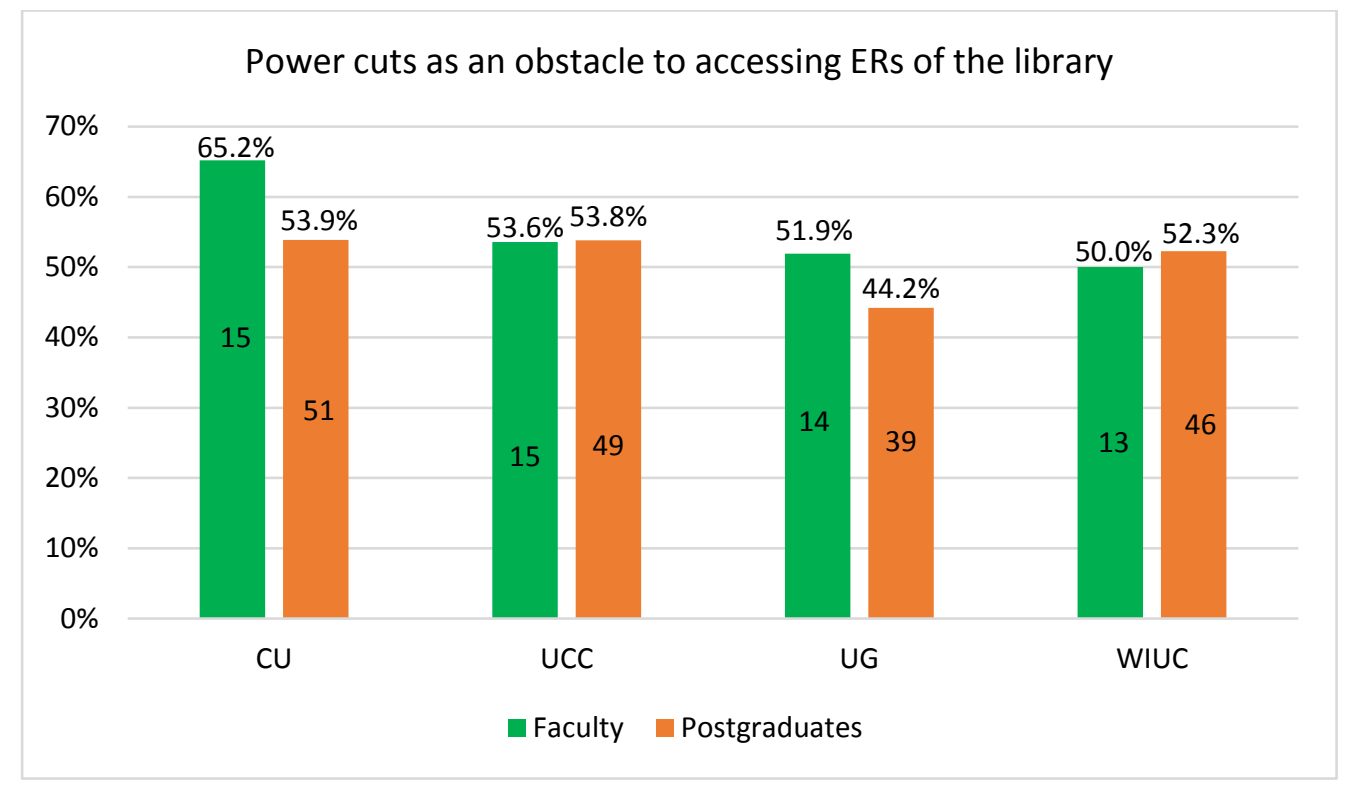

Figure 6. 9. A national factor as a challenge of using ERs of the library

As revealed in Figure 6.9 over half of faculty respondents from all institutions indicated power outage as a challenge. Similar findings were obtained from postgraduate students where about half of respondents from all case institutions indicated this as a challenge. This was a national challenge and therefore beyond the control of the case institutions. Ghana had been experiencing a persistent irregular and unpredictable power outage which made access to the ERs of the library not feasible.

\subsubsection{Institutional Challenges Faced by Respondents}

Faculty and postgraduate respondents highlighted some of the challenges they faced in their institution in accessing and using the ERs of the library. These are shown in Figure 6.10. 


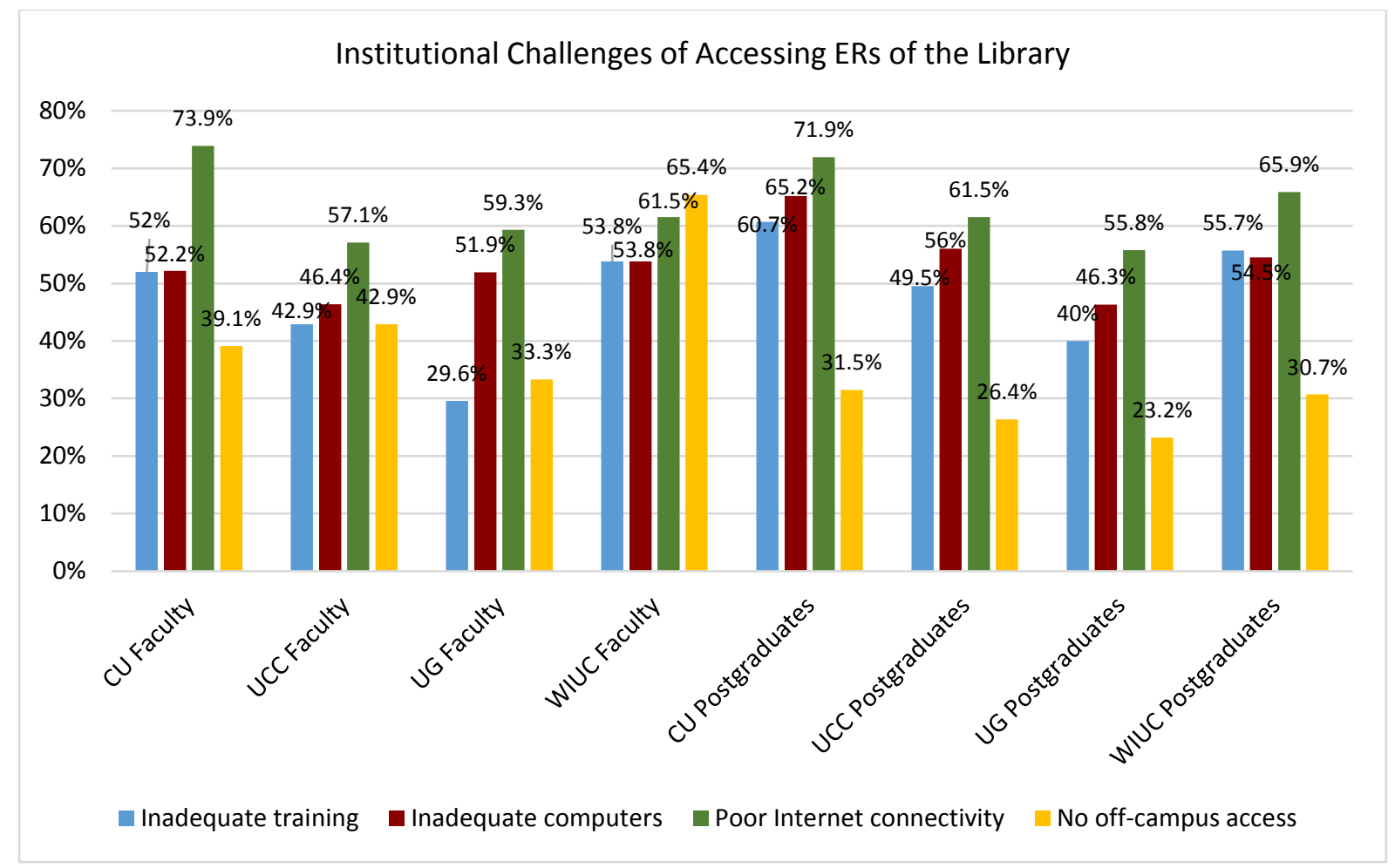

Figure 6. 10. Institutional challenges faced by respondents in accessing ERs

As revealed in Figure 6.10, the most prominent challenge indicated by faculty and postgraduate respondents in both public and private case institutions was poor Internet connectivity. This paralleled the findings from interviews with library staff in all case institutions which revealed unstable and slow Internet connectivity as a hindrance to accessing ERs of the library in all case institutions. Other major obstacles were inadequate computers and inadequate training. Taken together, the findings revealed that poor Internet connectivity, inadequate computers and inadequate training were more frequent in the private case institutions than their public case counterparts. These findings are consistent with the interview findings which revealed that situations were more pronounced in the private case institutions. Again, the results showed that inadequate training was more frequent among postgraduate students than faculty respondents in both public and private case institutions. This was partly supported by the interview findings. Findings from UG revealed more frequent training (quarterly) for faculty than postgraduate students (once in a semester). However, interview findings from UCC and CU revealed a comparatively more frequent training for postgraduate students than faculty as annual training was organised for postgraduate students whereas training programmes for faculty were organised occasionally. At WIUC, interview findings revealed equal training of faculty and postgraduate students on the ERs of the library as and when necessary. 
Again, lack of off-campus access appeared to be a great challenge to faculty than postgraduate students of UCC and WIUC (see Figure 6.10). Interview findings from UCC and WIUC revealed that their library was yet to provide off-campus access to the ERs of the library. Although the interview findings from UG and CU indicated that the library provided offcampus access to the ERs, about a third of both faculty and postgraduate respondents in the two institutions indicated lack of off-campus access as a challenge. It could be that even if the library provided off-campus access, respondents could not access due to infrastructural constraints such as lack of computer or poor download speed.

\subsubsection{ER-related Challenges}

Faculty and postgraduate respondents indicated challenges related to the nature of ERs which served as obstacles to using the ERS of the library. These are illustrated in Figure 6.11.

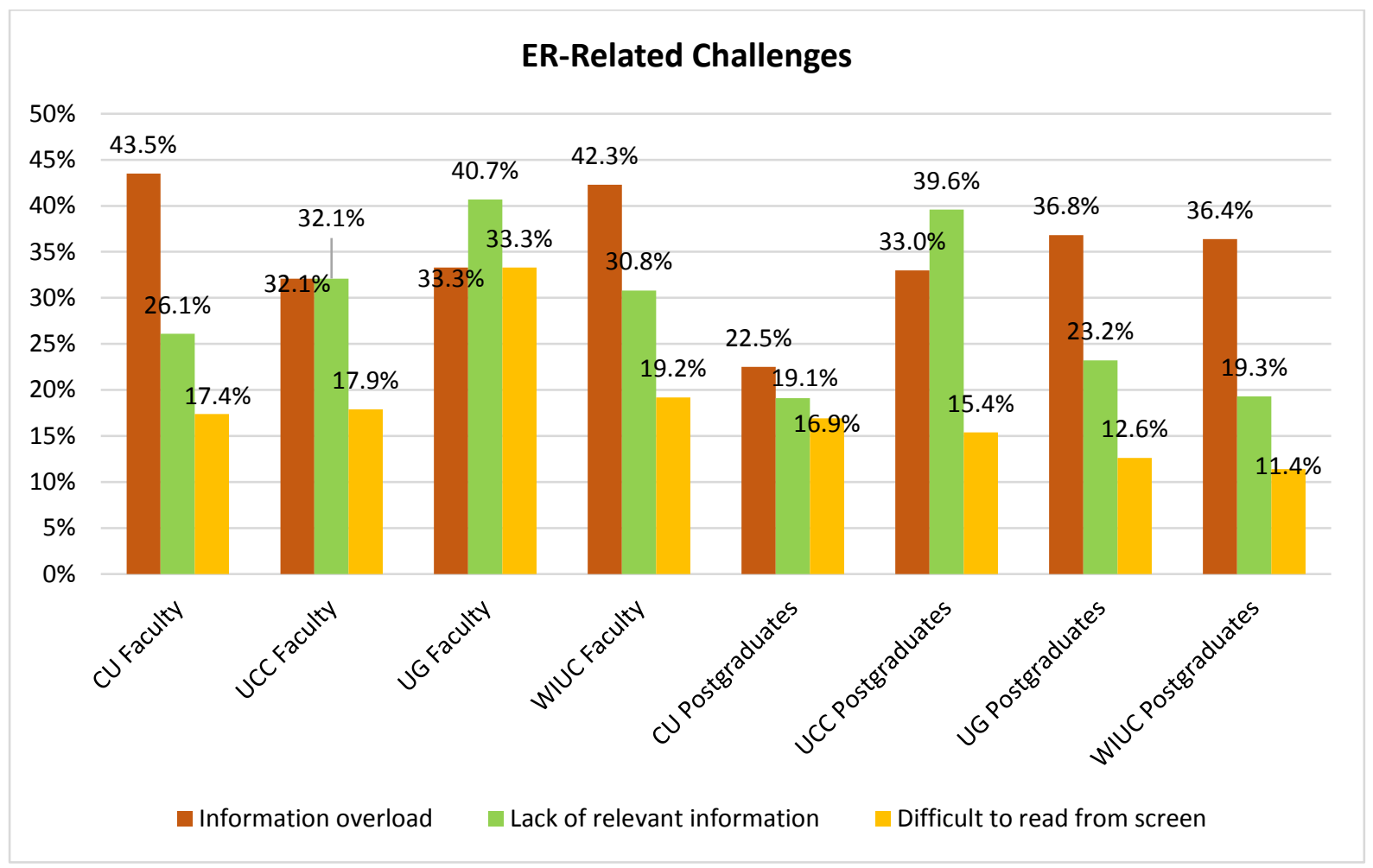

Figure 6. 11. ER-related challenges encountered by respondents in using ERs

The main challenges indicated by both faculty and postgraduate respondents were information overload and lack of relevant information (See Figure 6.11). Information overload as a challenge was more frequent among faculty respondents from the private case institutions (CU and WIUC) than the public case institutions (UG and UCC). Lack of relevant information was more frequent among faculty and postgraduate students from the public case institutions than 
their private counterparts. Taken together, the main challenges which were information overload and lack of relevant information appeared to be linked to institutional factors such as inadequate user training leading to lack of searching skills among respondents as well as inadequate user needs assessment by the library causing perceived irrelevant contents.

\subsubsection{An Individual Factor as a Challenge of Using ERs of the Library}

A personal factor indicated by faculty and postgraduate student respondents was lack of time for searching the ERs of the library and findings are depicted in Figure 6.12.

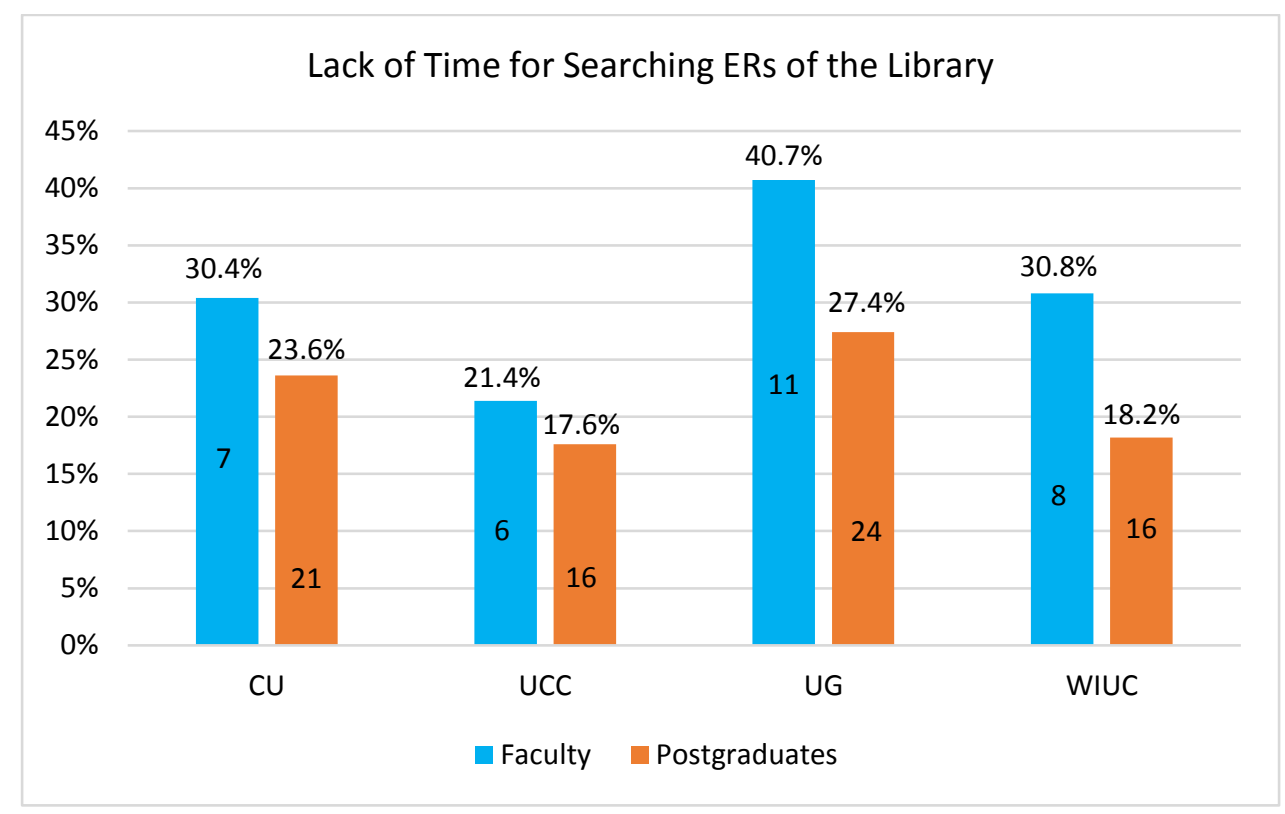

Figure 6. 12. An Individual factor as a challenge of using ERs

The results revealed that lack of time as a challenge was more frequent among faculty respondents than postgraduate respondents. That notwithstanding, lack of time for searching the ERs of the library was generally not a prominent challenge among respondents from all case institutions. 


\subsection{Factors Affecting the Usage of ERs of the Library}

One of the research questions this study aimed to address revolved around factors affecting the usage of ERs of the library in the case institutions. The study used chi-square test of independence in exploring relationships between variables. In cases where cells in cross-tabulations had low values, these were combined to meet the requirements for using chi-square test as prescribed by Vaughan (2003). Findings are presented in the following sub-sections.

\subsubsection{Demographic Characteristics and Usage of ERs}

The study sought to establish the relationship between demographic variables or factors and usage of ERs in the institutions studied. These factors included gender, age, discipline, and academic rank. Findings are presented next.

\subsubsection{Gender and Usage of ERs}

The research investigated whether there was any significant difference in the usage of ERs of the library by male and female respondents. Findings are depicted in Table 6.10.

Table 6. 10: A Cross-tabulation of Gender and Usage of ERs

\begin{tabular}{|c|c|c|c|c|c|c|c|c|c|c|c|c|}
\hline \multirow{4}{*}{ Gender } & \multicolumn{12}{|c|}{ Do you use electronic resources } \\
\hline & \multicolumn{6}{|c|}{ Faculty } & \multicolumn{6}{|c|}{$\begin{array}{l}\text { Postgraduates } \\
\end{array}$} \\
\hline & \multicolumn{2}{|c|}{ Yes } & \multicolumn{2}{|c|}{ No } & \multicolumn{2}{|c|}{ Total } & \multicolumn{2}{|c|}{ Yes } & \multicolumn{2}{|c|}{ No } & \multicolumn{2}{|c|}{ Total } \\
\hline & $\mathrm{N}$ & $(\%)$ & $\mathrm{N}$ & $(\%)$ & $\mathrm{N}$ & $(\%)$ & $\mathrm{N}$ & $(\%)$ & $\mathrm{N}$ & $(\%)$ & $\mathrm{N}$ & $(\%)$ \\
\hline Male & 42 & 68.9 & 19 & 31.1 & 61 & 58.7 & 105 & 52.0 & 97 & 48.0 & 202 & 55.6 \\
\hline Female & 36 & 83.7 & 7 & 16.3 & 43 & 41.3 & 96 & 59.6 & 65 & 40.4 & 161 & 44.4 \\
\hline Total & 78 & 75.0 & 26 & 25.0 & 104 & 100 & 201 & 55.4 & 162 & 44.6 & 363 & 100 \\
\hline
\end{tabular}

Note. $\chi^{2}(1, \mathrm{~N}=104)=2.23, p=.135 . \quad \chi^{2}(1, \mathrm{~N}=363)=1.82, p=.117$

As revealed in Table 6.10, although more females used the ERs of the library compared to males among faculty and postgraduate respondents, a chi-square test for independence (with Yates Continuity Correction) indicated no significant association between gender and usage of ERs among faculty, $\chi^{2}(1, \mathrm{~N}=104)=2.23, p=.135$ and postgraduate students, $\chi 2(1, \mathrm{~N}=363)=1.82, p$ $=.117$. Based on these findings, it can be concluded that gender did not affect the usage of ERs of the library. 


\subsubsection{Age and Usage of ERs in the Case Institutions}

The study sought to examine the association between age of respondents and usage of ERs of the library. Findings are revealed in Table 6.11.

Table 6. 11: A Cross-tabulation of Age and Usage of ERs

\begin{tabular}{|c|c|c|c|c|c|c|c|c|c|c|c|c|}
\hline \multirow{4}{*}{ Age group } & \multicolumn{10}{|c|}{ Do you use the ERs of the library } & & \\
\hline & \multicolumn{4}{|c|}{ Faculty } & \multicolumn{6}{|c|}{$\begin{array}{r}\text { Postgraduates } \\
\end{array}$} & \multirow{2}{*}{\multicolumn{2}{|c|}{ Total }} \\
\hline & \multicolumn{2}{|c|}{ Yes } & \multicolumn{2}{|c|}{ No } & \multicolumn{2}{|c|}{ Total } & \multicolumn{2}{|c|}{ Yes } & \multicolumn{2}{|c|}{ No } & & \\
\hline & $\mathrm{N}$ & $(\%)$ & $\mathrm{N}$ & $(\%)$ & $\mathrm{N}$ & $(\%)$ & $\mathrm{N}$ & $(\%)$ & $\mathrm{N}$ & $(\%)$ & $\mathrm{N}$ & $(\%)$ \\
\hline Under 39 years & 33 & 82.5 & 7 & 17.5 & 40 & 38.5 & 161 & 54.4 & 135 & 45.6 & 296 & 81.5 \\
\hline $40-49$ years & 31 & 68.9 & 14 & 31.1 & 45 & 43.2 & 35 & 61.4 & 22 & 38.6 & 57 & 15.7 \\
\hline Above 50 years & 14 & 73.7 & 5 & 26.3 & 19 & 18.3 & 5 & 50.0 & 5 & 50.0 & 10 & 2.8 \\
\hline Total & 78 & 75.0 & 26 & 25.0 & 104 & 100 & 201 & 55.4 & 162 & 44.6 & 363 & 100 \\
\hline
\end{tabular}

Note. $\chi^{2}(2, \mathrm{~N}=104)=2.11, p=.348 . \quad \chi^{2}(2, \mathrm{~N}=363)=1.07, p=.585$.

As revealed in Table 6.11, more 'younger' faculty used the ERs of the library whereas more 'older' postgraduate students used the ERs of the library. However, the frequencies revealed no association between age of faculty and usage of ERs, $\chi^{2}(2, \mathrm{~N}=104)=2.11, p=.348$; and age of postgraduate students and usage of ERs, $\chi 2(2, \mathrm{~N}=363)=1.07, p=.585$. It can be concluded based on the findings that usage of ERs of the library did not vary with age.

\subsubsection{Discipline and Usage of ERs}

The study investigated the association between the discipline to which respondents belonged and usage of ERs of the library. Findings are presented in Table 6.12.

Table 6. 12: A Cross-tabulation of Discipline of Respondents and Usage of ERs

\begin{tabular}{|c|c|c|c|c|c|c|c|c|c|c|c|c|}
\hline \multirow{4}{*}{$\begin{array}{l}\text { Discipline/ } \\
\text { Department/ } \\
\text { Faculty }\end{array}$} & \multicolumn{10}{|c|}{ Do you use the ERs of the library } & & \\
\hline & \multicolumn{6}{|c|}{ Faculty } & \multicolumn{6}{|c|}{ Postgraduates } \\
\hline & \multicolumn{2}{|c|}{ Yes } & \multicolumn{2}{|c|}{ No } & \multicolumn{2}{|c|}{ Total } & \multicolumn{2}{|c|}{ Yes } & \multicolumn{2}{|c|}{ No } & \multicolumn{2}{|c|}{ Total } \\
\hline & $\mathrm{N}$ & $(\%)$ & $\mathrm{N}$ & $(\%)$ & $\mathrm{N}$ & $(\%)$ & $\mathrm{N}$ & $(\%)$ & $\mathrm{N}$ & $(\%)$ & $\mathrm{N}$ & $(\%)$ \\
\hline Humanities & 23 & 71.9 & 9 & 28.1 & 32 & 30.8 & 59 & 48.8 & 62 & 51.2 & 121 & 33.3 \\
\hline Social Sciences & 35 & 79.5 & 9 & 20.5 & 44 & 42.3 & 87 & 57.2 & 65 & 42.8 & 152 & 41.9 \\
\hline Sciences & 20 & 71.4 & 8 & 28.6 & 28 & 26.9 & 55 & 61.1 & 35 & 38.9 & 90 & 24.8 \\
\hline Total & 78 & 75.0 & 26 & 25.0 & 104 & 100 & 201 & 55.4 & 162 & 44.6 & 363 & 100 \\
\hline
\end{tabular}


As shown in Table 6.12, although the highest usage observed among faculty and postgraduate respondents was within the social sciences and sciences respectively, the results indicated no significant association between discipline of respondents and usage of ERs among faculty in the case institutions, $\chi^{2}(2, \mathrm{~N}=104)=.84, p=.656$; and postgraduate students, $\chi^{2}(2, \mathrm{~N}=363)=3.55$, $p=.169$. Taken together, it can be concluded that the discipline to which respondents belonged did not affect the usage of ERs in the case institutions.

\subsubsection{Academic Rank and Usage of ERs}

The study also examined whether or not the academic rank of faculty respondents in the case institutions had any association with the usage of ERs of the library (see Table 6.13). Due to low cell values, options "professor" and "associate professor" were merged to meet the requirements of chi-square test.

Table 6. 13: A Cross-tabulation of Academic Rank of Faculty and Usage of ERs

\begin{tabular}{lcccccc}
\hline \multirow{2}{*}{ Academic Rank } & \multicolumn{6}{c}{ Do you use the ERs of the library } \\
& \multicolumn{2}{c}{ Yes } & \multicolumn{5}{c}{ No } & Total & \\
\cline { 2 - 7 } & $\mathrm{N}$ & $(\%)$ & $\mathrm{N}$ & $(\%)$ & $\mathrm{N}$ & $(\%)$ \\
\hline Prof./Assoc. Prof & 4 & 57.1 & 3 & 42.9 & 7 & 6.7 \\
Senior Lecturer & 20 & 83.3 & 4 & 16.7 & 24 & 23.1 \\
Lecturer & 35 & 71.4 & 14 & 28.6 & 49 & 47.1 \\
Assistant Lecturer & 19 & 79.2 & 5 & 20.8 & 24 & 23.1 \\
\hline Total & 78 & 75.0 & 26 & 25.0 & 104 & 100 \\
\hline
\end{tabular}

Note. $\chi^{2}(3, \mathrm{~N}=104)=2.64, p=.451$.

Although the highest usage of ERs was observed among Assistant Lecturers as can be seen by the frequencies cross-tabulated in Table 6.13, there was no significant association between academic rank of faculty and usage of ERs of the library in the case institutions, $\chi^{2}(3, \mathrm{~N}=104)=2.64, p=$ .451 . This shows that the usage of ERs by faculty did not vary with academic rank.

In summary, section 6.10.1 has examined the impact of demographic factors on the usage of ERs of the library. Chi-square tests revealed no association between demographic factors (gender, age, discipline, and academic rank) and usage of ERs of the library. It can therefore be concluded based on the findings that the demographic profile of respondents did not have any direct impact on the 
usage of ERs of the library. The next sub-section presents the contextual factors affecting the usage of ERs based on the findings.

\subsubsection{Contextual Factors Affecting the Usage of ERs of the Library}

The research identified various contextual factors as affecting the usage of ERs in the case institutions. These factors have been presented according to the factors in the UTAUT model and the literature which mainly included performance expectancy, effort expectancy, social influence and facilitating conditions. Findings are presented next.

\subsubsection{Performance Expectancy and Usage of ERs of the Library}

The study investigated whether there was any association between performance expectancy and usage of ERs in the case institutions. The results are presented in Table 6.14.

Table 6. 14: A Cross-tabulation of Performance Expectancy and Usage of ERs

\begin{tabular}{|c|c|c|c|c|c|c|c|c|c|c|c|c|}
\hline \multirow{4}{*}{$\begin{array}{l}\text { ERs of the } \\
\text { library are } \\
\text { useful }\end{array}$} & \multicolumn{12}{|c|}{ Do you use the ERs of the library } \\
\hline & \multicolumn{6}{|c|}{ Faculty } & \multicolumn{6}{|c|}{ Postgraduates } \\
\hline & \multicolumn{2}{|c|}{ Yes } & \multicolumn{2}{|c|}{ No } & \multicolumn{2}{|c|}{ Total } & \multicolumn{2}{|c|}{ Yes } & \multicolumn{2}{|c|}{ No } & \multicolumn{2}{|c|}{ Total } \\
\hline & $\mathrm{N}$ & $(\%)$ & $\mathrm{N}$ & $(\%)$ & $\mathrm{N}$ & $(\%)$ & $\mathrm{N}$ & $(\%)$ & $\mathrm{N}$ & $(\%)$ & $\mathrm{N}$ & $(\%)$ \\
\hline SD/Disagree & 11 & 64.7 & 6 & 35.3 & 17 & 16.3 & 24 & 36.4 & 42 & 63.6 & 66 & 18.2 \\
\hline Neutral & 21 & 56.8 & 16 & 43.2 & 37 & 35.6 & 54 & 34.4 & 103 & 65.6 & 157 & 43.2 \\
\hline SA/Agree & 46 & 92.0 & 4 & 8.0 & 50 & 48.1 & 123 & 87.9 & 17 & 12.1 & 140 & 38.6 \\
\hline Total & 78 & 75.0 & 26 & 25.0 & 104 & 100 & 201 & 55.4 & 162 & 44.6 & 363 & 100 \\
\hline
\end{tabular}

As revealed in Table 6.14, majority of the faculty and postgraduate respondents who perceived the ERs of the library to be useful used them. The results showed a significant association with large effect between performance expectancy and usage of ERs among faculty respondents, $\chi 2$ (2, $\mathrm{N}=104)=15.23, p=.000$ and among postgraduate respondents, $\chi 2(2, \mathrm{~N}=363)=97.39, p=.000$. It can be concluded based on the findings that faculty and postgraduate students were likely to use the ERs of the library when they perceived the resources as useful to their academic endeavours. 


\subsubsection{Effort Expectancy and Usage of ERs}

Table 6.15 depicts a cross-tabulation of effort expectancy and usage of ERs by respondents in the case institutions.

Table 6. 15: A Cross-tabulation of Effort Expectancy and Usage of ERs

\begin{tabular}{lccccccccccccc}
\hline & \multicolumn{1}{c}{ Faculty } \\
ERs of the & \multicolumn{1}{c}{ Do you use the ERs of the library } \\
library are easy & \multicolumn{2}{c}{ Yes } & \multicolumn{1}{c}{ No } & \multicolumn{1}{c}{ Total } & \multicolumn{3}{c}{ Yes } & \multicolumn{3}{c}{ No } & \multicolumn{2}{c}{ Total } \\
to use & $\mathrm{N}$ & $(\%)$ & $\mathrm{N}$ & $(\%)$ & $\mathrm{N}$ & $(\%)$ & $\mathrm{N}$ & $(\%)$ & $\mathrm{N}$ & $(\%)$ & $\mathrm{N}$ & $(\%)$ \\
\hline SD/Disagree & 11 & 73.3 & 4 & 26.7 & 15 & 14.4 & 30 & 51.7 & 28 & 48.3 & 58 & 16.0 \\
Neutral & 22 & 53.7 & 19 & 46.3 & 41 & 39.4 & 49 & 28.8 & 121 & 71.2 & 170 & 46.8 \\
SA/Agree & 45 & 93.8 & 3 & 6.3 & 48 & 46.2 & 122 & 90.4 & 13 & 9.6 & 135 & 37.2 \\
\hline Total & 78 & 75.0 & 26 & 25.0 & 104 & 100 & 201 & 55.4 & 162 & 44.6 & 363 & 100 \\
\hline
\end{tabular}

Note. $\chi^{2}(2, \mathrm{~N}=104)=18.92, p=.000 . \quad \chi^{2}(2, \mathrm{~N}=363)=115.72, p=.000$.

It can be observed from Table 6.15 although most faculty and postgraduate respondents disagreed with the assertion that the 'ERs of the library were easy to use', they used them. The results indicated a significant association with large effect between effort expectancy and usage of ERs among faculty respondents, $\chi^{2}(2, \mathrm{~N}=104)=18.92, p=.000$ and postgraduate students, $\chi^{2}(2$, $\mathrm{N}=363)=115.72, p=.000$. It can be concluded that faculty and postgraduate students were likely to use the ERs of the library when they perceived them as easy to use.

\subsubsection{Social Influence and Usage of ERs}

Social influence factors identified from the model and literature, and tested by the study included publicity by library, recommendation by colleagues, promotion by faculty and course work assignments (demands). These are presented next.

\subsection{Publicity by Library and Usage of ERs}

A Chi-square test was conducted to investigate the association between publicity by the library and usage of ERs among users. Table 6.16 depicts the findings. 
Table 6. 16: A Cross-tabulation of Publicity by the Library and Usage of ERs

\begin{tabular}{|c|c|c|c|c|c|c|c|c|c|c|c|c|}
\hline \multirow{4}{*}{$\begin{array}{l}\text { I receive alerts } \\
\text { from the } \\
\text { library }\end{array}$} & \multicolumn{12}{|c|}{ Do you use the ERs of the library } \\
\hline & \multicolumn{6}{|c|}{ Faculty } & \multicolumn{6}{|c|}{ Postgraduates } \\
\hline & \multicolumn{2}{|c|}{ Yes } & \multicolumn{2}{|c|}{ No } & \multicolumn{2}{|c|}{ Total } & \multicolumn{2}{|c|}{ Yes } & \multicolumn{2}{|c|}{ No } & \multicolumn{2}{|c|}{ Total } \\
\hline & $\mathrm{N}$ & $(\%)$ & $\mathrm{N}$ & $(\%)$ & $\mathrm{N}$ & $(\%)$ & $\mathrm{N}$ & $(\%)$ & $\mathrm{N}$ & $(\%)$ & $\mathrm{N}$ & $(\%)$ \\
\hline SD/Disagree & 9 & 47.4 & 10 & 52.6 & 19 & 18.3 & 49 & 39.5 & 75 & 60.5 & 124 & 34.1 \\
\hline Neutral & 10 & 66.7 & 5 & 33.3 & 15 & 14.4 & 36 & 41.4 & 51 & 58.6 & 87 & 24.0 \\
\hline SA/Agree & 59 & 84.3 & 11 & 15.7 & 70 & 67.3 & 116 & 76.3 & 36 & 23.7 & 152 & 41.9 \\
\hline Total & 78 & 75.0 & 26 & 25.0 & 104 & 100 & 201 & 55.4 & 162 & 44.6 & 363 & 100 \\
\hline
\end{tabular}

Note. $\chi^{2}(2, \mathrm{~N}=104)=11.51, p=.003 . \quad \chi 2(2, \mathrm{~N}=363)=46.49, p=.000$.

As indicated in Table 6.16, most of the faculty and postgraduate respondents who agreed to having received alerts or encouragement from the library to use the ERs used them. The results showed a significant association with large effect between publicity by the library and usage of the ERs by faculty respondents, $\chi 2(2, \mathrm{~N}=104)=11.51, p=.003$, and postgraduate students, $\chi 2(2, \mathrm{~N}=363)=$ $46.49, p=.000$. The findings therefore revealed that faculty and postgraduate students were more likely to use ERs of the library when the library promoted these resources to them.

\subsection{Recommendations by Colleagues and Usage of ERs}

This study also sought to establish whether recommendations by colleagues as revealed in the literature had any association with the usage of ERs in the case institutions. Findings are depicted in Table 6.17.

Table 6. 17: A Cross-tabulation of Recommendations by Colleagues and Usage of ERs

\begin{tabular}{|c|c|c|c|c|c|c|c|c|c|c|c|c|}
\hline \multirow{4}{*}{$\begin{array}{l}\text { Recommenda- } \\
\text { tions by } \\
\text { colleagues }\end{array}$} & \multicolumn{12}{|c|}{ Do you use the ERs of the library } \\
\hline & \multicolumn{6}{|c|}{ Faculty } & \multicolumn{6}{|c|}{$\begin{array}{r}\text { Postgraduates } \\
\end{array}$} \\
\hline & \multicolumn{2}{|c|}{ Yes } & \multicolumn{2}{|c|}{ No } & \multicolumn{2}{|c|}{ Total } & \multicolumn{2}{|c|}{ Yes } & \multicolumn{2}{|c|}{ No } & \multicolumn{2}{|c|}{ Total } \\
\hline & $\mathrm{N}$ & $(\%)$ & $\mathrm{N}$ & $(\%)$ & $\mathrm{N}$ & $(\%)$ & $\mathrm{N}$ & $(\%)$ & $\mathrm{N}$ & $(\%)$ & $\mathrm{N}$ & $(\%)$ \\
\hline SD/Disagree & 17 & 58.6 & 12 & 41.4 & 29 & 27.9 & 38 & 35.8 & 68 & 64.2 & 106 & 29.2 \\
\hline Neutral & 23 & 85.2 & 4 & 14.8 & 27 & 26.0 & 28 & 38.4 & 45 & 61.6 & 73 & 20.1 \\
\hline SA/Agree & 38 & 79.2 & 10 & 20.8 & 48 & 46.1 & 135 & 73.4 & 49 & 26.6 & 184 & 50.7 \\
\hline Total & 78 & 75.0 & 26 & 25.0 & 104 & 100 & 201 & 55.4 & 162 & 44.6 & 363 & 100 \\
\hline
\end{tabular}

Note. $\chi 2(2, \mathrm{~N}=104)=6.08, p=.048 . \quad \chi 2(2, \mathrm{~N}=363)=49.02, p=.000$.

From Table 6.17, majority of faculty and postgraduate students whose colleagues recommended the ERs of the library to them, used the resources. A chi-square test for independence indicated a significant association with small effect between recommendations by colleagues and usage of 
ERs by faculty respondents, $\chi^{2}(2, \mathrm{~N}=104)=6.08, p=.048$. For postgraduate respondents, the results revealed a significant association with large effect between recommendations by colleagues and usage of ERs in the case institutions, $\chi 2(2, \mathrm{~N}=363)=49.02, p=.000$. It can be concluded that faculty and postgraduate students were likely to use the ERs of the library when their colleagues or peers recommended the resources to them.

\subsection{Promotional Efforts by Faculty and Usage of ERs}

The study examined whether there was any association between the promotion of the ERs by faculty and usage among postgraduate respondents. Findings are presented in Table 6.18.

Table 6. 18: A Cross-tabulation of Promotion by Faculty and Usage of ERs by Students

\begin{tabular}{lcccccc}
\hline \multirow{2}{*}{\begin{tabular}{c} 
Lecturers recommend the \\
\multicolumn{1}{c}{ ERs of the library }
\end{tabular}} & \multicolumn{3}{c}{ Yes you use the ERs of the library } \\
\cline { 2 - 7 } & $\mathrm{N}$ & $(\%)$ & $\mathrm{N}$ & $(\%)$ & $\mathrm{N}$ & $(\%)$ \\
\hline SD/Disagree & 25 & 28.1 & 64 & 71.9 & 89 & 24.5 \\
Neutral & 22 & 34.9 & 41 & 65.1 & 63 & 17.4 \\
SA/Agree & 154 & 73.0 & 57 & 27.0 & 211 & 58.1 \\
\hline Total & 201 & 55.4 & 162 & 44.6 & 363 & 100 \\
\hline
\end{tabular}

Note. $\chi 2(2, \mathrm{~N}=363)=63.96, p=.000$.

It can be observed from Table 6.18 that, the majority of students who agreed or strongly agreed that 'lecturers recommended the ERs of the library' used the resources. The results depicted a significant association with large effect between promotion by faculty and usage of ERs among postgraduate respondents in the case institutions, $\chi 2(2, \mathrm{~N}=363)=63.96, p=.000$. It therefore shows that students were likely to use the ERs of the library when faculty promoted or recommended the resources to them.

\subsection{Course Work Assignments and Usage of ERs}

The study tested the association between course work assignments and usage of ERs by postgraduate respondents. The findings are depicted in Table 6.19. 
Table 6. 19: Association Between Course Work Assignments and Usage of ERs

\begin{tabular}{lcccccc}
\hline \multirow{2}{*}{$\begin{array}{c}\text { My course work entails } \\
\text { regular assignments }\end{array}$} & \multicolumn{2}{c}{ Do you use the ERs of the } \\
& \multicolumn{2}{c}{ Yes } & & No & \multicolumn{2}{c}{ Total } \\
\cline { 2 - 8 } & $\mathrm{N}$ & $(\%)$ & $\mathrm{N}$ & $(\%)$ & $\mathrm{N}$ & $(\%)$ \\
\hline SD/Disagree & 19 & 21.1 & 71 & 78.9 & 90 & 24.8 \\
Neutral & 26 & 33.3 & 52 & 66.7 & 78 & 21.5 \\
SA/Agree & 156 & 80.0 & 39 & 20.0 & 195 & 53.7 \\
\hline Total & 201 & 55.4 & 162 & 44.6 & 363 & 100 \\
\hline
\end{tabular}

Note. $\chi 2(2, \mathrm{~N}=363)=105.94, p=.000$.

As indicated in Table 6.19, the majority of the postgraduate respondents who agreed or strongly agreed that their course work entailed regular assignments used the ERs of the library. The chisquare test results indicated a significant association with large effect between course work assignments and usage of ERs among postgraduate respondents in the case institutions, $\chi^{2}$ (2, $\mathrm{N}=363)=105.94, p=.000$. The results show that when students are given regular course assignments that entailed research, it encouraged them to use the ERs of the library.

Taken together, it can be concluded that social influence determined in this study by publicity by the library, recommendations by colleagues, promotion by faculty, and course work assignments affected the use of ERs of the library in the case institutions. When faculty and students perceived that important others believed that they should use ERs of the library, they were likely to use them.

\subsubsection{Facilitating Conditions and Usage of ERs}

Facilitating conditions identified and tested in the study include searching skills, participation in ER training, user involvement in ER services and ease of access to the ERs.

\subsection{Searching Skills and Usage of ERs}

The literature on usage of ERs has indicated searching skills of users as influencing the usage of ERs in academic institutions. The study therefore sought to establish whether respondents' ability to retrieve information in e-format had any association with usage of the ERs of the library. Due to low values, cells were merged into two options to meet the requirements of chi-square test. The findings are presented in Table 6.20. 
Table 6. 20: A Cross-tabulation of Searching Skills and Usage of ERs

\begin{tabular}{|c|c|c|c|c|c|c|c|c|c|c|c|c|}
\hline \multirow{4}{*}{$\begin{array}{l}\text { Ability to } \\
\text { retrieve E- } \\
\text { information }\end{array}$} & \multicolumn{12}{|c|}{ Do you use the ERs of the library } \\
\hline & \multicolumn{6}{|c|}{ Faculty } & \multicolumn{6}{|c|}{ Postgraduates } \\
\hline & \multicolumn{2}{|c|}{ Yes } & \multicolumn{2}{|c|}{ No } & \multicolumn{2}{|c|}{ Total } & \multicolumn{2}{|c|}{ Yes } & \multicolumn{2}{|c|}{ No } & \multicolumn{2}{|c|}{ Total } \\
\hline & $\mathrm{N}$ & $(\%)$ & $\mathrm{N}$ & $(\%)$ & $\mathrm{N}$ & $(\%)$ & $\mathrm{N}$ & $(\%)$ & $\mathrm{N}$ & $(\%)$ & $\mathrm{N}$ & $(\%)$ \\
\hline SD/D/Neutral & 4 & 50 & 4 & 50 & 8 & 7.7 & 23 & 25.8 & 66 & 74.2 & 89 & 24.5 \\
\hline SA/Agree & 74 & 77.1 & 22 & 22.9 & 96 & 92.3 & 178 & 65.0 & 96 & 35.0 & 274 & 75.5 \\
\hline Total & 78 & 75.0 & 26 & 25.0 & 104 & 100 & 201 & 55.4 & 162 & 44.6 & 363 & 100 \\
\hline
\end{tabular}

Note. $\chi^{2}(1, \mathrm{~N}=104)=1.63, p=.202 . \quad \chi^{2}(1, \mathrm{~N}=363)=40.04, p=.000$.

From Table 6.20, it can be observed most faculty who strongly agreed they were able to retrieve information in e-format used the ERs of the library. However, a chi-square test for independence (with Yates Continuity Correction) showed no significant association between ability to retrieve information in e-format and usage of ERs by faculty respondents in the case institutions, $\chi^{2}$ (1, $\mathrm{N}=104)=1.63, p=.202$. Most postgraduate students who agreed to the statement that they were able to retrieve information in e-format used the ERs of the library. The results indicated a significant association with large effect between ability to retrieve information in e-format and usage of ERs among postgraduate respondents in the case institutions, $\chi 2(1, \mathrm{~N}=363)=40.04, p=$ .000 . It can be concluded that having the skills to search ERs did not affect usage of ERs among faculty in the case institutions. However, postgraduate students who had the ability to retrieve information in e-format were likely to use the ERs of the library.

\subsection{Participation in ER Training and Usage of ERs of the Library}

The study investigated whether user participation in ER training organised by the library had any association with the usage of ERs of the library. Table 6.21 depicts the results. 
Table 6. 21: A Cross-tabulation of Participation in ER Training and Usage of ERs

\begin{tabular}{lccccccccccccc}
\hline \multirow{2}{*}{$\begin{array}{l}\text { Participation in } \\
\text { training }\end{array}$} & \multicolumn{1}{c}{ Faculty } & \multicolumn{1}{c}{ Yo you use the ERs of the library } \\
& \cline { 2 - 16 } & $\mathrm{N}$ & $(\%)$ & $\mathrm{N}$ & $(\%)$ & $\mathrm{N}$ & $(\%)$ & $\mathrm{N}$ & $(\%)$ & $\mathrm{N}$ & $(\%)$ & $\mathrm{N}$ & $(\%)$ \\
\hline Yes & 55 & 85.9 & 9 & 14.1 & 64 & 61.5 & 84 & 81.6 & 19 & 18.4 & 103 & 28.4 \\
No & 23 & 57.5 & 17 & 42.5 & 40 & 38.5 & 117 & 45.0 & 143 & 55.0 & 260 & 71.6 \\
\hline Total & 78 & 75.0 & 26 & 25.0 & 104 & 100 & 201 & 55.4 & 162 & 44.6 & 363 & 100 \\
\hline
\end{tabular}

Note. $\chi^{2}(1, \mathrm{~N}=104)=9.15, p=.002 . \quad \chi^{2}(1, \mathrm{~N}=363)=38.42, p=.000$.

As illustrated in Table 6.21, over half of faculty and less than half of postgraduate respondents who had not participated in ER training used the ERs of the library. However, the chi-square test indicated a significant association with large effect between participation in ER training and usage of ERs by faculty, $\chi^{2}(1, \mathrm{~N}=104)=9.15, p=.002$, and postgraduate students, $\chi^{2}(1, \mathrm{~N}=363)=$ $38.42, p=.000$. The implication is that, faculty and postgraduate students who participated in ER training programmes organised by the library were more likely to use the ERs of the library.

\subsection{User involvement in ER Services and Usage of ERs of the Library}

User involvement in ER services means giving users the opportunity to participate in ER implementation activities to ensure that ER services are tailored towards the needs of users which could encourage maximum usage. Implementation activities include selection of contents, trial of new contents and evaluation of ERs. The study sought to investigate whether any association existed between respondents' involvement in ER services and usage. User involvement comprised four items in this study and findings are presented in the following sub-sections.

\section{a. Opportunity for Recommending ERs and Usage of ERs}

The study sought to examine whether there was any association between opportunity for recommending ERs to the library and usage of the ERs. Findings are shown in Table 6.22. 
Table 6. 22: A Cross-tabulation of Recommending ERs to the Library and Usage of ERs

\begin{tabular}{lccccccccccccc}
\hline \multirow{2}{*}{$\begin{array}{l}\text { User } \\
\text { Involvement in }\end{array}$} & \multicolumn{1}{c}{ Yes } & \multicolumn{1}{c}{ No } & \multicolumn{1}{c}{ Total } & \multicolumn{7}{c}{ Yes } & \multicolumn{1}{c}{ No } & \multicolumn{4}{c}{ Total } \\
ER selection & $\mathrm{N}$ & $(\%)$ & $\mathrm{N}$ & $(\%)$ & $\mathrm{N}$ & $(\%)$ & $\mathrm{N}$ & $(\%)$ & $\mathrm{N}$ & $(\%)$ & $\mathrm{N}$ & $(\%)$ \\
\hline Yes & 22 & 91.7 & 2 & 8.3 & 24 & 23.1 & 48 & 85.7 & 8 & 14.3 & 56 & 15.4 \\
No & 56 & 70.0 & 24 & 30.0 & 80 & 76.9 & 153 & 49.8 & 154 & 50.2 & 307 & 84.6 \\
\hline Total & 78 & 75.0 & 26 & 25.0 & 104 & 100 & 201 & 55.4 & 162 & 44.6 & 363 & 100 \\
\hline
\end{tabular}

Note. $\chi^{2}(1, \mathrm{~N}=104)=3.54, p=.060 . \quad \chi^{2}(1, \mathrm{~N}=363)=23.23, p=.000$.

Table 6.22 shows that the majority of faculty and about a half of the postgraduate respondents who indicated no opportunity for suggesting ERs to the library used the ERs. Findings from faculty respondents showed that the relation between opportunity for recommending ERs to the library and usage of the ERs was not significant, $\chi^{2}(1, \mathrm{~N}=104)=3.54, p=.060$. However, findings from postgraduate students revealed a significant association between opportunity for recommending ERs to the library and usage of the ERs by postgraduate students in the case institutions, $\chi^{2}$ (1, $\mathrm{N}=363)=23.23, p=.000$. It can be concluded based on the findings that opportunity for suggesting ERs did not affect its usage by faculty. However, postgraduate students were more likely to use the ERs of the library when given the opportunity to recommend contents to the library.

\section{b. Opportunity for Trial of ERs of the Library and Usage}

The study sought to find out whether there was any association between opportunity for participation in ER trial sessions and usage of ERs among respondents of the study. Findings are presented in Table 6.23.

Table 6. 23: A Cross-tabulation of Participation in ER Trial and Usage of ERs

\begin{tabular}{|c|c|c|c|c|c|c|c|c|c|c|c|c|}
\hline \multirow{4}{*}{$\begin{array}{l}\text { Participation in } \\
\text { ER Trial }\end{array}$} & \multicolumn{12}{|c|}{ Do you use the ERs of the library } \\
\hline & \multicolumn{6}{|c|}{ Faculty } & \multicolumn{6}{|c|}{ Postgraduates } \\
\hline & \multicolumn{2}{|c|}{ Yes } & \multicolumn{2}{|c|}{ No } & \multicolumn{2}{|c|}{ Total } & \multicolumn{2}{|c|}{ Yes } & \multicolumn{2}{|c|}{ No } & \multicolumn{2}{|c|}{ Total } \\
\hline & $\mathrm{N}$ & $(\%)$ & $\mathrm{N}$ & $(\%)$ & $\mathrm{N}$ & $(\%)$ & $\mathrm{N}$ & $(\%)$ & $\mathrm{N}$ & $(\%)$ & $\mathrm{N}$ & $(\%)$ \\
\hline Yes & 23 & 88.5 & 3 & 11.5 & 26 & 25.0 & 41 & 91.1 & 4 & 8.9 & 45 & 12.4 \\
\hline No & 55 & 70.5 & 23 & 29.5 & 78 & 75.0 & 160 & 50.3 & 158 & 49.7 & 318 & 87.6 \\
\hline Total & 78 & 75.0 & 26 & 25.0 & 104 & 100 & 201 & 55.4 & 162 & 44.6 & 363 & 100 \\
\hline
\end{tabular}

Note. $\chi^{2}(1, \mathrm{~N}=104)=2.46, p=.117 . \quad \chi^{2}(1, \mathrm{~N}=363)=24.92, p=.000$. 
As revealed in Table 6.23, majority of faculty and postgraduate respondents who had ever participated in the trial of ERs used the ERs of the library. However, a chi-square test for independence (with Yates Continuity Correction) indicated no significant association between participation in ER trial and usage of ERs by faculty, $\chi 2(1, \mathrm{~N}=104)=2.46, p=.117$. For postgraduate students, the results revealed a significant association with between participation in ER trial and usage of ERs, $\chi^{2}(1, \mathrm{~N}=363)=24.92, p=.000$. It can be concluded that user participation in ER trial did not affect the usage of ERs by faculty but postgraduate students who participated in the trial of ERs were more likely to use them.

\section{c. Opportunity for Providing Feedback on ERs of the Library and Usage of ERs}

The study investigated whether users having the opportunity to provide feedback on the library's ERs had any association with the usage of the ERs. Findings are shown in Table 6.24.

Table 6. 24: A Cross-tabulation of Opportunity for Feedback and Usage of ERs

\begin{tabular}{lccccccccccccc}
\hline & \multicolumn{1}{c}{ Faculty } \\
Opportunity & \multicolumn{1}{c}{ Do you use the ERs of the library } \\
for Feedback & \multicolumn{2}{c}{ Yes } & \multicolumn{1}{c}{ No } & \multicolumn{1}{c}{ Total } & \multicolumn{3}{c}{ Yes } & \multicolumn{4}{c}{ No } \\
on ERs & $\mathrm{N}$ & $(\%)$ & $\mathrm{N}$ & $(\%)$ & $\mathrm{N}$ & $(\%)$ & $\mathrm{N}$ & $(\%)$ & $\mathrm{N}$ & $(\%)$ & $\mathrm{N}$ & $(\%)$ \\
\hline Yes & 18 & 100 & 0 & 0.0 & 18 & 17.3 & 22 & 78.6 & 6 & 21.4 & 28 & 7.7 \\
No & 60 & 69.8 & 26 & 30.2 & 86 & 82.7 & 179 & 53.4 & 156 & 46.6 & 335 & 92.3 \\
\hline Total & 78 & 75.0 & 26 & 25.0 & 104 & 100 & 201 & 55.4 & 162 & 44.6 & 363 & 100 \\
\hline
\end{tabular}

Note. $\chi 2(1, \mathrm{~N}=104)=5.73, p=.017 . \quad \chi 2(1, \mathrm{~N}=363)=5.63, p=.018$.

As presented in Table 6.24, most faculty and postgraduate respondents who had not yet had the opportunity to provide feedback on the ERs used the resources. The chi-square value indicated a significant association with small effect between opportunity to provide feedback on the ERs and usage of the ERs by faculty, $\chi 2(1, \mathrm{~N}=104)=5.73, p=.017$ and by postgraduate students in the case institutions, $\chi^{2}(1, \mathrm{~N}=363)=5.63, p=.018$. It can be concluded based on the findings that faculty and postgraduate students were likely to use the ERs of the library when provided the opportunity for feedback on the ERs of the library. 


\section{d. Participation in ER Assessment Surveys and Usage of ERs}

The study sought to investigate whether user participation in ER assessment had any association with the usage of the ERs of the library. Findings are depicted in Table 6.25.

Table 6. 25: A Cross-tabulation of Participation in ER Assessment and Usage of ERs

\begin{tabular}{|c|c|c|c|c|c|c|c|c|c|c|c|c|}
\hline \multirow{4}{*}{$\begin{array}{l}\text { Opportunity } \\
\text { for ER } \\
\text { Assessment }\end{array}$} & \multicolumn{12}{|c|}{ Do you use the ERs of the library } \\
\hline & \multicolumn{6}{|c|}{ Faculty } & \multicolumn{6}{|c|}{$\begin{array}{r}\text { Postgraduates } \\
\end{array}$} \\
\hline & \multicolumn{2}{|c|}{ Yes } & \multicolumn{2}{|c|}{ No } & \multicolumn{2}{|c|}{ Total } & \multicolumn{2}{|c|}{ Yes } & \multicolumn{2}{|c|}{ No } & \multicolumn{2}{|c|}{ Total } \\
\hline & $\mathrm{N}$ & $(\%)$ & $\mathrm{N}$ & $(\%)$ & $\mathrm{N}$ & $(\%)$ & $\mathrm{N}$ & $(\%)$ & $\mathrm{N}$ & $(\%)$ & $\mathrm{N}$ & $(\%)$ \\
\hline Yes & 15 & 93.8 & 1 & 6.3 & 16 & 15.4 & 31 & 91.2 & 3 & 8.8 & 34 & 9.4 \\
\hline No & 63 & 71.6 & 25 & 28.4 & 88 & 84.6 & 170 & 51.7 & 159 & 48.3 & 329 & 90.6 \\
\hline Total & 78 & 75.0 & 26 & 25.0 & 104 & 100 & 201 & 55.4 & 162 & 44.6 & 363 & 100 \\
\hline
\end{tabular}

Note. $\chi^{2}(1, \mathrm{~N}=104)=2.46, p=.117 . \quad \chi^{2}(1, \mathrm{~N}=363)=17.90, p=.000$.

As revealed in Table 6.25, over half of faculty and postgraduate students who indicated they had not had the opportunity for ER assessment used the ERs of the library. The chi-square test for independence (with Yates Continuity Correction) indicated no significant association between participation in ER assessment surveys and usage of ERs by faculty respondents, $\chi 2(1, N=104)=$ 2.46, $p=.117$. However, for postgraduate students, there was a significant association between these two variables, $\chi^{2}(1, \mathrm{~N}=363)=17.90, p=.000$. The implication is that, participation in assessment of ERs of the library influenced its usage among postgraduate students but not faculty.

\subsection{Ease of Access and Usage of ERs}

The study sought to examine whether there was any association between ease of access to ICT facilities and usage of ERs in the case institutions. Findings are presented in Table 6.26.

Table 6. 26: A Cross-tabulation of Ease of Access and Usage of ERs

\begin{tabular}{|c|c|c|c|c|c|c|c|c|c|c|c|c|}
\hline \multirow{4}{*}{$\begin{array}{l}\text { I have easy } \\
\text { access to ICT } \\
\text { Facilities }\end{array}$} & \multicolumn{12}{|c|}{ Do you use the ERs of the library } \\
\hline & \multicolumn{6}{|c|}{ Faculty } & \multicolumn{6}{|c|}{ Postgraduates } \\
\hline & \multicolumn{2}{|c|}{ Yes } & \multicolumn{2}{|c|}{ No } & \multicolumn{2}{|c|}{ Total } & \multicolumn{2}{|c|}{ Yes } & \multicolumn{2}{|c|}{ No } & \multicolumn{2}{|c|}{ Total } \\
\hline & $\mathrm{N}$ & $(\%)$ & $\mathrm{N}$ & $(\%)$ & $\mathrm{N}$ & $(\%)$ & $\mathrm{N}$ & $(\%)$ & $\mathrm{N}$ & $(\%)$ & $\mathrm{N}$ & $(\%)$ \\
\hline SD/Disagree & 11 & 61.1 & 7 & 38.9 & 18 & 17.3 & 30 & 34.1 & 58 & 65.9 & 88 & 24.2 \\
\hline Neutral & 14 & 73.7 & 5 & 26.3 & 19 & 18.3 & 32 & 37.2 & 54 & 62.8 & 86 & 23.7 \\
\hline SA/Agree & 53 & 79.1 & 14 & 20.9 & 67 & 64.4 & 139 & 73.5 & 50 & 26.5 & 189 & 52.1 \\
\hline Total & 78 & 75.0 & 26 & 25.0 & 104 & 100 & 201 & 55.4 & 162 & 44.6 & 363 & 100 \\
\hline
\end{tabular}

Note. $\chi^{2}(2, \mathrm{~N}=104)=2.47, p=.291 . \quad \chi^{2}(2, \mathrm{~N}=363)=52.88, p=.000$. 
As depicted in Table 6.26, most faculty respondents who strongly disagreed to having easy access to ICT facilities used the ERs of the library. The results indicated no significant association between ease of access to ICT facilities and usage of ERs among faculty respondents in the case institutions, $\chi 2(2, \mathrm{~N}=104)=2.47, p=.291$. For postgraduate respondents, there was an association with large effect between ease of access to ICT facilities and usage of ERs, $\chi 2(2, \mathrm{~N}=363)=52.88$, $p=.000$. The results showed that ease of access did not affect usage of ERs by faculty whereas postgraduate students were more likely to use the ERs of the library if they had easy access to ICT facilities.

Taken together, the findings revealed that facilitating conditions affecting the usage of ERs of the library in the case institutions varied according to the category of respondents. Having the requisite searching skills, having the opportunity to recommend ERs to the library, participation in ER trial and ER assessment, and ease of access did not affect usage of the ERs by faculty respondents. However, these variables had significant association with usage of ERs of the library by postgraduate students.

Table 6.27 provides a summary of the chi-square tests of factors affecting the usage of ERs in the case institutions. 
Table 6. 27: A summary of Chi-square Tests of Factors Affecting the Usage of ERs

\begin{tabular}{|c|c|c|c|c|}
\hline Section & Factors & Respondents & Chi-square Test & $\begin{array}{l}\text { Statistical } \\
\text { significance }\end{array}$ \\
\hline 6.15 .1 & Demographic variables and Usa & & & \\
\hline 6.15.1.1 & Gender and Use & $\begin{array}{c}\text { Faculty } \\
\text { Postgraduates }\end{array}$ & $\begin{array}{l}\chi 2(1, N=104)=2.23, p=.135 \\
\chi 2(1, N=363)=1.82, p=.117\end{array}$ & $\begin{array}{l}\text { Not significant } \\
\text { Not significant }\end{array}$ \\
\hline 6.15.1.2 & Age and Use & $\begin{array}{c}\text { Faculty } \\
\text { Postgraduates }\end{array}$ & $\begin{array}{l}\chi 2(2, N=104)=2.11, p=.348 \\
\chi 2(2, N=363)=1.07, p=.585\end{array}$ & $\begin{array}{l}\text { Not significant } \\
\text { Not significant }\end{array}$ \\
\hline 6.15.1.3 & Discipline and Use & $\begin{array}{c}\text { Faculty } \\
\text { Postgraduates }\end{array}$ & $\begin{array}{c}\chi 2(2, N=104)=.84, p=.656 \\
\chi 2(2, N=363)=3.55, p=.169\end{array}$ & $\begin{array}{l}\text { Not significant } \\
\text { Not significant }\end{array}$ \\
\hline 6.15.1.4 & Academic rank and Use & Faculty & $\chi 2(2, N=104)=.65, p=.722$ & Not significant \\
\hline 6.15 .2 & $\begin{array}{l}\text { Performance expectancy and } \\
\text { Use }\end{array}$ & $\begin{array}{c}\text { Faculty } \\
\text { Postgraduates }\end{array}$ & $\begin{array}{l}\chi 2(2, N=104)=15.23, p=.000 \\
\chi 2(2, N=363)=97.39, p=.000\end{array}$ & $\begin{array}{l}\text { Significant } \\
\text { Significant }\end{array}$ \\
\hline 6.15 .3 & Effort expectancy and Use & $\begin{array}{c}\text { Faculty } \\
\text { Postgraduates }\end{array}$ & $\begin{array}{l}\chi 2(2, N=104)=18.92, p=.000 \\
\chi 2(2, N=363)=115.72, p= \\
.000\end{array}$ & $\begin{array}{l}\text { Significant } \\
\text { Significant }\end{array}$ \\
\hline 6.15 .4 & Social Influence and Use & & & \\
\hline 6.15.4.1 & $\begin{array}{l}\text { Publicity of ERs by library } \\
\text { and Use }\end{array}$ & $\begin{array}{c}\text { Faculty } \\
\text { Postgraduates }\end{array}$ & $\begin{array}{l}\chi 2(2, N=104)=11.51, p=.003 \\
\chi 2(2, N=363)=46.49, p=.000\end{array}$ & $\begin{array}{l}\text { Significant } \\
\text { Significant }\end{array}$ \\
\hline 6.15.4.2 & $\begin{array}{l}\text { Recommendation by } \\
\text { colleagues and Use }\end{array}$ & $\begin{array}{c}\text { Faculty } \\
\text { Postgraduates }\end{array}$ & $\begin{array}{l}\chi 2(2, N=104)=6.08, p=.048 \\
\chi 2(2, N=363)=49.02, p=.000\end{array}$ & $\begin{array}{l}\text { Significant } \\
\text { Significant }\end{array}$ \\
\hline 6.15.4.3 & $\begin{array}{l}\text { Promotional efforts by } \\
\text { faculty and Use }\end{array}$ & Postgraduates & $\chi 2(4, N=363)=63.96, p=.000$ & Significant \\
\hline 6.15.4.4 & Course assignments and Use & Postgraduates & $\begin{array}{l}X 2(4, N=363)=105.94, p= \\
.000\end{array}$ & Significant \\
\hline 6.15 .5 & Facilitating conditions and Use & & & \\
\hline 6.15.5.1 & $\begin{array}{l}\text { Ability to retrieve } \\
\text { information in e-format and } \\
\text { Use }\end{array}$ & $\begin{array}{c}\text { Faculty } \\
\text { Postgraduates }\end{array}$ & $\begin{array}{l}\chi 2(2, N=104)=1.63, p=.202 \\
\chi 2(2, N=363)=40.04, p=.000\end{array}$ & $\begin{array}{l}\text { Not significant } \\
\text { Significant }\end{array}$ \\
\hline 6.15.5.2 & $\begin{array}{l}\text { Participation in ER training } \\
\text { and Use }\end{array}$ & $\begin{array}{c}\text { Faculty } \\
\text { Postgraduates }\end{array}$ & $\begin{array}{l}\chi 2(1, N=104)=9.15, p=.002 \\
\chi 2(1, N=363)=38.42, p=.000\end{array}$ & $\begin{array}{l}\text { Significant } \\
\text { Significant }\end{array}$ \\
\hline 6.15.5.3 & User input in ER services & & & \\
\hline a. & $\begin{array}{l}\text { Opportunity for } \\
\text { recommending ERs and Use }\end{array}$ & $\begin{array}{c}\text { Faculty } \\
\text { Postgraduates }\end{array}$ & $\begin{array}{l}\chi 2(1, N=104)=3.54, p=.060 \\
\chi 2(1, N=363)=23.23, p=.000\end{array}$ & $\begin{array}{l}\text { Not significant } \\
\text { Significant }\end{array}$ \\
\hline b. & $\begin{array}{l}\text { Participation in ER trial and } \\
\text { Use }\end{array}$ & $\begin{array}{c}\text { Faculty } \\
\text { Postgraduates }\end{array}$ & $\begin{array}{l}\chi 2(1, N=104)=2.46, p=.117 \\
\chi 2(1, N=363)=24.92, p=.000\end{array}$ & $\begin{array}{c}\text { Not significant } \\
\text { Significant }\end{array}$ \\
\hline c. & $\begin{array}{l}\text { Opportunity for feedback } \\
\text { and Use }\end{array}$ & $\begin{array}{c}\text { Faculty } \\
\text { Postgraduates }\end{array}$ & $\begin{array}{l}\chi 2(1, N=104)=5.73, p=.017 \\
\chi 2(1, N=363)=5.63, p=.018\end{array}$ & $\begin{array}{l}\text { Significant } \\
\text { Significant }\end{array}$ \\
\hline d. & $\begin{array}{l}\text { Participation in ER } \\
\text { assessment and Use }\end{array}$ & $\begin{array}{c}\text { Faculty } \\
\text { Postgraduates }\end{array}$ & $\begin{array}{l}\chi 2(1, \mathrm{~N}=104)=2.46, p=.117 \\
\chi 2(1, \mathrm{~N}=363)=17.90, p=.000\end{array}$ & $\begin{array}{c}\text { Not significant } \\
\text { Significant }\end{array}$ \\
\hline 6.15.5.4 & Ease of access and Use & $\begin{array}{c}\text { Faculty } \\
\text { Postgraduates }\end{array}$ & $\begin{array}{l}\chi 2(2, N=104)=2.47, p=.291 \\
\chi 2(2, N=363)=52.88, p=.000\end{array}$ & $\begin{array}{c}\text { Not significant } \\
\text { Significant }\end{array}$ \\
\hline
\end{tabular}




\subsection{Summary of Key Findings on the Usage of ERs}

This chapter answered the research questions: How are ERs used in academic libraries in Ghana? What are the contextual factors surrounding the usage of ERs in academic libraries? and In what ways do these contextual factors affect the usage of ERs? Overall, findings from the surveys of faculty and postgraduate students corroborated and complemented findings from interviews with library staff. Generally, the findings revealed varying levels of awareness of the various ERs of the library among faculty and postgraduate respondents from both public and private institutions. Faculty respondents were generally more aware of ERs of the library than the postgraduate respondents in all four institutions, which reflected the target audience of promotional efforts of the case libraries. Awareness of the ERs of the library among postgraduate respondents was comparatively higher in the public universities than the private universities. Also, 'colleagues' was revealed as the pre-dominant mode of awareness of ERs of the library.

Usage of ERs was generally higher among faculty than postgraduate students in both public and private case institutions. Among postgraduate respondents, usage was higher in the public universities than their private case counterparts. Overall, online databases and E-journals were the most widely used in the case institutions. Whereas faculty mainly accessed ERs of the library from their offices, postgraduate students accessed the resources mainly from the library. in addition, the findings revealed that using mobile devices to access the ERs was gaining popularity among postgraduate students in both public and private case institutions which complemented inadequate institutional infrastructure. It was however revealed that alternative online resources were the first port of call in accessing scholarly information for most faculty and postgraduate respondents in the public and private case institutions. In addition, most respondents in the case institutions generally had a negative perception about the usefulness of the ERs of the library.

The findings further indicated low participation of faculty and postgraduate students in ER training programmes organised by the library in both public and private case institutions. This may have contributed to the lack of searching skills to use the ERs as indicated by respondents. Consequently, 'trial and error' was the predominant mode by which faculty and postgraduate students of both public and private case institutions accessed the ERs of the library. There was also an indication of minimal involvement of faculty and postgraduate respondents in the ER services 
of the library as less than a third of faculty and postgraduate students in both public and private case institutions had ever recommended contents to the library, participated in ER trial, provided feedback on the ERs or participated in ER assessment surveys. These results corroborated the findings from interviews with library staff, which pointed towards low user involvement in the implementation of ERs particularly in the selection and assessment of ERs.

Faculty and postgraduate respondents pointed out various challenges they faced in accessing the ERs of the library. These challenges were national (governmental), institutional (organisational), ER-related and individual (personal) factors. A national obstacle to accessing the ERs of the library as indicated by faculty and postgraduate respondents was frequent power cuts. A prominent institutional challenge highlighted by faculty and postgraduate respondents in both public and private case institutions was poor Internet connectivity. This paralleled the findings from interviews with library staff which revealed unstable and slow Internet connectivity as a hindrance to the management of and access to ERs in all case institutions. Comparatively, institutional challenges consisting of poor Internet connectivity, inadequate computers and inadequate training were more prevalent in the private case institutions than their public case counterparts. ER-related challenges highlighted by faculty and postgraduate respondents in the case institutions were information overload and lack of relevant information. A hindrance identified at the individual level was lack of time which was comparatively more frequent among faculty than postgraduate students. However, lack of time was generally not a prominent challenge based on the findings.

Using the four determinants in UTAUT and factors from the literature as a lens, the study examined five main factors surrounding the usage of ERs namely demographic profile, performance expectancy, effort expectancy, social influence and facilitating conditions. The findings revealed no association between the demographic profile of faculty and postgraduate respondents and usage of ERs of the library. Performance expectancy and effort expectancy were confirmed as having a significant association with usage of the ERs by faculty and postgraduate students which implied that faculty and students were likely to use the ERs of the library when they perceived them as useful and easy to use. Similarly, a significant association was revealed between social influence variables comprising publicity by the library, recommendation by colleagues, recommendation by faculty and course work demands. Regarding facilitating conditions, mixed findings were obtained 
from faculty and postgraduate respondents: whereas searching skills, opportunity for recommending ERs, participation in ER trial, opportunity for assessing ERs and ease of access to ERs did not affect usage of ERs by faculty, all these variables influenced usage of the ERs by postgraduate students. However, ER training and opportunity for providing feedback on the ERs both had a significant association with the usage of ERs by faculty and postgraduate students. It can be concluded that the findings supported the four main determinants of UTAUT to a considerable extent. 


\section{Chapter Seven}

\section{Discussion of Main Findings}

\subsection{Introduction}

The problem that informed this study was that few researchers have studied both concepts of management and usage of ERs in a single study to reveal how they are related. In addition, the literature on the management of ERs in libraries has predominantly focused on developed countries leaving a gap in the context of developing countries. This research therefore fills the gaps by studying both concepts with a focus on a developing country context. Furthermore, previous studies have suggested that academic libraries in Ghana are ineffective in managing ERs, which could explain the observed low usage of ERs. There is therefore a lack of understanding on how ERs are managed as well as the contextual factors surrounding the management and usage of these resources in Ghanaian universities. This necessitated an exploratory investigation to understand these issues and factors in order to recommend strategies for addressing them.

Based on the findings presented in Chapters Five and Six, this chapter discusses the management of ERs together with the usage of ERs in academic libraries; and the contextual factors surrounding the management and usage of ERs in academic libraries in Ghana. The TERMS framework and the initial model of contextual factors of management and usage are revised based on the findings. The chapter also discusses the ways in which the management of ERs affected their usage and vice versa in academic libraries.

\subsection{Planning for ERs in the Selected Academic Libraries}

Planning for ERs is deemed the most important component of ERM (Bothmann \& Holmberg, 2008) as it provides guidelines, goals, and objectives for current and future activities (Dadzie \& Walt, 2015). It entails policymaking, budgeting, and staffing (Bothmann \& Holmberg, 2008; Collins, 2009; Shu, 2012). Findings from Chapter Five revealed varying levels of planning for ERs in the case institutions which are discussed in the following sub-sections. 


\subsubsection{Policies for ERs}

Collection development policies (CDPs) for ERs are crucial in managing ERs as they inform stakeholders about guidelines for managing these resources (Johnson, 2009; Mangrum \& Pozzebon, 2012). CDPs for ERs assist in prioritisation, budget allocation and acquisitions (Mangrum \& Pozzebon, 2012). Also, for ERM to be effective, developing guidelines for the evolving and complex workflow becomes critical (Martin et al., 2009). These policies go beyond the general collection development policies to include issues such as licensing of ERs, user access and cataloguing of contents (Bothmann \& Holmberg, 2008). The literature has highlighted the fact that policies for ERs in libraries have been treated lightly and not given the due recognition even in libraries in the developed world (Mangrum \& Pozzebon, 2012; Pickett et al., 2011; Vickery, 2004).

As a principal component of planning for ERs, the study investigated policies for ERs in the case institutions. Data in Chapter Five revealed that, three case libraries (UCC, CU and WIUC) had developed CDPs which made provision for ERs. Data from the Balme Library (UG) showed no availability of any such policies. This supported the viewpoint of researchers such as Mangrum \& Pozzebon (2012) who argued that policies for ERs had not been given due recognition; and that some academic libraries in developing countries were yet to formulate and integrate ICT policies (Anie \& Achugbue, 2009; Dadzie \& Walt, 2015). This could lead to lack of clarity and inconsistency in ER activities and workflow.

To evaluate the CDPs of UCC, CU and WIUC libraries, a content analysis using an evaluation tool developed by Mangrum \& Pozzebon (2012) was adopted (findings presented in Chapter Five). The aim of the content analysis was to ascertain the extent to which the CDPs of case libraries addressed their ERs. The evaluation tool consisted of nine (9) major criteria with thirty-six (36) items. The nine criteria are cost, consortia, responsible parties, content, access, usability, assessment, licensing (user perspective) and licensing (library management). Findings revealed content as the most common criterion addressed in the CDPs of case libraries. In traditional CDPs, pre-selection and acquisition factors such as content assessment and demand are usually common. However, in the arena of ERs, other criteria are equally significant with regard to selection and acquisition. Middle ranked criteria were access, cost, usability, and licensing (user perspective). 
These criteria should equally be taken into consideration in content assessment as they can guide ER staff to adequately satisfy user information and access needs. The lowest ranked criteria revealed from the content analysis were consortia, assessment, licensing (library management) and responsible parties. However, these factors are equally crucial and when well detailed in the CDPs, it would guide the library or ER staff in the areas of consortia participation, renewal decisions, liability, and termination rights.

Although consortia subscription contributed greatly to the development of ERs at UCC, CU and WIUC libraries, their policies on ERs made minimal mention of consortium participation. This was consistent with findings by Mangrum and Pozzebon (2012) who revealed that the libraries investigated made minimal inclusion of consortia in their policies for ERs. More concerning is the fact that none of the CDPs analysed in this study made mention of responsible parties and licensing (library management). These factors are very significant for the fact that when responsible parties are clearly defined, it will promote clarity on ER workflow and eliminate misunderstanding. In addition, when policies regarding licensing are clearly stated, the library is less likely to accept unfavourable terms and agreements with adverse effects on ER services (Bothmann \& Holmberg, 2008). Generally, the content analysis indicated that UCC, CU and WIUC libraries made efforts to address ERs in their CDPs. However, policies on internal management of ERs ranked the lowest. These findings paralleled those of Mangrum \& Pozzebon (2012).

Policy development in the case institutions as highlighted in the analysis was not without challenges. Factors such as bureaucratic institutional procedures resulted in delayed ratification of policies, and communication of policies with stakeholders served as obstacles to the development and implementation of ER policies. These findings partly supported those of Bothmann \& Holmberg (2008) who conducted a similar study and revealed communication of policies with librarians as a challenge. However, other factors revealed by these authors including, staffing, time, and frequent change in relation to vendors and staff opinions, were not consistent with the findings of this study. The findings revealed varied perception on policies for ERs. Some interviewees perceived ER policies as not crucial since their library solely depended on consortia subscription, and the Consortium of Academic and Research Libraries in Ghana (CARLIGH) was responsible for the selection and acquisition aspects of the ER workflow. Other interviewees 
perceived the need for flexibility in ERM, which in their opinion could be hindered by ER policies, and this finding is similar to that of Bothmann \& Holmberg (2008). Although policy development and implementation may not be an easy task for libraries, documenting policies to guide the management of ERs can provide immediate benefits as well as for posterity.

\subsubsection{Budgeting for ERs}

Finance is the bedrock of libraries without which adequate ER services for users will not be feasible. The findings as presented in Chapter Five indicated that both public and private academic libraries relied solely on internal funding from their institution. This is consistent with the findings of Kaur and Walia (2016) who revealed in a similar study that institutional funding was the only source of funds for the libraries investigated. However, whereas the public case libraries had a separate library budget which allowed for a level of autonomy in budgeting for ERs, their private case counterparts did not have a separate library budget, and this had implications on budgeting for ERs of the library. For instance, the Balme Library (UG) and UCC library allocated over 50\% and 20\% respectively of the library's budget to ERs whereas CU and WIUC libraries did not have any such autonomy in their operations. Findings from UG compared favourably with studies that have revealed that academic libraries allocate more than $50 \%$ of their budget to ERs (Kaur and Walia, 2016; University of California San Diego Libraries, n.d.).

Providing ERs and services require adequate funding which appeared to be a challenge for all the case institutions and hindered the acquisition and sustainability of ERs. This finding supported conclusions drawn by other studies that academic libraries in Africa were mainly funded by parent institutions (Okojie, 2010; Ubogu \& Okiy, 2011) and funding was usually inadequate (Dadzie \& Walt, 2015; Jan \& Sheikh, 2011; Kwafoa et al., 2014). Inadequate funds for the library and ERs in particular appeared more pronounced in the private case institutions as these institutions did not receive government subvention unlike their public case counterparts. Amidst the financial crisis, various strategies were adopted aimed towards sustainable funding.

A common strategy adopted by both public and private case institutions was to join CARLIGH and share ER costs with other libraries. Another strategy was prioritisation, which led to cancellation of subscriptions to some ERs. For instance, subscriptions to contents on low demand 
were cancelled to make room for much needed contents. Also, print equivalents of e-contents were cancelled. It is worth noting that public case institutions took their budgeting efforts a step further than their private case counterparts by providing commercial services such as printing, photocopying, rental of premises to generate monies which went into institutional coffers to support internal funding. Notwithstanding these efforts towards sustainability, funding for the library and ERs in particular was generally inadequate which negatively affected ERM practices. Considering the rising cost of ERs amidst stagnant or shrinking budgets, a step in the right direction could be for libraries, with support from institutional authorities to seek external sources of funding to supplement institutional funding.

\subsubsection{Staffing for ERs}

Effective ERM is only possible when adequate skilled staff are available. Staffing for ERs has been highlighted in the literature as a major issue (Abrams, 2015; Bothman \& Holmberg, 2008; Elguindi \& Schmidt, 2012). Analysis from the interview findings revealed that the demands of managing ERs did not match the staffing levels in the case institutions. This finding was consistent with that of earlier studies such as Duranceau (2002) which also indicated that staff growth was not commensurate with the exponential growth of ERs of the library. Understaffing in both public and private case institutions led to challenges in effectively implementing ERs of the library. For example, in the two private case institutions, ERM comprising statistics, renewals, access provision, verification and authentication was assigned to a single professional librarian. The findings paralleled that of a similar study by Bothmann \& Holmberg (2008). This strategy in the view of Kulp \& Rupp-Serrano (2007, p.17) is a "dangerous game" because in the absence of the ER personnel, a vacuum would be created with adverse consequences on ER services of the library.

Although the public case institutions adopted a different structure for ER staffing whereby an ER unit consisting of professionals and paraprofessionals with the head of ERs overseeing the unit, key interviewees perceived staffing levels for ERs as inadequate. Understaffing was however more pronounced in the private case institutions, and beyond the control of both public and private case libraries as the government and institutional leaders respectively had suspended recruitment of employees. Compulsory annual staff leave and high library staff attrition in the public and private case institutions respectively further exacerbated the challenge of low staff strength. Understaffing 
as revealed in the findings tallied with related studies (Abrams, 2015; Adzobu, 2014; Elguindi \& Schmidt 2012) that revealed inadequate staffing in the technological environment.

From the findings, understaffing in both public and private case institutions affected ER workflow in areas such as troubleshooting access problems, systems support and information literacy education. These findings differed from those of Duranceau (2002) who reported staffing problems in the areas of licensing, cataloguing, record management for non-OPAC systems, site-monitoring for changes in content and access at MIT libraries and the University at Buffalo Libraries. As a strategy for addressing low staff strength, both public and private case institutions distributed less technical aspects of the ER workflow to other units of the library. For example, information literacy education for users which comprised training on ERs was delegated to heads of other units of the library. Also, in the public case institutions, heads of other units of the library sometimes maintained correspondence with vendors/publishers and conducted ER access checks. Distributing ER tasks to other units of the library eased the burden on the staff of ER unit and promoted effective ERM in the case libraries. This finding concurred with those of related studies (Abrams, 2015; Chamberlain \& Reece, 2014; England \& Shipp, 2013) that revealed that ER tasks were distributed across units of the libraries to address low staff strength coupled with the evolving nature of ER workflow. An advantage of the distributed approach is that it allows all library staff to familiarise themselves with ER responsibilities (Duranceau, 2002; Elguindi \& Schmidt, 2012) and can prevent any sabotage from staff of other units of the library (Bothman \& Holmberg, 2008).

Another strategy adopted by the public case libraries in addressing understaffing was prioritsation of ER tasks. For example, at the Balme Library (UG), based on the demands of students, all other IR works were suspended to facilitate digitisation of past examination questions. This finding echoed the findings of Bothmann \& Holmberg (2008) who revealed in a similar study that the libraries investigated prioritised tasks to make up for inadequate staffing. Generally, the findings provided evidence to suggest that the case libraries were adopting various strategies to address ER staffing challenges, and this facilitated the management of ERs.

An observation made from the interview findings concerned the position of head of ERs in both public and private case institutions. In the public case institutions, the position of head of ERs was 
on a rotational basis whereas in the private case institutions, this position was more or less for a long term. Both approaches come with pros and cons. Job rotation can facilitate ERM as it gives staff of other units the opportunity to familiarise themselves with ER roles and responsibilities so that in the case of absence of the head of ERs, other staff with experience could easily step in to act on their behalf. This can be a back-up plan to support the "dangerous game" (Kulp \& RuppSerrano 2007, p.17) of assigning a professional or two to ERM. Job rotation in libraries can also lead to job satisfaction (Odunlade, 2012) as it breaks the monotony of tasks reducing boredom among library staff. On the other hand, job rotation can be an obstacle to effective ERM particularly in the case of inadequate succession planning. This can lead to lack of clarity when there are ER staff changes and have adverse effects on ER services of the library. Job rotation also posed threats to consortium activities as revealed in Chapter Five for the reason that the consortium had to deal with new heads of ERs when there were staff changes which hindered the continuity of ER activities between CARLIGH and members. In this regard, having a long-term ER role becomes a strength and an enabler to ERM as it facilitates continuity of consortium activities for member libraries.

A defining facet of the constantly changing technological environment is the need for frequent training and capacity building (Elguindi \& Schmidt, 2012). ER staff therefore need to update their knowledge and skills to effectively manage these resources. The findings revealed the major role the consortium played in capacity building of ER staff of the case libraries. Both public and private case libraries relied on the "training of trainers sessions" organised by CARLIGH. This strategy for capacity building was perceived by key interviewees as cost effective as it formed part of the consortium package for member libraries. In other ways, capacity building through CARLIGH seemed to have encouraged best practices and promoted a level of standardisation of the skills of ER staff of member libraries irrespective of the size or type of library. The findings concurred with the viewpoint of Okeagu \& Okeagu (2008) who enumerated the advantages of consortium building as including reduction of costs through cost sharing and promotion of best practices. Other staffing factors revealed in the findings are discussed later in this chapter under section 7.6.2.3 of the study.

In summary, there were varying levels of planning for ERs in the institutions investigated. Cases institutions encountered operational challenges such as policy matter, inadequate funding, and 
understaffing which negatively affected planning for ERs of the library. The findings also revealed the impact of type and size of institution on the planning for ERs in the case institutions. There were notable differences between planning for ERs in public and private institutions. Budgeting for ERs for instance was affected by the type of institution. Public case institutions which operated a decentralised management structure allocated a separate budget to the library whereas private case libraries which operated under a centralised management structure did not have a separate library budget. A separate library budget provided the public case libraries a level of autonomy in budgeting for ERs unlike their private case counterparts which further challenged the operations of the library regarding ER services. Again, the size of institution impacted on staffing for ERs. Private case institutions which were smaller assigned a single professional to ERM whereas in the public case institutions, an ER unit made up of at least one professional librarian and paraprofessionals were assigned to the management of ERs. This made managing ERs more challenging in the private case institutions as ER responsibilities were basically the same irrespective of the size of institution or user population even though, in a smaller institution the load of information literacy education and user training may be less compared to their public case counterparts which had larger user population sizes. Generally, ERs were not adequately planned for in both public and private academic libraries although challenges were more pronounced in the private academic libraries.

\subsection{Implementing ERs in the Case Institutions}

Following the planning for ERs which takes into consideration policies, budgeting and staffing, the next stage is implementation of ERs. This section discusses the implementation of ERs in the case institutions in terms of ER workflow and the approach or model adopted by the case libraries.

\subsubsection{Workflow of ERs in the Case Institutions}

The workflow or lifecycle of ERs is an important component of ERM and can be a "cumbersome process" (Anbu, Kataria \& Ram (2013, p.300). This has attracted the interest of several authors (Emery \& Stone, 2013; Mackinder, 2014; Smith, 2016; Mangrum \& Pozzebon; 2012) who have broken down the ER workflow into manageable tasks for effective management. Using the TERMS framework proposed by Emery \& Stone (2013) as a lens for analysing ER workflow in the case institutions, various findings emerged. The TERMS framework (as presented in Chapter 
Three of this thesis) identifies six stages in the iterative lifecycle of ERs. These are Investigation of new content, Acquisition, Implementation, Ongoing evaluation and access, Annual review, and Cancellation and replacement review.

The findings revealed that investigation of contents in both public and private case institutions mainly considered relevance of content, cost and usage terms and conditions which paralleled the findings of a study by Kaur \& Walia (2016). Consortia purchasing based on package pricing was the main models for acquisition and pricing respectively adopted by the public and private case institutions. The findings differed from related studies (Kaur \& Walia, 2016) that revealed individual library fixed annual subscription as the main model for acquiring ERs in the cases investigated.

Regarding implementation, both public and private case libraries adopted IP based mode of authentication and access to ensure that only authorised users accessed the ERs of the library. Password-protected resources were perceived to be associated with unauthorised access. This finding compared with those of similar studies (Wadekar \& Nagarkar, 2018; Prakashe \& Tayade, 2015). A similar approach for providing access to ERs of the library was adopted by all case libraries where an A-Z list of ERs with their hyperlinks had been made available on the library homepage. Only two institutions (UG and CU) provided remote access through EZproxy, whereas UCC and WIUC libraries had not yet provided remote access to the ERs of the library. This meant that geographical location was a barrier to accessing the ERs which can negatively affect usage. It was observed that case institutions adopted various channels in marketing the ERs of the library. However, promotional or marketing activities in terms of awareness creation, training of users and staff were generally inadequate. These findings were similar to related studies (Ani et al., 2016; Kaur \& Walia, 2016; Wadekar \& Nagakar, 2018). Ongoing evaluation and access was usually conducted by obtaining annual usage statistics and informal feedback from users. In all the case institutions, contents were considered for cancellation or renewal based on level of usage, cost or budget availability.

The findings as presented generally revealed differences and similarities in the ER workflow adopted by the case libraries and these were accounted for by various factors including the size, 
type, and endowment of the institution. Firstly, staffing for ER workflow varied according to the type and size of institution. For instance, private case libraries (CU and WIUC) which were smaller assigned one professional librarian to ERM whereas public case libraries (UG and UCC) which were larger had an ER unit made up of at least one professional librarian and paraprofessionals managing the ERs of the library. This had implications on the workload of ER personnel in the case institutions resulting in heavier workload on ER staff in the private case libraries than their public case counterparts. Another difference observed in the workflow appeared to be related to how well-endowed case institutions were. The older public (UG) and private (CU) case libraries were comparatively well-established and better endowed than their younger public (UCC) and private (WIUC) case counterparts. This impacted on the ERs available in the institution and mode of acquiring ERs. For instance, UCC and WIUC libraries relied solely on consortium participation in acquiring ERs for the library whereas $\mathrm{UG}$ and $\mathrm{CU}$ adopted demand driven acquisition and made individual library subscription to other contents in addition to consortia subscription. This meant that their user community had access to a wider range of ERs compared to UCC and WIUC.

Furthermore, the type of institution determined the institutional management structure which affected ER workflow in the case institutions. For instance, in the private case institutions where management was centralised and institutional leaders solely controlled activities in the institution, individual library subscriptions were investigated and acquired by institutional leaders with little to no input from the library. For this reason, the ER workflow in the private case libraries for these contents was intercepted resulting in a lack of clarity particularly on the acquisition of these contents as this was outside the terrain of the library. The findings compare with those of Bothmann \& Holmberg (2008) who, in a similar study, revealed the interception of ER workflow in library by external parties. In the public case institutions where management was decentralised, the library oversaw the ER workflow of individual library subscriptions. This promoted clarity and enhanced the skills of ER staff in the areas of selection, negotiation and licensing of contents.

In spite of these differences, the findings revealed similarities in the workflow of ERs in the case institutions. Since consortium-based subscription was the main mode of acquisition in all four institutions, the consortium played a major role in the selection and acquisition of ERs. CARLIGH also played a major role in the capacity building of ER staff in all four case institutions, which 
accounted for some level of uniformity in the ER workflow and skills of ER staff in both private and public case libraries, small and larger case institutions, endowed and less-endowed institutions alike. For instance, CARLIGH selected and acquired contents on behalf of members for which reason the first two stages of the TERMS framework (Investigation of new content and Acquisition) were missing in the ER workflow in all case institutions for consortia subscription. This compares with the findings of similar studies such as Bothmann \& Holmberg (2008). Regarding the remaining stages of the framework (implementation, on-going evaluation and access; annual review and cancellation and replacement review), similar strategies were adopted by all case institutions which reflected the impact of capacity building of ER staff by CARLIGH.

An important component of ER workflow as highlighted in the literature is documentation (Bothmann \& Holmberg, 2008; Emery \& Stone, 2013). Documentation of ER workflow can facilitate consistency in ERM in cases where there are staffing changes. Even for existing staff, documented workflow can provide a point of reference for verification on any aspect of the workflow whenever required (Gregory, 2006). The findings as presented in Chapter Five pointed towards inadequate documentation of ER workflow in both public and private case institutions. Lack of documentation of ER workflow seemed to be linked to the organisational culture where documentation was not prioritised. Another factor accounting for poor documentation was the role of external parties in the ER workflow which made documentation a challenge and perceived as not needful. These findings differed from those of Bothmann \& Holmberg (2008) that revealed time and personnel as the hindrances to the documentation of ER workflow. However, although the documentation of ER workflow in the case institutions was not satisfactory, there appeared to be undocumented priorities that the libraries had established regarding the management of ERs.

Despite the challenges of ER workflow documentation, libraries need to take this aspect of the ER workflow seriously as it can facilitate succession planning and assist new staff in ensuring consistency and standardisation of ERM practices. Workflow documentation can also serve as a proof of justification to institutional leaders for increased staffing when assigned and unassigned responsibilities are highlighted in the documentation. According to Bothmann \& Holmberg (2008), 
documenting ER workflow can reveal tasks that are more important than others as well as those that are neglected, all aimed towards effective ERM. Another strategy is the use of an Electronic Resource Management System (ERMS) which facilitates the documentation of key information about the ER workflow. However, none of the case libraries made use of ERMS in managing their ERs. Using an ERMS was a new concept to key interviewees in all case institutions as they had little knowledge on it.

In summary, there were similarities and differences in the workflow of ERs in the case institutions. The similarities to a large extent were accounted for by the role of CARLIGH. The dynamics and differences in the ER workflow were mainly as a result of the type, size, and endowment of the institution.

\subsubsection{ERM Approach/Model Adopted by Case Libraries}

The literature has identified various approaches to facilitate ER workflow in libraries which include integrated approach, distributed approach, team approach and a single person approach (Abrams, 2015; England \& Shipp, 2013; Higa et al., 2005; Hsiung 2008; Stachokas, 2009). Table 7.1 provides an overview of the ERM approaches adopted by the case libraries based on the findings.

Table 7. 1: An Overview of the ERM Approaches Adopted by the Case Libraries

\begin{tabular}{lll}
\hline Type of Academic Library & \multicolumn{1}{c}{ Fundamental Approach } & Practical Approach \\
\hline Public & $\begin{array}{l}\text { Public case institutions which Operational challenges } \\
\text { were larger, adopted an integrated including inadequate } \\
\text { approach whereby an ER staffing and the evolving } \\
\text { unit/department made up of at ER workflow led to the } \\
\text { least one professional librarian adoption of a distributed } \\
\text { and paraprofessionals managed approach whereby ER } \\
\text { the ERs of the library. }\end{array}$ \\
& $\begin{array}{l}\text { duties were assigned to } \\
\text { staff of other units. }\end{array}$ \\
Private case institutions were Understaffing and the \\
smaller and one professional evolving nature of ER \\
librarian was assigned to manage workflow resulted in the \\
the ERs of the library.
\end{tabular}


Findings from both public and private case libraries revealed that the ERM approach adopted was on two levels namely fundamental and practical approaches. The findings as presented in Chapter Five showed that, the type and size of institution affected fundamental ERM approach adopted by the case libraries. Public case libraries which were larger, had established an ER unit/department made up of at least one professional librarian and paraprofessionals to manage the ERs of the library. On the contrary, private case libraries which were smaller assigned the management of ERs to one professional librarian.

However, operational challenges such as inadequate staffing coupled with the evolving nature of ER workflow provided an impetus for a practical approach in the selected cases. Both public and private case libraries adopted a distributed approach and assigned aspects of the ER workflow to staff of other units in the library. Collaboration with staff from other units of the library was therefore a theme that emerged from the findings from all case institutions, supporting the findings of related studies (Abrams, 2015; Chamberlain \& Reece, 2014; Shu, 2012; West \& Millar, 2011) which revealed the distributed approach as the current trend. This trend is becoming prevalent irrespective of the existence of ER units in libraries (Abrams, 2015; England \& Shipp, 2013; Hsiung, 2008).

However, the findings as presented in Chapter Five revealed that this approach posed a challenge to ERM in both public and private case institutions. The challenge revolved around communication between the head of ERs/ER unit and staff of other units of the library who played an ER-related role which resulted in misunderstandings. Despite this challenge, the approach appeared to be a solution for ER staffing challenges. Researchers (Chamberlain \& Reece, 2014; Collins, 2009; Hsiung, 2008; Shu, 2012) have advised that, for this approach to be successful, effective communication among stakeholders is paramount to avoid chaos. 


\subsection{A Review of the TERMS Framework}

One of the aims of the study was to apply the TERMS framework to a developing country context to reveal the extent to which ERM practices in academic libraries complied with the framework. This section presents a revised TERMS framework by revisiting the initial framework and discussing the changes based on findings from the analysis.

\subsubsection{Mapping the TERMS Framework Components to the Findings}

The study identified the stages of ER workflow after iterative processes of reading, sorting, comparing and clustering insights obtained from the interviews. The next action was mapping the main ideas in the findings with elements of the TERMS framework. The aim of aligning the TERMS framework to the findings was not to limit the data obtained but to provide a theoretical approach to facilitate the analysis of data and discussion. There are several key changes between the initial framework and the final framework. These changes are explained in terms of the components of TERMS, stakeholders or parties responsible for the various stages of TERMS, and interactions within the stages of the framework.

Findings as presented in Chapter Five indicated that, although efforts were being made to follow standard procedures, some components of the stages of TERMS were lacking in the ER workflow in the institutions investigated. For example, regarding Stage One (Investigation of new content), focusing on exact need, documenting specifications, building a team of experts, and conducting overlap analysis were not reflected in the data analysis. For Stage Two (Acquisition), documenting administrative metadata was not reflected in the findings. For Stage Four (Ongoing Evaluation and Access), the findings obtained did not reveal documentation of evaluation results. For Stage Five (Review), review of access queries, coverage changes and conducting overlap analysis were not indicated in the findings. For Stage Six (Cancellation/Replacement Review), final decisions were not documented per the findings obtained from the case studies. Components of the TERMS framework are mapped to the findings and presented in Figure 7.1. 


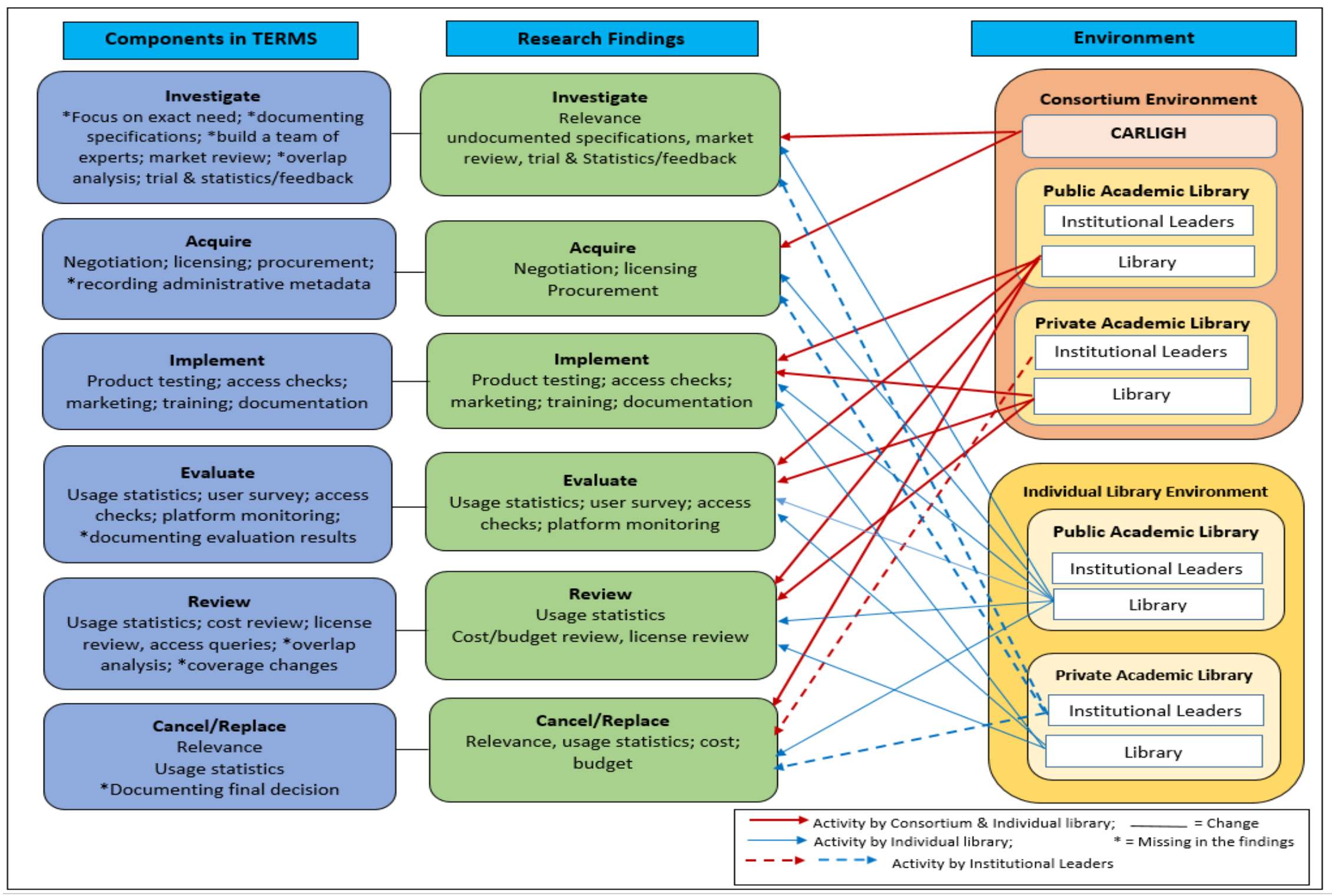

Figure 7. 1. Matching TERMS framework components to the findings 
Also, the findings as earlier discussed in Section 7.3.1 revealed that some aspects of ER workflow and, for that matter, TERMS framework were missing in the case libraries as these were carried out by parties external to the library. For example, in a consortium environment, the first two stages of TERMS (Investigation of new content and Acquisition) were mainly carried out by CARLIGH. For this reason, case institutions such as UCC and WIUC that solely depended on consortium subscription as the mode of acquiring ERs actively began their ER workflow from the third stage (Implementation) of TERMS.

Again, in an individual library subscription environment, the type of institution determined the span of control of the library over the ER workflow. For instance, for public case institutions, which had a decentralised management structure, the library spearheaded the acquisition of individual library contents, as pertained at the Balme Library (UG). On the other hand, private case institutional leaders spearheaded the acquisition of individual institutional contents with no input from the library, as pertained at CU library. Furthermore, institutional leaders spearheaded renewal/cancellation decisions. The interception by parties external to the library had repercussions on clarity of ER workflow among library staff which also contributed to lack of documentation. Case institutions which solely depended on consortia subscription or belonged to the private sector were missing two to three stages of the TERMS framework. For this reason, they had little clarity on the components of those stages which could negatively affect the management of these resources. Figure 7.1 also depicts responsible parties for the various stages of the TERMS framework in a consortium environment, and individual library environment in both public and private institutions.

Finally, the findings revealed that, beyond the logical flow assumed by the TERMS framework from stage One (Investigation) to stage Six (Cancellation and Replacement Review), there were backflows and interactions between various stages of the framework. Different stages of the framework affected each other not necessarily in a logical flow from one stage to the next. These are explained in the sub-section A Revised TERMS Framework. 


\subsubsection{A Revised TERMS Framework}

From the findings, a revised TERMS framework was developed. As earlier mentioned, the findings revealed bi-directional relationships between some of the stages of the framework and interactions between different stages of TERMS. Figure 7.2 presents the interactions and backflows within the various stages of the framework. Arrows have been used to identify these interactions. Solid unidirectional arrows have been used to depict the flow of interaction in the initial framework whereas dashed unidirectional and bidirectional arrows have been used to depict the new findings. 


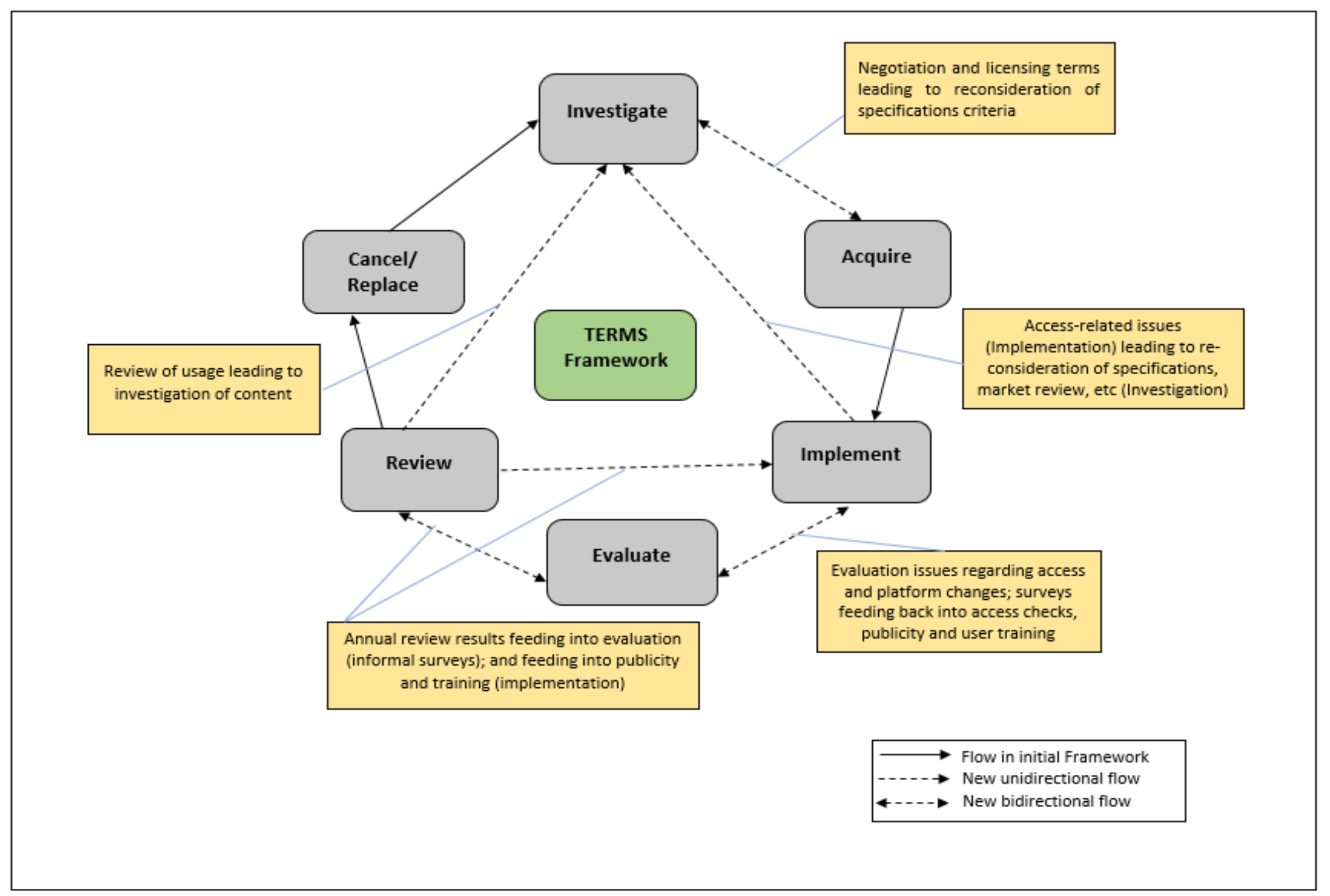

Figure 7. 2. Revised TERMS framework based on the findings 
As depicted in Figure 7.2, there was a bi-directional relationship between Investigation and Acquisition stages. For instance, after investigation of contents, the next stage is to acquire contents. Findings revealed that negotiations and licensing terms at this second stage sometimes fed back into the investigation stage where factors such as selection or specification criteria, albeit undocumented, were re-considered. Again, the findings established a bi-directional relationship between the Implementation and Evaluation stages. After Implementation which comprises access provision, publicity, training and documentation, the next stage is Ongoing evaluation. However, after on-going evaluation, issues regarding access, platform changes, survey outcomes and usage fed back into the Implementation stage where various tests and access checks were carried out. Evaluation outcomes also fed back into publicity and training efforts of the library where necessary.

The findings further revealed interactions between different stages of the TERMs framework without following the logical flow the framework depicts. There were interactions between the Review and Implementation stages; Review and Investigation stages; and Implementation and Investigation stages. It turned out that annual review results informed publicity and training programmes. For instance, both public and private case libraries indicated that, at the end of the year, subscriptions to contents that recorded low usage statistics were not outrightly cancelled, but these contents were promoted through increased publicity and training which are components of the Implementation stage. Usage levels were reviewed after a period and Cancellation/Replacement decisions were then made. This illustrates that from stage five (Review), the workflow went back to stage Three (Implementation) before moving on to the final stage Six (Cancellation/Replacement). There was also interaction between the Review and Investigation stages. For example, results on usage of ER contents following a review fed back into the Investigation stage where informal surveys were conducted to obtain feedback from users regarding relevance. Also, Implementation stage interacted with the Investigation stage. For instance, Implementation outcomes involving access-related issues led to a referral to the Investigation stage where specifications were re-considered, or the market reviewed for alternative contents. 
This sub-section has explained how the different stages of the TERMS framework interact with each other in an iterative manner. The findings revealed that, the workflow of ERs was not a smooth logical flow from one stage to another as TERMS supposes or prescribes. The crossconnections and bi-directional flows between the different stages of the revised framework show how the various stages of TERMS can interact and make input in other stages to serve as a basis for informed decision making throughout the ER workflow. These changes are likely to bring clarity to the ER workflow and assist novice ER staff towards a more effective management of ERs. In addition, it will promote consistency and standardisation of ERM practices in libraries. These new findings are therefore a refinement of the original TERMS framework.

\subsection{Usage of ERs in Academic Libraries}

Academic libraries exist to create a learning environment for the academic community by providing a variety of library resources and ultimately, training them to become competent users (Korobili et al., 2006). Developing and sustaining ERs/services require huge financial resources. For this reason, academic libraries are required by their institution to justify financial investments through ensuring maximum usage of these resources (Taylor \& Heath, 2012). This section discusses the usage of ERs in relation to awareness, usage, perception and behaviour of respondents towards the ERs of the library based on the findings.

\subsubsection{Awareness of ERs}

Awareness of ERs is crucial in promoting the usage of ERs. The findings as presented in Chapter Six revealed that faculty in both public and private institutions were generally more aware of the ERs of the library than postgraduate students. The results reflected the focus of awareness creation efforts by the library and were consistent with the findings obtained from the interviews, which revealed that publicity of ERs of the library were more tailored towards faculty than postgraduate students. Case libraries adopted this approach so that faculty would become ambassadors of the ERs of the library by encouraging usage among students. However, unequal promotional efforts among the various groups of users could have contributed to the observed low usage of these resources by postgraduate students. In the case of lack of interest among faculty, there would be unwillingness to promote ERs of the library to students. The findings as presented in Chapter Six also indicated a comparatively higher awareness of ERs of the library among postgraduate students 
in the public case institutions than their private counterparts. This shows a probable variation in the awareness creation efforts of libraries in the public and private institutions.

Various channels of awareness creation as indicated in the literature can be adopted in promoting the ERs of the library. As presented in the survey findings, 'colleagues' was the dominant channel of awareness of the ERs among both faculty and postgraduate students in the public and private institutions. This showed the role of users in facilitating the implementation of ERs of the library through awareness creation among their peers making up for the inadequate promotional efforts of the library. This finding could explain the varying levels of awareness of the various ERs of the library, as users could only promote the ERs/services that they were aware of. For instance, online databases and e-journals were the most popular among both faculty and postgraduate students whereas other types of ERs/services such as the Institutional Repository (IR) were less popular. The findings paralleled those of related studies (Bassi \& Camble, 2011; Deans \& Durrant, 2016; Madhusudhan, 2010) which revealed colleagues and friends as the most popular modes of awareness of ERs of the library. These findings however varied from other studies that revealed other channels of awareness creation such as library website and library orientation (Ankrah \& Atuase, 2018).

Generally, awareness of ERs and promotional efforts by case libraries in both public and private institutions left much to be desired. Lack of awareness has negative effects on the usage of ERs as it is almost impossible for users to make use of what they are unaware of. Lack of awareness particularly among postgraduate students as indicated in the survey findings was supported by the interview findings, which unveiled the repercussions of lack of awareness of the ERs on the quality of students' academic performance. Lack of awareness of ERs appear to be a peculiar challenge for academic libraries in developing countries as highlighted in various studies (Ani et al., 2016; Chauhan \& Mahajan, 2014; Dadzie \& Walt, 2015; Damilola, 2013; Das \& Achary, 2014). The importance of awareness creation of services cannot be overemphasised and should therefore form an important component of the implementation of ERs in libraries (Emery \& Stone, 2013; Hosburgh, 2014). 


\subsubsection{Level of Usage of the ERs of the Library}

Academic institutions invest a great deal in ERs which are necessary for teaching, research, and learning. Faculty and students are privileged to have access to the ERs of their library at no direct subscription cost to them. They are thus expected to make maximum use of these resources. It is therefore appropriate that these ERs are used by faculty and students to obtain value for financial investments, and contribute to the achievements of academics (Kwadzo, 2015). Data obtained from the surveys revealed varying levels of usage of ERs of the library. Usage of ERs of the library was generally higher among faculty than postgraduate students in all case institutions. This may have been accounted for by the teaching and research responsibilities of faculty for which reason ERs were more relevant to them than students. Among postgraduate students, usage was comparatively higher in the public case institutions than the private case institutions. This may have been as a result of the differences in infrastructural developments with the private case institutions being more challenged than their public case counterparts as revealed in the surveys and interviews. Generally, usage of ERs of the library was low as depicted in the findings from both library staff and users. Low usage of ERs of the library has been pointed out by similar studies (Ani et al., 2016; Deans \& Durrant, 2016; Dadzie \& Walt, 2015; Ukachi, 2015).

For libraries to assess the relevance of its ERs, it is crucial to determine the kinds of ERs used by users and the amount of time they spend in using them. Findings as presented in Chapter Six revealed that online databases and e-journals were the most widely used ERs in the case institutions. These findings are expected since online databases and e-journals had higher awareness levels among respondents which may have translated into corresponding usage levels. It is worth noting that although a higher percentage of faculty than postgraduate students in the public and private case institutions used the ERs of the library, the postgraduate students tended to spend more time in accessing the ERs of the library than faculty. It could mean that faculty were better equipped with skills for searching these resources which made them spend less time in accessing and retrieving relevant information whereas the postgraduate students required more time to maneuver their way around the ERs of the library.

It is also important for libraries to ascertain the location or device from which users mostly access ERs of the library to appreciate the challenges they may encounter while using these resources. 
Findings revealed that faculty and students mostly accessed the ERs from their offices and the library respectively. Considering inadequate infrastructure in the library/institution as revealed in the surveys and interviews particularly in the private case institutions, this is likely to hinder the usage of these resources by students thereby contributing to the observed low usage. Interestingly, mobile phones as a device for accessing ERs of the library appeared to be gaining popularity among postgraduate students unlike faculty. Academic libraries could take advantage of this alternative and promote accessing ERs of the library via mobile devices to complement the library's limited number of computers. For instance, mobile applications can be developed for users to download onto their mobile devices to provide quick and easy access to ERs of the library. The findings differed from related studies that revealed off-campus access (Thomas et al., 2012) and department (Chauhan \& Mahajan, 2014) as the main location for accessing ERs of the library.

Information search strategies adopted by users can also suggest the relevance and perception or value users place on ERs of the library. As presented in the data analysis, the first port of call for most faculty and postgraduate students in accessing information were alternative sources of information on the Internet. Reasons provided for this choice included high recall of search outputs, quick access, and ease of access. Most respondents perceived ERs of the library as not easy to use and not providing adequate search results. These responses suggested inadequate searching skills caused by inadequate user training, and inadequate user needs analysis by the library which may have contributed to the observed low usage of ERs of the library. The findings were similar to those of Dukic \& Striskovic (2015), Das \& Achary (2014), Bhat \& Mudhol (2014), Bassi \& Camble (2011) which showed that alternative resources on the Internet were the respondents' first port of call in accessing information. It however differed from the findings of other related studies that indicated the library's ERs (Madhusudhan, 2010; Liu, 2006) and print resources (Zha et al., 2012) as the first point of accessing information. In the study conducted by Liu (2006) for example, respondents perceived ERs of the library to be easy to use and convenient to access.

Training users to be able to access and use the ERs of the library is an important aspect of implementing ERs, as some contents may have less intuitive user interfaces. The data analysis also showed a generally low participation of faculty and postgraduate students in training on ERs 
of the library in all case institutions. This complements the interview findings, which revealed infrequent training sessions for users at UCC, CU and WIUC, and the low turnout to ER training sessions in all case institutions. With the low participation in ER training, it is therefore not surprising that the most popular technique adopted by faculty and postgraduate respondents in using ERs of the library was 'trial and error' in both public and private institutions. This was similar to the findings of related studies such as Wu \& Chen (2012). 'Trial and error' as a technique for access can have implications on the motivation of faculty and postgraduate students to access and use the ERs of the library which could have contributed to the observed low usage of the ERs.

Views of users on the training organised by the library was sought, and faculty and postgraduate respondents perceived the training as not adequately equipping users with the skills needed for searching the ERs of the library. Moreover, unsuitable training time and lack of awareness of training programmes were indicated. This pointed towards failure of the library to conduct adequate user needs analysis to know the kind of training required by users, and inadequate publicity of training sessions which in the long run could have repercussions on the usage of the ERs. Other challenges of accessing and using ERs of the library were indicated which are discussed under section 7.6 of this chapter.

The results show that, faculty and postgraduate students required quicker, more convenient, and easier ways of accessing information for their academic endeavours. Alternative resources available on the web that appear more sophisticated and yet user friendly are slowly breaking the monopoly of academic libraries as the sole source of scholarly information (Jacobs, 2007). These rival resources provide users with a benchmark for comparing and assessing ERs of the library. For this reason, a change in the practices of libraries to encourage users to make use of the ERs of the library is of paramount significance if they are to survive in this competitive technological environment (Lewis, 2007; Sorensen \& Sarjeant-Jenkins, 2016).

\subsubsection{Perception and Behaviour Towards ERs of the library}

The literature has highlighted the role of perception in the acceptance of technology or ERs by users (Dukic \& Striskovic, 2015; Ukachi, 2015; Venkatesh et al., 2003). Perception of ERs refers to the way in which users regard, understand and use ERs (Dukic \& Striskovic, 2015). Perception 
influences the behaviour of users towards the ERs of the library: positive perception about these resources will likely foster high usage (Buchana et al., 2013; Egberongbe, 2011) whereas negative perception hampers usage (Dzandu \& Boateng, 2013; Ukachi, 2015).

There were similarities and differences in the perception and behaviour of faculty and postgraduate students towards the ERs of the library as revealed in the survey findings. Both faculty and postgraduate students used alternative sources of information available on the Internet more than the ERs of the library although they perceived themselves as possessing the necessary skills to use ERs of the library. It was deduced from the survey findings that faculty and postgraduate students perceived the ERs of the library as not more useful than other freely available resources on the web. In addition, they considered using ERs of the library as prolonging information search compared to alternative resources online that provided quick and convenient access to information. These findings pointed towards inadequate promotion of ERs of the library as supported by findings from interviews with library staff. This contributed to the observed low usage of ERs of the library and showed the reason why respondents relied heavily on alternative online resources as first port of call when searching for information. Many interviewees perceived the need for increased promotion to encourage maximum use of ERs of the library.

There were also differences between the perception of faculty and postgraduate students towards the ERs of the library. Whereas faculty respondents believed their academic outputs had improved as a result of using the ERs of the library, postgraduate students who used the ERs did not perceive as much improvement in their academic performance. In addition, faculty were more satisfied with the ERs of the library than the postgraduate students. Comparatively, more faculty than postgraduate students perceived using ERs of the library as reducing information search time. This may have been accounted for by the fact that more faculty than postgraduate students had participated in ER training organised by the library and/or were therefore better equipped with skills for searching the ERs. Also, teaching and research responsibilities could have explained why usage of the ERs of the library was higher among faculty than postgraduate students in both public and private case institutions. 
Generally, the survey findings revealed negative perception of faculty and postgraduate students on the ERs of the library, which contributed to the observed low usage of these resources. Users' perception and expectations of libraries are constantly changing due to the availability of rival resources on the web (Liu, 2006). For this reason, academic libraries need to make every effort to discover users' perceptions/misperceptions on the ERs of the library and put in place measures to promote increased usage.

\subsection{Factors Affecting the Management and Usage of ERs}

This section discusses the factors identified in Chapters Five and Six as surrounding the management and usage of ERs of the library. The study identified three main factors as affecting the management and usage of ERs in the case institutions which are governmental, organisational and individual factors. Considering that a factor can be an enabler or a barrier, these factors are presented as such based on their impact on ERM and usage.

\subsubsection{Governmental Factors as Hindrances}

Analysis of the interview findings revealed that policies and regulations by the Ghanaian government had a considerable impact on ER services in the case institutions. These policies and regulations were found to be hindering the management of ERs in the areas of staffing and funding, and usage of the ERs. Figure 7.3 presents a summary of governmental factors as hinderances to ERM and ER usage. 


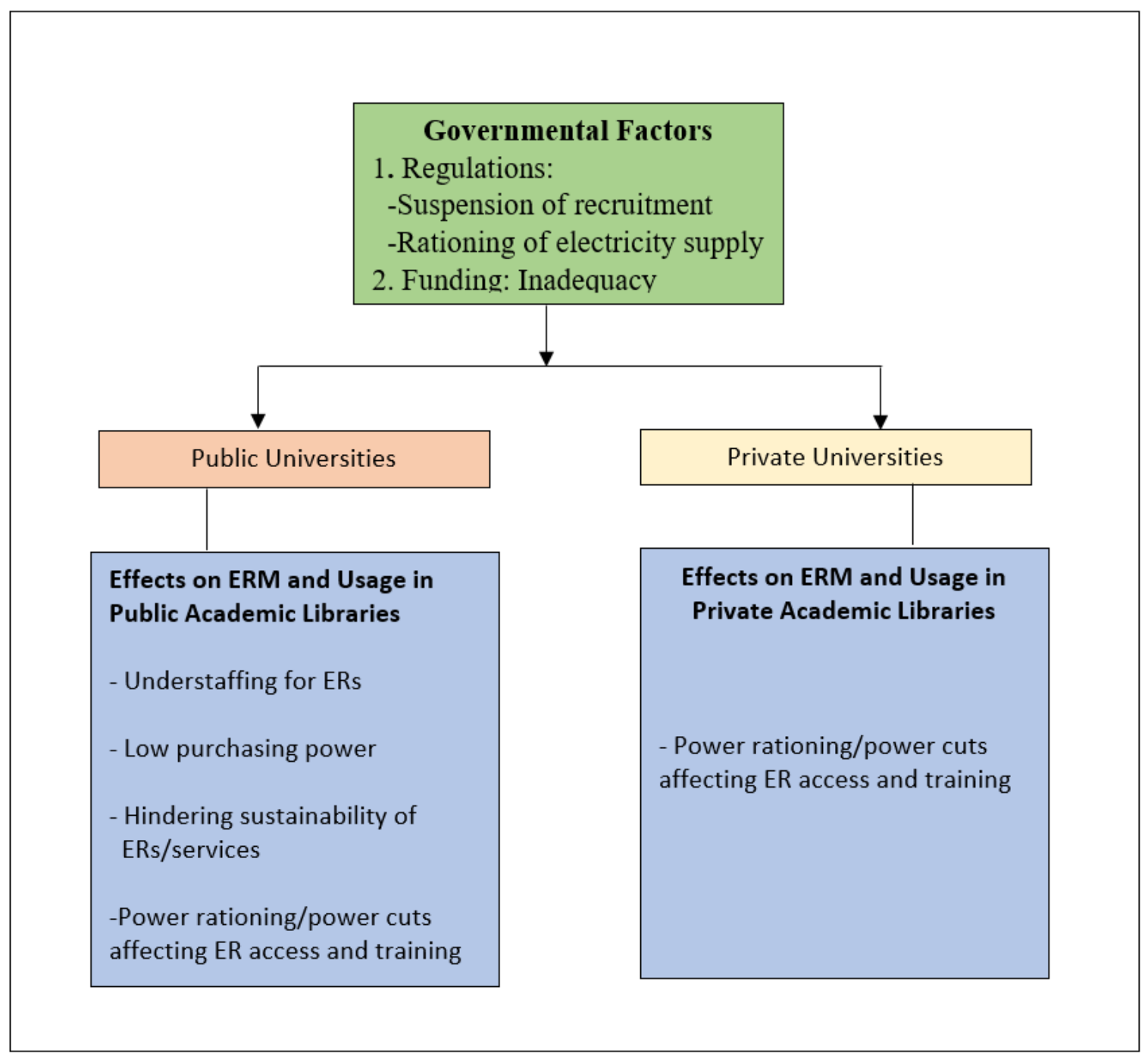

Figure 7. 3. Government factors as hindrances to ERM and ER usage

The Ghanaian government like any other government has the power to influence most aspects of society. Institutions, particularly those in the public sector, are bound by government regulations. Employment in the public sector for instance is controlled by the government. Contrary to the assertion made by Fullan (2007) in examining the role of government in educational change that governmental activities encouraged continuous advancements in education, government regulations as revealed in the findings appeared to have hindered the management and usage of ERs. For example, in Chapter Five, the findings showed that recruitment of employees in the public case institutions had been suspended following a directive from the government in its effort to 
manage public wage bill. This form of control by the government negatively affected staffing for ERs in the public case libraries. UG and UCC libraries were consequently understaffed for which reason the few available staff were compelled to take on extra duties and work extra hours to make up for the low staff strength. This could have debilitating effects on staff productivity as existing staff may be easily overwhelmed by additional duties.

In addition, limited funding from government to the case institutions was a hindering factor to the management of ERs. Ghana government through budgetary allocation to parent institutions, funds public academic libraries. As part of the budgetary policy, $10 \%$ of government subvention to public universities is allocated to the library. However, the findings revealed that funding provided by government to the public institutions was inadequate. Cuts to university budgets coupled with high inflation rate served as a major financial challenge for public academic libraries. This lowered the purchasing power of academic libraries and consequently, acquisition and sustainability of ERs. Both public academic libraries received less than the stipulated $10 \%$ of institutional budget and key interviewees from UG and UCC expressed how inadequate library funding hindered the acquisition and sustainability of ERs of the library.

Another governmental factor revealed in the interview and survey findings as affecting the management and usage of ERs was power rationing which resulted in frequent power cuts. Ghana had been experiencing a persistent irregular and sometimes unpredictable power outage popularly referred to as "dumsor" (“off-and-on” of electricity supply) (Ghana Web, 2018). In the early 2019, the country experienced an unexpected and more intense power rationing with led to the coining of the term "dumsaa" ("indefinite off" of electricity supply) which is superior to "dumsor". Access to ERs is fundamentally facilitated by electricity supply. For this reason, frequent power cuts made access to ERs of the library and training sessions organised by the library not feasible.

In summary, governmental factors hindered the availability of human and non-human resources required for effective ERM and ER usage in the case institutions. 


\subsubsection{Organisational Factors}

The findings as presented in Chapters Five and Six revealed several factors as enabling or hindering ER services in the case institutions. Organisational factors mainly revolved around systems (organisational structures), logistics and activities in the organisation that had positive and negative impact on ERM and ER usage. These factors include collaboration among stakeholders, policy development for ERs, staffing for ERs, availability of resources, plans and investment for sustainability, institutional management structure, institutional commitment, communication, and usage of ERs. These factors are depicted in Figure 7.4.

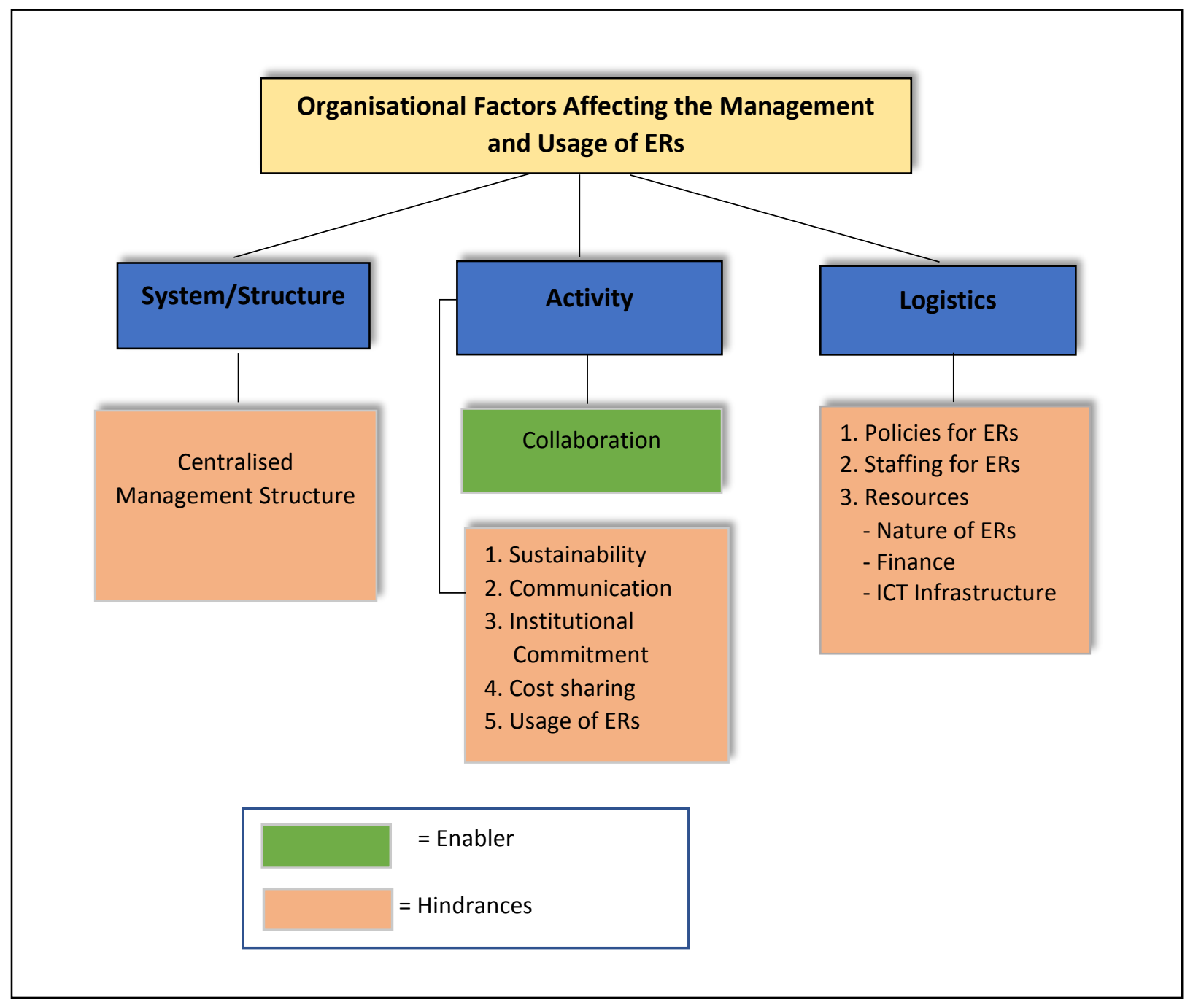

Figure 7. 4. Organisational factors affecting the management and usage of ERs 


\subsubsection{Collaboration with Stakeholders as an Enabler}

Analysis of the interview findings as presented in Chapter Five indicated that collaboration among stakeholders led to positive outcomes which facilitated ERM in the case institutions. Internal collaboration between the ER unit and other units of the library in carrying out ER duties served as a partial solution to the staffing challenges that case institutions faced. For example, heads of other units carried out ER related duties such as information literacy education, access checks and correspondence with publishers and providers, which eased the burden on understaffed ER units in both public and private case libraries, while enhancing ER services. The findings also revealed a collaboration although minimal, between staff of ERs unit and the user community in promoting ERs, and scheduling ER training which led to a relatively increased attendance to training and usage of ERs. For instance, UG, CU and WIUC libraries encouraged faculty to create awareness of ERs among students.

\subsection{The Role of CARLIGH as a Consortium}

The findings also revealed collaboration at the national level through consortium participation, which facilitated ERM in both public and private case institutions particularly in the areas of acquisition and sustainability of ERs, capacity building and advocacy. Through collaboration, case libraries were able to combine resources and share the cost of subscription to ERs and obtain discounted pricing through the negotiation efforts of CARLIGH. In addition, CARLIGH was able to collaborate with international bodies such as International Network for the Availability of Scientific Publications (INASP) and Electronic Information for Libraries (EIFL) to obtain funding for the consortium and other free resources for members. For example, case libraries had access to Research4Life databases at no direct cost but by virtue of being members of CARLIGH. Joining the consortium eased the financial burden on the institutions and promoted efficient use of limited budget. Collaboration among case libraries through CARLIGH also provided a level of uniformity

in capacity building of ER staff in both the endowed and less endowed case libraries as CARLIGH provided frequent "training of trainers" sessions. Again, the findings as presented in Chapter Five revealed the advocacy role played by CARLIGH to assist members in obtaining institutional support. For instance, in the case where institutional leaders, particularly in the private case libraries, were reluctant to release funding for ERs, CARLIGH executives met with these leaders to advocate on behalf of the library. Generally, collaboration among stakeholders influenced the 
management and usage of ERs in the case institutions and this should be deepened for more positive outcomes.

With the increased demands of the technological environment, collaboration becomes crucial for the survival of libraries (Hsiung, 2008). Other authors (Delaney \& Bates, 2015; Massis, 2016) have stressed the need for academic libraries to adopt collaborative ways in their service delivery to remain relevant to stakeholders. Generally, the findings revealed internal collaboration within the library, collaboration within the institution, and external collaboration as influencing ERM and ER usage in the case institutions.

\subsubsection{Lack of Policies for ERs as a Hindrances}

Collection development policies (CDPs) for ERs play a critical role for its effective management as highlighted by several authors (Johnson, 2009; Mangrum \& Pozzebon, 2012). Findings from the interviews and as discussed in Section 7.2.1 of this chapter revealed the lack of/inadequate policies for ERs which supported various viewpoints in the literature indicating that policies for ERs had not received the necessary attention (Dadzie \& Walt, 2015; Kaur \& Walia, 2016; Pickett et al., 2011). For instance, data obtained from the Balme Library (UG) indicated no policies for ERs whereas at UCC, CU and WIUC libraries, policies for ERs embedded in the CDPs of the library were missing vital components on internal management of ERs. Lack of/inadequate policies for ERs can lead to inconsistencies in ERM practices in the case institutions as staff did not have well documented frames of reference. This also contributed to lack of clarity on ER workflow as revealed in Chapter Five. For instance, some of the interview questions were not adequately addressed by interviewees due to lack of clarity on the workflow of ERs. Lack of policies for the ERs of library therefore served as a hindrance to the management of ERs in both public and private case institutions. The need for well-documented ER policies has been identified as the initial step in planning for ERs and it ensures consistency in ER procedures (Johnson et al., 2012). It is therefore necessary for academic libraries in Ghana to develop well-documented policies for effective management of ERs of the library. 


\subsubsection{Staffing Challenges as a Hindrance to ERM}

Staffing greatly affects the success of the management of ERs in libraries (Abrams, 2015). The literature has pointed out that staffing in libraries has not kept up with ER responsibilities (Abrams, 2015; Adzobu, 2014; Duranceau, 2002; Elguindi \& Schmidt, 2012). Analysis revealed various staffing challenges as obstacles to ERM in the case institutions. Challenges included low staff strength, inadequate skills, lack of clarity on ERM and staff motivation.

Bothmann \& Holmberg (2008) have argued that, inefficiencies surrounding ERM are mainly as a result of understaffing. As earlier discussed under section 7.2.3, the interview findings revealed inadequate staffing as negatively affecting the management of ERs in both public and private case institutions. Staff recruitment had been suspended in the public and private case institutions following directives by the government and institutional leaders respectively. Low staff strength increased the workload and responsibilities of ER staff. In addition, case libraries were only able to implement ERs and services that the few available staff could support. However, various strategies were adopted by the public and private case institutions as a coping mechanism which included prioritisation of ER tasks, distribution of duties to heads of other units of the library.

Acquiring new skills beyond those required in a traditional library setting is paramount in managing ERs effectively. Lack of skilled personnel has been indicated in the literature as a major obstacle to the management of ERs in libraries (Duranceau, 2002; Bothmann \& Holmberg, 2008; Kaur \& Walia, 2016). Findings as analysed in Chapter Five revealed lack of ICT and ERM skills among ER staff in the case institutions. Various factors were perceived by interviewees as contributing to lack of skills among ER staff, which included lack of training. Interview findings from both public and private case institutions revealed that not all ER staff had training opportunities. Furthermore, ER staff who participated in the "training of trainers" sessions organised by CARLIGH did not impact the knowledge and skills acquired to others. For this reason, there was no flow-on effect to other library staff. In addition, gaps in LIS education in Ghana was perceived as contributing to inadequate skills of library staff. The emphasis on traditional information management in the LIS curriculum in Ghana was perceived to produce graduates who were not well-equipped for the dynamics of the technological environment. These graduates when absorbed into the library profession without adequate training were unable to 
perform effectively on the job due to lack of ICT skills and this negatively affected staff productivity. Another contributing factor was the role of external parties in the workflow of ERs. For instance, interviewees opined that CARLIGH spearheading the selection and acquisition aspects of the workflow contributed to a lack of clarity on the ERM process. This re-echoed the views of Bothmann \& Holmberg (2008) who argued that the role of external parties in ER workflow contribute to a lack of clarity on ERM and workflow documentation challenges.

Another staffing issue revolved around motivation. Interviewees perceived lack of incentives as not motivating ER staff in carrying out tasks and duties. It appeared certain aspects of the ER workflow such as user training were considered as extra duties not fundamental to the ER workflow. For this reason, staff who carried out these duties expected to receive incentives in addition to regular salary. This could lower the commitment level and job satisfaction of ER staff and consequently impact on productivity in terms of managing the ERs. Granted that providing incentives to staff can boost their morale. However, the findings pointed towards inadequate understanding on ER responsibilities and lack of clarity on ER workflow since training provision forms an important component of implementing ERs. Other contributing factors of low staff motivation as revealed by interviewees were poor communication between the ER unit and other units of the library, and lack training as earlier discussed.

\subsubsection{Resource-related Factors as Hindrances}

The literature has highlighted the availability of both human and non-human resources as one of the main factors affecting the management and usage of ERs. These resources include ERs, financial resources, and ICT infrastructure. Analysis of the interview and survey findings found inadequate resources and other resource-related factors as hindering the management and usage of ERs.

\subsection{Technical Complexities of ERs as a Hindrance}

A major factor surrounding ERM as indicated in the literature stems from the nature of ERs. ERs are associated with various complexities and technicalities such as rapid growth, and different packages from various vendors and publishers all of which make managing these resources fundamentally a challenge (Anku, Kataria \& Ram, 2013; Elguindi \& Schmidt, 2012; Jacobs, 
2007). Interviewees perceived the technical nature of ERs as a hindrance to ERM. For example, the unstable nature of ERs, which manifested in URL changes and IP authentication issues impeded ER access and usage. Also, due to the volatile nature of ERs, contents on CDs could not be accessed and uploaded onto the IR. Another challenge as presented in the findings had to do with the content of ERs. Subscription based ERs mostly came in the form of a package for which reason case libraries had no option than to accept both relevant and irrelevant contents of the package. This demotivated users and ultimately contributed to the low usage of ERs of the library. The findings compared favourably with related studies which revealed technical challenges associated with ERs (Abrams, 2015; Bothmann \& Holmberg, 2008; Dadzie \& Walt, 2015; Erb \& Erb, 2015; Ugwu \& Onyegyiri, 2014) and lack of relevant ER content (Madhusudhan, 2010; Wu \& Chen, 2012).

\subsection{Inadequate Financial Resources as a Hindrance to ERM}

Sufficient funding is required to adequately satisfy user information needs and sustain library services if libraries are to remain relevant in this technological environment (Dadzie \& Walt, 2015). The findings revealed that all four case libraries received internal funding from their institution, which was largely inadequate. Inadequate funding as earlier discussed (see section 7.2.2), and rising costs of ERs served as an obstacle to the management of ERs in the case libraries. Institutional leaders requested for usage statistics of ERs of the library as a proof of relevance to justify financial investments, which resulted in library budget cuts in the case where usage of the ERs was low. This consequently lowered the purchasing power of the library hindering the acquisition and sustainability of ERs and services. The findings paralleled those of similar studies (Bothmann \& Holmberg, 2008; Kaur \& Walia, 2016). That notwithstanding, public and private case institutions adopted some measures to curb inadequate finance, which included joining the consortium, cancellation and replacement of contents on low demand, and requesting for more funding from institutional leaders.

\subsection{Inadequate ICT Infrastructure as a Hindrance to ERM}

The availability of ICT infrastructure such as computers and network connectivity play a major role in the management and usage of ERs as indicated in the literature (Damilola, 2013; Das \& Achary, 2014; Prakashe \& Tayade, 2015). A common theme that emerged from the interview and 
survey findings as analysed in Chapter Five was inadequate infrastructure. Both public and private case institutions had ICT infrastructural challenges which hindered the management and usage of ERs in the case institutions. These challenges included inadequate computers, lack of training facilities, poor Internet connectivity and frequent power cuts which served as obstacles to ER training sessions organised by the library and usage of the resources. The findings were similar to other studies (Ani et al., 2016; Deans \& Durrant, 2016; Dukic \& Striskovic, 2015; Kaur \& Walia, 2016). Inadequate computers and Internet interruptions however appeared more pronounced in the private case libraries than the public case libraries. This may be attributed to the fact that private case institutions did not receive funding from the government unlike their public case counterparts and therefore, had more constraints in acquiring adequate computers and bandwidth to facilitate the exploitation of ERs of the library.

ICT infrastructure largely determines the quality of ER services. For this reason, it is important that academic institutions find alternative sources of funding, and prioritise investment in ICT infrastructure which would encourage maximum usage of these resources.

Section 7.6.2.4 has looked at resource-related factors (ERs, finance, and infrastructure) affecting the management and usage of ERs in the case institutions. Generally, the findings revealed that both public and private case institutions were challenged with inadequate human and non-human resources. Resource-related constraints generally appear to be a major issue in developing countries where academic institutions are challenged with budgetary constraints, high cost of ICT facilities, inadequate ICT skills and unstable power supply (Ani et al., 2016; Deans \& Durrant, 2016; Dukic \& Striskovic, 2015; Ukachi, 2015; Thompson \& Pwadura, 2014).

\subsubsection{Lack of Investment for Sustainability as a Hindrance}

Providing adequate ER services entails investment for sustainability particularly in the areas of funding, capacity building and infrastructure. Findings from the interviews and surveys provided evidence to indicate that case institutions were not able to adequately maintain and sustain ERs and services which contributed to the observed low usage of ERs of the library. There were issues related to maintaining the system that provided both on and off-campus access to the ERs of the library. For instance, at CU, the library had experienced Internet interruption which lasted for over 
a month and hindered ER usage and training sessions. At the Balme Library (UG), technical challenges led to the suspension of content upload onto the IR for over a year. Similarly, at UCC, access to the IR was interrupted for over a month due to technical challenges. There were also cases of deteriorating and inaccessible CD contents, which hindered the development of IR.

Various factors appeared to have accounted for the challenge of maintaining and sustaining ER services in the case institutions. For example, UCC, CU and WIUC libraries did not have adequate funding for infrastructural maintenance for which reason a number of the existing inadequate computers were dysfunctional. Maintaining subscriptions to ERs was also a challenge particularly for the private case libraries partly due to the fact they did not have a separate library budget and had to rely on institutional leaders for approval. Again, interviewees perceived a low commitment of the IT department in their institution, which led to delays in resolving technical issues such as Internet connectivity downtime. However, delays in resolving technical issues appeared to be related to inadequate skills of IT personnel rather than low commitment. All these challenges served as obstacles to the access and usage of ERs. For libraries to provide effective ER services, the ability to maintain ERs and ICT infrastructure becomes crucial. Lack of investment for sustainability of ER services as a hindrance to the management and usage of ERs in the case institutions compared with Okogwu \& Ozioko (2018).

\subsubsection{Centralised Management Structure as a Hindrance}

The institutional management structure adopted by the case institutions in achieving organisational goals and objectives impacted on the management of ERs of the library. The findings as presented in Chapter Five showed that the private case institutions adopted a fundamentally centralised management structure whereas their public case counterparts operated a decentralised management structure. These structures and systems largely determined the span of control of the library regarding planning for ERs and the ER workflow. For example, public case academic libraries had a separate library budget, and a budget for ERs while private case academic libraries had no separate budget. Furthermore, non-library decision makers in the private case institutions oversaw aspects of the ER workflow, particularly the selection and acquisition of individual library contents as well as the renewal of ERs of the library. The consequences were that, private case 
libraries had less autonomy in the acquisition and sustainability of ERs and ICT infrastructure which hindered the management of ERs of the library.

Again, the interception of ER workflow by institutional leaders contributed to the lack of clarity on ERM particularly in those areas of the ER workflow that were controlled by institutional leaders. On the contrary, public case libraries had a considerable level of autonomy in their ERM practices. For instance, having a separate budget allowed the library to budget separately for the acquisition and sustainability of ERs and ICT infrastructure. Also, less interception by institutional leaders promoted clarity on ER workflow within the library.

\subsubsection{Low Institutional commitment}

The interview findings revealed low institutional support as a major factor hindering the management of ERs in the case institutions. Interviewees opined that appreciation of the role of the library and the value placed on ERs would translate into prioritisation of the needs of the library. There was a perceived lack of interest and commitment by institutional leaders to needs of the library which manifested in unwillingness to invest in the library particularly in the ERs of the library. There was a consensus that Ghanaian leaders were generally not interested in libraries or information management. Allocation of insufficient resources and delays in providing support to the library hindered the management of ERs in the case libraries which ultimately affected usage. This finding compared with Boamah \& Liew (2017).

\subsubsection{Poor Communication as a Hindrance}

Effective communication is paramount for a successful ERM (Elguindi \& Schmidt, 2012; Hsiung, 2008). ER staff need to engage with stakeholders including vendors, institutional leaders, library staff, and the user community on a regular basis for effective ERM and usage (Bothmann \& Holmberg, 2008, Ullah, 2015; Green, 2013). Analysis of the interview findings revealed communication issues involving ER staff and stakeholders, particularly institutional leaders, fellow library staff, and the user community which negatively affected the management and usage of ERs in both public and private case institutions. 
Communication with institutional leaders as an aspect of managing ERs of the library entails advocacy whereby the library needs to demonstrate value to justify financial investments in ERs (Bothmann \& Holmberg, 2008). Key interviewees perceived lack of advocacy skills as hindering ERM as the library failed to effectively communicate its objectives and needs to institutional leaders which led to a lack of understanding on the value of ERs, and unwillingness to invest adequately in human and non-human resources needed to manage the ERs of the library. Consequently, ER services of the library were negatively affected.

Communication with fellow library staff is key if ERM activities are to be a success. This appears to be most challenging for ER staff (Bothmann \& Holmberg, 2008). Findings as presented in Chapter Five highlighted poor communication between the ER unit and other units of the library. For example, some heads of other units of the library and paraprofessionals who played an ERrelated role were not fully aware of the ERs of the library and ongoing ER activities in the library. There appeared to be inadequate strategies for communication within the library among library staff. This resulted in a lack of clarity on ER services for which reason these staff were unable to provide adequate user support. Poor communication also occurred at the consortium level where member libraries delayed in responding to correspondence from CARLIGH executives, as well as the failure of representatives of member libraries to relay discussions at CARLIGH meetings back to their institution. This resulted in delayed decision-making and initiatives at the consortium level, which negatively affected ER services of member libraries.

The findings also revealed issues regarding communication with users. Communication with users involve publicity, instruction and reinstruction on the use of ERs of the library (Bothmann \& Holmberg, 2008). Public and private case libraries adopted various channels for awareness creation, which included orientation for new faculty and students, notices, and newsletters. The case libraries also provided information literacy education and training on ERs to faculty and students. At the time this study was being conducted, only UCC had inculcated information literacy programme which included training on ERs into the institutional curriculum for first year students. In spite of these efforts, the findings generally showed inadequate publicity and inadequate training on ERs of the library particularly at UCC, CU and WIUC. 
The literature has highlighted the importance of training users to equip them with the requisite skills for searching ERs. Inadequate training often translates into lack of searching skills, which can contribute to low usage as revealed in other studies (Deans \& Durrant, 2016; Chauhan \& Mahajan, 2014; Ani et al., 2016). Statistical tests as presented in Chapter Six indicated a strong association between training/searching skills and usage of ERs of the library. The findings showed that, users who participated in ER training or who were skilled in searching ERs were likely to use the ERs of the library. The survey respondents generally perceived the ER training organised by the library as not adequate to equip them with the requisite searching skills. Lack of awareness and unsuitable timing of ER training were also indicated. These findings supported the interview findings as key interviewees perceived inadequate publicity and training as contributing to the low level of awareness and low usage of the ERs of the library which ultimately affected the academic output and performance of users, particularly students.

Another aspect of communicating with users entails investigating their information needs and involving them in the ER workflow (Atkinson, 2018; Emery \& Stone, 2013). Input from faculty and students in the selection and evaluation of ERs of the library is necessary if these resources are to be relevant to them. Generally, the findings from both surveys and interviews revealed a minimal involvement of faculty and students of public and private case institutions in the selection and evaluation of ERs of the library. Not many of them had ever recommended contents to the library, participated in trial sessions, provided feedback on the ERs, or participated in user surveys to evaluate the ERs of the library. However, the statistical tests conducted in Chapter Six showed that when users, particularly postgraduate students, participated in these activities, they were likely to use the ERs. This meant that, low input from the users in these activities may have contributed to the observed low usage of ERs of the library in the case institutions.

\subsubsection{Consortium Cost Sharing Model as a Hindrance}

In an era where academic libraries particularly in developing countries are challenged with recurrent budgetary constraints, it is proving difficult to maintain adequate services for academics who require access to quality information (Jan \& Sheikh, 2011; Dadzie \& Walt, 2015; Kaur \& Walia, 2016). One approach which academic libraries in Ghana have taken in tackling this challenge is to form the consortium CARLIGH (Asamoah-Hassan, 2008; Asamoah-Hassan \& 
Frempong, 2008). Findings from the interviews revealed that although database subscriptions via the consortium was perceived as beneficial for member institutions, the cost sharing model implemented by CARLIGH served as a hindrance to effective management of ERs in the case institutions. The consortium adopted cost per use or equal share model, which required members to pay a uniform flat fee for database subscriptions. This was perceived by smaller member institutions as problematic for the reason that CARLIGH was not a homogenous consortium but made up of institutions of widely different sizes. On the contrary, larger member institutions were in support of the adopted cost sharing model. Satisfaction with the cost sharing model was consequently low among institutional leaders of smaller member universities which resulted in low commitment and delayed payments of database subscriptions. This hindered sustainability of ERs of the library and operations of CARLIGH. Taking into consideration the heterogenous nature of the consortium, it is necessary for the consortium to adopt a cost sharing model which would encourage high commitment of members to facilitate sustainability of ERs and smooth operations of CARLIGH.

\subsubsection{Low Usage of ERs of the Library as a Hindrance}

Academic libraries expect faculty and students to make use of ERs of the library to enhance their academic output and performance, and to justify financial investments. Findings as presented in Chapters Five and Six revealed low usage of ERs of the library which was a great concern for most of the interviewees at both the individual and consortium levels. Interviewees perceived users' preference for alternative sources of information and inadequate searching skills as the main factors contributing to the observed low usage of the ERs of the library. The survey findings complemented the interview findings as faculty and postgraduate respondents pointed out inadequate searching skills, inadequate computers, poor Internet connectivity, lack of relevant content and information overload as hindrances to accessing the ERs. Low usage of ERs of the library compared with related studies (Adeyoyin, Idowu \& Sowole, 2016; Cameron \& Siddall, 2015; Dukic \& Striskovic, 2015), and had implications on the management of the ERs particularly with regard to budget allocation as institutional leaders were unwilling to invest in ERs that were underused. For example, subscriptions to useful ERs that had low usage levels were cancelled resulting in frustration among users who found those resources to be useful. Generally, usage of ERs affected budgetary allocation, acquisition, and sustainability of ERs of the library. 
In summary, section 7.6.2 has discussed the various organisational factors, which served as enablers and hindrances to the management and usage of ERs in the public and private case institutions. An enabler was collaboration with stakeholders whereas hindrances included lack of policies for ERs, staffing challenges, resource-related factors, lack of investment for sustainability, centralised management structure, low institutional commitment, poor communication with stakeholders, consortium cost sharing model, and low usage of ERs of the library.

\subsubsection{Individual Factors}

The literature has indicated various individual factors as either enabling or hindering the management and usage of ERs in academic institutions. Individual factors identified as affecting ERM and ER usage in the case institutions included religion, social factors, attitudinal factors, and perception. These have been shown in Figure 7.5.

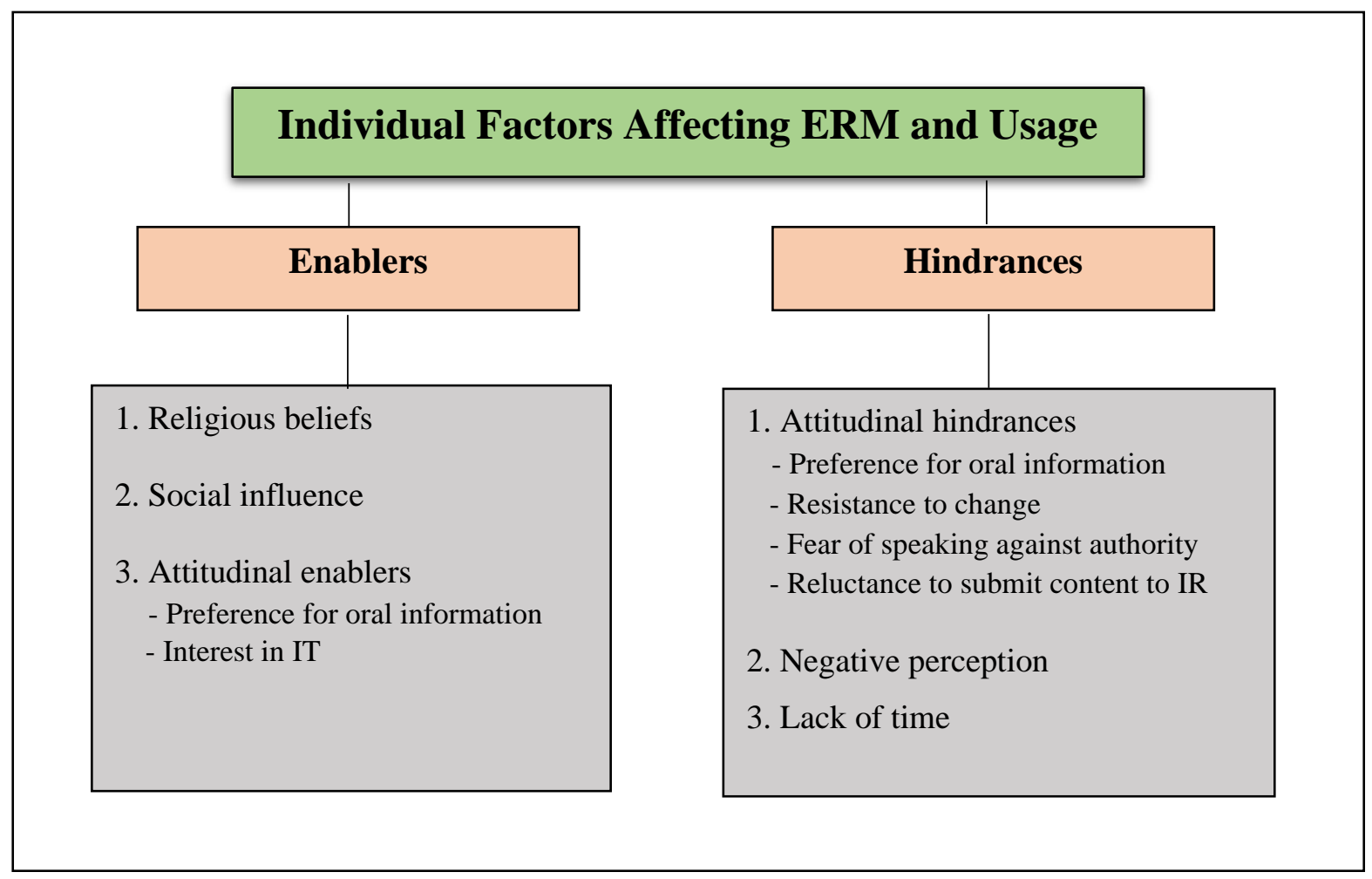

Figure 7. 5. Individual factors affecting ERM and ER usage 


\subsubsection{Religious Beliefs as an Enabler}

Religion forms an important aspect of the lives of Ghanaians (Assimeng, 2010). Ghanaians are highly religious and believe in the Supreme Being for Divine Assistance. The Global Religiosity Index 2012 indicated Ghana as the most religious country in the world with 96 percent of Ghanaians perceiving themselves as religious (Gallup International, 2012). Furthermore, statistics reveal that approximately 71 percent of the Ghanaian population identify as Christians (International Religious Freedom Report, 2017). It is a popular belief among Ghanaians that every good thing comes through the intervention and Grace of God. They carry this belief along and apply it to all spheres of life including the workplace. To most Ghanaians, everything is possible and attainable when submitted to God. Religious beliefs were revealed in the findings as positively affecting the management of ERs in both public and private case institutions. It became apparent that some interviewees acknowledged God for positive outcomes and believed in Him for more positive outcomes going forward.

There have been instances where people had integrated work with faith and had become passive waiting for Divine Assistance to overcome challenges. However, that was not the case in this study. Religious beliefs gave the interviewees a positive outlook even as they took the necessary initiatives and actions. This translated into a positive attitude among interviewees which would facilitate effective ERM amidst surrounding impediments.

\subsubsection{Social Influence as an Enabler}

Social factors have been indicated as playing a significant role in the acceptance of technology or ERs (Venkatesh et al., 2003; Mbabu et al., 2013; Chirra \& Madhusudhan, 2009). Social influence as defined by Venkatesh et al., (2003, p.451) is "the degree to which an individual perceives that important others believe that he or she should use the new system”. The survey findings revealed a strong association between recommendation by colleagues and superiors and usage of ERs of the library. Faculty and students were likely to use the ERs of the library when their colleagues/peers promoted the resources to them. Also, when faculty recommended the ERs of the library to students and/or gave regular course assignments that entailed research, students were likely to use the ERs. The findings therefore supported this assumption of the UTAUT model (Venkatesh et al., 2003) and related studies (Mbabu et al., 2013; Chirra \& Madhusudhan, 2009). 
It is therefore necessary for academic libraries to collaborate more with users, particularly faculty and students in leadership positions, to increase promotion of ERs of the library among their colleagues/peers and students.

\subsubsection{Attitudinal Factors Affecting ERM and Usage}

Various attitudinal factors emerged from the findings as affecting the management and usage of ERs in the case institutions. These include preference for oral information, interest in IT, resistance to change, fear of speaking against authority and reluctance to submit contents to IR.

\subsection{Preference for Informal /Oral Information as an Enabler}

Observation through the analysis of the data as presented in Chapter Five revealed the preference for oral information or informal dissemination of information as facilitating ERM in both public and private case libraries. For example, at CU, key interviewees obtained feedback on students' use of online databases from faculty by word of mouth. Similarly, at UG, feedback on contents were obtained from faculty by word of mouth either in person or via phone calls. These strategies, although informal and inadequate, provided a quicker means of assessing the ERs of the library which informed awareness creation and ER training efforts of the library in the case institutions.

\subsection{Preference for Informal /Oral Information as a Hindrance}

Although preference for oral information was identified as enabling the management of ERs in the case institutions, in some instances this factor served as an obstacle to effective ERM. The findings revealed a general lack of interest in reading and writing particularly in the areas of documentation and communication. The predominance of oral information appeared to have led to less documentation, which translated into lack of well-documented policies and workflow of ERs. This affected clarity on ER workflow and succession planning in the library which can be detrimental to ER services. It also affected the depth of information obtained from interviewees as some had no point of reference to adequately address the interview questions. Oral information, with associated embellishments and limitations of the human memory (Alemna, 1992) coupled with the fact that library staff may not always be available, does not make it a viable means of recording information on ER workflow for future reference. 
The findings also revealed that, preference for oral information fueled poor writing culture which caused written communication challenges particularly at the consortium level between CARLIGH and member representatives. For instance, there were delayed responses from members and in some instances no response to correspondence from CARLIGH executives. Delays in correspondence negatively affected the decision making of the consortium and ER planning and implementation activities. These findings were similar to related studies (Boamah, Dorner \& Oliver, 2012).

\subsection{Interest in Information Technology (IT) as an Enabler}

The findings as presented in Chapter Five suggested interest in IT among library staff which translated into the desire to keep up with the constantly changing technological landscape. This led to various efforts on the part of the library aimed at providing adequate ER services to encourage effective use of these resources. For example, efforts included monitoring the IT environment for current trends and developments, and personal development through selfeducation or formal education. Also, some staff of other units of the library exhibited interest in the ER services of the library and proactively participated in ER-related activities. The positive outlook towards IT and interest in ERs was a step in the right direction towards effective management of ERs of the library. For instance, the interest and participation in ER activities by staff of other units of the library lessened the burden on the understaffed ER unit. Bothmann \& Holmberg (2008) argue that, the participation of other staff of the library in ERM can encourage their full support and prevent resistance from them.

\subsection{Resistance to Change as Attitudinal Hindrance}

Another attitudinal hindrance revealed in the findings was resistance to change among both library staff and users. Interviewees perceived some library staff and users as accustomed to traditional methods of information storage and retrieval and therefore not seeing the value of ERs of the library. For example, interviewees recounted incidents where some library staff had resisted IT related initiatives in the library. In addition, some users, particularly older faculty appeared to be accustomed to using print information resources for which reason anything ER-related was not welcomed. This was confirmed during the data collection for this study where some professors objected to participating in the survey explaining that, they only preferred and used print 
documents. The resistance could be linked to lack of skills causing technophobia where some library staff and users may have perceived themselves as not adequately equipped to survive in the technological environment. It is therefore incumbent on the part of ER units/staff to increase ER awareness creation and training efforts for both library staff and users. The findings were consistent with Mwilongo (2017).

\subsection{Fear of Speaking Against Authority}

An observation made through the data analysis suggested fear of speaking against institutional authorities or decisions made by institutional leaders. For example, some interviewees were careful not to provide any information that could tarnish the image of institutional leaders and even provided justification for inadequate resources including underfunding of libraries. This attitude does not foster advocacy skills in library staff, which is vital in communicating to authorities the value of ERs and the need for adequate human and non-human resources.

\subsection{Reluctance to Submit Contents to IR}

Another negative attitude revealed in the findings was reluctance of users, particularly faculty to submit their intellectual contents to the IR due to plagiarism and copyright concerns. Key interviewees highlighted efforts being made to develop appropriate policies which would protect the interest of users who submit their contents to the IR. It is worth noting that, plagiarism and copyright concerns were not only prevalent among users but also among library staff who worked at the IR unit. For example, some IR staff were reluctant to upload certain contents on the IR due to uncertainties surrounding plagiarism. All these negatively affected the development and management of the IR at UG, UCC and CU. The findings compared with related studies (Boamah \& Liew, 2017; Cullen \& Chawner, 2009).

\subsubsection{Negative Perception of Users on the ERs of the Library}

The literature has revealed that the perception of users affects the usage of ERs (Dukic \& Striskovic, 2015; Ukachi, 2015). Performance expectancy and effort expectancy (as defined in Chapter Three of this thesis) are among the main determinants of acceptance of technology (Venkatesh et al., 2003). The statistical tests as presented in Chapter Six indicated a strong association between performance expectancy and effort expectancy, and usage of ERs of the 
library. The findings showed that when faculty and postgraduate students perceived the ERs of the library as useful (performance expectancy) and easy to use (effort expectancy), they were likely to use the resources. However, the findings generally revealed a negative perception of respondents on the ERs of the library. The resources were perceived as not being a quick means of accessing information and not being more useful than rival resources on the Internet. Consequently, the first port of call in searching for scholarly information was rival resources freely available on the Internet. The negative perception of respondents contributed to the observed low usage of ERs in both public and private case institutions.

\subsubsection{Lack of Time as a Hindrance}

The literature has shown that lack of time can hinder the usage of ERs in academic institutions. Duties and responsibilities of users can serve as obstacles to using the ERs of the library. For instance, a study by Malemia (2014) revealed that increased workload of faculty due to large class size hindered the usage of ERs of the library as they were mostly preoccupied with academic responsibilities such as examination invigilation and script marking. Damilola (2013) also revealed excessive academic workload as preventing students from making use of the ERs of the library. Analysis of the survey findings in this study also revealed lack of time as hindering the usage of ERs of the library which supported the findings of these related studies (Malemia, 2014; Damilola, 2013).

This sub-section (section 7.6.3) has discussed the various individual factors that served as enablers (religion, social and attitudinal factors) and hindrances (attitudinal factors, perception and time) to the management and usage of ERs of the library in the case institutions.

Section 7.6 has presented a discussion of the factors surrounding the management and usage of ERs in the case institutions. Several factors were identified which have been categorised as governmental, organisational and individual factors. The findings revealed that these factors had varying effects on the phenomenon. The next section discusses the revision of initial model of factors based on the factors identified in the findings. 


\subsection{Revision of Model of Contextual Factors}

This section revisits the initial factors and presents a revised model of contextual factors affecting the management and usage of ERs based on the analysis and discussion of interview and survey findings, and document analysis.

\subsubsection{Change Between Initial and Revised Models of Factors of ERM and Usage}

This section explains how factors have changed between the initial conceptual model of factors and the revised model based on the analysis of CDPs, interview and survey findings. There are a number of key changes between the initial and the revised model.

The main factors of the UTAUT model (performance expectancy, effort expectancy, social influence and facilitating conditions) are subsumed under individual and organisational factors. The reason for this is that, performance expectancy and effort expectancy formed the basis of the perception of users on ERs of the library, which is an individual factor. Social influence was also considered an individual factor since it had to do with interpersonal interactions. Facilitating conditions mainly had to do with contextual environment influenced by the efforts of the library/institution which either hindered or encouraged usage of ERs of the library and this was subsumed under organisational factors.

In addition, factors identified from the literature were mainly grouped under organisational and individual factors. Policies for ERs, availability of resources, sustainability, communication, searching skills/training were related to the library and its activities. For this reason, these factors were subsumed under organisational factors. Perception and social factors found in the literature were subsumed under individual factors. However, demographic profile, identified in the literature as affecting the usage of ERs, was omitted in the final model, as this was not reflected in the findings.

\subsubsection{The Revised Model of Factors Affecting the Management and Usage of ERs}

As earlier stated, the identified factors have been categorised into three main groups which are governmental, organisational and individual. These factors had varying levels of influence on the 
management and usage of ERs in the case institutions. Figure 7.6 depicts the revised model of factors affecting the management and usage of ERs based on the findings. 


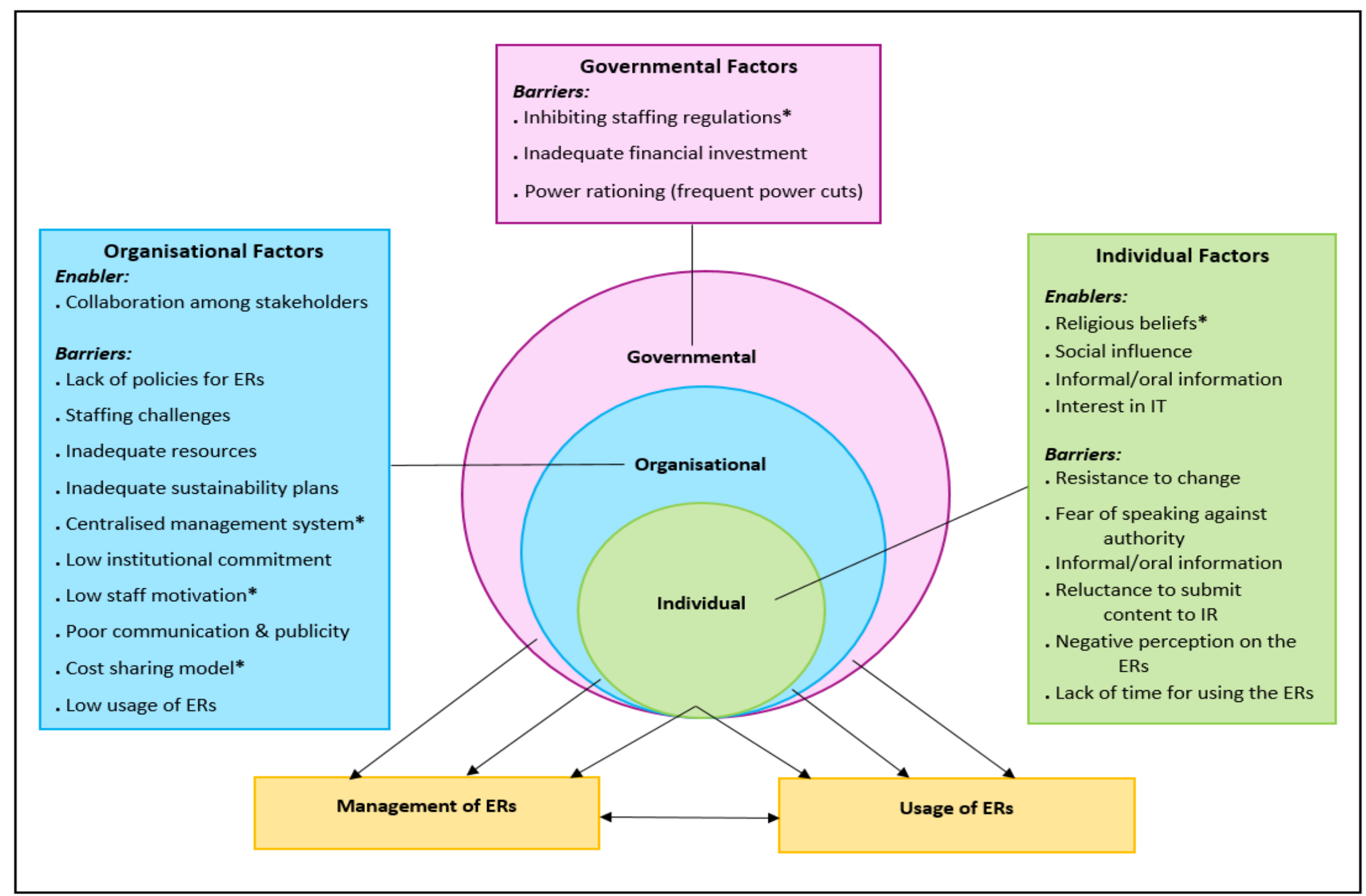

Figure 7. 6. Model of factors affecting the management and usage of ERs in Ghana $*$ = New Finding 
Generally, factors in the revised model were in accordance with factors in the initial framework which comprised the UTAUT model and factors from the literature. However, new factors emerged that were not in the initial model. A governmental factor which affected ERM particularly in the public institutions was staffing regulations. Centralised management structure, low staff motivation and consortium cost sharing model emerged as organisational factors affecting the management of ERs in the case institutions. At the individual level, religion also emerged as a factor influencing the management of ERs. As earlier indicated, the revised model excludes demographic factors as they were not supported by the findings of this study.

\subsection{How the Management and Usage of ERs of the Library are Related}

One of the research questions this study seeks to address revolves around the ways in which the management of ERs affects its usage and vice-versa. Findings from the interviews and surveys revealed an association between the management and usage of ERs in the case institutions. This association was bidirectional as activities of library staff (management) affected how users made use of the ERs of the library. By the same token, activities of users had an impact on the planning and implementation of these resources. Figure 7.7 depicts the association between management and usage of ERs based on the findings. 


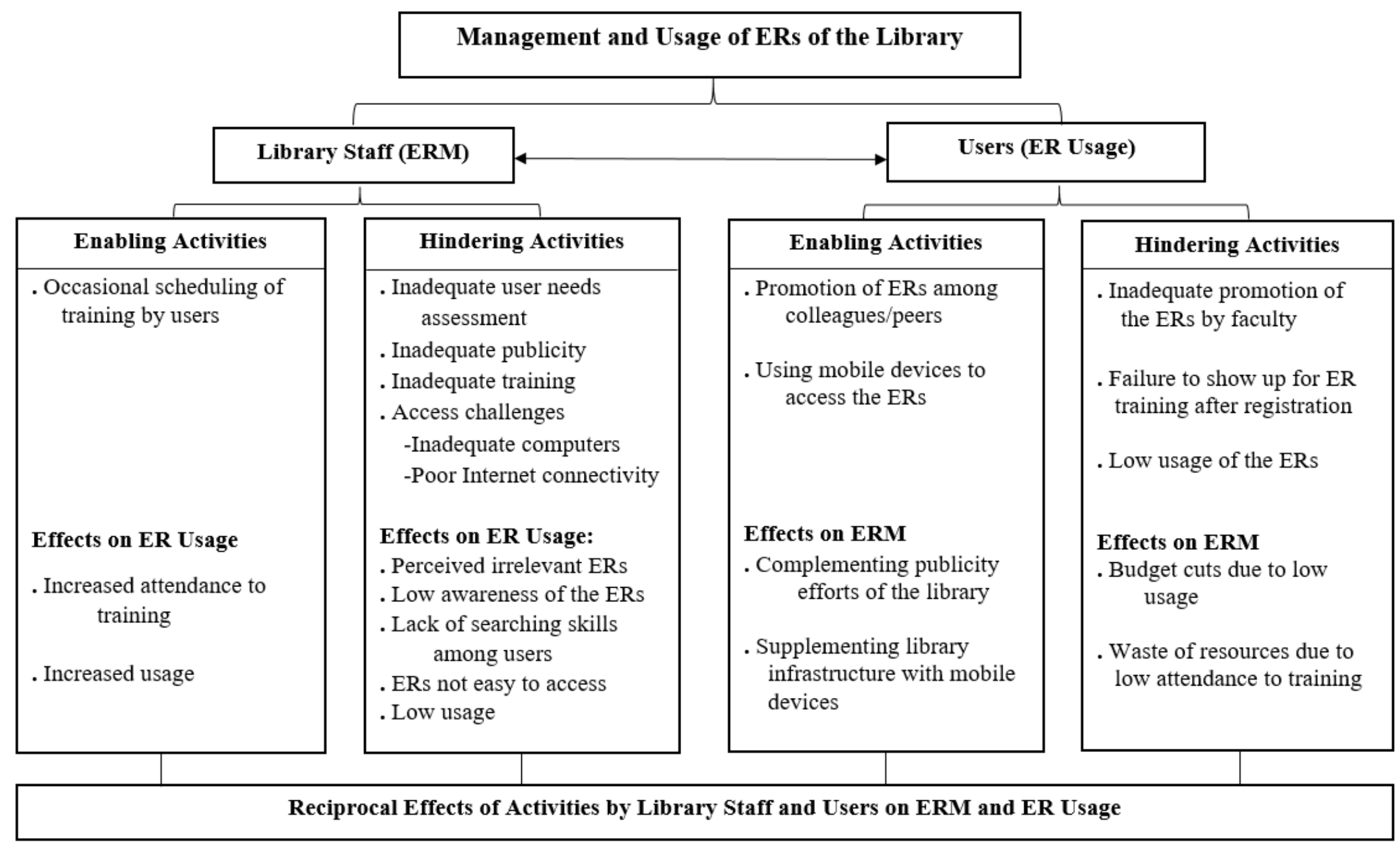

Figure 7. 7. Association between management and usage of ERs 


\subsubsection{Impact of ERM on ER Usage}

Various activities of library staff contributed both negatively and positively to the usage of ERs of the libraries. These activities were in the areas of selection of ERs, access provision, publicity, user training and evaluation of ERs. The findings established minimal involvement of users in the selection of ERs. Contents to a large extent were selected based on perceived relevance rather than conducting adequate user needs analysis. In tandem, faculty and postgraduate students indicated lack of relevant content as a limitation of using the ERs of the library which contributed to the observed low usage. Again, management of ERs particularly in the area of access provision hindered the usage of ERs. For example, challenges such as inadequate computers, poor infrastructural maintenance which manifested in broken down computers, poor Internet connectivity, and lack of remote access (at UCC and WIUC) were obstacles users had to grapple with in using the ERs of the library.

Findings from the interviews also indicated inadequate outreach and publicity by the library which resulted in a general low awareness of the various ERs of the library. This was supported by the survey findings as 'colleagues' was revealed as the dominant mode of awareness of the ERs of the library. Training on ERs for users was generally inadequate as highlighted in the interview and survey findings. Consequently, lack of searching skills was one of the challenges of using the ERs of the library as pointed out by the survey respondents. Due to inadequate searching skills, users were sometimes overwhelmed by the search outputs generated by the ERs of the library and therefore identified information overload as a hindrance to using the resources. In addition, respondents from the case institutions who had participated in ER training organised by the library perceived the training as not adequately equipping them with skills for searching the ERs of the library. Again, training schedules were perceived by faculty and postgraduate students as not suitable which contributed to the observed low attendance to ER training and pointed towards inadequate collaboration or communication between the library and users to ascertain their training needs and requirements. Inadequate training contributed to the underusage of the ERs of the library. The findings also indicated inadequate user feedback in evaluating the ERs of the library. For example, there were instances where subscriptions to contents had been cancelled and yet those contents were perceived as useful by some users, which left these users frustrated. All these accounted for the low usage of ERs in the case institutions. 
Even though management of ERs in the case institutions hindered usage of the ERs, the findings revealed activities of library staff that facilitated the usage of ERs. There were efforts by the case libraries, although minimal, to collaborate with users for ER promotion, training and evaluation of ERs which encouraged usage of the resources. For instance, case libraries that occasionally allowed users to suggest or schedule training observed an increase in attendance to training sessions, which contributed to increased usage of ERs of the library. Increased usage consequently facilitated the management of ERs as high usage of the resources provided a justification for financial investments thereby fueling continual financial support from institutional decision makers.

\subsubsection{Impact of ER Usage on ERM}

While activities of library staff negatively affected ER usage, activities of users similarly affected the management of ERs negatively. Low usage of the ERs of the library impacted on the management of ERs particularly in the area of budgeting for ERs. Institutional decision makers required high usage statistics for sustainability decisions. For this reason, low usage translated into budget cuts which further challenged the case libraries in acquiring and sustaining ERs and services. The findings also revealed low attendance to training organised by the library as affecting the implementation of ERs. For instance, users sometimes registered for ER training organised by the library in collaboration with providers but never showed up for the training. This resulted in waste of resources expended in organising these training programmes. There was also low referral of students to the ERs of the library by faculty. Some faculty respondents argued that, they accessed the ERs and made available to student hard copies of relevant contents for which reason referral of students to the ERs was perceived as needless. This did not encourage usage of the ERs by students as the findings showed a significant relationship between recommendation by faculty and usage of the ERs by postgraduate students. It ultimately hindered the management of these resources particularly in the areas of budgeting and sustainability of ERs and services.

However, some activities of users were identified as enablers to ERM. The survey findings from all case institutions revealed that faculty and postgraduate facilitated the implementation of ERs of the library by creating awareness among their peers. It turned out that "colleagues" was the most popular channel of awareness creation of ERs of the library among faculty and postgraduate 
students. This complemented the publicity efforts of the library. The findings also revealed that, the use of mobile phones to access ERs of the library was gaining popularity among postgraduate students in both public and private case institutions. This served as a substitute for using the computers in the library and provided a partial solution to the problem of inadequate computers that the case libraries faced.

Generally, the findings revealed bi-directional ways in which the management and usage of ERs were related. Activities of library staff and users served at enablers and hindrances to ERM and ER usage at various stages. However, there were more hindering activities than enabling activities by both library staff and users. If libraries are to provide ERs that are tailored towards the exact needs of users to attract maximum usage, these associations should be taken into consideration to make informed decisions and take necessary actions.

\subsection{Chapter Summary}

This chapter has discussed the management and usage of ERs in the case institutions. Various factors affecting these activities have been discussed which are governmental, organisational and individual. The findings revealed more hindering factors than enablers. A revised TERMS framework and revised model of factors of ERM and usage have been presented with explanation based on the findings.

By exploring how ERs are managed and used as well as identifying enabling and hindering factors in the selected academic libraries in Ghana, the study has provided relevant findings to serve as a point of reference to academic libraries and other stakeholders in Ghana and other developing countries for improved practices to encourage maximum usage of ERs of the library. The next chapter presents a summary, research implications and conclusion of this study. 



\section{Chapter Eight}

\section{Summary, Research Implications and Conclusion}

\subsection{Introduction}

This research sought to investigate the management and usage of ERs in academic libraries in Ghana. The motivation for the study was that, few researchers had studied both concepts of management and usage of ERs in a single study to reveal how they are related. Studying both concepts is necessary for informed practices which would encourage maximum usage of ERs. In addition, little research had focused on the management of ERs in the context of developing countries leaving a gap in the literature. Furthermore, previous studies suggested that academic libraries in Ghana were ineffective in managing ERs, which could have contributed to the observed low usage of ERs. There was therefore a lack of understanding on how ERs were managed and the contextual factors surrounding the management and usage of these resources in Ghanaian universities. These provided an inspiration for an exploratory research to understand the issues and factors to recommend strategies for addressing them. The study addressed the following research questions (RQs):

1. How are ERs managed and used in academic libraries in Ghana?

2. a. What are the contextual factors surrounding the management and usage of ERs in academic libraries in Ghana?

b. In what ways do these contextual factors affect the management and usage of ERs in academic libraries in Ghana?

3. In what ways does the management of ERs affect its usage and vice versa?

To answer the above research questions, the TERMS framework, an adapted UTAUT model and factors from previous research served as lenses for data collection, analysis and discussion. The study adopted a combination of qualitative and quantitative research methods to help understand the management of ERs, and to explore factors affecting the management and usage of ERs in academic libraries in Ghana. The concurrent parallel mixed methods approach employed semistructured interviews, surveys, and document analysis. Library staff who played ER-related roles 
or were knowledgeable about ERs of the library, and members of the governing council of the Consortium for Academic and Research Libraries in Ghana (CARLIGH) were interviewed mainly on the management of ERs, whereas faculty and postgraduate students were surveyed mainly on the usage of ERs. Collection development policies (CDPs) of case libraries were also obtained and analysed.

This chapter of the thesis provides a summary of the major findings from both qualitative and quantitative analysis of data in relation to the research problem and research questions. This is followed by a report on implications for theory and practice, and directions for further studies.

\subsection{Summary of the Research}

This study explored the management and usage of ERs in selected academic libraries in Ghana and the main findings are presented in Chapter Five (Findings on the Management of ERs) and Chapter Six (Findings on the Usage of ERs). Key findings from the interviews, document analysis and surveys are discussed in Chapter Seven. The synthesis of findings from library staff and users provided a holistic view on ERs in academic libraries in Ghana. This section summarises the findings of the study in relation to the research questions.

\subsubsection{Research Question 1}

RQ. 1. How are ERs managed and used in academic libraries in Ghana?

The findings revealed that there were varying levels of planning for ERs in the institutions studied. Case institutions encountered operational challenges including lack of policies for ERs, inadequate funding and understaffing which hindered planning for ERs of the library. Policies for ERs were not given the due recognition in both public and private case institutions as some institutions lacked ER policies whereas others had incomplete policies on ERs. The findings also highlighted the impact of type and size of institution on planning for ERs as there were notable differences in planning for ERs in the public and private institutions. Public case institutions operated a decentralised management structure whereby the library was allocated a separate budget and had a level of autonomy in budgeting for ERs. In contrast, the management structure in the private case institutions was centralised providing the library with less autonomy and no separate library budget 
which further challenged the ER services of the library. Also, the size of institution appeared to have impacted on staffing for ERs. Private case institutions which were smaller adopted a singleperson approach whereas public case institutions assigned ERM to an ER unit made up of at least one professional librarian and a few paraprofessionals. Generally, ERs of the library were not adequately planned for in both public and private case institutions due to lack of well documented ER policies, inadequate funding, and staffing challenges. However, challenges were more pronounced in the private case libraries as the library had less autonomy, acute financial constraints, and acute staffing challenges.

Regarding implementation of ERs, which basically comprises establishing ER workflow and adopting an approach for the workflow, the study employed the TERMS framework as a lens for analysis and discussion. The stages of the ER workflow as specified by TERMS are Stage One (Investigation of new content); Stage Two (Acquisition); Stage Three (Implementation); Stage Four (Ongoing evaluation and access); Stage Five (Annual review) and Stage Six (Cancellation and replacement review). As discussed in Chapter Seven, although efforts were being made to follow standard procedures, some components of the TERMS framework were absent in the ER workflow in both public and private case institutions. For example, regarding Stage One (Investigation of new content), focusing on exact need, documenting specifications, building a team of experts, and conducting overlap analysis were not reflected in the findings.

For Stage Two (Acquisition), documenting administrative metadata was not reflected in the findings. For Stage Four (Ongoing evaluation and access), the findings obtained did not reveal the documentation of evaluation results. For Stage Five (Review), the review of access queries, coverage changes and conducting overlap analysis were not indicated in the findings. For Stage Six (Cancellation and replacement review), final decisions were not documented per the findings obtained. Also, the findings as discussed in Section 7.3.1 revealed that some stages of the ER workflow were missing in the case libraries as these were carried out by parties external to the library. For example, in a consortium environment, the first two stages of TERMS (Investigation of new content and Acquisition) were mainly carried out by CARLIGH. For this reason, case institutions such as UCC and WIUC that solely relied on the consortium as mode of acquiring ERs actively began their ER workflow from the third stage (Implementation) of TERMS. The 
implication of this is that, ER staff lacked knowledge on those stages that were carried out by the consortium. In other words, there was a gap in the skills and knowledge of library staff on ERM practices. It also challenged the documentation of ER workflow.

The study also found that, outside consortia subscription, the type of institution determined the span of control of the library over the ER workflow. For instance, in public case institutions the library spearheaded the acquisition of individual library subscriptions and contents as pertained at the Balme Library (UG). On the other hand, private case institutional leaders spearheaded the acquisition and renewal of individual library contents with little to no input from the library as pertained at CU library. This was accounted for by the different management structures adopted in public and private case institutions. The interception of ER workflow by parties external to the library had repercussions on clarity of ER workflow among library staff which also contributed to inadequate documentation of ER workflow. Taken together, case institutions which depended solely on consortia subscription or belonged to the private sector were missing two to three stages of the TERMS framework. For this reason, they had little clarity on the components of those stages of the ER workflow. Again, the findings revealed cross-connections and bi-directional flows between the different stages of the TERMS framework indicating how the different stages interact in the workflow of the ERs. These new findings can provide further guidelines to novice ER staff and therefore can serve as a refinement of the TERMS framework.

The size and type of institution also determined the fundamental ERM approach adopted by the case libraries. Public case libraries which were larger, had established an ER unit/department made up of a minimum of one professional librarian and a few paraprofessionals to manage ERs of the library. On the contrary, private case libraries which were smaller assigned the management of ERs to a single professional librarian. However, operational challenges including inadequate staffing and the evolving nature of ER workflow provided an impetus for both public and private case institutions to distribute aspects of the ER workflow such as ER training and information literacy education to staff of other units of the library to lessen the burden on ER staff/units.

The study also examined the usage of ERs of the library in terms of awareness, use and the perception of faculty and postgraduate students. Generally, awareness of the various ERs among 
faculty and postgraduate students was low due to inadequate promotional efforts by the case libraries. The findings also revealed that, while levels of usage of ERs varied, they were generally low. Usage was comparatively higher among faculty than postgraduate students in both public and private case institutions. Among postgraduate students, usage was higher in the public case institutions than the private case libraries. Faculty and postgraduate students generally had a negative perception on the usefulness of ERs of the library which may have contributed to the observed low usage levels.

\subsubsection{Research Question 2}

$R Q .2 a$. What are the contextual factors surrounding the management and usage of ERs of the library?

2b. In what ways do these contextual factors affect the management and usage of ERs of the library?

The findings provided insight into factors affecting the management and usage of ERs. These factors were at the governmental, organisational and individual levels. The factors have been discussed in Section 7.6 of this thesis. Government factors which revolved around regulations and funding had negative impacts on the management and usage of ERs in the institutions investigated. The study found that case institutions particularly those in the public sector were bound by government regulations on recruitment which contributed to understaffing for ERs of the library. Another government regulation had to do with the rationing of electricity supply which resulted in frequent power cuts and hindered access to the ERs and ER training organised by the library. Last but not the least, inadequate funding from government to public case institutions was a barrier to the management of ERs. However, it appeared "half a loaf was better than none" as their private case counterparts were not eligible for any government grants and were therefore more challenged. Budget cuts coupled with the high inflation rate lowered the purchasing power of academic libraries and consequently affected the acquisition and sustainability of ERs of the library.

Organisational factors identified from the findings comprised the various activities, systems or structures and logistics in the case institutions that served as enablers or hindrances. Activities included collaboration, sustainability, communication with stakeholders, and usage of ERs. 
Collaboration within the library between ER staff and staff of other units of the library, and external collaboration through consortia participation led to positive outcomes, which facilitated ERM in the case institutions. For instance, collaboration within the library assisted in addressing understaffing for ERs whereas collaboration through the consortium facilitated acquisition of ERs, capacity building of ER staff and mediated advocacy for the case libraries. Also, the findings highlighted sustainability issues which manifested in the lack of planning and investment for sustainability which hindered ER services in the case institutions. For example, there were issues relating to maintenance of the system that provided access to the ERs as well as inadequate migration plans, hardware deterioration, lack of planning and investment for training, and low commitment.

Poor communication with stakeholders including institutional leaders, fellow library staff and users was also highlighted as an obstacle to effective management and usage of ERs of the library. Poor communication with institutional leaders manifested in inadequate advocacy for the cause of the library, which contributed to insufficient financial investments. Poor communication with fellow library staff also affected awareness of the various ERs of the library, clarity of ER workflow and delays in the operations of the consortium. Again, poor communication with users translated into inadequate user needs assessment and evaluation, inadequate publicity, and inadequate user training which culminated in low awareness of the ERs, perceived irrelevant contents and inadequate searching skills among users, all of which resulted in the observed low usage of the resources. In addition, low usage of ERs of the library was an organisational challenge which had negative implications on the management of ERs particularly regarding budgeting for ERs as institutional leaders found little need for financial investments in the case where ERs were underused. Factors accounting for low usage of the ERs included user preference for rival online resources, inadequate awareness creation and inadequate user training by the library, inadequate computers, poor Internet connectivity and lack of relevant or local content.

Another organisational factor revolved around the systems and structures adopted by case institutions in achieving organisational goals. The centralised management structure adopted by the private institutions hindered ERM in the case libraries as the library lacked control over some aspects of the ER workflow and resources to facilitate ER services including a separate library 
budget. Again, a major hindering organisational factor pointed out was low institutional commitment. This was perceived as a result of lack of appreciation of the role of the library by institutional leaders for which reason the needs of the library were not prioritised in allocating institutional resources. Furthermore, the findings indicated organisational factors relating to logistics as hinderances to the management and usage of ERs. Logistics included policies for ERs, transportation for mobility to facilitate promotion of the ERs at various campuses and other required resources. For example, lack of well-documented policies for ERs in the case institutions negatively affected succession planning and clarity on ERM practices among library staff. Also, both public and private case institutions were generally challenged with inadequate human and non-human resources such as inadequate funding, inadequate computers, poor Internet connectivity and inadequate skilled staff. Other resource-related obstacles included technical complexities of ERs all of which hindered the management and usage of ERs of the library.

At the individual level, various factors served as enablers or hinderances to the management and usage of ERs of the library. These were religious beliefs, social influence, attitudinal factors, perception, and lack of time. Religious beliefs served as an enabler in the instance where belief in God gave library staff a positive outlook amidst the challenges of managing ERs. However, this factor could be an obstacle to ERM in the instance where library staff tended to be passive and did not take the necessary actions since they were relying on God to resolve challenges. Another individual factor shown in the results was social influence. Social influence has been identified by the UTAUT model (Venkatesh et al., 2003) and previous research (Mbabu et al., 2013; Chirra \& Madhusudhan, 2009) as influencing the acceptance and use of technology/ERs. The findings of the study supported the literature as people with whom the respondents had contacts influenced their uptake of the ERs of the library.

Attitude was another individual factor that impacted on the management and usage of ERs in the case institutions. Preference for informal or oral information in obtaining user feedback was an attitudinal enabler, which provided a quicker means of assessing the ERs, awareness creation and training efforts of the library. However, this became a hindrance as overreliance on oral information led to less documentation of policies and ER workflow which affected clarity on ER workflow and succession planning. Another attitudinal enabler was interest in IT and the ER 
services of the library which manifested in proactive participation of non-ER staff in ER-related activities. This lessened the burden on ER units/staff.

There were attitudinal hindrances to effective management and usage of ERs in the case institutions. The findings revealed resistance to change among library staff and users as some preferred traditional methods of accessing and using information. For this reason, ER services of the library were not welcomed. Additional attitudinal hindrance included fear of speaking against authorities and reluctance to submit contents to the IR. Analysis of the data suggested fear of speaking against institutional authorities among library staff which was less likely to foster advocacy skills needed to project the value of ERs to institutional leaders for adequate budget allocation and support. The development of IR in both public and private case institutions was negatively affected by concerns among users regarding plagiarism and copyright which led to a reluctance to submit intellectual content to the IR.

Other individual factors identified as hindrances were perception of users on the ERs and time factor. The findings revealed that faculty and postgraduate students generally had a negative perception on the usefulness of the ERs of the library. Again, time for accessing and using the ERs of the library was a challenge for some faculty and postgraduate students due to workload and responsibilities. All these factors joined forces and led to the observed low usage of ERs of the library. Addressing these factors would facilitate effective management of ERs of the library, which could encourage greater usage of the resources. The initial model of factors was revised based on the findings.

\subsubsection{Research Question 3}

RQ3: In what ways does the management of ERs affect its usage and vice versa?

The study established various ways in which the management and usage of ERs affected each other. These were in the areas of selection, access provision, publicity, training, evaluation, and usage of ERs. Activities of library staff that hindered usage of ERs included inadequate user needs assessment and minimal involvement of users in the selection of ERs as selection was mainly based on perceived usefulness by library staff. This negatively affected the perception of faculty 
and postgraduate students on the ERs of the library as the resources were generally perceived as not useful to their information needs. Another management-related factor which hindered the usage of ERs was related to access provision. Infrastructural and access related challenges such as inadequate and broken-down computers, and poor Internet connectivity prevented users from effectively accessing and using the ERs of the library.

Again, user training organised by case libraries generally did not encourage user attendance and usage of the ERs. Training-related issues identified from the findings revolved around training awareness, training content, frequency, mode, and timing of training sessions. Users perceived training programmes organised by the library as not adequately equipping them with the skills needed for searching the ERs. Some also indicated lack of awareness of ER training, unsuitable training schedules and unsuitable mode of training. Alternative modes of training were suggested including online tutorials on the ERs. The findings also indicated inadequate user feedback in evaluating ERs of the library, which led to the cancellation of subscription to contents that were perceived as useful by some users. On the other hand, there were some activities by library staff which encouraged the usage of ERs. Case libraries that occasionally allowed users to make input in the scheduling of training sessions observed increased attendance to training with a corresponding increase in ER usage which provided a basis for budgetary support from the institution.

By the same token, activities of users had implications on the management of ERs particularly in the areas of training, budgeting for ERs, and publicity of ERs. Failure of users to attend training programmes organised by the library even after signing up to indicate interest resulted in a waste of human and non-human resources expended in organising such training programmes. Also, low usage of ERs of the library negatively affected budgeting for ER acquisition and sustainability as institutional leaders required value for money and were unwilling to invest in underused ERs. Again, faculty made minimal referral of students to the ERs of the library even though promotional efforts of all case libraries were tailored more towards faculty, and furthermore, the study's results showed a statistically significant association between referral by faculty and usage of ERs by students. This contributed to low usage which fed into inadequate financial investment by 
institutional leaders. If referral of students to the ERs by faculty was high, there could be a corresponding increase in usage statistics to attract institutional commitment.

There were however some activities of users that contributed to effective management of the ERs. Faculty and students facilitated the implementation of ERs of the library by creating awareness among their colleagues and peers. Colleagues as revealed in the survey findings was the most popular channel of awareness of ERs of the library and it can be said that this complemented inadequate publicity efforts of the library. Also, amidst infrastructural constraints in both public and private case institutions, the use of mobile phones to access the ERs of the library was gaining popularity especially among postgraduate students. This served as a supplement to the inadequate computers in the library. Generally, the findings revealed bi-directional ways in which the management and usage of ERs of the library were related.

Like any other research, this study has limitations which are related to both the context of the study and research design. Firstly, the research was carried out within a limited period (September 2017 - January 2018). Also, the findings are specific to Ghana. Again, many interviewees had limited understanding of the management of ERs which had the potential to negatively affect responses to the interview questions and the depth of discussion. Furthermore, the findings may not be generalisable to other universities due to the convenience, and disproportionate sampling techniques, and small sample sizes used in the surveys. These limitations have been detailed in the Methodology Chapter (Chapter Four, section 4.13) of the thesis.

\subsection{Implications and Contributions of the Study}

This section discusses the theoretical and practical contributions of the study findings.

\subsubsection{Implications for Theory}

This study contributes to the understanding of management and usage of ERs in a developing country context. Little research has investigated the two aspects: management and usage of ERs in a single study to explore how they are related. In addition, there has been little previous work on how academic libraries in a developing country such as Ghana are managing their resources in the electronic environment. Furthermore, there is a lack of understanding of the enabling and 
hindering factors of ERM and ER usage in Ghana. As academic libraries in Ghana rely more on ERs, an understanding of these factors could contribute to effective ERM practices to encourage high usage of these resources. This research therefore adds to existing literature by providing a developing country context on the phenomenon of ERM and usage in academic libraries.

More importantly, this research contributes to theory by providing further insights into the TERMS framework and UTAUT model and extends their application to a developing country context as the study drew from components of these frameworks in exploring the phenomenon. By applying the TERMS framework and an initial conceptual model of factors based on UTAUT and the literature, the research findings identified emergent factors that were absent in the TERMS framework and initial conceptual model of factors. The revised TERMS framework based on mapping of TERMS components to the findings revealed interconnections among the various stages of TERMS. The findings further indicated that in a consortium environment and private academic library environment, some stages of the framework were absent in the library's ER workflow, as these were the responsibilities of external parties including CARLIGH and institutional leaders respectively.

In addition, some factors indicated in the findings were not present in the initial conceptual framework of factors. These were inhibiting staffing regulations by the government, institutional management structure, staff motivation, consortium cost sharing model and religious beliefs. Suspension of recruitment following the directive by government contributed to understaffing in the public case libraries. In addition, the study identified centralised management structure as resulting in the lack of control of private case libraries over some stages of the ER workflow as non-library institutional leaders intercepted and performed those stages of the workflow. The interception coupled with the communication gaps between institutional leaders and library staff led to a lack of knowledge and clarity among library staff on those aspects of the ER workflow performed by institutional leaders. Also, lack of incentives was perceived as lowering staff motivation and had the potential to affect the commitment level of ER staff. Again, the cost per use sharing model adopted by CARLIGH raised concerns among members and led to the delay of consortium activities related to ERs. Finally, religious beliefs served as an attitudinal enabler, 
which gave library staff a positive and "can do" attitude towards the management of ERs amidst operational challenges.

In summary, the main contributions of this study are that, it extends the application of TERMS and UTAUT models to a developing country perspective and presents a refinement of the TERMS framework and a conceptual model of factors affecting the management and usage of ERs. The revised frameworks provide a basis for further investigation on the phenomenon in Ghana or other developing countries. In addition, the study identifies the main contextual factors affecting the management and usage of ERs in academic libraries in Ghana. Finally, the study contributes to the theoretical understanding of the association between the management and usage of ERs in academic libraries.

\subsubsection{Implications for Practice}

The study has important implications for LIS practice. The findings provide insight into the practices of managing and using ERs, and how these two aspects affect each other in academic libraries as well as highlighting enabling and hindering factors surrounding both concepts. As the study revealed that ERs were inadequately managed and used in academic institutions in Ghana, it creates awareness of causal issues and recommends strategies for effective ERM practices that could lead to increased usage of ERs of the library. It also creates awareness among stakeholders such as institutional leaders and users on ways in which their actions or inactions impact on ERs and services of the library.

The study therefore has implications for academic libraries in Ghana. As strategies for effective management and usage of ERs of the library, academic libraries should give policies for ERs the due recognition and develop well-documented policies and workflows to guide ERM practices. This will provide a point of reference for existing library staff and facilitate succession planning which would ensure consistencies in ER activities. Well-documented policies can also provide justification for institutional support regarding resource allocation. Also, academic libraries in Ghana should improve and expand their infrastructure by acquiring state-of-the-art ICTs, adequate bandwidth, and adequate computers and also maintain ICT infrastructure to facilitate on-campus and remote access to ERs of the library. In addition, academic libraries can address frequent power 
outage, which is a national issue, by acquiring standby generators to ensure constant electricity supply. With adequate computers, reliable Internet connectivity, constant electricity supply and remote access, users will perceive the ERs as easy to access, which would greatly influence their decision to exploit the ERs of the library.

Also, the government and institutional leaders need to recognise the significant role academic libraries play in institutional development and support the library accordingly with adequate resources including funding, ICT infrastructure, and respond to staffing and capacity building needs of the library. In so doing, the ER services of the library would be attractive to the user community to encourage maximum usage, which will ultimately enhance the quality of academic productivity of faculty and students. Again, academic libraries can advocate for centralised funding whereby ERs are centrally funded at government level for the benefit all public and private academic and research institutions to enhance the educational and research sector of the country to promote national development. Government providing centralised funding for ERs will enable academic institutions to adequately sustain the ER services of the library and ensure continuous renewal of ER subscriptions for uninterrupted access.

Also, academic libraries with support from institutional leaders should solicit for funding from external sources to supplement institutional funding. In addition to soliciting for external funding, public academic libraries could extend library fee to include ER fee to be paid by students. Private academic libraries should also consider charging library fee, which would cover ER fee to be paid by students. This will not only supplement the library's funds, but may provide students with an impetus for using the ERs of the library so as to obtain value for money, as it is sometimes the case that people undervalue perceived "free stuff" or "stuff" devoid of financial commitments with the mindset that they have nothing to lose should they choose not to use them.

Again, there is the need for academic libraries to constantly demonstrate their value to their user community by advocating for institutional support and intensifying the marketing of ERs and services using various channels including email and text messages. Also, users should be made aware of the implications of low usage of ERs as it negatively affects institutional support in terms of budgeting for the ERs. In addition, it is recommended that academic libraries implement 
discovery tools and federated search systems to improve discoverability of ERs of the library and facilitate quick access to the resources. There should also be effective communication regarding submission of intellectual contents to the IR to eliminate concerns about plagiarism and copyright among users that result in reluctance in submitting intellectual outputs.

In addition, libraries need to conduct adequate user needs analysis by involving users in the selection and assessment of ERs and taking feedback from users seriously. Only then will the library be able to subscribe to contents that are relevant to the needs of users. More so, frequent training sessions should be organised by the library taking into consideration training content, the timing and mode of training required by users, which would boost attendance to training and encourage optimum usage of ERs of the library. For example, library staff should take into consideration the institutional academic calendar when scheduling ER training sessions to avoid training sessions clashing with concurrent activities on campus which could result in low attendance to training. As pertained at the Balme Library (UG), vendors and providers should be invited to provide training on the ERs from time to time to attract high attendance. Also, library staff should follow up when users do not attend training even after signing up for the training. In addition, academic libraries can reward those who frequently use ERs of the library or acknowledge them by posting their profile on the library website. This will increase awareness and motivate users particularly students to make maximum use of the ERs, which would attract institutional recommitment. Furthermore, information literacy programmes which include training on ERs of the library should be inculcated in institutional curricula as pertained at UCC for first year students. However, this should not only target undergraduate students but also postgraduate students. Again, academic libraries should consider developing mobile applications for convenient access and management of ERs of the library.

It is also important for Library and Information Science (LIS) educators in Ghana to develop LIS curricula that incorporate courses and programmes on skills and knowledge required by the current electronic environment. In addition, the curricula in library schools should not be solely theory focused but should make provision for pragmatic training of students particularly postgraduate students. However, this can only be feasible when there is adequate ICT infrastructure. Library schools in Ghana should therefore be provided with the state-of-the- art ICT infrastructure to 
facilitate a balanced pragmatic and theoretical training of students. Finally, ER-specific internships should be included in LIS programmes so that students can have real life experiences regarding the management of ERs in order to be equipped as much as possible to meet the demands of the job market.

Furthermore, frequent training programmes should be organised for all library staff to equip them with ICT and ERM skills which include selection, licensing and negotiation, implementation, and evaluation skills. In addition, library staff should adopt personal development strategies by improving their knowledge on ICT skills and frequently upgrading their skills and competencies. Institutional support should be provided to make this possible. For example, library staff should be allowed time to go for training and provision of financial support to cover training costs. Again, library staff should be receptive to technology and any changes the library may decide to embrace to remain relevant in the technological environment. There should also be effective communication among staff involved in ER activities, and between ER unit and other units of the library so that all staff will be kept in the loop regarding the ERs of the library. Again, ER staff should also be given incentives from time to time for organising training sessions to motivate them towards high commitment and productivity.

Private case institutions should also rethink their centralised management structure and provide the library with a separate budget and a considerable level of autonomy in their operations to facilitate effective ERM. It is also suggested that universities, especially the small ones outsource parts of TERMS to CARLIGH to compensate for the discrepancies in funding regarding the cost per use sharing model adopted by the consortium for members. However, for outsourcing to be successful, effective communication between CARLIGH and members is paramount. On the other hand, CARLIGH can adopt the cost per user model whereby subscription fee for members is determined by the size of institution which would lessen the financial burden on smaller institutions. Again, CARLIGH should provide a holistic training on the management of ERs for member libraries. In this way, member libraries will be knowledgeable about all the stages of the ER workflow including those functions that are carried out by the consortium on behalf of member libraries. This will enhance knowledge and clarity on ERM practices in the library. 
Despite the obstacles to the management and usage of ERs, the findings revealed a number of enabling factors which, this study recommends should continue. Collaboration within the library between ER units and non-ER units as well as collaboration with other libraries through consortia participation are commendable and should be strengthened. There are further opportunities for academic libraries to work collaboratively within the library, within the institution and with CARLIGH to address the missing components in ER policies and workflows revealed in the findings. Academic libraries should collaborate with users by conducting adequate user needs analysis and involving users in the selection of ERs. By so doing, ER services will be tailored towards the exact needs of users. In addition, a team of experts as recommended by TERMS can be formed involving head of ERs, subject librarians, faculty, and institutional leaders to be responsible for the selection of ERs of the library. Inadequate documentation, inadequate overlap analysis and inadequate analysis of coverage changes as revealed in the findings can be addressed by case libraries with training or support from CARLIGH. Again, awareness creation of the ERs by faculty and students among their peers is laudable and should be encouraged. However, faculty should increase promotion of the ERs of the library to students, especially postgraduate students. Furthermore, faculty should give regular assignments to students, and design coursework and assignments in such a way that students are referred to use the ERs of the library. By so doing, awareness of the ERs and attendance to training will increase with a likely corresponding increase in the usage of these resources.

Although the study was conducted in Ghana and the findings are particularly relevant to the Ghanaian setting, the findings can also support LIS practice in similar developing countries such as those in Africa. It can provide a point of reference from which they can draw lessons. The study also provides advanced countries with insight into ERM practices in developing countries to facilitate advisory efforts tailored towards the developing country context. The findings are also useful to LIS educators in Ghana and other developing countries as it informs them on contemporary relevant issues such as requisite skills and expectations of practitioners to inform the development of LIS curricula in the country. Finally, the findings have implications for policy and decision making regarding prioritisation and allocation of resources for effective ERM and usage in academic libraries as surrounding factors are revealed. 


\subsection{Recommendations for Further Research}

This study has identified some areas, which can provide directions for further investigation. Firstly, the study investigated the management and usage of ERs in two public and two private institutions respectively. The study recommends that similar studies be undertaken in a larger number of public and private institutions in Ghana using a larger number of participants to confirm the findings of the study. Future research should also extend study participants to include the perspectives of other stakeholders such as institutional leaders and undergraduate students to provide other dimension to the findings on ERs in academic institutions, which may have not reflected in this study. Again, this study was limited to academic libraries. It would therefore be useful to conduct a comparative study involving other types of libraries such as special libraries and research institutes in Ghana. More so, similar studies can be conducted in other developing country contexts.

Since the study discussed ERs as a whole rather than a variety of tools, it is suggested that future studies investigate the usage of variety of tools and interfaces in academic libraries to provide further depth to the findings on ERs in academic institutions in Ghana. In this era of Google generation, a study needs to be conducted to examine the role of Google search engine and rival resources on the Internet in accessing ERs in academic institutions within the Ghanaian context. Furthermore, the study noted that the use of mobile phones as a means of accessing ERs of the library was gaining popularity among postgraduate respondents. It is suggested that further research be conducted on the usage of mobile devices for accessing ERs of the library in Ghanaian universities to assist academic libraries in discovering how to take advantage of this medium to promote maximum usage of the ERs of the library.

Finally, further studies could focus on the revised TERMS framework and the model of contextual factors, which are the theoretical contributions of this study. Research should be conducted to evaluate these frameworks by testing its applicability using a larger number of cases and other types of libraries in Ghana. Since the context of this research is a developing country, the frameworks can also be tested in other developing countries such as Nigeria and Kenya. 


\subsection{Conclusion}

This study sought to investigate the management and usage of ERs in academic libraries in Ghana. It has been motivated by the intention to study both concepts of management and usage of ERs in academic libraries identified as a gap in the literature, to explore how these two concepts are related for better recommendations to inform practice. Also, little research had studied the management of ERs in academic libraries in the developing countries. In addition, previous research suggested that academic libraries in Ghana were ineffective in managing their ERs. To address the research problem, this study investigated the management (planning and implementation) and usage of ERs in academic libraries in Ghana using both qualitative and quantitative methods. Qualitative methodology was used for investigating the aspect of management of ERs whereas quantitative methodology was applied to the investigation of the usage of ERs.

Academic libraries in Ghana are experiencing great changes in their collection development and services as print collections are gradually giving way to ERs. For this reason, ERM is becoming an important and yet a challenging function in these libraries. The findings of the study have revealed that academic libraries in Ghana face many challenges in their efforts to provide ER services to users. This research therefore brings to the attention of academic libraries, LIS curriculum developers, policy and decision makers in Ghana the various factors surrounding the management and usage of ERs in academic libraries for all stakeholders to take necessary actions to improve LIS practice and ER acceptance for ER services in academic libraries to be a success. 


\section{References}

Abbott, A. (1988). The system of professions: An essay on the division of expert labor. Chicago, IL: The University of Chicago Press.

Abrams, K. R. (2015). Electronic resource management and design. Journal of Electronic Resources Librarianship, 27(3), 151-164.

ACRL Research Planning \& Review Committee (2014). Top trends in academic libraries. College and Research Libraries News, 75 (6), 294-302.

Adeleke, D.S., \& Nwalo, K. I. N. (2017). Availability, use and constraints to use of electronic information resources by postgraduate students at the University of Ibadan. International Journal of Knowledge Content Development \& Technology, 7(4), 51-69.

Adeyoyin, S.O., Idowu, T.A., \& Sowole, A.O. (2016). Awareness, access, and use of electronic information resources among the Seminarians in Nigeria. Journal of Religious and Theological Information, 15(1-2), 1-18.

Adzobu, N.Y.A. (2014). Building digital collections in a public university library in Ghana: Priority setting, and user needs assessment. Collection Building, 33(2), 38-45.

Adzobu, N.Y.A. (2014). Testing the Andrews Framework of Strategy Formulation and Implementation: Case study of the University of Cape Coast digital library in Ghana. International Journal of Knowledge Content Development and Technology, 4(2), 49-65.

Agyen-Gyasi, K., Corletey, A., \& Frempong, A.T. (2010). Open Access Institutional Repositories: Issues and challenges. Retrieved from http://ir.knust.edu.gh/bitstream/Open\%2020Institutional\%Repositories\%20I.pdf.

Aina, R.F. (2014). Awareness, accessibility and use of electronic databases among academic staff of Babcock University Business School. Kuwait Chapter of the Arabian Journal of Business and Management Review, 3(6), 40-47.

Ajzen, I. (1991). The Theory of Planned Behavior: Organisational behaviour and human decision, $50(2), 179-211$.

Akussah, M., Asante, E., \& Adu-Sarkodee, R. (2015). Impact of electronic resources and usage in academic libraries in Ghana: Evidence from koforidua Polytechnic \& All Nations University College, Ghana. Journal of Education and Practice, 6(33), 33-38.

ALA (1986). ALA World Encyclopaedia of Library and Information Science. Chicago: ALA.

Albitz, R. (2008). Licensing and managing electronic resources. Oxford: CHANDOS Publishing.

Alemna, A.A. (1992). Towards a new emphasis on oral tradition as an information source in African libraries. Journal of Documentation, 48(4), 422-249. 
Alsalmi, J., Liew, C. L., \& Chawner, B. (2011, September). Social factors influencing the adoption and development of Electronic Theses and Dissertations (ETD) programmes in the Arab Gulf States. Proceedings of the 14th International Symposium on Electronic Theses and Dissertations. Symposium conducted at Cape Town, South Africa.

Alsalmi, J.M., Liew, C.L., \& Chawner, B. (2014). The influence of contextual factors on the adoption and development of Electronic Thesis and Dissertations (ETD) programmes in the Arab Gulf states. Library Management, 35 (4/5), 355-363.

Anaraki, L. N., \& Babalhavaeji, F. (2013). Investigating the awareness and ability of medical students in using electronic resources of the integrated digital library portal of Iran: A comparative study. The Electronic Library, 31(1), 70 - 83.

Anbu, J.P.K., Kataria, S., \& Ram, S. (2013). Dynamics of managing electronic resources: Electronic resource management system (ERMS) initiatives. DESIDOC Journal of Library and Information Technology, 33(4), 300-305.

Ani, O. E., \& Ahiauzu, B. (2008). Towards effective development of electronic information resources in Nigerian university libraries. Library Management, 29(6/7), 504-514.

Ani, V. A., Ani, E. O., Ugwu, C. O., Nwachukwu, A. I., Obianuko, J. C., Ndaji, G. I., \& Maduchie, E. E. (2016). Strategies for enhancing the utilisation of Information and Communication Technology (ICT)-based library resources in research. Library Philosophy and Practice (e- journal), Paper 1310. Retrieved from http://digitalcommons.unl.edu/libphilprac/1310

Anie, S., \& Achugbue, E.I. (2009). Library information and communication technology in Nigerian universities. Library Hi Tech News, 26(7), 8-10.

Ankrah, E., \& Atuase, D. (2018). The use of electronic resources postgraduate students of the University of Cape Coast. Library Philosophy and Practice (e-journal). 1632. Retrieved from https://digitalcommons.unl.edu/libphilprac/1632

Ansari, M. N. (2010). Use of electronic resources among academics at the University of Karachi. Library Philosophy and Practice (e-journal).

Arif, M., Ameen, K., \& Rafiq, M. (2016). Factors affecting student use of web-based services: Application of UTAUT in the Pakistani context. The Electronic Library, 36(3), 518-534.

Asamoah-Hassan, H. (2008, August). The Consortium of Academic and Research Libraries in Ghana (CARLIGH), the journey so far. Paper presented at the IFLA Academic and Research Libraries Section Satellite Conference on consortia and collaborative arrangements, Quebec City.

Asamoah-Hassan, H., \& Frempong, A.T. (2008, October). Access to e-journals and e-publishing initiatives in Ghana: success, challenges and lessons learnt. Paper presented at the CODESRIA conference on Electronic Publishing and Dissemination, Dakar, Senegal.

Asefeh, A., \& Nosrat, R. (2007). Awareness and use of digital resources in the libraries of Isfahan University of Medical Sciences, Iran. The Electronic Library, 25(3), 316-327. 
Assimeng, M. (2010). Religion and social change in West Africa (2nd ed.). Accra: Woeli Publication Services.

Atkinson, J. (Ed.). (2018). Collaboration and the academic library: Internal and external, local and regional, national and international. Oxford: Chandos Publishing.

Awwad, M., \& Al-Majali, S. (2015). Electronic library services acceptance and use. The Electronic Library, 33(6), 1100-1120.

Baro, E. E., Endouware, B. C., \& Ubogu, J. O. (2011). Awareness and use of online Information resources by medical students at Delta University in Nigeria. Library Hi Tech News, 28(10), 11-17.

Barrett, A. (2005). The information-seeking habits of graduate student researchers in the Humanities. Journal of Academic Librarianship, 31(4), 324-331.

Bass, A., Fairlee, J., Fox, K., \& Sullivan, J. (2005). The information behaviour of scholars in the humanities and social sciences. Seattle: University of Washington.

Bassi, M. D., \& Camble, E. (2011). Gender differences in use of electronic resources in university libraries of Adamawa state, Nigeria. Library Philosophy and Practice. Retrieved from http://digitalcommons.unl.edu/libphilprac/549

Bawden, D., Holtham, C., \& Courtney, N. (1999). Perspectives on information overload. Aslib Proceedings, 51(8), 249-255.

BBC News (2015). Eight surprising consequences of Ghana's power outages. Retrieved from https://www.bbc.com/news/world-africa-32721265

Benbasat, I., Goldstein, D. K., \& Mead, M. (1987). The case research strategy in studies of Information Systems. MIS Quarterly, 11(3), 369-386.

Bhat, I., \& Mudhol, M.V. (2014). Use of e-resources by faculty and students of Sher-EKashmir Institute of Medical Science (SKIMS). Journal of Library \& Information Technology, 34(1), 28-34.

Bielavitz, T. (2010). The Balanced Scorecard: A systemic model for evaluation and assessment of learning outcomes? Evidence Based Library and Information Practice, 5(2), 35-46.

Boamah, E. \& Liew, C.L. (2017). Conceptualising the digitisation and preservation of indigenous knowledge: The importance of attitudes. In S. Choemprayong, F. Crestani, \& S.J. Cunningham (Eds.), Digital libraries: Data, information and knowledge for digital life (6580). Cham, Switzerland: Springer.

Boamah, E., Dorner, D.G., \& Oliver, G. (2012). Stakeholders' attitude towards the management and preservation of digital cultural heritage resources in Ghana. Australian Academic \& Research Libraries, 43(4), 300-317.

Bogozzi, R. P. (2007). The legacy of the Technology Acceptance Model and a proposal for a paradigm shift. Journal of the Association for Information Systems, 8(4), 244-254. 
Boss, S.C., \& Schmidt, L.O. (2007). Electronic resources (ER) management in the academic library: process vs. function. Collection Management, 32(1/2), 117-140.

Bothmann, R., \& Holmberg, M. (2008). Strategic planning for electronic resource management. In Electronic Resource Management in Libraries (16-28). Retrieved from https://doi.org/10.4018/978-1-59904-891-8.ch002

Branscome, B.A. (2013). Management of electronic serials in academic libraries: The results of an online survey. Serials Review, 39, 216-226.

Breeding, M. (2004). The many facets of managing electronic resources. Computers in Libraries, 24(1), 25-33.

Breeding, M. (2008). Helping you buy: Electronic resource management systems. Computers in Libraries, 28(7), 6-18, 94-96.

Brown, J. F., Nelson, J. L., \& Wineburgh-Freed, M. (2005). Customized electronic resources management system for a multi-library university: Viewpoint from one library. The Serials Librarian, 47(4), 89-102.

Bryman, A. (2004). Social research methods (2nd ed.). New York: Oxford University Press.

Buchanan, T., Sainter, P., \& Saunders, G.J. (2013). Factors affecting faculty use of learning technologies: Implications for models of technology adoption. Journal of Computing in Higher Education, 23(1), 1-11.

Calvert, P.J., \& Neo, E. (2012). Facebook and the diffusion of innovation in New Zealand public libraries. Journal of Librarianship and Information Science, 44(4), 227-237.

Cameron, C., \& Siddall, G. (2015). Academic staff perceptions and use of reading lists for book ordering. SCONUL Focus, (64), 41-44.

Campbell-Meier, J. (2011). A framework for institutional repository development. Advances in Library Administration and Organization, 30, 151-158.

Campbell-Meier, J. (2015). Faculty adoption of open access publishing in the University System of Georgia. Journal of Technologies in Knowledge Sharing, 11(1), 1-10.

CARLIGH (2016). CARLIGH strategic plan for 2016-2020. Accra: CARLIGH.

CARLIGH (2017). The Consortium of Academic and Research Libraries in Ghana. Retrieved from https://www.carligh.org/

Carrol, A.J., Corlett-Rivera, K., Hackman, T., Zou, J. (2016). E-book perceptions and use in STEM and non-STEM disciplines: A comparative follow-up study. Portal: Libraries and the Academy, 16(1), 131-162.

Cavana, R. Y., Delahaye, B. L., \& Sekaran, U. (2001). Applied business research: Qualitative and quantitative methods. Queensland: John Wiley \& Sons.

Central University (2019). Central University, Ghana. Retrieved from http://central.edu.gh/ 
Chamberlain, C., \& Reece, D. (2014). Library reorganization, chaos, and using the core competencies as a guide. The Serials Librarian, 66 (1-4), 248-252.

Chauhan, S. K., \& Mahajan, P. (2014). Use of UGC-Infonet e-resources by social science academics in Indian universities: An evaluation study. The Journal of Academic Librarianship 40, 359-366.

Chawner, B. (2004, February). Free/open source software: New opportunities, new challenges. In 12th VALA Biennial Conference e Breaking boundaries: Integration \& Interoperability, Retrieved from www.vala. org. au/vala2004/2004pdfs/33chawn. pdf.

Chirra, R., \& Madhusudhan, M. (2009). Use of electronic journals by doctoral research scholars of Goa University, India. Library Hi Tech News, 26(10), 12-15.

Collins, M. (2009). Evolving workflows: Knowing when to hold'em, knowing when to fold'em. The Serials Librarian, 57(3), 261-271.

Colquitt, J.A., \& Zapata-Phelan, C.P. (2007). Trends in theory building and theory testing: A fivedecade study of the Academy of Management Journal. Academy of Management Journal, 50(6), 1281-1303.

Compeau, D.R., \& Higgins, C.A. (1995). Application of social cognitive theory to training for computer skills. Information Systems Research, 6, 118-143.

Conger, J.E. (2004). Collaborative electronic resource management: From acquisitions to assessment. Westport, Connecticut: Libraries Unlimited.

COUNTER Online Metrics (2017). COUNTER_Counting Online Usage of Networked Electronic Resources. Retrieved from http://www.projectcounter.org/.

Creswell, J. W. (2005). Educational research: Planning, conducting, and evaluating quantitative and qualitative research. (2nd ed.). Upper Saddle River, N.J.: Merrill.

Creswell, J. W., \& Plano Clark, V. L. (2011). Designing and conducting mixed methods research. (2nd ed.). Thousand Oaks, CA: Sage Publications.

Creswell, J.W. (1998). Qualitative inquiry and research design: Choosing among five traditions. Thousand Oaks, CA: Sage Publications.

Creswell, J.W. (2003). Research Design. Qualitative, quantitative, and mixed methods approaches. Thousand Oaks, CA: Sage Publications.

Creswell, J.W. (2012). Research Design: qualitative, quantitative and mixed methods approach. Los Angeles: SAGE Publications.

Cullen, R., \& Chawner, B. (2008). Institutional repositories in New Zealand: comparing institutional strategies for digital preservation and discovery. Proceedings of the IATUL Conferences. Paper 18. Retrieved from http://docs.lib.purdue.edu/iatul/2008/papers/18 
Cullen, R., \& Chawner, B. (2009, March). Institutional repositories and the role of academic libraries in scholarly communication. In Asia-Pacific conference on library \& information education \& practice (268-277). Retrieved from https://wiki.lib.sun.ac.za/images/6/63/2013-dlib.pdf

Dadzie, P. S. (2005). Electronic resources: Access and usage at Ashesi University College. Campus-wide Information Systems, 22(5), 290-297.

Dadzie, P.S., \& Walt, T.V. (2015). Access and use of digital resources: A survey of their value for faculty in three Ghanaian universities. LIBRI, 65(1), 57-70.

Dadzie, P.S., \& Walt, T.V. (2015). Digitising university libraries in Ghana: How technology is facilitating access to digital content and services. Mousaion, 33(3), 95-114.

Dadzie, P.S., \& Walt, T.V. (2015). Planning for digitization of university libraries in Ghana: Challenges and prospects. Library Philosophy and Practice (e-journal). Paper 1206. Retrieved from http://digitalcommons.unl.edu/libphilprac/1206

Daly, J., Kellehear, A., \& Gliksman, M. (1997). The public health researcher: A methodological guide. Australia: Oxford University Press.

Damilola, O.A. (2013). Use of electronic resources by distance students in Nigeria: The case of the National Open University, Lagos and Ibadan Study Centers. Library Philosophy and Practice (e-journal). Paper 915.

Daniel, J. (2012). Sampling essentials: Practical guidelines for making sampling choices. Thousand Oaks, CA: SAGE Publications, Inc.

Das, K.C., \& Achary, J. (2014). Information needs, information seeking behaviour and use of electronic resources by research scholars and faculty in the university and research libraries of Odisha. International Research: Journal of Library and Information Science, $4(4), 552-566$.

David, A.C., \& Liezl, B.M. (2012). The development of a collection development policy. Library Philosophy and Practice, Paper 804.

Davis, F.D. (1989). Perceived usefulness, perceived ease of use, and user acceptance of information technology. MIS Quarterly, 13(3), 319-340.

Davis, F.D., Bagozzi, R.P., \& Warshaw, P.R. (1992). Extrinsic and intrinsic motivation to use computers in the workplace. Journal of Applied Social Psychology, 22, 1111-1132.

Deans, M.O. \& Durrant, C.F. (2016.) An investigation into the knowledge and use of electronic library resources in Jamaican community colleges. Journal of Web Librarianship,10(4), 239-266.

Decman, M. (2015). Modeling the acceptance of e-learning in mandatory environments of higher education; The influence of previous education and gender. Computers in Human Behavior, (49), 272-281. 
Delaney, G., \& Bates, J. (2015). Envisioning the academic library: A reflection on roles, relevancy and relationships. New Review of Academic Librarianship, 21(1), 30-51.

Denscombe, M. (2007). The good research guide: For small-scale social research projects. (3rd ed.). Maidenhead: Open University Press.

DeVellis, R.F. (2003). Scale development: Theory and applications (2 $2^{\text {nd }}$ ed.). Newbury Park, California: Sage Publications.

Dhanavandan, S., Esmail, S.M., \& Nagarajan, M. (2012). Use of electronic resources at Krishnasamy College of Engineering and Technology Library, Cuddalore. Library Philosophy and Practice (e-journal) Paper 698.

Dubé, L., \& Paré, G. (2003). Rigor in Information Systems positivist case research: Current practices, trends, and recommendations. MIS Quarterly, 27(4), 597-636.

Dukic, D., \& Striskovic, J. (2015). Croatian University students' use and perception of electronic resources. Library and Information Science Research, 37(3), 244-253.

Duranceau, E. F., \& Hepfer, C. (2002). Staffing for electronic resource management: The results of a survey. Serials Review, 28(4), 316-320.

Dzandu, M.D., \& Boateng, H. (2013). Unraveling the dilemma of the information search process: The application of Wilson's model in a Ghanaian university setting. International Journal of Digital Services, 3(3), 22-37.

Dzandza, P., \& Alemna, A. (2011). Challenges and prospects of consortia: A case study of the Consortium of Academic and Research Libraries in Ghana (CARLIGH). Alexandria, 22(1), 19-37.

Egberongbe, H.S. (2011). The use and impact of electronic resources at the University of Lagos. Library Philosophy and Practice (e-journal). Paper 472.

Elguindi, A.C., \& Schmidt, K. (2012. Electronic resource management: practical perspectives in a new technical services model. New Delhi: CHANDOS Publishing.

Emery, J., \& Stone, G. (2013). Techniques for electronic resource management. Chicago, IL: ALA.

Emery, J., \& Stone, G. (2013). Techniques for electronic resource management. Library Technology Reports, 49(2), 1-3.

Engel, D., \& Robbins, S. (2008). Evolving roles for electronic resources librarians. In H. Yu, and S. Breivold, (Eds.), Electronic resource management in libraries: Research and practice (105-118). Hershey: Information Science Publishing.

England, L., \& Shipp, K. (2013). ERM ideas and innovations: Flexible workflows for constantly changing ERM environments. Journal of Electronic Resources Librarianship, 25(3), 218225. 
England, L.A., \& Miller, S.D. (2016). Maximizing electronic resource management in libraries: Applying business process management. Amsterdam: CHANDOS Publishing.

Erb, A.E., \& Erb, B. (2015). An investigation into the use of LibGuides for electronic resources troubleshooting in academic libraries. The Electronic Library, 33(3), 573- 589.

Erb, R.A. (2015). The impact of reorganization of staff using the core competencies as a framework for staff training and development. The Serials Librarian, 68(1-4), 92-105.

Evans, G.E. (2004). Developing library and information centre collection (4 ${ }^{\text {th }}$ ed.). Westport, CT: Libraries Unlimited.

Farley, T., Broady-Preston, J., \& Hayward, T. (1998). Academic libraries, people and change A case study of the 1990s. Library Management,19(4), 238-251.

Ferguson, D.A., \& Perse, E.M. (2000). The World Wide Web as a functional alternative to television. Journal of Broadcasting \& Electronic Media, 44(2), 155-174.

Fishbein, M., \& Ajzen, I. (1975). Belief, attitude, intention and behaviour: An introduction to theory and research. Reading, MA: Addison-Wesley.

Fornell, C., \& Larcker, D.F. (1981). Evaluating structural equation models with unobservable variables and measurement error. Journal of Marketing Research, 18(1), 39-50.

Franklin, B. (2012). Surviving to thriving: Advancing the institutional mission. Journal of Library Administration, 52(1), 94-107.

Fry, A. (2013). A hybrid model for managing standard usage data: principles for e-resource statistics workflow. Serials Review, (39), 21-23.

Fullan, M. (2007). The new meaning of education change ( $4^{\text {th }}$ ed.). New York: Teachers College Press.

Gallup International (2012). Global index of religiosity and atheism. Retrieved from https://sidmennt.is/wp-content/uploads/Gallup-International-um-tr\%C3\%papBA-ogtr\%C3\%BAleysi-2012.pdf

Gardiner, D., McMenemy, D., \& Chowdhury, G. (2006). A snapshot of information use patterns of academics in British universities. Online Information Review, 30(4), 341-359.

Gefen, D., \& Straub, D. (2005). A practical guide to factorial validity using PLS-Graph-tutorial and annotated example. Communications of the AIS, 16(5), 91-105.

Geller, M. (2006). ERM: Staffing, services, and systems. Library Technology Reports 42(2), 2225.

GhanaWeb. (2014). The country Ghana: Background information. Retrieved from http://www.ghanaweb.com/GhanaHomePage/country_information/

GhanaWeb. (2017). History of Ghana. Retrieved from http://www.ghanaweb.com/GhanaHomePage/country_information/ 
GhanaWeb (2018). Dumsor not back - ECG. Retrieved from https://www.ghanaweb.com/GhanaHomePage/NewsArchive/Dumsor-not-back-ECG-

Google Maps (2017). West Africa Map. Retrieved from https://www.google.co.nz/maps/place/West+Africa/

Green, H. (2013). Libraries across land and sea: Academic library services on international branch campuses. College \& Research Libraries, 74(1), 9-23.

Gregor, S. (2006). The nature of theory in information systems. MIS Quarterly, 30(3), 611- 642.

Gregory, V. L. (2006). Selecting and managing electronic resources: A how-to-do-it manual for librarians (Rev. ed.). New York: Neal-Schuman Publishers.

Greig, F. (2014). Approaching the modern ERM: A Plymouth perspective. The Serials Librarian, 67(2), 183-190.

Guba, E. G., \& Lincoln, Y. S. (1994). Competing paradigms in qualitative research. In N. K. Denzin and Y.S. Lincoln (Eds.), Handbook of qualitative research. Thousand Oaks, CA: Sage.

Guba, E. G., \& Lincoln, Y. S. (2005). Paradigmatic controversies, contradictions and emerging confluences. In N. Denizin \& Y. Lincoln (Eds.), The Sage Handbook of Qualitative Research.( $3^{\text {rd }}$ ed $)$. Thousand Oaks, CA: Sage.

Hair (Jr.), J.F., Hult, G.T.M., Ringle, C.M., \& Sarstedt, M. (2014). A primer on partial least squares structural equation modeling (Pls-Sem). Los Angeles, CA: Sage Publications.

Hamlett, A. (2016). Keeping up with the flow: Electronic resource workflow and analysis. The Serials Librarian, 70(1-4), 168-174.

Harnad, S. (2006). Maximizing research impact through institutional and national open-access self-archiving mandates [En línea]. CRIS2006. Open Access Institutional Repositories. Current Research Information Systems, 1113.

Harrod's Librarians' Glossary and Reference Book. ( $9^{\text {th }}$ Ed.). (2000). Aldershot: Gower.

Hartnett, E. (2014). NASIG's core competencies for electronic resources librarians revisited: An analysis of job advertisement trends, 2000-2012. The Journal of Academic Librarianship, 40 (3-4), 247-258.

Hawthorne, D. (2008). History of electronic resources. In H. Yu, \& S. Breivold (Eds.), Electronic Resource Management in Libraries: Research and Practice (1-15). Hershey, PA: IGI Global. doi:10.4018/978-1-59904-891-8.ch001

Higa, M.L., Bunnett, B., Maina, B., Perkins, J., Ramos, T., Thompson, L., \& Wayne, R. (2005). Redesigning a library's organizational structure. College and Research Libraries, 66(1). 41-58.

Higgins, S. (2017). Managing academic libraries: Principles and practice. Amsterdam: Chandos Publishing. 
Hosburgh, N. (2014). Managing the electronic resources lifecycle: Creating a comprehensive checklist using Techniques for Electronic Resource Management (TERMS). The Serials Librarian, 66(1-4), 212-219.

Hsiung, L. (2008). Expanding the role of the electronic resources (ER) librarian in the hybrid library. Collection Management, 32(1-2), 31-47.

Hulseberg, A., \& Monson, S. (2009). Strategic planning for electronic resources management: A case study at Gustavus Adolphus College. Journal of Electronic Resources Librarianship, 21(2), 163-171.

IFLA (2012). Key issues for e-resources collection development: A guide for libraries. Retrieved from http://www.ifla.org/files/acquisiton-collection development/publications/key\%20Issues $\% 20$ for $\%$

International Religious Freedom Report (2017). Ghana 2017 International Religious Freedom Report. Retrieved from https://www.state.gov/documents/organization/280990.pdf

Jacobs, M.(Ed.) (2007). Electronic resources librarianship and management of digital information: Emerging professional roles. Binghamton: The Haworth Press.

Jaguszewski, J.M., \& Williams, K. (2013). New roles for new times: Transforming liaison roles in research libraries. Washington, DC: Association of Research Libraries. Retrieved from https://www.arl.org/wp-content/uploads/2015/12/nrnt-liaison-roles-revised.pdf

Jan, S.U., \& Sheikh, R.A. (2011). Automation of university libraries: A comparative analysis of Islamabad and Khyber PukhtoonKhwa, Pakistan. Library Philosophy and Practice (ejournal). Paper 578. Retrieved from http://unllib.unl.edu/LPP/

Jewell, T. (2001). Selection and presentation of commercially available electronic resources: Issues and practices. Washington, DC: Council on Library and Information Resources.

Jewell, T. (2008). DLF electronic resource management initiative, Phase II: Final report. Washington, D.C.: Digital Library Federation and Council on Library and Information Resources.

Jewell, T. D., Anderson, I., Chandler, A., Farb, S. E., Parker, K., \& Robertson, N. D. (2004). Electronic resource management. The report of the DLF initiative. Washington, DC: Digital Library Federation. Retrieved from http://www.diglib.org/pubs/dlf102.

Johnson, P. (2009). Fundamentals of collection development and management. Chicago: American Library.

Johnson, S., Evensen, O. G., Gelfand, J., Lammers, G., Sipe, L., \& Zilper, N. (2012). Key issues for e-resource collection development: A guide for libraries. IFLA, 3-32.

Jones, R. E., Andrew, T., \& MacColl, J. (2006). The institutional repository. Oxford: CHANDOS Publishing. 
Joo, J., \& Sang, Y. (2013). Exploring Koreans' smartphone usage: An integrated model of the Technology Acceptance Model and Uses and Gratifications theory. Computers in Human Behavior, 29(6), 2512-2518.

Joshipura, S. (2008). Selecting, acquiring, and renewing electronic resources. In H. Yu \& S. Breivold (Eds.), Electronic resource management in libraries: Research and practice. Hershey: Information Science Publishing.

Kaur, M., \& Walia, P.K. (2016). Collection development of electronic resources in management libraries of India. Collection Building, 35(3), 73-83.

Kenchakkanavar, A.Y. (2014). Types of e-resources and its utilities in library. International Journal of Information Sources and Services, 1(2), 97-104.

Khan, G., \& Bhatti, R. (2016). An analysis of collection development in the university libraries of Pakistan. Collection Building, 35(1), 22-34.

Kim, J. (2010). Faculty self-archiving: Motivations and barriers. Journal of the American Society for Information Science and Technology, 61(9), 1909-1922.

Kiondo, E. (2004). Around the world to: The University of Dar es Salaam Library: Collection development in the electronic information environment. Library Hi Tech News, 21(6), 1924.

Korobili, S., Malliari, A., \& Zapounidou, S., (2011). Factors that influence information seeking behaviour: The case of Greek graduate students. Journal of Academic Librarianship, 37(2), 155-165.

Korobili, S., Tilikidou, I., \& Delistavrou, A. (2006). Factors that influence the use of library resources by faculty. Library Review, 55(2), 91-105.

Kothari, C. R. (2004). Research methodology: Methods and techniques. Delhi: Wiley Eastern.

Krieger, D.A. (1994). Keeping faith at work: The christian in the workplace. Nashville: Abingdon.

Kulp, C., \& Rupp-Serrano, K. (2007). Organizational approaches to electronic resources acquisition. Collection Management, 30(4), 3-29.

Kumar, R. (2005). A research methodology: A step-by-step guide for beginners ( $2^{\text {nd }}$ ed.). London: SAGE Publications.

Kumekpor, T. K. B. (1999). Research Methods and Techniques of Social Research. Accra: Sonlife Press.

Kwadzo, G. (2015). Awareness and usage of electronic databases by Geography and Resource Development and Information Studies graduate students in the University of Ghana. Library Philosophy and Practice. Retrieved from http://digitalcommons.unl.edu/libphilprac/1210 
Kwafoa, P.N.Y., Imoro, O. \& Afful-Arthur, P. (2014). Assessment of use of electronic resources among administrators and faculty in the University of Cape Coast. Library Philosophy and Practice. Retrieved from http://digitalcommons.unl.edu/cgi/viewcontent.cgi?article=2805\&context=libphilprac

Lamothe, A.R. (2013). Comparing linear relationships between e-book usage and university student and faculty populations: The differences between e-reference and e-monograph collections. Journal of Electronic Resources Librarianship, 25(1), 1-15.

Lee, A. S. (1989). A scientific methodology for MIS case studies. MIS Quarterly, 13(1), 33-50.

Lewis, D.W. (2007). A strategy for academic libraries in the first quarter of the 21 st century. College and Research Libraries, 68(5), 418-434.

Liew, C.L. (2014). Towards dynamic and evolving digital libraries. The Electronic Library, 32(1), $2-6$.

Lincoln, Y. S., \& Guba, E. G. (1985). Naturalistic inquiry. Beverly Hills: Sage Publications.

Lincoln, Y.S. \& Guba, E.G. (1998). Do inquiry paradigms imply inquiry methodologies? In D.M. Fetterman (ed.), Qualitative approaches to evaluation in education: The silent scientific revolution. London: Praeger.

Liu, F., \& Myers, M. D. (2011). An analysis of the AIS basket of top journals. Journal of Systems and Information Technology, 13(1), 5-24.

Liu, Z. (2006). Print vs. electronic resources: A study of user perceptions, preferences, and use. Information Processing and Management, 42(2), 583-592.

Lombard, M., Snyder-Duch, J., \& Bracken, C. C. (2010). Practical resources for assessing and reporting intercoder reliability in content analysis research projects. Retrieved from https://www.researchgate.net/profile/Cheryl_Bracken/publication/242785900_Practica 1_Resources_for_Assessing_and_Reporting_Intercoder_Reliability_in_Content_Analysis _Research_Projects/links/0deec52e14791a0d6f000000.pdf

Mackinder, L. (2014). The seemingly endless challenge: Workflows. The Serials Librarian, 67(2), $158-165$.

Madhusudhan, M. (2010). Use of electronic resources by research scholars of Kurukshetra University. The Electronic Library, 28(4). 492 - 506.

Makori, E.O. (2015). Micro factors influencing use of electronic information resources among postgraduate students in institutions of higher learning in Kenya. Library Hi Tech News, $32(1), 18-21$.

Malemia, L. (2014). The use of electronic journal articles by academics at Mzuzu University, Malawi. Library Philosophy and Practice (e-journal). Paper 1097.

Mangrum, S., \& Pozzebon. M.E. (2012). Use of collection development policies in electronic resource management. Collection Building, 31(3), 108-114. 
Mapulanga, P. (2012). Adequacy or inadequacy of budgets for University of Malawi Libraries (UML). The Bottom Line: Managing Library Finances, 25(3), 115 - 122.

Martey, A. (2004). ICT in distance education in Ghana. Library Hi Tech News, 21(5), 16-18.

Martin, H., Robles-Smith, K., Garrison, J., \& Way, D. (2009). Methods and strategies for creating a culture of collections assessment at comprehensive universities. Journal of Electronic Resources Librarianship, 21(3-4), 213-236.

Massis, B. (2016). Libraries engaging through connected learning. New Library World, 117(7/8), $540-543$

Mbabu, L. G., Bertram, A., and Varnum, K. (2013). Patterns of undergraduates' use of scholarly databases in a large research university. Journal of Academic Librarianship, 39(2), 189 193.

McCracken, E. (2007). Description of and access to electronic resources (ER): Transitioning into the digital age. Collection Management, 32(3-4), 259-275.

McDowell, C. (2007). Evaluating institutional repository deployment in American academe since early 2005: repositories by the numbers, Part 2, D-Lib Magazine, 13(9). Retrieved from http://www.dlib.org/dlib/september07/mcdowell/09mcdowell.html

Meadow, C. T. (1988). Back to future: Making and interpreting the database industry timeline. Database, 11(5), 14-16.

Miles, M.B. \& Huberman, A.M. (1994). Qualitative data analysis: An expanded sourcebook (2 $2^{\text {nd }}$ ed.). Thousand Oaks, CA: Sage Publications.

Miles, M. B., Huberman, A. M., \& Saldana, J. (2014). Qualitative data analysis: A methods sourcebook. Thousand Oaks, CA: Sage Publications.

Millar, L. (Ed) (2009). Understanding the context of electronic records management: Module 1. London: International Records Management Trust.

Miller, R. (2008). Acts of vision: The practice of licensing. Collection Management, 32(1), 173190.

Moore, G.C., \& Benbasat, I. (1991). Development of an instrument to measure the perceptions of adopting an Information Technology innovation. Information Systems Research, 2(3), 192222.

Murdock, D. (2010). Relevance of electronic resource management systems to hiring practices of electronic resources personnel. Library Collections, Acquisitions \&Technical Services, $34(1), 25-42$.

Mwilongo, K.J. (2017). The $21^{\text {st }}$ century collection development in academic library management. Sinhgad Institute of Management \& Computer Application (SIMCA), 5 - 10.

Myers, M. D. (1997). Qualitative research in Information Systems. MIS Quarterly, 21(2), 241242. 
NASIG (2012). Conference program: NASIG 27th annual conference. Retrieved from http://www.nasig.org/uploaded_files/92/files/CPC/2012/2012_NASIG_ConferenceProgr am.pdf.

Ndinoshiho, J. M. (2010). The use of electronic information services by undergraduate nursing students at the University of Namibia's Northern Campus: A descriptive study. Information Development, 26(1), 57 - 65.

Neal, J. G. (2011, March). Stop the madness: The insanity of ROI and the need for new qualitative measures of academic library success. In D. M. Mueller (Ed.), A declaration of interdependence: Proceedings of the ACRL 2011 Conference, Philadelphia, PA. Chicago, IL: ACRL.

Negahban, M. B. \& Talawar, V.G. (2009). Dependency on e-resources among social science faculty in Iranian universities. Chinese Librarianship: An International Electronic Journal, 28(1-7). Retrieved from http://www.iclc.us/cliej/cl28NT.pdf

Nettey, J. (2019, May 15). The role of investigative journalists in Ghana. The Herald. Retrieved from http://theheraldghana.com/the-role-of-investigative-journalists-in-ghana/

Neuman, W. L. (2007). Basics of social research: Qualitative and quantitative approaches (2 ${ }^{\text {nd }}$ Ed.). New York: Pearson.

Nisha, F., \& Ali, N.P.M. (2013). Awareness and use of e-journals by IIT Delhi and Delhi University library users. Collection Building, 32(2). 57-64.

Nwagwu, E. W., Adekannbi, J. \& Bello, O. (2009). Factors influencing use of the Internet: A questionnaire survey of the students of University of Ibadan, Nigeria. The Electronic Library, 27(4), 718-734.

Odunlade, R.O. (2012). Managing employee compensation and benefits for Job Satisfaction in libraries and information centres in Nigeria. Library Philosophy and Practice (e-journal). 714.

Oh, J. C., \& Yoon, S. J. (2014). Predicting the use of online information services based on a modified UTAUT model. Behaviour \& Information Technology, 33(7), 716-729.

Ohler, L.A., Schmidt, K., Shipp, K., England, L., Gilbert, M., \& Lowe, R. (2015). ERM ideas and innovations. Journal of Electronic Resources Librarianship, 27(2), 111-120.

Okeagu, G., \& Okeagu, B. (2008). Networking and resource sharing in library and information services: The case for consortium building. Information, Society and Justice, 1(2), 255262.

Okello-Obura, C. (2010). Assessment of the problems LIS postgraduate students face in accessing e-resources in Makerere University, Uganda. Collection Building, 29(3), 98-105.

Okogwu, F., \& Ozioko, R. (2018). Challenges of collection development of electronic resources in university libraries in South East Nigeria. Library Philosophy and Practice, 1-21. Retrieved from http://search.proquest.com/docview/2166932117/ 
Okojie, V. (2010). Innovative financing for university libraries in sub-Saharan Africa. Library Management, 31(6), $404-419$.

Okorie, C.N., \& Agboola, I.O. (2012). Availability and use of electronic resources in agricultural university libraries. PNLA Quarterly, 76(3), 40-48.

Okoye, M.O., \& Ugwuanyi, C.F. (2012). Management of electronic resources by cataloguers in Nigeria federal university libraries. Retrieved from http://www.unlib.unl.edukpp/

Olasina, G. (2018). Factors of best practices of e-learning among undergraduate students. Knowledge Management \& E-Learning: An International Journal, 10(3), 265-289.

Orlikowski, W. J., \& Baroudi, J. J. (1991). Studying information technology in organizations: Research approaches and assumptions. Information Systems Research, 2(1), 1-28.

Owolabi, K. A., Ajiboye, B.A., Lawal, O.W., \& Okpeh, S.C. (2012). Use of electronic information sources (EIS) by faculty in Nigerian universities. Library Philosophy and Practice. Retrieved from https://digitalcommons.unl.edu/libphilprac/721

Oye, N. D., Iahad, N. A., \& Rabin, Z. A. (2011). A Model of ICT acceptance and use for teachers in higher education institutions. International Journal of Computer Science \& Communication Networks, 1(1), 22-40.

Oye, N. D., Noorminshah, A., \& NorZairah, A. R. (2011). Examining the effect of Technology Acceptance Model on ICT usage in Nigerian tertiary institutions. Journal of Emerging Trends in Computing and Information Sciences, 2(10), 433-545.

Ozoemelem, O.A. (2009). Use of electronic resources by postgraduate students of the Department of Library and Information Science of Delta State University, Abraka, Nigeria. Library Philosophy and Practice. Retrieved from http://unlib.unl.edu/lpp/lpp2009.htm.

Padhi, N. (2018). Acceptance and usability of OER in India: An investigation using UTAUT model. Open Praxis, 10(1), 55-65.

Pallant, J. (2001). SPSS survival manual: A step by step guide to data analysis using SPSS for windows. Philadelphia: Open University Press.

Parsons, T. (1956). Suggestions for a sociological approach to theory of organizations - I. Administrative Quarterly, 1, 63-85.

Patra, N. K., \& Jha, S. (2014). Comparative analysis of electronic resource management systems (ERMS): A web study. In N.K. Patra, B. Kumar \& A.K. Pani (Eds.), Progressive Trends in Electronic Resource Management in Libraries (118-146). Hershey: Information Science Publishing.

Patton, M.Q. (2002). Qualitative research and evaluation methods. London: Sage Publications.

Perry, C. (1994). A Structured approach to presenting PhD theses: Notes for candidates and their supervisors. School of Marketing, Advertising and Public Relations, Queensland University of Technology. 
Pesch, O. (2008). Library standards and e-resource management: A survey of current initiatives and standards efforts. Serials Librarian, 55(3), 481-486.

Pesch, O. (2009). ERMs and the e-resource lifecycle [PowerPoint slides]. Retrieved from http://tinyurl.com/ERLifeCycle

Pickard, A. J. (2007). Research methods in information. London: Facet.

Pickard, A.J. (2013). Research methods in Information. ( $2^{\text {nd }}$ ed.). London: Facet Publishing.

Pickett, C., Stephens, J., Kimball, R., Ramirez, D., Thornton, J., \& Burford, N. (2011). Revisiting an abandoned practice: The death and resurrection of collection development policies. Collection Management, 36(3), 165-181.

Pinfield, S. (2005). A mandate to self-archive? The role of open access institutional repositories. Serials, 18(1), 30-34.

Pomerantz, S.B. (2010). The role of the acquisitions librarian in electronic resources management. Journal of Electronic Resources Librarianship, 22(1-2), 40-48.

Prakashe, V.A., \& Tayade, S. (2015). Study of e-resources of Indian Institute of Management (IIM) Libraries in India. DESIDOC Journal of Library and Information Technology, 35(3), 217-222.

Rathmel, A., Currie, L., \& Enoch, T. (2015). "Big deals" and squeaky wheels: Taking stock of your stats. The Serials Librarian, 68(1-4), 26-37.

Rogers, E.M. (1995). The diffusion of innovations. (5 $5^{\text {th }}$ ed.). New York: Free Press.

Ryan, A. B. (2006). Post-positivist approaches to research. In Researching and writing your thesis: A guide for postgraduate students (12-26). MACE: Maynooth Adult and Community Education.

Sadeh, T., \& Ellingsen, M. (2005). Electronic resource management systems: The need and the realization. New Library World, 106(5/6), 208-218.

Sanchez, V.B. (2005). Collection development policies in university libraries: A space for reflection. Collection Building, 24(1), 35-43.

Sasikala, C., Nagaratnamani, G., \& Dhanraju, V. (2014). Pattern of collection development in academic libraries in Andhra Pradesh: A study. IOSR Journal of Humanities and Social Science, 19(2), 5-18.

Sheeja, N. K. (2010). Sciences versus social sciences: A study of information-seeking behaviour and user perceptions of academic researchers. Library Review, 59(7), 522-531.

Shu, Z. (2012). The research of digital resource technique in libraries. International Conference on Information Technology and Management Science (ICITMS 2012) Proceedings. Retrieved from https://link.springer.com/content/pdf/10.1007\%2F978-3-642-349102_15.pdf 
Smith, K. (2016). Managing electronic resource workflows using ticketing system software. Serials Review, 42(1), 59-64.

Sorensen, C., \& Sarjeant-Jenkins, R. (2016). Sustainable growth with sustainable resources: Change management, participative consultation and grassroots planning for a new future. Library Management, 37(3), 114-124.

Stachokas, G. (2009). Electronic resources and mission creep: Reorganizing the library for the twenty-first century. Journal of Electronic Resources Librarianship, 21(3-4), 206-212.

Stachokas, G. (2012). Making electronic resources accessible. In R. O. Weir (Ed.), Managing electronic resources: A LITA guide. Chicago, IL: ALA Techsource.

Stanton, K.V., \& Liew, C.L. (2012). Open access theses in institutional repositories: an exploratory study on the perceptions of doctoral students. Information Research, 17(1). Paper 507. Retrieved from http://www.informationr.net/ir/17-1/paper507.html

Steinerová, J., \& Šušol, J. (2007). Users’ information behaviour - a gender perspective. Information Research, 12(3). Paper 320. Retrieved from http://informationr.net/ir/paper320

Stoffle, C.J., Renaud, R. \& Veldof, J.R. (1996), Choosing our futures. College and Research Libraries, 57(3), 213-225.

Su, D. (Ed.) (2007). Collection Development Issues in the online environment. Binghamton, NY: Haworth Information Press.

Sukovic, S. (2008). Convergent flows: humanities scholars and their interactions with electronic texts. Library Quarterly, 78(3), 263-284.

Sutton, S. \& Davis, S. (2011) Core competencies for electronic resources librarians. The Serials Librarian, 60(1-4), 147-152.

Swain, D. P. (2010). Students' keenness on use of e-resources. The Electronic Library, 28(4), 580591.

Swanson, E. B. (1988). Information System Implementation: Bridging the gap between design and utilization. Homewood, IL: Irwin

Tahir, M., Mahmood, K., \& Shafique, E. (2010). Use of electronic information resources and facilities by humanities scholars. The Electronic Library, 28(1), 122-136.

Taylor, M., \& Heath, F. (2012), Assessment and continuous planning: The key to transformation at the University of Texas libraries. Journal of Library Administration, 52(5), 424-435.

Taylor, S., \& Todd, P. (1995). Decomposition and crossover effects in the Theory of Planned Behavior: A study of consumer adoption intentions. International Journal of Research in Marketing, 12(2), 137-155.

Tella, A., \& Mutula, S.M. (2008). Gender difference in computer literacy among undergraduate students at the University of Botswana: Implication for library use. Malaysian Journal of Library \& Information Science, 13 (1), 59-76. 
TERMS Facebook group (2017). Techniques of Electronic Resource Management (TERMS)

Retrieved from https://www.facebook.com/groups/174086169332439

Thomas, D., Davidson, C., Kyrillidou, M., \& Plum, T. (2012). Measuring use of licensed electronic resources. Library Management, 33(6/7), 374 - 388.

Thompson, E.S., \& Pwadura, J. (2014). Library automation at the University for Development Studies: Challenges and prospects. New Review of Academic Librarianship, 20(1), 66-77.

Toms, E. G., \& O'Brien, H. L. (2008). Understanding the information and communication technology needs of the e-humanist. Journal of Documentation, 64 (1), 102-130.

Tury, S., Robinson, L., \& Bawden., D. (2015). The Information seeking behaviour of distance learners: A case study of the University of London International Programmes. The Journal of Academic Librarianship, 41(3), 312-321.

Ubogu, J.O., \& Okiy, R.B. (2011). Sources of funds in academic libraries in Delta State, Nigeria. Library Philosophy and Practice (e-journal). Paper 676.

UCC (2019). The University of Cape Coast. Retrieved from http://www.uccghanaportal.com/

UG (2019). The University of Ghana. Retrieved from http://www.ug.edu.gh

Ugwu, C.I., \& Onyegiri, D.C. (2013). Management problems of electronic information resources: A case study of UNN library. International Journal of Library and Information Science, 5(5), 126-133.

Ukachi, N.B. (2015). Information literacy of students as a correlate of their use of electronic resources in university libraries in Nigeria. The Electronic Library, 33(3), 486-501.

Ullah, A. (2015). Examining collaboration among central library and seminar libraries of leading universities in Pakistan. Library Review, 64(4/5), 321-334.

University of California San Diego Libraries (n.d.). Budget and planning, Retrieved from http://libraries.ucsd.edu/collections/budget/index.html.

Van Raaij, E.M., \& Schepers, J.J.L. (2008). The acceptance and use of a virtual learning environment in China. Computers \& Education, 50(3), 838-852.

Velasquez, D., \& Campbell-Meier (2018). Marketing practices in Australian libraries: Is promotion enough? Journal of the Australian Library and Information Association, 67(2), 116-130.

Venkatesh, V., Morris, M.G., Davis, G.B., \& Davis, F.D. (2003). User acceptance of information technology: Toward a unified view. MIS Quarterly, 27(3), 425-478.

Vickery, J. (2004). Making a statement: Reviewing the case for written collection development policies. Library Management, 25(8/9), 337-342.

Vohra, V. (2014). Using the multiple case study design to decipher contextual leadership behaviors in Indian organizations. Electronic Journal of Business Research Methods, 12(1), 54-65. 
Wadekar, P. P., \& Nagarkar, S.P. (2018). Current practices of management of online databases at university libraries in Maharashtra state of India, Library Management, 38(8/9), 569-582.

Walsham, G. (1995b). Interpretive case studies in IS research: Nature and method. European Journal of Information Systems, 4(2), 74-81.

Walsham, G. (2006). Doing interpretive research. European Journal of Information Systems, 15(3), 320-330.

West, W.L., \& Miller, H.S. (2011). Electronic journals: Cataloging and management practices in academic libraries, Serials Review, 37(4), 267-274.

WIUC (2019). Wisconsin International University College. Retrieved from http://www.wiucghana.edu.gh/

Wolverton, R.E., (Jr) \& Davidson, K. (2011). E-resource round up. Journal of Electronic Resources Librarianship, 23(1), 68-95.

Wu, M., \& Chen, S. (2012). How graduate students perceive, use, and manage electronic resources. Aslib Proceedings, 64 (6), 641 - 652.

Yin, R. (2003). Case study design and research: Design and methods. ( $3^{\text {rd }}$ ed.). Thousand Oaks, CA: Sage Publications.

Yin, R. (2014). Case study research: Design and methods. (5 ${ }^{\text {th }}$ ed.). Thousand Oaks, CA: Sage Publications.

Yin, R. K. (1994). Discovering the future of the case study method in evaluation research. Evaluation Practice, 15(3), 283-290.

Yu, H. \& Breivold, S. (2008). Electronic resource management in libraries: Research and practice. Hershey: Information Science Reference.

Zha, X., Li, J. and Yan, Y. (2012). Understanding usage transfer from print resources to electronic resources: A survey of users of Chinese university libraries. Serials Review, 38(2), 93-98. 



\title{
Appendices
}

\section{Appendix A: Participant Information Sheet}

\author{
Research Project Title: Electronic Resource Management and Usage in Academic Libraries: The \\ Ghanaian Context
Researcher: Winifred Bentil, School of Information Management, Victoria University of Wellington

As part of the completion of my $\mathrm{PhD}$, this study is designed to investigate the management and usage of electronic resources in academic libraries. The project aims to take a holistic view of electronic resource management and usage in academic libraries to explore how they are related. It seeks to determine how electronic resources are planned, implemented and used as well as the contextual factors surrounding these activities. This study intends to provide recommendations supported by sound research for managing electronic resources to facilitate effective use of these resources. Victoria University requires, and has granted, approval from the School's Human Ethics Committee.

I am inviting the Librarian, Head of Electronic Resources, Heads of Units and key employees in the library as well as executives of CARLIGH, whose duties are related to electronic resources to participate in an interview of about an hour. Permission will be asked to audio-record the interview, and a transcript of the interview will be sent to participants for checking.

Participation is voluntary, and you will not be identified personally in any written report produced as a result of this research, including possible publication in academic conferences and journals. However, your institution will be named in the published results. All materials collected will be kept confidential and will be viewed only by myself and my supervisors as detailed below. The thesis will be submitted for marking to the School of Information Management, and subsequently deposited in the University Library. Should any participant wish to withdraw from the project, they may do so within two weeks after the interview and the data collected up to that point will be destroyed. All data collected from participants will be destroyed within 5 years after the completion of the project.

If you have any questions or would like to receive further information about the project, please contact me at winifred.bentil@vuw.ac.nz or you may contact my supervisors Dr Chern Li Liew, Senior Lecturer at chernli.liew@vuw.ac.nz and Dr Brenda Chawner, Senior Lecturer at brenda.chawner@vuw.ac.nz. 



\section{Appendix B: Participant Consent Form}

\section{Research Project Title: Electronic Resource Management and Usage in Academic Libraries: The Ghanaian Context}

\section{Researcher: Winifred Bentil, School of Information Management, Victoria University of Wellington}

I have been given and have understood an explanation of this research project. I have had an opportunity to ask questions and have them answered to my satisfaction.

I understand that I may withdraw myself (or any information I have provided) from this project, without having to give reasons, by e-mailing winifred.bentil@vuw.ac.nz within two weeks after the interview.

I understand that any information I provide will be kept confidential to the researcher and their supervisors, the published results will not use my name, and that no opinions will be attributed to me in any way that will identify me. However, my institution will be named in the published results.

I understand that the data I provide will not be used for any other purpose or released to others.

I understand that, if this interview is audio recorded, the recording and transcripts of the interviews will be erased within 5 years after the conclusion of the project. Furthermore, I will have an opportunity to check the transcripts of the interview.

Please indicate (by ticking the boxes below) which of the following apply:

I would like to receive a summary of the results of this research when it is completed.

I agree to this interview being audio recorded.

Signed:

Name of participant:

Date: 



\section{Appendix C: Interview Protocol}

A brief description of the research to the participant before the interview begins. This description will highlight the objectives of the research which are to investigate how ERs are managed and used, contextual factors affecting these activities and exploration of how the two concepts are related. It will also include the benefits of the research to the institution. Furthermore, interviewees will be assured of confidentiality.

\section{INTERVIEW GUIDE FOR UNIVERSITY LIBRARIAN}

\section{Introductory Questions:}

1. Please describe your professional background.

2. Kindly tell me about your role and responsibilities.

\section{Management of Electronic Resources (ERs) in the Library}

\section{ER Services and ICT Infrastructure}

3. What are the ER services provided by the library?

4. Briefly describe the overall ICT infrastructure of your library/institution.

5. What is being done by the library to sustain or enhance its ICT infrastructure?

6. Do you play any direct role related to the ERs of the library?

\section{Policies for ERs}

7. Are there specific policies to guide ERs activities in the library?

a. How long have these policies been in implementation?

b. Who are the people involved in the development of these policies?

c. How effective have these policies been so far regarding implementation? How often are they reviewed?

\section{Finance/Budgeting for Electronic Resources}

8. What are the sources of funding for the library?

9. What is the annual budget allocated to the library?

10. What percentage of the library's budget is allocated to ERs?

11. How adequate is the funding allocated to the electronic resources provided by the library? 
12. What strategies are in place to ensure sustainable funding for ERs?

\section{Staffing and Training for ER Services}

13. Which unit of the library is responsible for managing ERs of the library? (selection, acquisition, implementation etc).

14. Has the library had to employ people specifically to manage e-resources?

15. What are the mechanisms for discovering required competencies, knowledge base/skills of the staff in charge of ERs?

16. How does the library meet the training needs of the staff in charge of ERs? (frequency of training).

17. Are there any staffing challenges regarding ERs?

\section{Partnership/Collaboration}

18. How has your membership of CARLIGH impacted on the ER services? Selection, acquisition?

19. Are there any challenges of consortia purchasing?

\section{Impact of ERs on the Library}

20. How have ERs impacted on the library and its services?

a. Organisational structure of the library?

b. Do you perceive a need for a change in the organisational structure in the future? Why or Why not?

c. What innovative strategies are being adopted to cope with the technological environment?

\section{Usage of ERs}

21. Are there any mechanisms for tracking the usage of ERs?

22. What is your opinion on the level of usage of the ERs provided by the library?

23. What strategies have been put in place to promote the usage of ERs?

24. What is the role of the library in supporting digital literacy programmes in the institution? 


\section{Conclusion}

25. What do you think are enablers and hindrances of effective ERM?

26. In what ways do you think these challenges can be overcome?

27. Do you have any other issues you would like to comment on?

\section{INTERVIEW GUIDE FOR ELECTRONIC RESOURCE LIBRARIAN}

\section{Introductory Questions:}

1. Please describe your professional background.

2. Kindly tell me about your role and responsibilities.

\section{Planning for Electronic Resources (ERs) in the Library ICT Infrastructure}

3. Please describe the ERs and ICT infrastructure of your library/institution.

4. What is being done by the library to sustain its ICT infrastructure?

\section{Policies for ERs}

5. Are there specific policies in the library to guide ER activities?

a. How effective have these policies been so far regarding implementation and renewal?

\section{Budgeting for ERs}

6. How adequate is the funding allocated to the ERs provided by the library?

7. Are there any measures being taken by the library for sustainable funding?

\section{Staffing for ERs}

8. Which unit(s) of the library is/are responsible for managing ERs? (Selection, acquisition, etc?) job titles?

a. What are the strengths and challenges of this ERM arrangement or approach?

9. Has the library had to employ people specifically to assist in managing e-resources?

10. Are there any mechanisms for discovering required competencies, knowledge base/skills of ER staff? 
11. Drawing from your experience, what are the required competencies of ER librarians?

12. How does the library meet the training needs of the staff in charge of ERs? (frequency of training).

13. Are there any staffing challenges with regard to the ERs?

\section{Implementing of ERs in the Library}

\section{ER Workflow}

14. Please describe the various activities in the ER workflow.

\section{Selection}

15. How are ERs selected by the library?

a. Modes of discovery.

b. Criteria for selection?

\section{Trial}

16. Do you have opportunities for ER trial?

a. Please describe activities during a trial session - Duration, etc.

b. Trial statistics? (Who/which unit is responsible for taking trial statistics?)

\section{Licensing and Acquisition}

17. Briefly describe the procedures involved in negotiation, licensing, and acquisition of ERs.

a. Mode(s) of acquisition.

b. What are the issues involved in managing licensing agreements?

c. Who are the players involved in negotiating licensing agreements for ERs?

d. What factors are mainly considered in the terms of agreement? (Number of simultaneous users, perpetual access, etc.)

e. Have you had any training on the negotiation of license for ERs?

f. Briefly describe the pricing model(s) of acquiring the ERs. (Price per unit, price per user, price per use, package subscription, consortia purchasing).

g. What are the general e-resource acquisition challenges faced by the library and how are they being addressed? 


\section{Implementation}

18. Please describe the activities and procedures that are carried out after acquisition?
a. Who is/are responsible for these activities?
b. What are the challenges faced in carrying out these activities?

\section{Access}

a. Kindly describe the activities carried out in providing access to ERs of the library.

b. Who/which unit is responsible for these activities?

c. Access restriction - (on-campus, off-campus, ID\& password/IP address etc).

d. What support is provided to users?

e. How are ER-related issues tracked? (A central site for tracking?).

\section{Administrative functions}

19. What administrative management functions are carried out once access to these resources is provided? (URL maintenance, etc).

\section{Evaluation}

20. How are the ERs evaluated? Criteria for evaluation, frequency, responsibility, etc?

21. How are ERs preserved for future or perpetual access?

\section{Impact of ERs on the Library}

28. How have ERs impacted on the library and its services?

d. Impacted on the organisational structure of the library.

e. Do you perceive a need for changes in the organisational structure of the library? Please explain.

f. What innovative strategies are being adopted by the library to cope with the technological environment?

\section{Usage of ERs}

29. Are there any mechanisms for tracking the usage of ERs?

30. What is your opinion on the level of usage of the ERs? 
31. What strategies are adopted for promotion?

32. What role does the library play in supporting digital literacy programmes in the institution?

\section{Conclusion}

33. What in your opinion are enablers and hindrances to effective ERM?

34. In what ways do you think these hindrances can be overcome?

35. Do you have any other issues you would like to comment on?

\section{INTERVIEW GUIDE FOR HEADS OF UNIT(S)}

1. Please describe your professional background.

2. Kindly tell me about your role and responsibilities.

3. Do you play any direct role related to the ERs of the library?

4. What is your opinion on the organisational structure for managing the ERs of the library?

5. How have ERs impacted on your role and responsibilities?

6. How have ERs impacted on the library and its services?

7. How often do you participate in ICT training programmes organised for library staff?

8. In your opinion, what are the challenges facing the library in providing ER services?

9. Do you have any further comments on the ERs provided by the library?

\section{INTERVIEW GUIDE FOR CHAIR OF CARLIGH}

\section{Introductory Questions:}

1. Please describe your professional background.

2. Kindly tell me about your role and responsibilities.

\section{Management of Electronic Resources (ERs) of the Consortium}

\section{ER Services and ICT Infrastructure}

3. Do you play any direct role related to the ERs of the consortium?

\section{Policies for ERs}

4. Are there specific policies to guide ERs activities of the consortium?

a. How long have these policies been in implementation? 
b. Who are the people involved in the development of these policies?

c. How effective have these policies been so far regarding implementation and renewal?

\section{Finance/Budgeting for Electronic Resources}

5. How does CARLIGH obtain funding for ERs?

6. What strategies are in place to ensure sustainable funding for ERs?

\section{Challenges}

7. Are there any challenges of consortia purchasing?

\section{Conclusion}

8. What do you think are enablers and hindrances of effective ERM?

9. In what ways do you think these challenges can be overcome?

10. Do you have any other issues you would like to comment on?

\section{INTERVIEW GUIDE FOR ELECTRONIC RESOURCE CHAIR OF CARLIGH}

\section{Introductory Questions:}

1. Please describe your professional background.

2. Kindly tell me about your role and responsibilities.

\section{Planning for Electronic Resources (ERs) of the Consortium}

\section{Electronic Resources}

3. Please describe the ERs of the consortium.

\section{Policies for ERs}

4. Are there specific policies to guide ER activities of the consortium?

a. How effective have these policies been so far regarding implementation? Frequency of renewal? 


\section{Budgeting for ERs}

5. How does the consortium obtain funding for ERs?

6. Are there any measures being taken by the consortium for sustainable funding?

\section{Implementing of ERs in the Library}

\section{ER Workflow}

7. How are ERs discovered and selected by the consortium for members? Modes of discovery, selection criteria, etc.

8. Please describe the acquisition process.

a. Trial session - Duration, assessment, etc.

b. Procedures involved in negotiation and licensing of ERs.

c. Pricing models

d. Cost sharing model for members

9. Are there any acquisition challenges faced by CARLIGH?

\section{Implementation}

10. Please describe the activities and procedures that are carried out after acquisition.

a. What are the challenges faced in carrying out these activities?

Access

11. Kindly describe the activities involved in providing members with access to ERs of the consortium.

a. Availability of support for member libraries.

\section{Administrative functions}

12. What administrative management functions are carried out once members have access to these resources?

\section{Evaluation}

13. How are the ERs evaluated? Criteria for evaluation, frequency, responsibility, etc? 


\section{Usage of ERs}

14. What is your opinion on the level of usage of the ERs?

15. What role does the consortium play in supporting digital literacy programmes in the member institutions?

\section{Conclusion}

16. What in your opinion are enablers and hindrances to effective ERM by members?

17. In what ways do you think these hindrances can be overcome?

18. Do you have any other issues you would like to comment on?

\section{INTERVIEW GUIDE FOR TREASURER OF CARLIGH}

\section{Introductory Questions:}

1. Please describe your professional background.

2. Kindly tell me about your role and responsibilities.

\section{Planning for Electronic Resources (ERs) of the Consortium}

\section{Budgeting for ERs}

3. How does the consortium obtain funding for ERs?

4. Are there any measures being taken by the consortium for sustainable funding?

\section{Implementing of ERs in the Library}

\section{ER Workflow}

7. How are ERs discovered and selected by the consortium for members?

8. Please describe the acquisition process - pricing model(s), cost sharing model, etc.

9. Are there any acquisition challenges faced by CARLIGH?

10. Kindly describe any training you have had on negotiation and licensing of ERs.

10. Please describe the activities and procedures that are carried out after acquisition.

\section{Challenges}

11. What are the challenges faced by the consortium with regard to ERs? 


\section{Conclusion}

16. What in your opinion are enablers and hindrances to effective ERM by members?

17. In what ways do you think these hindrances can be overcome?

18. Do you have any other issues you would like to comment on? 


\section{Appendix D: Survey Questionnaire on the Usage of E-Resources}

(Questionnaire set 1: To be completed by Faculty)

\section{SECTION A: BIOGRAPHIC DATA}

1. Name of University: a) CU [ ] b) UCC [ ] c) UG [ ] d) WIUC [ ] e) Other (Please specify).

2. Gender: Male [ ] Female [ ]

3. Age: a) 20-29 [ ] b) 30-39 [ ] c) 40-49 [ ] d) 50-59 [ ] e) 60 and above [ ]

4. Faculty/ Department (Tick where appropriate)

a) Humanities [ ] b) Social Sciences [ ] c) Sciences [ ] d) Engineering [ ] e)Other.

5. Please tick where appropriate

a) Professor [ ] b) Associate Professor [ ] c) Senior Lecturer [ ] d) Lecturer [ ] e)Assistant Lecturer [ ] f) Other.

\section{SECTION B: AWARENESS OF ELECTRONIC RESOURCE SERVICES}

6. Which of the following electronic resources of the university library are you aware of? Tick as many as applicable.
a) Online databases [ ] b) CD ROM [ ]
c) E-book [ ] $\quad$ d) E-Journal [ ]
e) Institutional Repository [ ] f) Don't know of any [ ]
g) Other (please specify)

7. How did you get to know about these resources?
a) Orientation [ ]
b) Notices [ ]
c) Colleague [ ]
d) Newsletters [ ]
e) Library Website
f) Through this survey [ ]
g) Friends [ ]
h) Training by the library [ ]
i) Other (please specify).

\section{SECTION C: USE OF ELECTRONIC RESOURCES}

8. Do you use the electronic resources of the University library?

a) Yes [ ] b) No [ ]

9. If not, why not? (After answering question 9, skip to question 13) 
10. If yes to question 8 , how many hours do you averagely spend in using the electronic resources of the university library?

a) Up to 2 hours in a day [ ] b) 2 to 4 hours in a day [ ] c) Up to 2 hours in a week [ ] d) 2 to 4 hours in a week[ ] e) Up to 2 hours in a month [ ] f) 2 to 4 hours in a month [ ] g) Up to 4 hours in a semester [ ] h) Other (kindly specify)...

11. From which location/device do you mostly access the electronic resources of the library? Tick as many as applicable.

a) Office [ ] b) Computer lab/Library [ ] d) Cybercafé [ ] e) Home [ ]

f) Mobile phone [ ] g) Other (please specify)

12. Which type of electronic resources of the library do you usually use? Tick as many as applicable.

a) Online databases [ ] b) CD ROM [ ]

c) E-book [ ] $\quad$ d) E-Journal [ ]

e) Institutional Repository [ ] f) Other (Please specify)

13. Where do you typically begin your search for information on a particular topic?

a) Print documents [ ] b) Library website [ ] c) Alternative resources on the Internet [ ]

d) Other (specify).

14a. I prefer using alternative resources on the Internet to the e- resources of the library. Please specify your agreement/disagreement with the statement.

a) Strongly disagree [ ] b) Disagree [ ] c) Neither agree nor disagree [ ] d) Agree [ ] e) Strongly agree [ ]

14b. Please explain your response to question 14a.

15. Tick as many as applicable regarding the electronic resources of your institutional library.

a) I have ever recommended ERs to the library [ ]

b) I have ever used ERs during a trial period [ ]

c) I have had an opportunity to provide feedback on the ERs [ ]

d) I have participated in a survey/research to assess ERs [ ]

e) None of the above [ ] 
For questions 16-19, please specify your agreement/disagreement with each of the following statements. Strongly disagree (SD); Disagree (D); Neither agree nor disagree (NA/D); Agree (A); Strongly agree (SA)

\begin{tabular}{|c|c|c|c|c|c|c|}
\hline No. & Question & SD & D & NA/D & $\mathbf{A}$ & $\mathbf{S A}$ \\
\hline 16. & $\begin{array}{l}\text { I am able to retrieve relevant information in } \\
\text { electronic format. }\end{array}$ & & & & & \\
\hline 17. & $\begin{array}{l}\text { I am encouraged by library staff to use the e- } \\
\text { resources of the library. }\end{array}$ & & & & & \\
\hline 18. & $\begin{array}{l}\text { Recommendations by colleagues influence my } \\
\text { decision to use the electronic resources of the } \\
\text { library. }\end{array}$ & & & & & \\
\hline 19. & $\begin{array}{l}\text { I have easy access to the required facilities to use } \\
\text { electronic resources. }\end{array}$ & & & & & \\
\hline
\end{tabular}

20. I refer students to the electronic resources of the library for some assignments.

a) Very often [ ] b) Quite often [ ] c. Often [ ] d) Occasionally [ ] e) Yet to refer students [ ] f)Don't see the need to do so [ ]

\section{SECTION D: TRAINING IN THE USE OF ELECTRONIC RESOURCES}

21. How have you learned to use the electronic resources of the library?
a) Trial and error [ ]
b) Orientation / Training by the library [ ]
c) Self-trained [ ]
d) Guidance from colleagues [ ]

e) Guidance from other library staff [ ]

f) Other.

22. Have you ever attended any training provided by the library on the use of electronic resources of the library? If No, skip to Question 22b.

a) Yes [ ] b. No [ ]

22a. If yes, do you think the training you received met your needs?
a) Yes [ ]
b) Somehow [
] c) No [ ]

22b. If you have never attended any training provided by the library, provide reasons.

a. Training not available [ ] b. Didn't know where to get training [ ] c. I am fairly competent [ ]

d. E-resources are self-explanatory on the website [ ] e. Attended similar training elsewhere [ ]

f. Other

23. How often does the library provide training on the use of electronic resources?

a) Very often [ ] b) Often [ ] c) Once in a while [ ] d) Not at all [ ] e) Not sure [ ] 
24. Please comment on the type of training you desire or expect from the library.

For questions 25-38, please specify your agreement/disagreement with each of the following statements? Strongly disagree (SD); Disagree (D); Neither agree nor disagree (NA/D); Agree (A); Strongly agree (SA)

\begin{tabular}{|l|l|l|l|l|l|l|}
\hline No. & Question & SD & D & NA/D & A & SA \\
\hline 25. & $\begin{array}{l}\text { I am confident using the electronic resources of the } \\
\text { library. }\end{array}$ & & & & \\
\hline 26. & $\begin{array}{l}\text { I am proficient in the use of the library's electronic } \\
\text { resources. }\end{array}$ & & & & \\
\hline 27. & $\begin{array}{l}\text { The training I received from the library has } \\
\text { enhanced my ability to use e-resources. }\end{array}$ & & & & \\
\hline
\end{tabular}

\section{SECTION E: PERCEPTION ON ELECTRONIC RESOURCES OF THE LIBRARY}

\begin{tabular}{|c|c|c|c|c|c|c|}
\hline No. & Question & SD & D & NA/D & $\mathbf{A}$ & SA \\
\hline 28. & $\begin{array}{l}\text { I use alternative resources on the Internet rather than } \\
\text { electronic resources of the library. }\end{array}$ & & & & & \\
\hline 29. & $\begin{array}{l}\text { I am familiar with the e-resources of the library and } \\
\text { find it easy to use. }\end{array}$ & & & & & \\
\hline 30. & $\begin{array}{l}\text { Using the electronic resources of the library } \\
\text { simplifies finding information. }\end{array}$ & & & & & \\
\hline 31. & $\begin{array}{l}\text { Using electronic resources of the library reduces the } \\
\text { time required for finding information compared to } \\
\text { alternative resources on the Web. }\end{array}$ & & & & & \\
\hline 32. & $\begin{array}{l}\text { Electronic resources of the library are more useful } \\
\text { than alternative resources freely available on the } \\
\text { Web. }\end{array}$ & & & & & \\
\hline 33. & $\begin{array}{l}\text { I possess the necessary knowledge and skills to use } \\
\text { the electronic resources of the library. }\end{array}$ & & & & & \\
\hline 34. & $\begin{array}{l}\text { It takes a lot of effort to become skillful at using the } \\
\text { electronic resources of the library. }\end{array}$ & & & & & \\
\hline 35. & $\begin{array}{l}\text { It is easy to get relevant information using the } \\
\text { electronic resources of the library. }\end{array}$ & & & & & \\
\hline 36. & $\begin{array}{l}\text { My academic outputs have improved as a result of } \\
\text { using the electronic resources of the library. }\end{array}$ & & & & & \\
\hline 37. & $\begin{array}{l}\text { Overall, it is easy to use the library's electronic } \\
\text { resources. }\end{array}$ & & & & & \\
\hline 38. & $\begin{array}{l}\text { I am satisfied with the library's electronic resource } \\
\text { services. }\end{array}$ & & & & & \\
\hline
\end{tabular}


39.

Please

explain

your

response

to

question

38.

\section{SECTION F: CHALLENGES IN USING ELECTRONIC RESOURCES}

For questions 40-41, please rate how much you agree or disagree with each of the following statements? Strongly disagree (SD); Disagree (D); Neither agree nor disagree (NA/D); Agree (A); Strongly agree (SA)

\begin{tabular}{|l|l|l|l|l|l|l|}
\hline No. & Question & SD & D & NA/D & A & SA \\
\hline 40. & $\begin{array}{l}\text { I can access the electronic resources of the library } \\
\text { whenever I want. }\end{array}$ & & & & \\
\hline 41. & $\begin{array}{l}\text { Academic workload/teaching responsibilities prevent } \\
\text { me from making time to use the electronic resources } \\
\text { of the library. }\end{array}$ & & & \\
\hline
\end{tabular}

42). What are some of the limitations you encounter in using e-resources of the library? Select as many as applicable.
a) Information overload [ ]
b) provides unorganised Information [ ]
c) Inadequate searching skills [ ]
d) Lack of relevant information [ ].
e) Lack of time for searching [ ]
f) Difficult to read from screen [ ]
g) Inadequate networked computers [ ]
h) Access time charges [ ]
i) Limited opening time for access to computers [ ] j) Poor Internet connectivity [ ]
k) Not easy to use [ ]
1) No off campus access [ ]
m) Frequent power cuts [ ]
n) Other (specify).

43. Any additional comments on difficulties or challenges in using e-resources of the library?

\section{SECTION G: SUGGESTIONS TO IMPROVE AWARENESS AND USE}

44. Electronic resources of the library have been well publicised to members of the university community?
a) Strongly disagree [
] b) Disagree [
] c) Neither agree nor disagree [
] d) Agree [ ]
] e) Strongly agree [ ]

45. What could the library do to promote and improve the use of e-resources? Select as many as applicable.
a) More awareness programmes [ ]
b) Training should be improved [ ]
c) Reduction of access time cost [ ] 
d) Provision of relevant resources [ ]

e) Solving network problems [ ]

f) Provision of more networked computers [ ]

g) Extended opening time for access to computers [ ]

h) Use of generators to solve power cuts [ ]

i) Other suggestions.

46. To conclude this survey, do you have any additional comments you would like to make regarding the electronic resources provided by the library?

Thank you 


\section{SURVEY QUESTIONNAIRE ON THE USAGE OF E-RESOURCES}

(Questionnaire Set 2: To be completed by Postgraduate Students)

\section{SECTION A: BIOGRAPHIC DATA}

1. Name of University: a) CU [ ] b) UCC [ ] c) UG [ ] d) WIUC [ ] e) Other (Please specify....

2. Gender: Male [ ] Female [ ]

3. Age: a) 20-29 [ ] b) 30-39 [ ] c) 40-49 [ ] d) 50-59 [ ] e) 60 and above [ ]

4. Faculty/ Department (Tick where appropriate)

a) Humanities [ ] b) Social Sciences [ ] c) Sciences [ ] d) Engineering [ ] e)Other.

\section{SECTION B: AWARENESS OF ELECTRONIC RESOURCE SERVICES}

5. Which of the following electronic resources of the university library are you aware of? Tick as many as applicable.
a) Online databases [ ] b) CD ROM [ ]
c) E-book [ ] $\quad$ d) E-Journal [ ]
e) Institutional Repository [ ] f) Don't know of any [ ]
g) Other (please specify)

6. How did you get to know about these resources?
a) Orientation [ ]
b) Notices [ ]
c) Colleague [ ]
d) Newsletters [ ]
e) Library Website [
f) Through this survey [ ]
g) Friends [ ]
h) Lecturers/Tutors [ ]

i) Other (please specify).

\section{SECTION C: USE OF ELECTRONIC RESOURCES}

7. Do you use the electronic resources of the University library?

a) Yes [ ] b) No [ ]

8. If not, why not? (After answering question 8, skip to question 12) 
9. If yes to question 7, how many hours do you averagely spend in using the electronic resources of the university library?

a) Up to 2 hours in a day [ ] b) 2 to 4 hours in a day [ ] c) Up to 2 hours in a week [ ] d) 2 to 4 hours in a week[ ] e) Up to 2 hours in a month [ ] f) 2 to 4 hours in a month [ ] g) Up to 4 hours in a semester [ ] h) Other (kindly specify)...

10. From which location/device do you mostly access the electronic resources of the library? Tick as many as applicable.

a) Office [ ] b) Computer lab/Library [ ] c) Cybercafé [ ] d) Home [ ] e) Mobile phone [ ] f) Other (please specify)

11. Which type(s) of electronic resources of the library do you usually use? Tick as many as applicable.

a) Online databases [ ] b) CD ROM [ ]

c) E-book [ ] $\quad$ d) E-Journal [ ]

e) Institutional Repository [ ] f) Other (please specify)

12. Where do you typically begin your search for information on a particular topic?

a) Print documents [ ] b) Library website [ ] c) Alternative resources on the Internet [ ]

d) Other (specify).

13a. I prefer using alternative resources on the Internet to the e- resources of the library. Please specify your agreement/disagreement with the statement.

a) Strongly disagree [ ] b) Disagree [ ] c) Neither agree nor disagree [ ] d) Agree [ ] e) Strongly agree [ ]

13b. Please explain your response to question $13 \mathrm{a}$.

14. Tick as many as applicable regarding the electronic resources of your institutional library.

a) I have ever recommended ERs to the library [ ]

b) I have ever used ERs during a trial period [ ]

c) I have had an opportunity to provide feedback on the ERs [ ]

d) I have participated in a survey/research to assess ERs [ ]

e) None of the above [ ] 
For questions 15-20, please specify your agreement/disagreement with each of the following statements. Strongly disagree (SD); Disagree (D); Neither agree nor disagree (NA/D); Agree (A); Strongly agree (SA)

\begin{tabular}{|l|l|l|l|l|l|l|}
\hline No. & Question & SD & D & NA/D & A & SA \\
\hline 15. & $\begin{array}{l}\text { I am able to retrieve relevant information in } \\
\text { electronic format. }\end{array}$ & & & & \\
\hline 16. & $\begin{array}{l}\text { I am encouraged by other students to use e-resources } \\
\text { of the library. }\end{array}$ & & & & \\
\hline 17. & $\begin{array}{l}\text { I am encouraged by library staff to use the e- } \\
\text { resources of the library. }\end{array}$ & & & & \\
\hline 18. & $\begin{array}{l}\text { I am encouraged by my lecturers/supervisors to use } \\
\text { the e-resources of the library. }\end{array}$ & & & & \\
\hline 19. & $\begin{array}{l}\text { Assignments and recommendations by lecturers } \\
\text { influence my decision to use the electronic resources } \\
\text { of the library. }\end{array}$ & & & & \\
\hline 20. & $\begin{array}{l}\text { I have easy access to the required facilities to use } \\
\text { electronic resources. }\end{array}$ & & & & \\
\hline
\end{tabular}

\section{SECTION D: TRAINING IN THE USE OF ELECTRONIC RESOURCES}

21. How have you learned to use the electronic resources of the library? Tick as many as applicable.
a) Trial and error [ ]
b) Orientation / Training by the library [ ]
c) Self-trained [ ]
d) Guidance from other students [ ]
e) Guidance from other library staff [ ]
f) Other.

22. Have you ever attended any training provided by the library on the use of electronic resources of the library? If no, skip to Question 22b
a) Yes [ ]
b) No [ ]

22a. If yes, do you think the training you received met your needs?
a) Yes [ ]
b) Somehow [
] c) No [ ]

22b. If you have never attended any training provided by the library, provide reasons.

a) Training not available [ ] b) Didn't know where to get the training [ ] c) I am fairly competent [

] d) E-resources are self-explanatory on the website [ ]

e) Attended similar training elsewhere [ ]

f) Other.

23. How often does the library provide training on the use of electronic resources?

a) Very often [ ] b) Often [ ] c) Once in a while [ ] d) Not at all [ ] e) Not sure [ ] 
24. Please comment on the type of training you desire or expect from the library.

For questions 25-38, please rate how much you agree or disagree with each of the following statements? Strongly disagree (SD); Disagree (D); Neither agree nor disagree (NA/D); Agree (A); Strongly agree (SA)

\begin{tabular}{|l|l|l|l|l|l|l|}
\hline No. & Question & SD & D & NA/D & A & SA \\
\hline 25. & $\begin{array}{l}\text { I am confident using the electronic resources of the } \\
\text { library. }\end{array}$ & & & & \\
\hline 26. & $\begin{array}{l}\text { I am proficient in the use of the library's electronic } \\
\text { resources. }\end{array}$ & & & & \\
\hline 27. & $\begin{array}{l}\text { The training I received from the library has } \\
\text { enhanced my ability to use the e-resources. }\end{array}$ & & & & \\
\hline
\end{tabular}

SECTION E: PERCEPTION ON ELECTRONIC RESOURCES OF THE LIBRARY

\begin{tabular}{|c|c|c|c|c|c|c|}
\hline No. & Question & SD & D & NA/D & $\mathbf{A}$ & SA \\
\hline 28. & $\begin{array}{l}\text { I use alternative resources on the Internet rather than } \\
\text { electronic resources of the library. }\end{array}$ & & & & & \\
\hline 29. & $\begin{array}{l}\text { I am familiar with the e-resources of the library and } \\
\text { find it easy to use. }\end{array}$ & & & & & \\
\hline 30. & $\begin{array}{l}\text { Using the electronic resources of the library } \\
\text { simplifies finding information. }\end{array}$ & & & & & \\
\hline 31. & $\begin{array}{l}\text { Using the electronic resources of the library reduces } \\
\text { the time required for finding information compared } \\
\text { to alternative resources on the Web. }\end{array}$ & & & & & \\
\hline 32. & $\begin{array}{l}\text { Electronic resources of the library are more useful } \\
\text { than other alternative resources freely available on } \\
\text { the Web. }\end{array}$ & & & & & \\
\hline 33. & $\begin{array}{l}\text { I possess the necessary knowledge and skills to use } \\
\text { electronic resources of the library. }\end{array}$ & & & & & \\
\hline 34. & $\begin{array}{l}\text { It takes a lot of effort to become skilful at using the } \\
\text { electronic resources of the library. }\end{array}$ & & & & & \\
\hline 35. & $\begin{array}{l}\text { It is easy to get relevant information using the } \\
\text { electronic resources of the library. }\end{array}$ & & & & & \\
\hline 36. & $\begin{array}{l}\text { My academic performance has improved as a result } \\
\text { of using electronic resources of the library. }\end{array}$ & & & & & \\
\hline 37. & $\begin{array}{l}\text { Overall, it is easy to use the library's electronic } \\
\text { resources. }\end{array}$ & & & & & \\
\hline 38. & $\begin{array}{l}\text { I am satisfied with the library's electronic resource } \\
\text { services. }\end{array}$ & & & & & \\
\hline
\end{tabular}


39. Please explain your response to question 38

SECTION F: CHALLENGES IN USING ELECTRONIC RESOURCES

For questions 40-41, please rate how much you agree or disagree with each of the following statements? Strongly disagree (SD); Disagree (D); Neither agree nor disagree (NA/D); Agree (A); Strongly agree (SA)

\begin{tabular}{|l|l|l|l|l|l|l|}
\hline No. & Question & SD & D & NA/D & A & SA \\
\hline 40. & $\begin{array}{l}\text { I can access the electronic resources of the library } \\
\text { whenever I want. }\end{array}$ & & & & \\
\hline 41. & $\begin{array}{l}\text { Academic workload prevents me from making time } \\
\text { to use the electronic resources of the library. }\end{array}$ & & & & \\
\hline
\end{tabular}

42). What are some of the limitations you encounter in using e-resources of the library? Select as many as applicable.
a) Information overload [ ]
b) provides unorganised Information [ ]
c) Inadequate searching skills [ ]
d) Lack of relevant information [ ].
e) Lack of time for searching [ ]
f) Difficult to read from screen [ ]
g) Inadequate networked computers [ ]
h) Access time charges [ ]
i) Limited opening time for access to computers [ ] j) Poor Internet connectivity [ ]
k) Not easy to use [ ]
1) No off campus access [ ]
m) Frequent power cuts [ ]
n) Other (specify)

\section{SECTION G: SUGGESTIONS TO IMPROVE AWARENESS AND USE}

43. Electronic resources of the library have been well publicised to members of the university community?
a) Strongly disagree [
] b) Disagree [
] c) Neither agree nor disagree [
] d) Agree [ ]
] e) Strongly agree [ ]

44. What could the library do to promote and improve the use of e-resources? Select as many as applicable.
a) More awareness programmes [ ]
b) Training should be improved [ ]
c) Reduction of access time cost [ ]
d) Provision of relevant resources [ ]
e) Solving network problems [ ]
f) Provision of more networked computers [ ]
g) Extended opening time for access to computers [ ]
h) Use of generators to solve power cuts [ ]
i) Other suggestions. 
45. To conclude this survey, do you have any additional comments you would like to make regarding the electronic resources provided by the library?

Thank you 